Dr. Andrés Salom - Dr. Álvaro Piazze

\title{
TRATAMIENTO
}

MÍNIMAMENTE INVASIVO

DE LA ENFERMEDAD

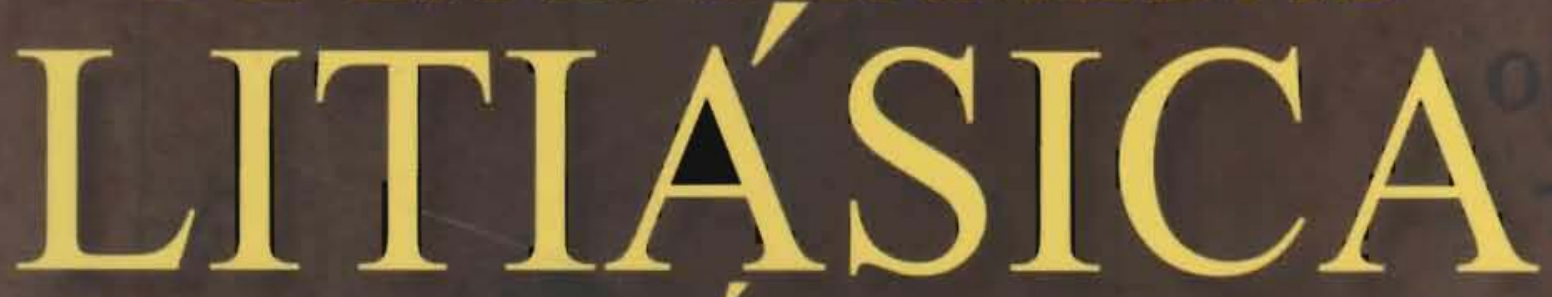

DE LA VÍA BILIAR
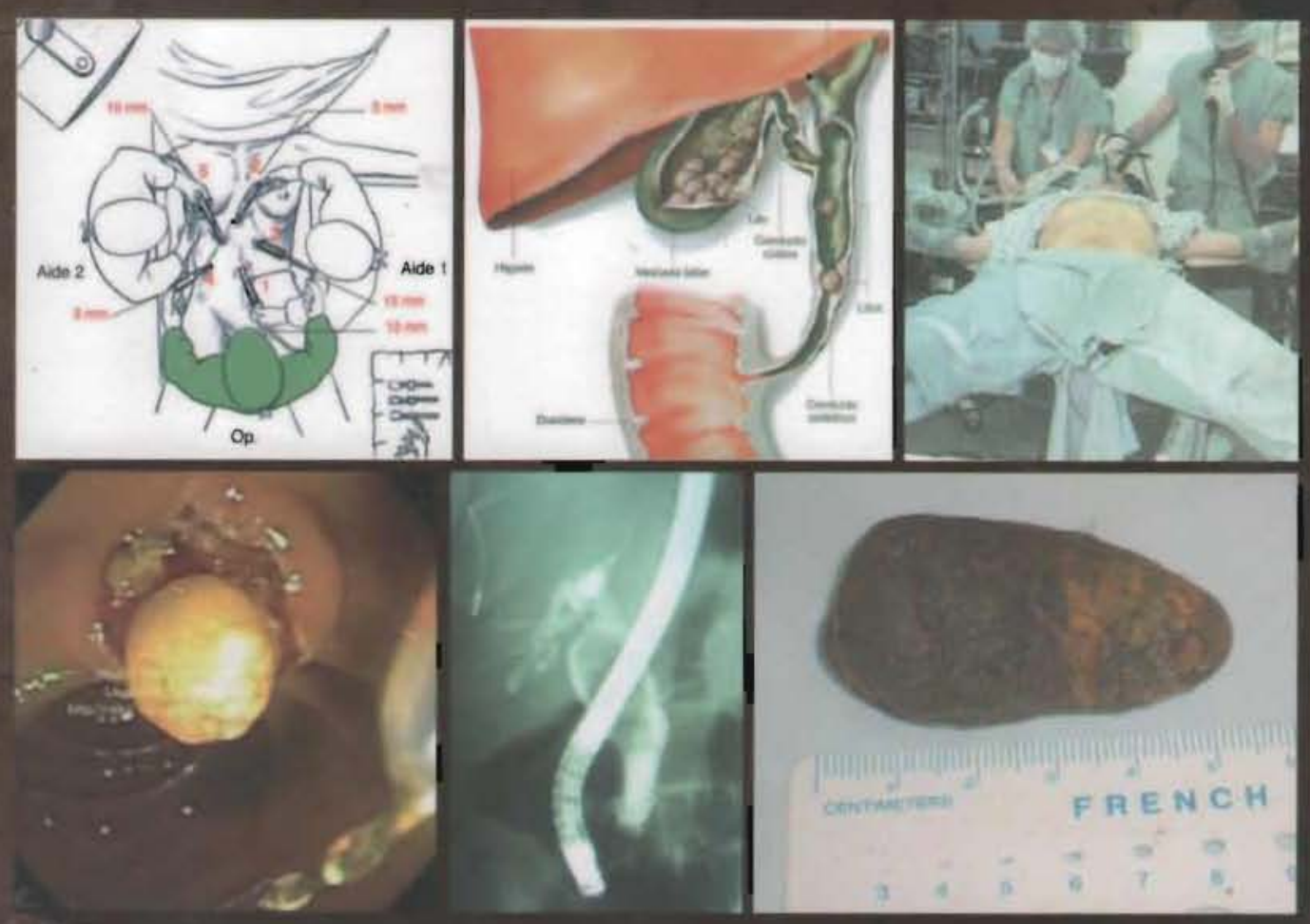

Relato oficial

$63^{\circ}$ Congreso Uruguayo de Cirugía Montevideo - Noviembre 2012 


\section{TRATAMIENTO \\ MÍNIMAMENTE INVASIVO DE LA ENFERMEDAD \\ LITIÁSICA DE LA VÍA BILIAR}

\section{Relato oficial \\ 63 Congreso Uruguayo de Cirugía}

Montevideo

Dr. Andrés Salom - Dr. Alvaro Piazze 


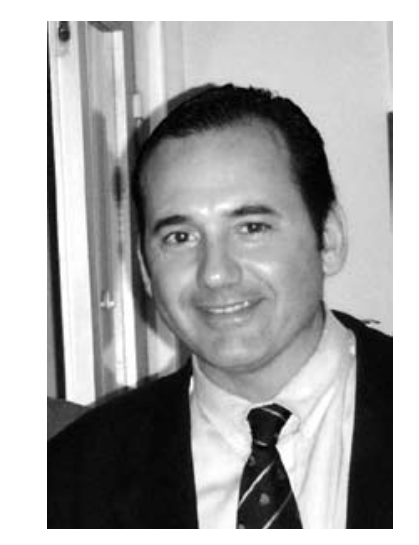

\section{Dr. Andrés Salom}

Especialista en Cirugía.

Ayudante de Clase Grado I, Dpto. Anatomía, Prof. Dr. Gonzalo Estapé y Prof. Dr. Victor Soria, Facultad de Medicina, Universidad de la República, año 1986-90.

Colaborador honorario del Dpto. Básico de Cirugía, Prof. Dr. Alberto del Campo y Prof. Dr. Nisso Gateño, Facultad de Medicina, Universidad de la República, año 1984-92.

Practicante Interno Titular, M.S.P. y Facultad de Medicina, año 1989-91.

Residente de Cirugía, Servicio de Cirugía de Postgraduados, Prof. Dr. Luis Perrone, Hospital Pasteur, Facultad de Medicina, Universidad de la República, año 1992-95.

Asistente de Clínica Quirúrgica "1", Prof. Dr. Gonzalo Estapé, Hospital Pasteur, Facultad de Medicina, Universidad de la República, año 1996-2000.

Profesor Adjunto de Clínica Quirúrgica, Prof. Dr. Raúl Morelli y Prof. Dr. Gustavo Veirano, Hospital de Clínicas, Facultad de Medicina. Universidad de la República, año 2001-9.

Profesor Adjunto del Departamento de Emergencia del Hospital de Clínicas, Prof. Dr. Augusto MüIler, año 2012.

Cirujano del Dpto. y Servicio de Cirugía General del Hospital Central de las FF.AA, desde el año 1996, Jefe de la Seccional de Cirugía Laparoscópica a partir del año 2006.

Cirujano Grado 3 Titular del Sanatorio Asociación Española y de la Unidad de Cirugía Especializada Hepatobiliopancreática desde el año 2009.

Cirujano Grado 3 Titular del Sanatorio Casa de Galicia, desde el año 2009.

Sociedad de Cirugía del Uruguay: vocal (año 2010), prosecretario (año 2011), secretario (año 2012).

Miembro Correspondiente Extranjero de la Asociación Argentina de Cirugía, desde el año 2004. 


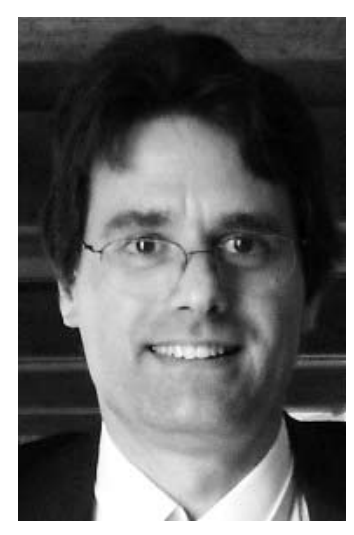

\section{Dr. Alvaro Piazze}

Especialista en Cirugía.

Especialista en Gastroenterología.

Diplomado en Endoscopia digestiva.

Practicante Interno Titular, M.S.P. y Facultad de Medicina, año 1986-9.

Ayudante de Clase Grado I, Dpto. Cirugía, Prof. Dr. Nisso Gateño, Facultad de Medicina, Universidad de la República, año 1988-90.

Ayudante de Clase Grado I, Dpto. Anatomía, Prof. Dr. Gonzalo Estapé, Facultad de Medicina, Universidad de la República, año 1987-90.

Residente de Cirugía, Clínica Quirúrgica "1", Prof. Dr. Bolivar Delgado, Hospital Pasteur, Facultad de Medicina, Universidad de la República, año 1989-92.

Asistente de Clínica Quirúrgica "F", Prof. Dr. Nisso Gateño, Hospital de Clínicas, Facultad de Medicina, Universidad de la República, año 1993-6.

Asistente de Clínica de Nutrición y Digestivo, Prof. Dr. Elbio Zeballos, Hospital de Clínicas Facultad de Medicina, Universidad de la República, año 1997-2000.

Profesor Adjunto de Clínica de Nutrición y Digestivo, Prof. Dr. Elbio Zeballos, Hospital de Clínicas, Facultad de Medicina, Universidad de la República, año 2000-4.

Presidente de la Sociedad Uruguaya de Endoscopia Digestiva, año 2002-4.

Presidente del II Congreso Uruguayo de Endoscopia Digestiva, año 2004.

Coordinador Técnico del Centro de Cirugía endoscópica interdisciplinaria, Dpto. Cirugía, Hospital Policial, año 2009 al presente.

Profesor Adjunto de Cirugía endoscópica, Unidad Docente Asistencial, Centro Nacional de Cirugía Hepatobiliopancreática, ASSE- Facultad de Medicina, HCFFAA, año 2011 al presente. 


\section{DEDICATORIA}

A Patricia, Camila y Martina por acompañarme en todos mis emprendimientos y ser una fuente permanente de amor y alegrías.

A mis padres, siempre presentes desde lo más íntimo.

Andrés

A todas aquellas personas que a lo largo de mi formación me brindaron un consejo, una orientación, para llevar adelante y culminar cada emprendimiento por difícil que pareciera: Profesores, Maestros, Compañero, Amigos.

Especial dedicación a mi familia, esposa e hijos, por darme la energía, brillo y sentido a la vida, más allá de la vida profesional.

Álvaro 


\section{AGRADECIMIENTOS}

Agradezco a las autoridades del 63 Congreso Uruguayo de Cirugía, en particular a su Presidente, el Dr. Augusto Müller, por haberme concedido el alto honor de realizar este relato.

Agradezco a mis Maestros, Profesores, Colegas y Amigos de la cirugía por todo lo que me han aportado generosamente en mi formación durante todos estos años y a la Licenciada Cecilia Valenzuela por su invalorable ayuda en la búsqueda de la bibliografía consultada y en la corrección de los capítulos.

Andrés

A todos los colegas que me confiaron el estudio y tratamiento endoscópico de miles de pacientes a lo largo de más de 20 años de dedicación.

A los integrantes de los equipos de trabajo en cada una de las Instituciones que hace posible la tarea específica, con especial mención a los Asistentes de endoscopia.

Al Dr. Ignacio Toscani, Dr. Carlos Adorno, Dr. Sebastián Fraga y Dra. Susana Reyes por su compromiso en la revisión de las historias clínicas de los pacientes que integran la casuística presentada en el capítulo correspondiente.

Álvaro 


\section{Índice}

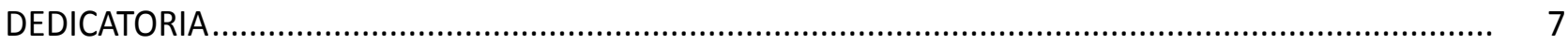

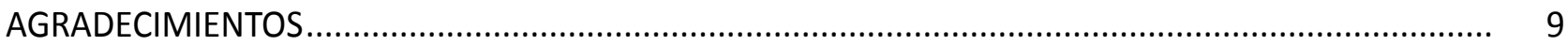

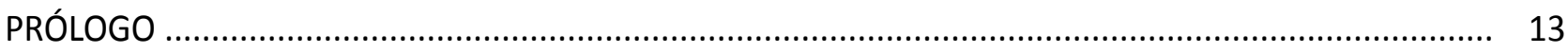

Dr. Luis Gramática, Dr. Francisco Suárez Anzorena

Capítulo 1

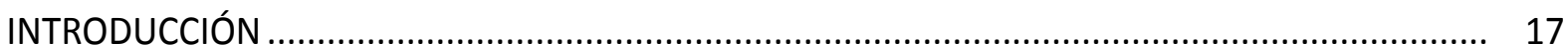

Dres. Andrés Salom y Alvaro Piazze

Capítulo 2

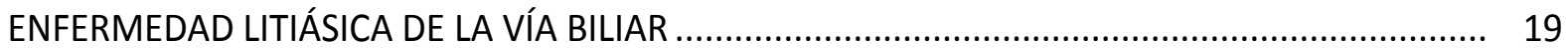

Dr. Andrés Salom

Capítulo 3

CIRUGÍA LAPAROSCÓPICA DE LA VÍA BILIAR ACCESORIA. Colecistectomía Laparoscópica.

Dr. Andrés Salom

Capítulo 4

CIRUGÍA LAPAROSCÓPICA DE LA VÍA BILIAR PRINCIPAL

Dr. Andrés Salom

Capítulo 5

TRATAMIENTO ENDOSCÓPICO DE LA LTIASIS DE LA VÍA BILIAR PRINCIPAL.

Dr. Álvaro Piazze

Capítulo 6

TRATAMIENTO PERCUTÁNEO DE LA LITIASIS BILIAR

Dr. Álvaro Piazze

Capítulo 7

CASUÍSTICA

Dr. Andrés Salom y Dr. Alvaro Piazze

Capítulo 8

ALGORITMO DE TRATAMIENTO

Dres. Andrés Salom y Alvaro Piazze 


\title{
PRÓLOGO
}

\author{
Dr. Luis Gramática \\ Prof. de Cirugía de la Facultad de Ciencias Médicas. \\ Universidad Nacional de Córdoba, Argentina.
}

Transcurría noviembre de 2003, durante el desarrollo del 54 Congreso Uruguayo de Cirugía, en la ciudad de Colonia del Sacramento, donde había sido invitado a participar en una mesa redonda sobre "Cirugía laparoscópica: una nueva forma de realizarse la cirugía o simplemente un abordaje diferente", cuando conozco al Dr. Andres Salom, que actuaba como coordinador y con mucha sencillez y humildad intercambiamos algunos conceptos y pronto percibí su gran interés por la cirugía videolaparoscopica en general y de las vías biliares en particular, que unido al orgullo que siento de haber sido formado en el Servicio de Cirugía General del Hospital Nacional de Clínicas de Córdoba, que dirigiera el eminente Profesor Pablo Luis Mirizzi y que conservó su nivel académico en las últimas décadas dirigido con gran dedicación por mi padre, hizo que rápidamente fundáramos la base de una de las más hermosas amistades que me ha dado la profesión.

La cirugía de la vía biliar recorrió un largo camino para llegar a su estado actual de desarrollo, y fue posible gracias al aporte de numerosos cirujanos del mundo, donde se destacó en el Uruguay el Prof. Raúl Praderi. También en este sentido, es muy destacable, la gran contribución de nuestro maestro Mirizzi con la opacificación intraoperatoria de las vías biliares el 16 de junio de 1931 logrando la primera colangiografía que reiteradamente hemos propuesto en su justo homenaje denominarla "Mirizzigrafia". Posteriormente aparecen la ecografía y otros métodos por imágenes que facilitan el estudio y diagnóstico de la compleja patología biliar. Así llegamos a los fines de los 80, concretamente en marzo de 1987, cuando Philippe Mouret en Lyon realiza la primera colecistectomía laparoscópica en una paciente en la que se había planeado una ooforectomia por esta vía con posterior colecistectomía convencional en el mismo acto operatorio. Al día siguiente, Mouret se encontró con una paciente malhumorada, vestida y lista para retirarse pues consideraba que la cirugía de la vesícula no se había concretado al no presentar dolor ni evidenciar la herida quirúrgica. En ese momento, nació uno de los procedimientos más revolucionarios de la cirugía y que con el tiempo, quizás en un vertiginoso desarrollo y permanentes cambios de paradigmas, llevo a la colecistectomía videolaparoscópicaa ser considerada el "Gold estándar" en todo el mundo.

Mi querido colega y amigo Andrés, también se sintió atraído desde los inicios de su brillante carrera quirúrgica por la video laparoscopía y tuvo el gran mérito de haber avanzado hacia el tratamiento de la patología litiasica de la vía biliar principal con esta técnica, camino que todavía por distintas razones, ya sean económicas o tecnológicas, no han desandado todavía muchos centros quirúrgicos del mundo. Su pasión por este capítulo, acompañado de su natural seriedad y corrección, lo llevó a que el Presidente del 63 Congreso Uruguayo de Cirugía lo distinguiera como Relator Oficial del tema "Tratamiento mínimamente invasivo de la enfermedad litiásica de la vía biliar". 
Por estas razones, no dudo que este relato, será una fuente de consulta de residentes y cirujanos jóvenes y un orgullo para todos sus amigos y fundamentalmente para toda su hermosa familia.

Dr. Luis Gramática 


\title{
Dr. Francisco Suárez Anzorena
}

\author{
Jefe de la Sección de Radiología Intervencionista del Hospital de Clínicas \\ y del Hospital Austral de la ciudad de Buenos Aires, Argentina.
}

Desde que en 1962 publicara su trabajo de extracción transfistular de la litiasis residual del colédoco el Dr. Rodolfo Mazzariello, inicio el camino de la cirugía de invasión mínima. Cuando Kawai realizó la primera colangiografía endoscópica retrógrada en 1974, él hacia la papilotomia anterógrada con el Dr. Magnanini. Este punto de inflexión marco el camino para que muchos cirujanos continúen realizando cirugías endoscópicas y cirugías percutáneas. Desde que mi amigo, el Dr. Álvaro Piazze Pagés emprendió el camino de la mininvasividad por vía endoscópica, de la mano del Dr. Claudio Navarrete, sin duda marcó un camino sin retorno a estas nuevas técnicas.

El tratamiento de la litiasis coledociana es un desafío en su diagnóstico y tratamiento, ha variado y se ha mejorado con las imágenes más precisas y menos invasivas con el advenimiento de la colangiografia por resonancia magnética. Su tratamiento se va modificando de acuerdo a los conocimientos en cirugía laparoscópica, endoscópica y percutánea. El algoritmo se va adecuando de acuerdo a las posibilidades de los pacientes, el grupo tratante y las tecnologías disponibles.

El elegir este tema de actualidad, da la perspectiva que ante estos avances la Sociedad Quirúrgica Uruguaya, y en este momento y en la persona del Dr. Alvaro Piazza Pagés apuestan a un futuro de excelencia.

Es un lujo y un privilegio, poder presentar este trabajo, pues es el resultado de años de interés, entrega y búsqueda de los mejores procedimientos para solucionar con menor injuria esta patología a los pacientes que a diario concurren a su consulta. Su experiencia en este campo y sus resultados son dignos de ser evaluados por los más exigentes colegas en cualquier parte del mundo.

Es un placer y un honor hacer la presentación de su labor intensa y fecunda, y ejemplo para las generaciones que le siguen, no solo por su jerarquía científica, sino también por su humildad y su función dentro de la sociedad como médico y padre de familia.

En este sentido quiero agradecer su confianza en darme la posibilidad para hacer un prologo sencillo, pero a su vez con admiración y el orgullo de ser su amigo.

Dr. Francisco Suárez Anzorena 


\section{Capítulo 1}

\section{INTRODUCCIÓN}

\section{Dres. Andrés Salom y Alvaro Piazze}

El tratamiento quirúrgico de la patología litiásica de la vía biliar ocupa el primer lugar en frecuencia dentro de las cirugías abdominales del aparato digestivo y un lugar central en la cirugía general debido fundamentalmente a dos hechos: el primero es por la elevada incidencia y prevalencia de esta patología en los países occidentales como el Uruguay y el segundo se debe a la historia natural de esta enfermedad, en la que el tratamiento quirúrgico debe realizarse por la aparición de síntomas y/o complicaciones.

Es probable que con el paso del tiempo y el avance en el conocimiento de la etiopatogenia y de sus bases genéticas y moleculares, el tratamiento quirúrgico de esta enfermedad pase a ser una curiosidad histórica; pero en la actualidad es el único camino eficaz. Está destinado a extraer los cálculos junto con la vesícula biliar, dado que es el sitio habitual de formación de los mismos, explorar y dejar la vía biliar principal libre de éstos.

Hoy, con los procedimientos quirúrgicos mínimamente invasivos, tratamos de lograr la excelencia en la forma de extirpar un órgano en el que se producen cálculos y extraerlos de los ductos biliares cuando pasan o se forman en ellos, con la menor morbilidad y mortalidad.

Las vías biliares tienen características especiales, dado que se tratan de delgados conductos con una distribución espacial intrincada y en extremo variable, rodeadas de estructuras vitales, por donde circula la bilis.

Por esta razón, la cirugía biliar ha sido abordada en forma exhaustiva por cirujanos de todo el mundo que han procurado revelar los secretos de la anatomía y fisiopatología del sistema biliar. Se ha transitado un largo camino en el cual numerosos y destacados cirujanos de todos los continentes han realizado sus aportes para crear un arsenal de técnicas quirúrgicas que se han ido perfeccionando a lo largo del tiempo, hasta llegar a estándares de efectividad y de morbi-mortalidad excelentes en manos no sólo de grandes especialistas, sino también del cirujano general que cotidianamente resuelve quirúrgicamente estas patologías.

El público y la comunidad médica muchas veces subestiman la complejidad y las potenciales complicaciones de una cirugía tan simple como la colecistectomía, la cual cualquier cirujano mínimamente entrenado podría realizar, pero advierten su magnitud e importancia cuando aparecen las complicaciones.

En la última etapa de la cirugía biliar, a partir del año 1997, irrumpe la cirugía laparoscópica, basada en el desarrollo de la tecnología y la capacidad de los cirujanos para iniciar todo un nuevo aprendizaje, en la que se desarrollan los procedimientos mínimamente invasivos. 
Es importante destacar que el tratamiento de la patología litiásica de la vía biliar requiere cada vez más de una participación multidisciplinaria, dejando de ser de patrimonio exclusivo del cirujano.

Los médicos radiólogos comenzaron aportando elementos diagnósticos y posteriormente terapéuticos, actuando sobre la vesícula biliar (colecistostomía percutánea) y sobre la vía biliar principal, dilatando estenosis, extrayendo cálculos y colocando drenajes y stents.

Los endoscopistas comenzaron realizando colangiografías por vía endoscópica retrógrada para luego pasar al intervencionismo con la realización de las papilotomías, extracción de cálculos y colocación de drenajes y stents.

Actualmente en condiciones ideales el manejo terapéutico de la enfermedad litiásica de la vía biliar, debe realizarse en forma mínimamente invasiva y debe ser patrimonio de un equipo multidisciplinario integrado por gastroenterólogos, endoscopistas, radiólogos y cirujanos.

Los procedimientos mínimamente invasivos han desplazado en gran medida a la cirugía abierta por laparotomía, aunque ésta mantiene su vigencia, principalmente frente a la presencia de complicaciones o en situaciones especiales como se detallará más adelante.

El objetivo de este relato es analizar el tratamiento mínimamente invasivo de la enfermedad litiásica de la vía biliar, transmitiéndoles nuestra experiencia.

Luego de dedicarnos durante y desde hace muchos años a esta patología, se realiza una puesta a punto de las técnicas de cirugía laparoscópica y procedimientos endoscópicos y percutáneos, desde un enfoque multidisciplinario aportado por cirujanos y endoscopistas, para lograr los mejores resultados, con la más baja morbilidad y mortalidad en el manejo tan frecuente de esta afección. 


\title{
Capítulo 2
}

\section{ENFERMEDAD LITIÁSICA DE LA VÍA BILIAR}

\author{
Dr. Andrés Salom
}

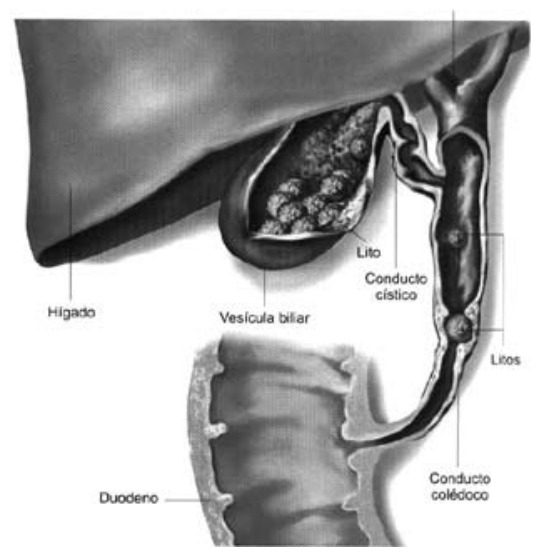

Figura 1. Litiasis biliar.

La litiasis biliar (LB) es una causa importante de morbilidad en el mundo entero.

Durante el año 2000 en los Estados Unidos se registraron 750.000 consultas externas por LB, constituyéndose en la causa más común de internación por trastornos digestivos y es la colecistectomía la operación abdominal de coordinación que se realiza con más frecuencia, con un promedio de 2.2 colecistectomías por cada 1000 habitantes por año ${ }^{1,2}$.

El tratamiento de esta enfermedad tiene un impacto económico muy alto, siendo los costos del tratamiento de la LB sintomática por paciente en Estados Unidos de U\$S 11.584 y en Alemania de aproximadamente de U\$S $28003^{3}$.

La prevalencia de esta enfermedad varía ampliamente de acuerdo a factores étnicos, genéticos, socioeconómicos, de género y geográficos.

Entre las poblaciones con mayor incidencia de esta enfermedad están los indios Pima del sur de Arizona ( $70 \%$ de las mujeres tienen litiasis después de los 25 años de edad), Mapuche,los escandinavos ( $50 \%$ de la población con más de 50 años de edad), grupos de amerindios de Alaska, Canadá, Estados Unidos, Bolivia y Chile ${ }^{4}$. 
En Argentina la prevalencia que mostraron algunos estudios es de un promedio del 20.5 al $28.8 \% \%^{5,6}$.

Las poblaciones con menor incidencia son las situadas al sur del desierto del Sahara en África y en Asia. En esta última hay una prevalencia de cálculos pigmentados, siendo mayor en China que en Japón ${ }^{7,8}$.

\section{Edad y sexo}

La prevalencia acumulativa de los cálculos biliares aumenta con la edad.

El sexo es el factor de riesgo que tiene más incidencia en cuanto al desarrollo de cálculos biliares.

La mayoría de las series muestran una prevalencia en las mujeres del 5 al $20 \%$ entre los 20 y 55 años de edad y del 25 al $30 \%$ después de los 50 años.

La prevalencia en los hombres es de aproximadamente la mitad de la existente en las mujeres del mismo grupo etario.

Existe una predisposición genética y la raza negra es menos propensa a padecer esta enfer-

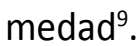

Se han identificado factores de riesgo que aumentan la posibilidad de que se formen los cálculos. Éstos, como ya se ha expresado son: la edad y el sexo, la obesidad, la pérdida de peso, la nutrición parenteral, el embarazo y la paridad, algunos fármacos, la dieta, el perfil lipídico y algunas enfermedades sistémicas.

La obesidad determina un aumento de la litogénesis, lo que puede ser explicado por una mayor secreción de colesterol hacia la bilis ${ }^{10}$.

De acuerdo a estudios recientes, la pérdida rápida de peso es un factor de riesgo para la formación de cálculos de colesterol. Aproximadamente el $25 \%$ de los pacientes obesos que se someten a una restricción dietética estricta desarrollan una litiasis biliar y hasta un $50 \%$ de los pacientes sometidos a un bypass gástrico desarrollan barro biliar o cálculos biliares en la vesícula, dentro de los seis primeros meses posteriores a la intervención quirúrgica ${ }^{11}$.

La nutrición parenteral total (NPT) ha sido asociada con el desarrollo de colecistitis alitiásica, colelitiasis y colecistitis. Hasta el $45 \%$ de los pacientes adultos ${ }^{12}$ y el $43 \%$ de los niños desarrollarán cálculos biliares después de tres o cuatro meses de NPT ${ }^{13}$.

El embarazo es un factor de riesgo importante en cuanto al desarrollo de barro y cálculos biliares. La bilis se torna más litogénica como resultado del aumento de los estrógenos, lo que determina un aumento de la secreción de colesterol y la sobresaturación de la bilis. El volumen de la vesícula se duplica y se desarrolla estasis lo que también promueve la formación de barro y cálculos biliares. Después del parto la motilidad de la vesícula se normaliza y la bilis retorna al estado previo al embarazo. El barro biliar desaparece después del parto en el 60 a $70 \%$ de las mujeres y los cálculos biliares en el 20 al 30\% de las veces ${ }^{14}$.

El estrógeno es el fármaco u hormona más estudiada que se asocia con la formación de cálculos biliares.

En cuanto a la dieta y al perfil lipídico, la hipertigliceridemia se asocia con un aumento en la formación de cálculos en la vía biliar ${ }^{15}$.

En cuanto a las enfermedades sistémicas, la diabetes se asocia con un mayor número de complicaciones asociadas a la colelitiasis. 
Las enfermedades del íleon (Crohn) son un factor de riesgo reconocido en cuanto a la formación de cálculos ${ }^{16}$.

\section{Morfología y composición de los cálculos}

Los cálculos están compuestos por los componentes de la bilis: colesterol, ácidos biliares y sales de calcio. Pueden ser de colesterol o pigmentarios.

Los cálculos de colesterol son los más frecuentes (60 a 80\%), pudiendo estar compuestos sólo por colesterol, o ser éste el principal constituyente químico, denominándose a éstos: mixtos. Cuando son de colesterol puro generalmente son grandes y de color blanco-amarillento. Los mixtos son más frecuentes que los anteriores, generalmente múltiples y más pequeños.

Con respecto a la etiopatogenia hay tres defectos principales que están íntimamente involucrados en la formación de los cálculos biliares: la sobresaturación con colesterol, la nucleación acelerada y la hipomotilidad de la vesícula biliar.

Los cristales de colesterol se forman en el gel de mucina y son atrapados por dicho gel, que se acumula por la hipersecreción en la vesícula y la evacuación defectuosa. Las moléculas de glucoproteínas de mucina también parecen actuar como agentes en la aglomeración de los cristales necesarios para la formación de los cálculos (diagrama de Venn).

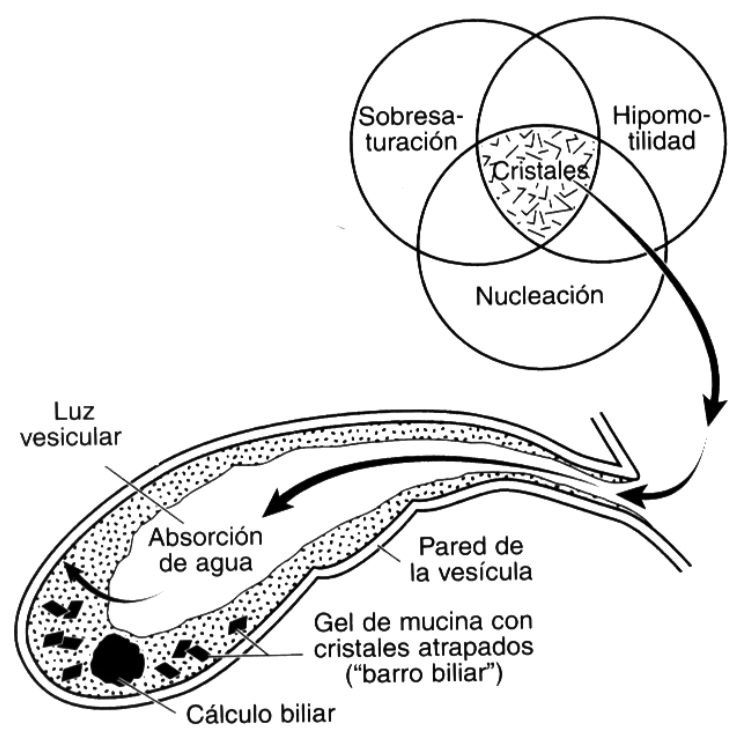

Figura 2. Diagrama de Venn. (Tomado de Sleisenger, Enfermedades Gastrointestinales y Hepáticas)

Las sales biliares representan el tercer factor de importancia en la composición de la bilis y son críticas en la determinación de la solubilización del colesterol.

En la bilis sobresaturada el primer paso en la formación de un cálculo biliar es la nucleación.

Los cálculos pigmentarios son del 10 al 25\% de todos los cálculos biliares y pueden ser de pigmento negro o marrón.Están pigmentados como resultado de la precipitación de la bilirrubina.

Los cálculos de pigmento negro tienden a formarse en la vesícula biliar y están compuestos por bilirrubinato de calcio, además de carbonato y fosfato de calcio. Se encuentran más frecuentemente en cirróticos, en la fibrosis quística, en el Síndrome de Gilbert, en las enfermedades hemolíticas congé- 
nitas, en pacientes operados del corazón ${ }^{17}$, etc. Son irregulares, pequeños y se originan en los senos de Rokitanski-Aschoff. Pueden coexistir con cálculos de colesterol e incluso servir de factores de nucleación para los mismos ${ }^{18}$.

Los cálculos de pigmento marrones se observan generalmente en los conductos biliares y son causados por éstasis biliar e infección por Escherichia coli, que producen enzimas que hidrolizan los componentes biliares comunes, causando la precipitación de bilirrubinato y palmitato de calcio, pudiéndose generar un ciclo vicioso de infección, éstasis y más infección ${ }^{19}$.

\section{Clínica y evolución natural de la enfermedad}

La evolución natural de la enfermedad se define en dos grupos de pacientes: los sintomáticos y los que permanecen asintomáticos.

Los estudios de necropsias demuestran que la mayor parte de los pacientes con litiasis se mantienen asintomáticos y el $80 \%$ de las litiasis son diagnosticadas por hallazgos ecográficos ${ }^{20}$.

Poder determinar la verdadera incidencia de complicaciones en los pacientes con cálculos es crítico, para poder proporcionar recomendaciones terapéuticas racionales y eficaces en relación a costo beneficio, pero la información disponible es aún escasa y muy variable.

El estudio de pacientes con litiasis asintomáticos de Gracie y Ransohoff, comprendió a 123 pacientes seguidos durante 15 años, volviéndose sintomáticos el 10\%, 15\% y 18\% a los 5, 10 y 15 años; y ninguno presentó complicaciones ${ }^{21}$.

El riesgo de que la litiasis asintomática se torne sintomática es de un $2 \%$ anual; el que genere complicaciones es de un $0.3 \%$ anual y el de desarrollar un cáncer de vesícula es del $0.02 \%$ anual ${ }^{22,23}$.

Según la reunión de consenso de Estrasburgo realizada en el año 1991 la litiasis biliar puede presentarse en forma asintomática, sintomática y complicada ${ }^{24}$.

Las complicaciones son la presencia de una colecistitis aguda, litiasis de la vía biliar principal con o sin colangitis, pancreatitis aguda y fístulas biliodigestivas con o sin cuadros de oclusión intestinal (íleo biliar).

El dolor es el síntoma característico de esta afección. Se caracteriza por aparecer luego de la ingesta generalmente de alimentos ricos en grasas, ser continuo más que intermitente como lo sugiere la palabra cólico, aumentar gradualmente durante un período de 15 minutos a una hora o más antes de desaparecer lentamente. En una tercera parte de los casos tiene un comienzo más súbito y puede cesar más bruscamente.

Habitualmente se localiza en el hipocondrio derecho (HD), se irradia al epigastrio, hombro derecho y dorso, calmar con la ingesta de antiespasmódicos y se acompaña de nauseas y vómitos.

En el examen físico se observa dolor a la palpación del HD.

Cuando es menor de 12 horas de duración se le denomina cólico hepático y generalmente es debido a la obstrucción parcial del conducto cístico en forma intermitente.

Cuando es mayor de 6 horas de evolución, no calma con la administración de antiespasmódicos y se acompaña de fiebre, generalmente está traduciendo la presencia de una complicación: una colecistitis aguda, como consecuencia de la impactación de la litiasis a nivel del conducto cístico o del cuello vesicular.

Cuando los episodios dolorosos se reiteran y se prolongan en el tiempo se les denomina cólicos subintrantes. 
En alrededor del $30 \%$ de los pacientes que experimentan un episodio doloroso, no se repite en los 2 años siguientes, pero el $70 \%$ presentan un riesgo anual del $6 \%$ de padecer nuevos episodios ${ }^{25}$ y un $1 \%$ necesitan una intervención quirúrgica de urgencia ${ }^{26}$.

La reiteración de estos episodios dolorosos durante varios años, permite diagnosticar la presencia de una colecistopatía obstructiva crónica.

La presencia de episodios inflamatorios en la vía biliar va generando sucesivas alteraciones inflamatorias de la vesícula y de la vía biliar, lo que va alterando la anatomía y la normal arquitectura de la vía biliar, adquiriendo su máxima expresión en los Sindromes de Mirizzi.

Se debe realizar un correcto interrogatorio y examen a los pacientes, a los efectos de no confundir las manifestaciones clínicas de esta enfermedad con otras patologías digestivas (gastritis, colon irritable, tumores, etc).

Los síntomas de dispepsia tipo dismotilidad no son atribuibles a esta enfermedad y generalmente persisten luego de la colecistectomía.

La presencia de un síndrome infeccioso con fiebre y chuchos se observa en las formas complicadas con colecistitis o colangitis aguda.

\section{Complicaciones}

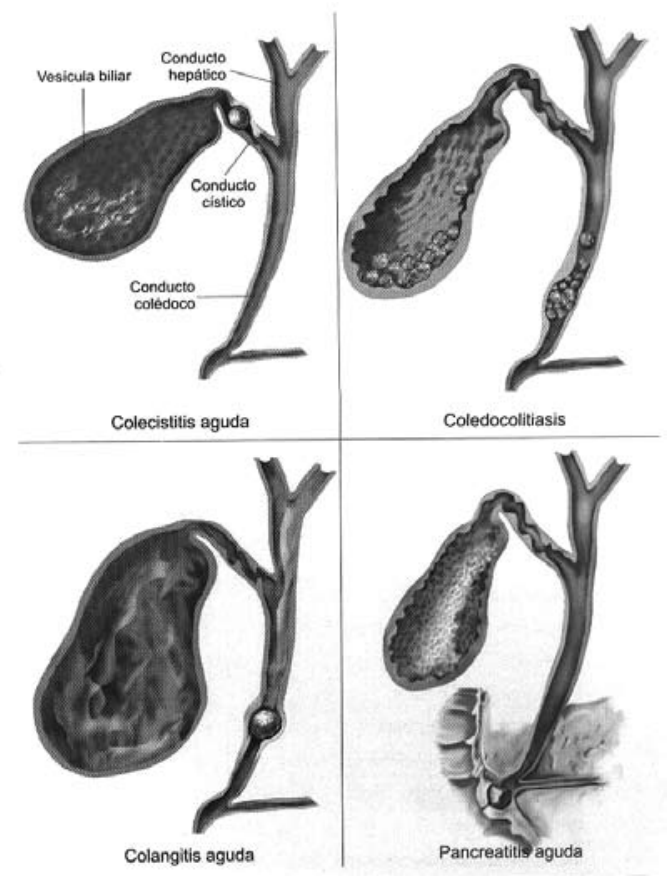

Figura 3. Complicaciones de la litiasis biliar.

Las formas complicadas de la litiasis biliar son poco frecuentes, con un índice anual del 3 al $8 \%{ }^{25}$.

La complicación más frecuente es la colecistitis aguda (CA).

En éstas, además del dolor intenso y prolongado, se asocia en el examen físico la presencia de una vesícula palpable y dolorosa, o su equivalente que es el signo de Murphy.

Más del $90 \%$ de los casos se debe a la obstrucción del conducto cístico por un cálculo. El resto se produce en ausencia de cálculos (CA alitiásica) y se relaciona con traumatismos, cuadros sépticos, afec- 
ciones sistémicas autoinmunes, diabetes, SIDA, tumores de la vía biliar, pólipos vesiculares, adenopatías periportales, parásitos y cuerpos extraños ${ }^{27}$.

La obstrucción del conducto cístico determina un proceso inflamatorio en el que secundariamente en más de la mitad de los casos se agrega una infección bacteriana, siendo los gérmenes más frecuentemente involucrados: Gran (-) como Escherichia Coli, Klebsiella, Enterobacter, Bacteroides, Clostridium, Fusobacterium y Enterococos ${ }^{28}$.

El proceso puede evolucionar a la acumulación de pus en la luz vesicular dando lugar a la formación de un empiema (piocolecisto), abscesos intrahepáticos, formación de un plastrón perivesicular o la ruptura vesicular con derrame de bilis y secreciones a la cavidad abdominal causando una peritonitis biliar.

La litiasis de la vía biliar principal es generalmente secundaria, como consecuencia de la migración transcística de los cálculos vesiculares y tiene una incidencia de aproximadamente el $15 \%{ }^{29}$.

La LVBP puede ser además primitiva, al formarse en la VBP a partir de una infección y/o éstasis y cuerpos extraños.

La presencia de cálculos en la VBP pueden determinar la aparición de las siguientes complicaciones: ictericia obstructiva, colangitis aguda y pancreatitis.

El diagnóstico de litiasis de la VBP se basa en elementos clínicos, de laboratorio e imagenológicos.

Los elementos clínicos son: dolor epigástrico, pérdida de selectividad del mismo frente a la ingesta de alimentos exitobiliares, ictericia, coluria y episodios de pancreatitis aguda.

Se denomina colangitis aguda a la infección bacteriana de los conductos biliares como consecuencia de la dificultad al flujo normal de la bilis generalmente debida a una obstrucción litiásica y que se presenta con signos de infección sistémica.

Se observa litiasis coledociana en aproximadamente el 10 al $20 \%$ de los pacientes con litiasis vesicular y solo el $0.2 \%$ presentarán una $\mathrm{CA}^{30,31}$.

Las colangitis se caracterizan por presentarse en alrededor del $70 \%$ de los casos con la clásica tríada de Charcot, dada por dolor, fiebre e ictericia ${ }^{32}$.

Pueden observarse disfunciones sistémicas múltiples en las formas sépticas, siendo generalmente la insuficiencia renal la más frecuente. Cuando se asocia además una depresión del sensorio y cuadros de shock conforman la llamada péntada de Reynolds ${ }^{33}$.

La pancreatitis aguda se asocia en más del $80 \%$ de los casos a la presencia de una litiasis biliar; siendo las causas más frecuentes en el resto de los casos, el alcoholismo, dislipoproteinemias, hipercalcemias, parasitosis, etc ${ }^{34,35}$.

El mecanismo etiopatogénico que explica la producción de la pancreatitis aguda es la presencia de un cálculo y su impactación en la papila ${ }^{36}$, o su pasaje y migración al duodeno ${ }^{37,38,39}$.

El 70 al $80 \%$ de los pacientes con pancreatitis aguda presentan formas leves o moderadas que responden rápidamente al tratamiento médico. El resto son formas severas graves con complicaciones locales y sistémicas debidas a la presencia de necrosis pancreática y peripancreática que puede infec$\operatorname{tarse}^{40}$.

Las formas muy graves con mortalidad precoz son debidas al síndrome de respuesta inflamatoria sistémica con shock y fallas orgánicas múltiples.

En los cuadros de pancreatitis aguda el dolor generalmente se irradia al dorso y a la izquierda y pueden aparecer signos de irritación peritoneal en el examen abdominal y distensión abdominal en el hemiabdomen superior por el íleo regional. 
Del 15 al 20\% de los casos se presentan con ictericia debido a una litiasis coledociana, edema de la cabeza del páncreas o hemólisis.

La fiebre es debida al síndrome de respuesta inflamatoria sistémica.

Los signos de Grey-Turner y el de Cullen indican la presencia de una PA grave y son muy infrecuentes y pueden presentarse en otros procesos como las hemorragias retroperitoneales.

Las fístulas biliares son la comunicación anormal que se establece, como consecuencia de los sucesivos episodios inflamatorios producidos por los cálculos, entre los distintos sectores de la vía biliar entre sí (fístulas bilio-biliares) o con el tubo digestivo (fístulas biliodigestivas).

Estas dos formas de fístulas se denominan también, fístulas biliares internas (FBI), en contraposición a las externas, siendo la litiasis biliar la etiología más frecuente (90\%).

En cuanto a su mecanismo de producción, las fístulas de etiología litiásica son espontáneas o primarias.

En el año 1948 Mirizzi describió el síndrome del hepático común, producido por el estrechamiento del conducto hepático común por un cálculo impactado en el infundíbulo vesicular ${ }^{41}$. El proceso inflamatorio determinado por el cálculo, va comprometiendo la integridad anátomo funcional del hepatocolédoco, pudiéndose producir una fístula que puede involucrar al hepático común, al colédoco o a ambos conductos, determinando en muchos casos una obstrucción de la vía biliar principal.

Entre el 30 al 60\% de las FBI presentan una litiasis coledociana asociada ${ }^{42,43}$.

Se denomina de acuerdo a la clasificación de Mc Sherry como Mirizzi tipo I a los casos con compresión hepatocoledociana y Mirizzi tipoll cuando se produce una fístula bilio-biliar ${ }^{44}$.

Csendes y colaboradores consideran la presencia de cuatro tipos, de acuerdo a la magnitud del compromiso de la pared de la vía biliar principa ${ }^{45}$.

Las fístulas biliodigestivas tienen una mayor incidencia, siendo las más frecuentes las colecistoduodenales (70 al 80\%), colecistocolónicas (10\%), más raramente colecisto-gástricas y colédocoduodenales (3 a $5 \%$ ) y combinadas ${ }^{46}$.

Se asocian a la presencia de una litiasis coledociana hasta en el $50 \%$ de los $\operatorname{casos}^{43}$.

Cuando se produce el pasaje de generalmente un voluminoso cálculo al tubo digestivo, el cuadro se puede manifestar como una oclusión intestinal alta por obstrucción a nivel píloro-duodenal (Sindrome de Bouveret) o a nivel del intestino delgado distal, generalmente el íleon (íleo biliar). En estos cuadros de íleo biliar, es característica la presencia de oclusiones intestinales intermitentes.

El paso de un cálculo al colon a través de una fístula colecistocolónica no origina cuadros de oclusión intestinal; si episodios de diarrea con coloración verdínica de las materias por el pasaje de bilis a la luz del colon, siempre que el conducto cístico esté permeable.

\section{Métodos de estudio complementario}

El estudio de elección para confirmar el diagnóstico de litiasis biliar es la ecografía abdominal. 


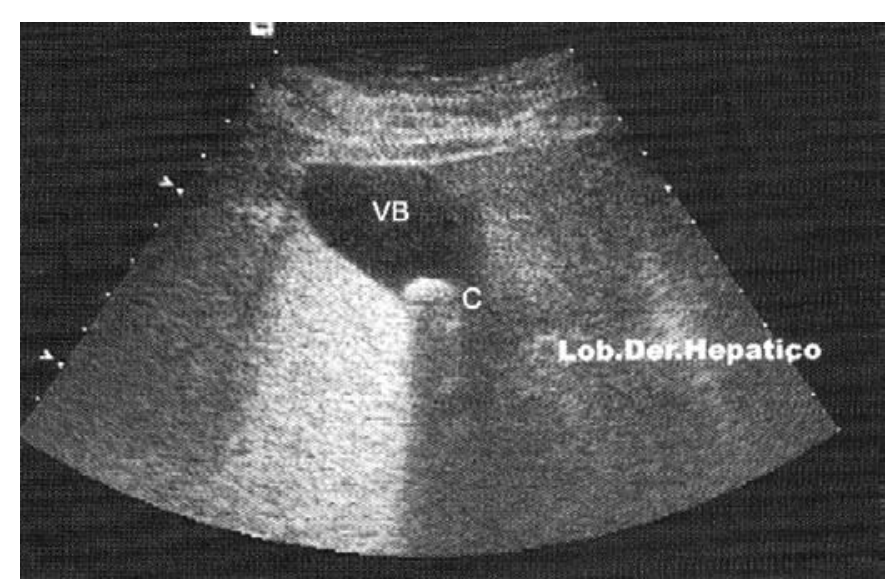

Foto 1. Ecografía abdominal.

Es muy sensible y específico para realizar la detección de los cálculos vesiculares y evaluar el calibre de la vía biliar. Si bien es un estudio operador dependiente, tiene una sensibilidad y especificidad de alrededor del $96 \%{ }^{47}$.

Con este estudio se puede determinar: la presencia, número y tamaño de los cálculos; características de la vesícula (tamaño, forma, grosor y características de sus paredes, presencia de edema, pólipos o tumores); dilatación de la vía biliar en su sector intra y extrahepático. Se pueden detectar cálculos de hasta $2 \mathrm{~mm}$ de diámetro.

A nivel de la vía biliar pueden verse signos directos, como es la presencia de cálculos o indirectos, como es la dilatación secundaria a la obstrucción.

Tiene la ventaja de ser un estudio no invasivo y de bajo costo, por lo que debe ser considerado como un examen imprescindible frente a un cuadro clínico de probable filiación biliar, que complementa el examen clínico.

La radiografía simple de abdomen carece de sensibilidad y especificidad para evaluar la presencia de litiasis. Sólo el $50 \%$ de los cálculos pigmentados y el $20 \%$ de los cálculos de colesterol contienen calcio suficiente como para ser visualizados.

Puede ser utilizada en la evaluación de los pacientes con complicaciones poco frecuentes como lo son las colecistitis enfisematosas o las fístulas bilioentéricas y en la detección de una vesícula en porcelana.

También se puede detectar la presencia de aerobilia cuando existe una fístula biliodigestiva.

La tomografía axial computada (TAC), tiene una menor sensibilidad y especificidad en la detección de litiasis vesicular, comparada con la ecografía.

Es un método más sensible que la ecografía abdominal en la detección de litiasis coledociana, mientras que la TAC helicoidal tiene en algunas series una sensibilidad similar a la colangiopancreatografía por resonancia magnética y a la ecoendoscopía ${ }^{48}$.

Tiene valor fundamentalmente en diagnosticar la presencia de complicaciones de la litiasis biliar o descartar diagnósticos diferenciales, fundamentalmente con la patología tumoral de la vía biliar.

Puede detectar la presencia de líquido perivesicular, gas, abscesos en la colecistitis aguda y valorar la presencia de tumores del hígado, la vesícula o la vía biliar. 
Es un método más sensible para valorar el páncreas, sobre todo cuando se sospecha un cuadro de pancreatitis aguda. Es más conveniente solicitarla ante la duda diagnóstica, luego de las 72 horas del inicio del cuadro, ya que antes es difícil poner en evidencia si existe necrosis pancreática ${ }^{49}$.

La TAC helicoidal con contraste endovenoso de doble fase es de gran valor en demostrar las alteraciones de la microcirculación, para determinar la presencia y extensión de la necrosis y la presencia de gas en presencia de infección.

La colangiopancreatografía por resonancia nuclear magnética nuclear (CP-RM) permite reconstruir una imagen tridimensional de la vía biliar con altísima sensibilidad para detectar cálculos y tumores. Tiene la ventaja con respecto a la colangiografía endoscópica retrógrada (CER) de ser no invasiva, si bien carece de potencial terapéutico.

Tiene una sensibilidad del 90\% para poder detectar cálculos a nivel de la VBP y éste disminuye significativamente cuando son pequeños ${ }^{50,51}$.

Ocupa un lugar privilegiado en la evaluación de un paciente con sospecha de litiasis de la VBP, por su especificidad y ser un método de estudio no invasivo.

Aporta una información de capital importancia para planificar y seleccionar la mejor táctica quirúrgica.

La CP-RM es un buen método para establecer necrosis pancreática con una sensibilidad similar a la TAC en los cuadros de pancreatitis aguda, siendo sobre todo útil en aquellos pacientes en los que está contra indicada la administración de contraste.
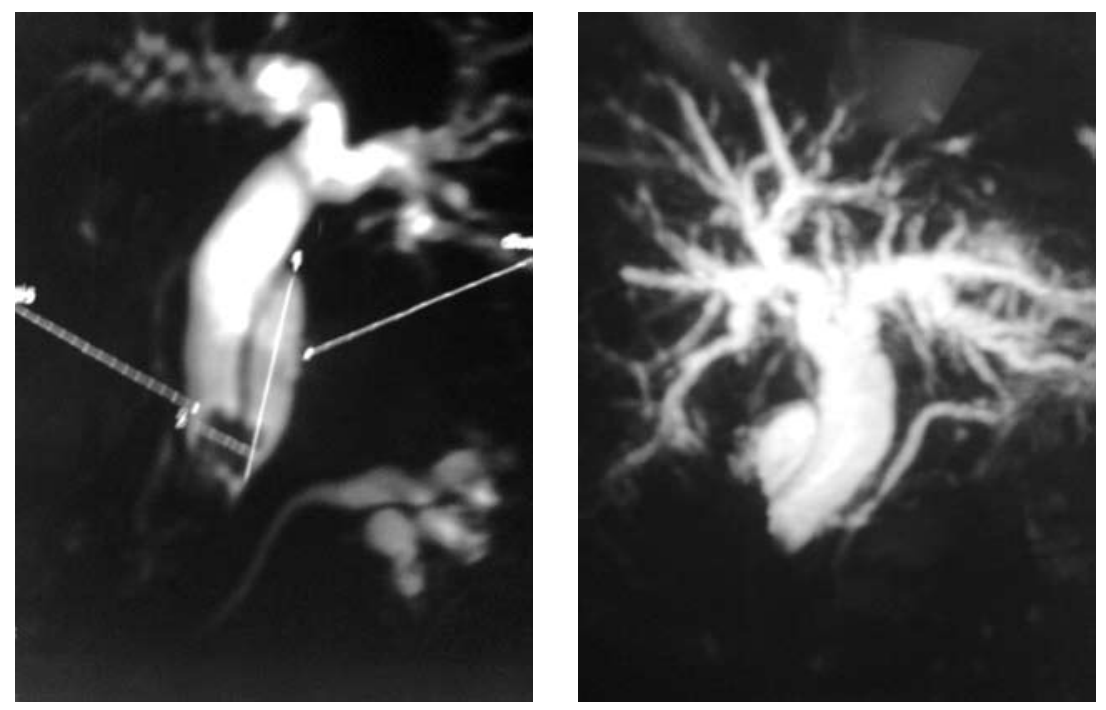

Foto 2. Colangiorresonancia.

La ecoendoscopía (EE) es un método menos frecuentemente utilizado, pero que tiene un lugar importante en el diagnóstico de la litiasis biliar. 

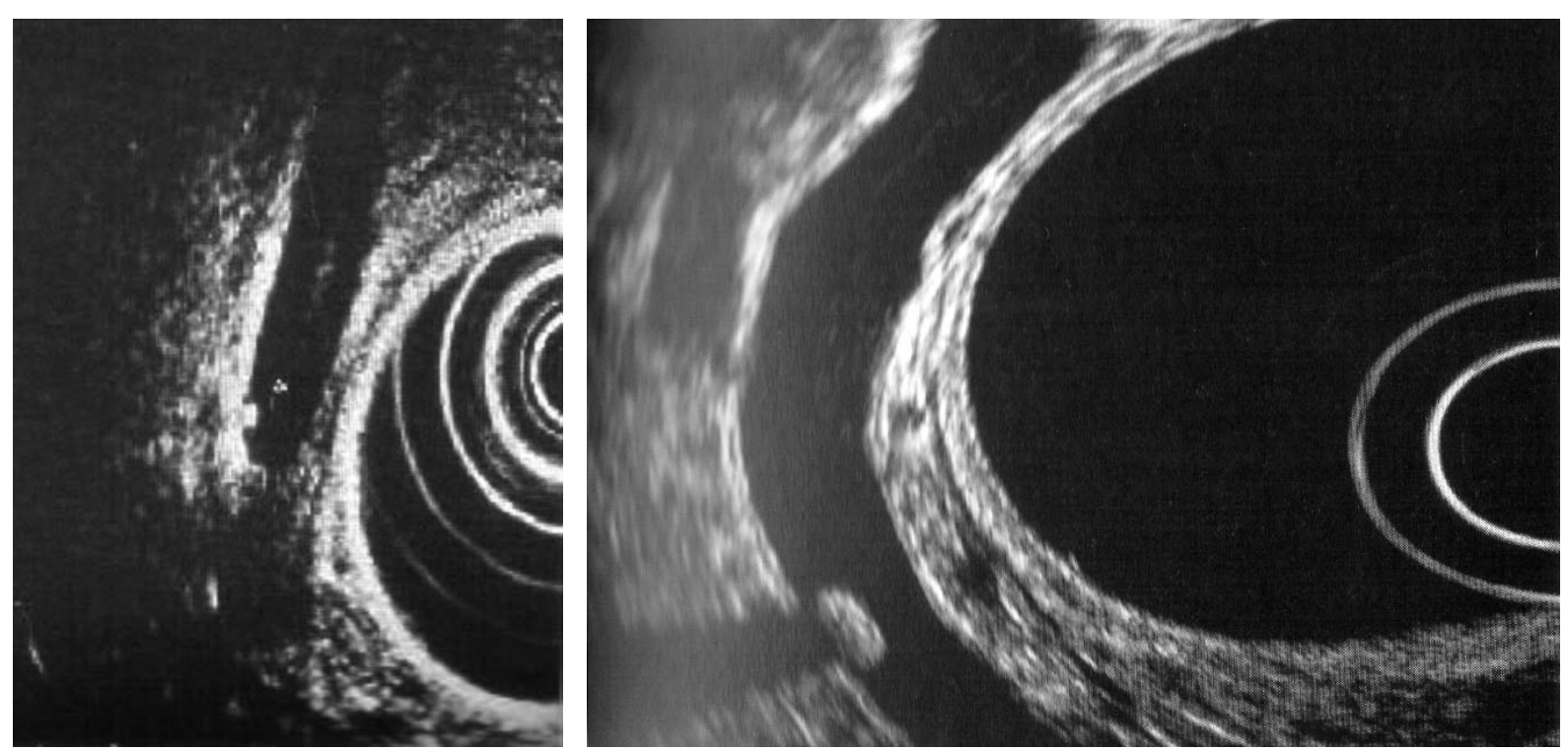

Foto 3. Ecoendoscopías que muestran la presencia de pequeñas litiasis en el colédoco distal.

Es excelente en el diagnóstico de microlitiasis de la vesícula biliar, con una sensibilida de casi el $100 \%^{52,53}$.

El resultado en el diagnóstico de coledocolitiasis, no está relacionado con el tamaño de los cálculos, ni con el diámetro de la vía biliar. Tiene una sensibilidad y especificidad mayor del $90 \% \%^{54,55,56}$.

Su papel en la relación con otras técnicas de diagnóstico depende, principalmente del entorno (experiencia del cirujano y del endoscopista intervencionista) y de las circunstancias del diagnóstico.

Las ventajas principales de este método son su elevada sensibilidad y especificidad.

Cuando se opta por este método de estudio como modalidad de imagen para identificar cálculos en la VBP, es conveniente asociarlo a la CER para poder realizar su extracción terapéutica ${ }^{57}$.

La ecolaparoscopía hepatobiliar intraoperatoria, es un método de estudio no invasivo, extremadamente operador dependiente y puede ser útil en algunas situaciones. Tiene mayor precisión para detectar cálculos intrahepáticos. Es más difícil de evaluar el tercio distal de la VBP, por la interposición del gas duodenal. Se utiliza más en la evaluación de pacientes con tumores hepatobiliares y pancreáticos, cuando se realiza su tratamiento por cirugía laparoscópica.

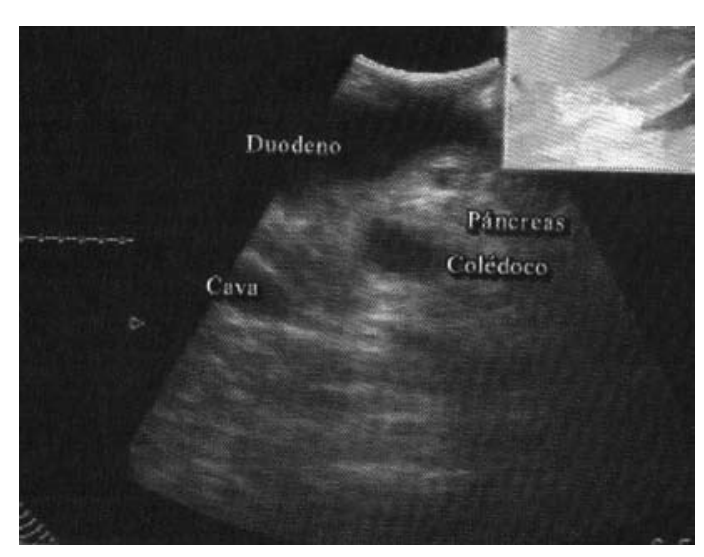

Foto 4. Ecolaparoscopía. 
La colangiografía endoscópica retrógrada (CER), se acepta actualmente, debe ser indicada en pacientes con evidencia de litiasis coledociana, con un criterio fundamentalmente terapéutico y no solo diagnóstico, dado que se trata de un método invasivo con morbilidad y mortalidad.
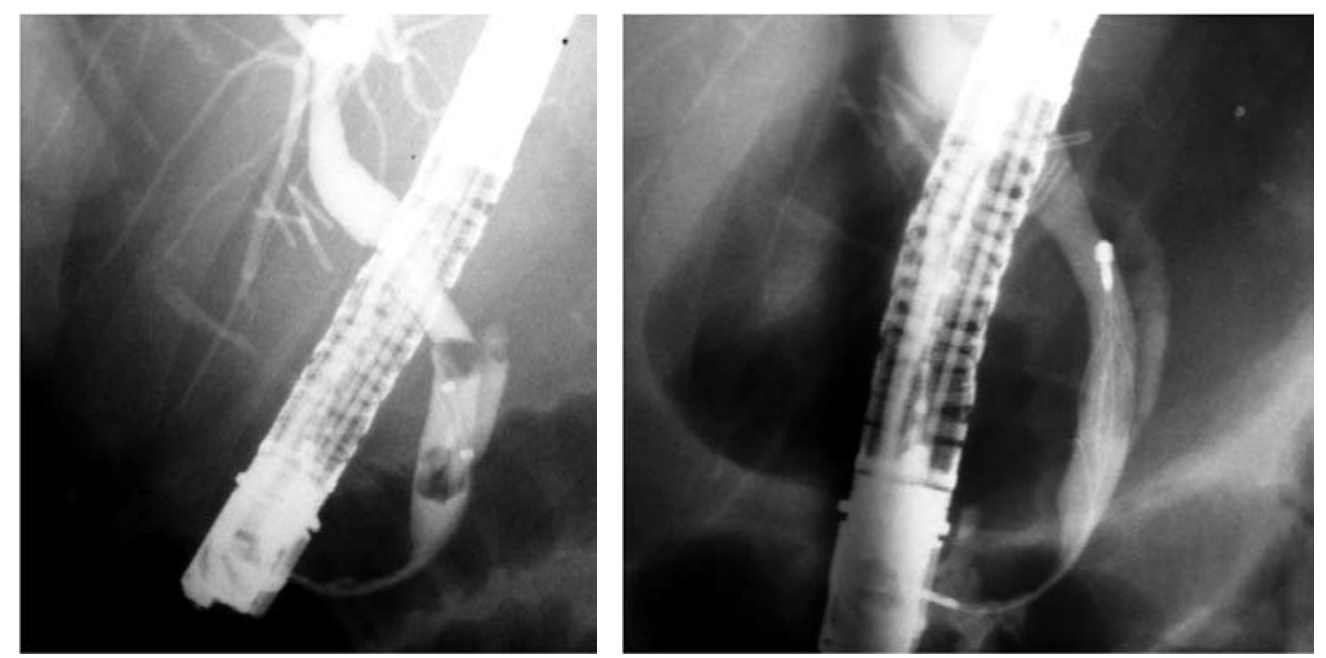

Foto 5. Colangiografía endoscópica retrógrada (CER) con extracción de litiasis.

Los exámenes de laboratorio no aportan datos, para el diagnóstico de litiasis biliar no complicada, aunque sí tienen valor para predecir la posibilidad de litiasis de la vía biliar principal.

La determinación de la bilirrubinemia, fosfatasa alcalina (FA), gamma glutamil transpeptidasa (GGT) y la 5 nucleotidasa tienen un elevado valor predictivo negativo, siendo el de la GGT mayor del $97 \%$. La bilirrubinemia tiene la especificidad más alta de $87.5 \%{ }^{58}$.

\section{Tratamiento}

Es probable que con el paso del tiempo y el avance en el conocimiento de la patogenia, de sus bases genéticas y moleculares, la cirugía de la vía biliar para el tratamiento de esta enfermedad pase a ser una curiosidad histórica; pero, en la actualidad el único tratamiento eficaz es el quirúrgico. Está destinado a extraer los cálculos junto con la vesícula biliar, sitio habitual de formación de los mismos, explorar y dejar la vía biliar principal libre de éstos.

Actualmente, con los procedimientos quirúrgicos mínimamente invasivos, tratamos de encontrar la excelencia en la forma de eliminar un órgano en el que se producen cálculos con sus complicaciones al pasar a los ductos biliares, con la menor morbilidad, de forma de tener la menor cantidad de complicaciones y secuelas.

El tratamiento médico destinado a lograr la disolución de los cálculos con la administración de ácidos biliares: quenodesoxicólico y ursodesoxicólico (UDCA), es costoso, prolongado, caro y es eficaz sólo para cálculos de colesterol de $5 \mathrm{~mm}$ o menos, con vesícula funcionante; lográndose la disolución de los cálculos en el $50 \%$ de los pacientes y con una tasa de recurrencia a los 5 años del 30 al 50\%

Por estos motivos, en la actualidad no tiene indicación, reservando esta posibilidad para pacientes con contraindicaciones para la cirugía o para la prevención, por ejemplo en pacientes obesos que perderán peso. 
El tratamiento con litotricia extracorpórea actualmente no tiene indicación dado que es poco eficaz, costoso y puede determinar complicaciones como colangitis, pancreatitis y colecistitis por migración de fragmentos litiásicos ${ }^{60}$.

El tratamiento médico en base a la utilización de analgésicos antiespasmódico se realiza frente a los cuadros de dolor biliar, con el criterio de aliviar los síntomas, hasta la realización del tratamiento quirúrgico definitivo.

Los antibióticos se indican frente a los cuadros de colecistitis, colangitis y con criterio profiláctico en las cirugías electivas. Generalmente se indica ampicilina sulbactan o cefalosporinas de segunda generación, dado que son eficaces contra los gérmenes más frecuentemente involucrados (gran negativos: $\mathrm{E}$ Coli).

\section{Tratamiento quirúrgico}

La cirugía temprana, realizada al inicio de comenzado los síntomas, disminuye la morbilidad, la frecuencia de conversión, el tiempo operatorio y de internación ${ }^{61}$.

En las formas clínicas de litiasis vesicular sintomática, el tratamiento quirúrgico está universalmente aceptado y está destinado a tratar los síntomas y evitar la aparición de complicaciones ${ }^{62}$.

En los pacientes asintomáticos se indica la cirugía con un criterio profiláctico, para evitar la aparición de síntomas o complicaciones.

La contraindicación de realizar la cirugía con un criterio profiláctico, se invoca la morbimortalidad de la colecistectomía, siendo la morbilidad de ésta del 5 al $20 \%$ y la mortalidad del $0.09 \%$, con un riesgo de lesión de la vía biliar del 0.2 al $1.9 \%{ }^{64}$.

Para muchos autores, la indicación de la colecistectomía en pacientes asintomáticos tiene un riesgo estadísticamente similar a adoptar una actitud expectante.

De acuerdo a la historia natural de la enfermedad, el riesgo de que el paciente se torne sintomático o tenga una complicación es bajo, si bien es frecuente observar que muchos pacientes debutan la sintomatología biliar, con la complicación (colecistitis aguda, colangitis o pancreatitis).

Con respecto a la posibilidad de desarrollar un cáncer de vesícula biliar, la incidencia de cáncer en pacientes con litiasis es de 1 en 10.000, comparado con 1 en 30.000 en pacientes sin litiasis ${ }^{65}$.

De acuerdo a estas observaciones, en la litiasis asintomática no hay pautas actuales que marquen la indicación absoluta de realizarse su tratamiento quirúrgico.

Con la incorporación de la cirugía laparoscópica, se disminuyó la morbilidad por el abordaje, lo que resultó como consecuencia un incremento en el número de colecistectomías.

La colecistectomía profiláctica estaría indicada en: pacientes obesos por la posibilidad de cirugía bariátrica y posible aparición de síntomas por la pérdida de peso ${ }^{66}$; en niños y pacientes jóvenes por la perspectiva de muchos años de vida con la aparición de síntomas y/o complicaciones ${ }^{67}$; en la vesícula en porcelana por tener un $7 \%$ de posibilidades de desarrollar un cáncer ${ }^{68,69}$, en pólipos vesiculares mayores de un centímetro o de rápido crecimiento ${ }^{70}$; en anemia de células falciformes ${ }^{71,72}$ y en pacientes en lista de espera para trasplante de órganos sólidos ${ }^{73,74}$.

Se debe tener en cuenta que no hay estudios randomizados que demuestren definitivamente los beneficios de la cirugía profiláctica en estos grupos de pacientes ${ }^{75}$. 


\section{Tratamiento de las formas complicadas}

El tratamiento de la colecistitis aguda es principalmente quirúrgico, existiendo la posibilidad de terapéuticas adicionales como son la descompresión percutánea (colecistostomía).

Se debe realizar un tratamiento médico preoperatorio en base a analgésicos, antiinflamatorios y antibióticos en base a cefalosporinas de segunda generación y metronidazol o amoxicilina más ácido clavulánico ${ }^{76}$.

En cuanto a la oportunidad del tratamiento quirúrgico, la cirugía temprana dentro de las primeras noventa y seis horas de la fase aguda es la mejor opción ${ }^{77}$.

Pasado este período, si la operación no se realizó sea por un retardo en la consulta o por dificultades diagnósticas, la operación puede ser diferida hasta que el proceso inflamatorio agudo haya cesado.

Los pacientes diabéticos o inmuno-comprometidos tienen mayor riesgo de presentar formas graves: perforadas, gangrenosas y enfisematosas y se indica la colecistectomía en forma temprana.

La colecistectomía laparoscópica ha sido aceptada por consenso como el procedimiento de elección para el tratamiento de la colecistitis aguda, si bien las dificultades de la cirugía, el porcentaje de conversión, las complicaciones y los riesgos de lesión de la vía biliar son mayores con respecto a la cirugía electiva ${ }^{78}$.

Si existe un gran complejo inflamatorio que impide la disección y el reconocimiento de las estructuras anatómicas del pedículo hepático, la realización de una colecistostomía, ya sea con resección parcial o no de la vesícula y la colocación de una sonda Pezzer es una opción válida.

La colecistostomía percutánea es indicada en situaciones especiales: la presencia de pacientes con un riesgo quirúrgico muy elevado por comorbilidades, en CA alitiásicas y en pacientes ancianos y en estado crítico sin respuesta al tratamiento médico conservador. Esta técnica tiene como ventaja la posibilidad de poder realizarse con anestesia local, pudiéndose asociar o no con la realización de una colecistectomía electiva ${ }^{79}$.

El tratamiento de la LVBP está destinado a extraer los cálculos de la vía biliar principal. Esto puede realizarse por vía endoscópica, percutánea, laparoscópica y por cirugía abierta.

Actualmente la tendencia de los principales centros de referencia es realizar el tratamiento por procedimientos mínimamente invasivos, ya sea por vía laparoscópica y endoscópica, sola o combinadas, como veremos más adelante.

En los pacientes con cuadros de colangitis aguda el tratamiento está destinado a realizar una adecuada antibioticoterapia y el drenaje biliar.

El $80 \%$ de los pacientes evolucionan favorablemente con el tratamiento médico y el drenaje biliar se plantea de forma electiva en las formas de colangitis simples, debiendo realizarse en forma urgente en pocas horas en las formas graves con sepsis. lidad ${ }^{80,81}$.

La terapéutica endoscópica es más segura que la cirugía por presentar una menor morbimorta-

La colecistectomía se puede realizar en segundo lugar en forma electiva y en forma ideal por abordaje laparoscópico.

Actualmente el tratamiento ideal de un paciente con una pancreatitis aguda biliar (PAB) es discutido y existen discrepancias.

Es importante destacar que el manejo del tratamiento médico y quirúrgico de estos pacientes depende de la severidad del cuadro. 
En las formas leves y moderadas se realiza el tratamiento médico inicial que consiste en reposo digestivo, adecuada hidratación y analgesia; difiriéndose el tratamiento quirúrgico los primeros días. Hay cierto consenso en aceptar la realización del tratamiento quirúrgico de la patología biliar, durante su internación, que consiste en la realización de la colecistectomía idealmente por laparoscopía con exploración radiológica de la VBP ${ }^{82,83,84}$.

En los pacientes que presentan una PA grave el tratamiento quirúrgico está contraindicado dada su elevada morbimortalidad, llegando incluso en algunas series a ser superior al $50 \%{ }^{85}$.

Se indica en algunos casos, como por ejemplo frente a la presencia de complicaciones locales tales como necrosis pancreática infectada, abscesos, pseudoquistes infectados y trombosis de vasos regionales.

El enfoque terapéutico se realiza con un equipo multidisciplinario con la realización de procedimientos quirúrgicos mínimamente invasivos percutáneos, endoscópicos, laparoscópicos o cirugía abierta.

La PA define en sus inicios su forma anatomoclínica y la secuencia evolutiva se da fundamentalmente en aquellos pacientes que no fueron tratados precozmente en forma correcta.

La litiasis responsable de los cuadros de PAB, se enclava por un corto período de tiempo y generalmente en la mayoría de los casos es expulsada al duodeno.

Oría y colaboradores publicaron un trabajo prospectivo y comparativo de una serie de 103 pacientes divididos en dos grupos, no demostrando una disminución de la morbilidad y mortalidad con la realización de una CER precoz ${ }^{86}$.

El tratamiento de los pacientes con fístulas biliares internas (FBI) es quirúrgico.

Los pacientes con síndrome de Mirizzi son los más complejos de resolver, dadas las alteraciones anatómicas que determinan en la vía biliar, siendo la incidencia de este síndrome del 0.1 al $0.7 \%{ }^{43,87}$.

Se debe tener especial precaución de no lesionar la VBP, para lo cual puede llegar a ser necesario en los casos que existe un pedículo congelado, con alteraciones inflamatorias que hagan muy difícil identificar con claridad la VBP, colecistostomías con extracción de los cálculos, dejando una sonda Petzer, o colecistectomías parciales tipo Pribran.

Es muy importante realizar una colangiografía intraoperatoria transcística o por punción, para definir la anatomía de la vía biliar y descartar la presencia de una litiasis coledociana, la cual deberá ser extraída.

Puede ser necesaria la realización de una biopsia extemporánea para descartar la presencia de una patología tumoral maligna.

El tratamiento de los síndrome de Mirizzi tipo II, va desde la colocación de un tubo de Kehr en la zona de la fístula con o sin rafia de la pared de la vía biliar, hasta los procedimientos de derivación biliar con la realización de una hepaticoyeyunoanastomosis latero-lateral o termino-lateral, de elección esta última para algunos autores ${ }^{88}$.

El tratamiento por laparoscopía puede ser realizado, si bien estos pacientes deben ser operados por cirujanos muy entrenados y con mucha experiencia en cirugía biliar laparoscópica y con una adecuada infraestructura. Las tasas de conversión son elevadas ${ }^{42,43}$, debiéndose siempre evaluar la necesidad de realizar una colecistostomía o colecistectomías parciales, ante el riesgo de lesionar la VBP.

Los pacientes que presentan una FBD con un síndrome de Bouveret pueden ser resueltos en circunstancias favorables con la extracción del cálculo por vía endoscópica.

En los pacientes con un cuadro de oclusión intestinal por un íleo biliar, con mal terreno o añosos y mal estado general, se debe resolver la oclusión mediante la realización por laparotomía y extracción 
del cálculo por una enterotomía transversal antemesentérica distal al sitio de la obstrucción, sobre tejido sano, dejando la resolución de la patología biliar para otra oportunidad de ser necesario.
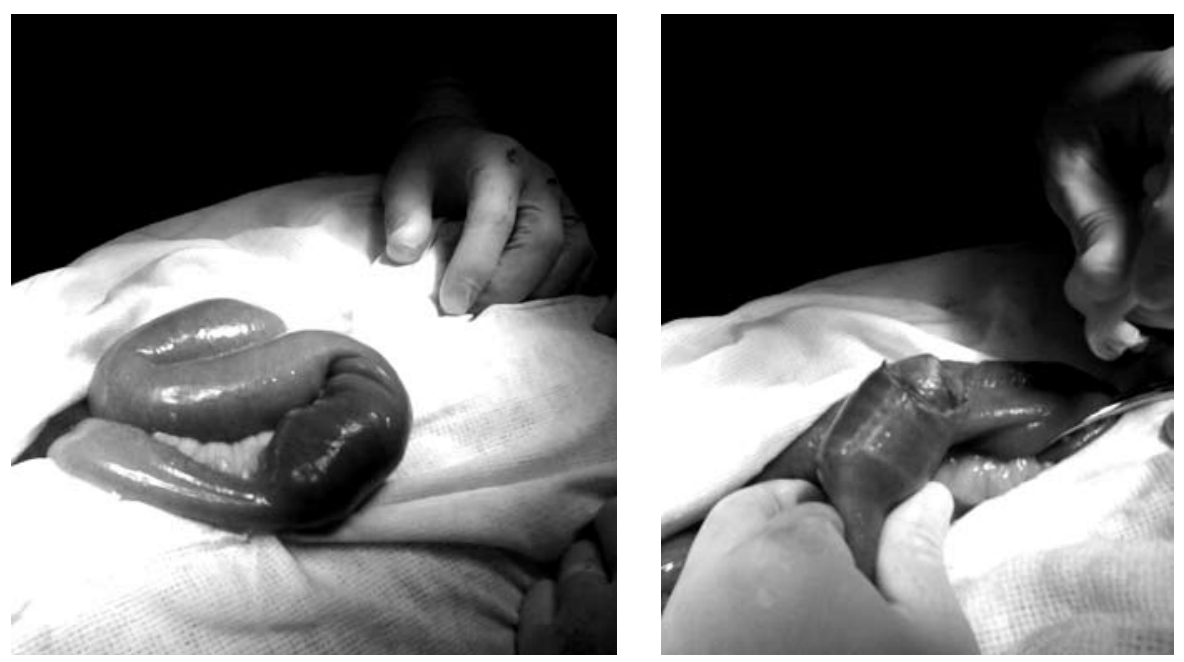

Foto 6. Íleo biliar.

Cuando las FBD no están complicadas, la tendencia mundial es resolver el polo biliar en el mismo acto operatorio, prestando especial atención a resolver la presencia de una litiasis de la VBP asociada.

Cuando se realiza el diagnóstico de ambas patologías en el preoperatorio, puede plantearse la extracción de la litiasis coledociana por vía endoscópica previo a la cirugía y realizar la colecistectomía y el cierre de la fístula por vía laparoscópica.

\section{Bibliografía}

1) Lambou-Gianoukos S, Heller SJ. Lithogenesis and bile metabolism. Surg Clin N Am 2008; 88: 1175-94.

2) Shaffer EA. Gallstone disease: epidemiologyof gallbladder Stone disease. Best Pract Res Clin Gastroenterol 2006; 20:981-96.

3) Sauerland S. Epidemiology of Biliary Lithiasis. En: Borzellino G, Cordiano C. Biliary Lithiasis. Basic science, Current diagnosis and management. Italia: Springer-Verlag; 2008, p. 16.

4) Galman C, Miquel JF, Perez RM et al. Bile acid synthesis is increased in Chilean Hispanics with gallstones and in gallstone high-risk Mapuche Indians. Gastroenterology 2004; 126:741-8.

5) Brasca AP, Pezzotto SM, Berli D, Villavicencio R, Fay O, Gianguzzo MP et al. Epidemiology of gallstone disease in Argentina: prevalences in the general population and European descendants. Dig Dis Sci. 2000; 45:2392-8.

6) Serra, CA, Martellotto G, Galli SB. Frecuencia de litiasis en 1500 autopsias. Rev. Argent Cir 1991; 61:85-8.

7) Chen $\mathrm{CH}$, Huang MH, Yang JC, Nien CK, Etheredge GD, Yang CC et al. Prevalence and risk factors of gallstone disease in an adult population of Taiwan: an epidemiological survery. J Gastroenterol Hepatol 2006; 21 : 1737-43.

8) Nomura H, Kashiwagi S, Hayashi J, Kajiyama W, Ikematsu H, Noguchi A et al. Prevalence of gallstone disease in a general population of Okinawa, Japan. Am J Epidemiol. 1988; 128: 598-605.

9) Biss K, Ho KJ, Mikkelson B, Lewis L, Taylor CB. Some unique biologic characteristics of the Masai of East Africa. N Engl J Med. 1971; 284:694-9. 
10) Thijs C, Knipschild P, Leffers P. Is gallstone disease caused by obesity or by dieting? Am j Epidemiol 1992; 135:274-80.

11) Shiffman ML, Sugerman HJ, Kellum JM, Brewer WH, Moore EW. Gallstone formation after rapid weight loss: a prospective study in patients undergoing gastric bypass surgery for treatment of morbid obesity. Am J Gastroenterol 1991; 86:1000-5.

12) Pitt HA, King W 3rd, Mann LL, Roslyn JJ, Berquist WE, Ament ME et al. Increased risk of cholelithiasis with prolonged total parenteral nutrition. Am J Surg 1983; 145: 106-12.

13) Roslyn JJ, Berquist WE, Pitt HA, Mann LL, Kangarloo H, DenBesten L et al. Increased risk of gallstones in children receiving total parenteral nutrition Pediatrics 1983;71:784-9.

14) Valdivieso V, Covarrubias C, Siegel F, Cruz F. Pregnancy and cholelithiasis: Pathogenesis and natural course of gallstones diagnosed in early puerperium. Hepatology 1993; 17: 1-4.

15) Barbara L, Sama C, Morselli Labate AM, Taroni F, Rusticali AG, Festi D et al. A population study on the prevalence of gallstone disease: The Sirmione Study. Hepatology 1987; 7: 913-7.

16) Whorwell PJ, Hawkins R, Dewbury K, Wright R. Ultrasound survery of gallstones and other hepatobiliary disorders in patients with Crohn's disease. Dig Dis Sci 1984; 29: 930-3.

17) Cetta F, Montalto G. Gallstone formation after open cardiac surgery. Am J Gastroenterol. 1997; 92: 1069-70

18) Cotta F. Classification, composition and structure of gallstones. Relevance of these parameters for clinical presentation and treatment. En Borzellino G, Cordiano C. Biliary Lithiasis. Basic science, Current diagnosis and management. Italia: Springer-Verlag; 2008: 51-62.

19) Kaufman HS, Magnuson TH, Lillemoe KD, Frasca P, Pitt HA. The role of bacteria of bacteria in gallbladder and common duct stone formation. Ann Surg 1989; 209: 584-91.

20) Gibney EJ. Asimptomatic gallstones. Br J Surg 1990; 77: 368-72.

21) Gracie WA, Ransohoff DF. The naturaly history of silent gallstones: the inocent gallstone is not a myth. N Engl J Med 1982; 307: 798-800.

22) Friedman GD, Raviola CA, Fireman B. Prognosis of gallstones with mild or no syntoms: 25 years of follow-up in a health maintenance organization. J Clin Epidemiol 1989; 42: 127-36.

23) Paumgartner G, Carr-Locke DL, Dubois F, Roda E, Thistle JL. Strategies in the treatment of gallstone disease. Working team report. Gastroenterology International 1993; 6: 65-75.

24) Conference europeenne de consensus, Strasbourg. La lithiase vesiculaire: strategie therapeutique. Ann Chir 1991; 46: 11-23.

25) Friedman GD. Natural of asymptomatic and symptomatic gallstone. Am J Surg 1993; 165: 399-404.

26) Lee VS, Chari RS, Cucchiaro G, Meyers WC. Complications of laparoscopic cholecystectimy (Review). Am J Surg 1993; 65: 527-32.

27) Petersen JM, Knight TT. Gunshot cholecystitis. J Clin Gastroenterol 1995; 21: 320-2.

28) Johannsen EC, Madoff LC. Infections of the liver and biliary system. En: Mandell GL, Benett JE, Dolin R, editors. Principles of practice of infectious diseases. $6^{\text {th }}$ ed. Philadelphia: Elseiver; 2005. p. 951-8.

29) Williams EJ, Green J, Beckingham I, Parks R, Martin D, Lombard M. Guidelines of the management of common bile duct stones. Gut 2008; 57: 1004-21.

30) Neuhaus H, Feussner H, Ungeheuer A, Hoffmann W, Siewert JR, Classen M. Prospective evaluation of the use of endoscopic retrograde cholangiography before laparoscopic cholecystectomy. Endoscopy. 1992; 24: 745-9.

31) McSherry CK, Ferstenberg H, Calhoun WF, Lahman E, Virshup M. The naturaly history of diagnosed gallstone disease in symptomatic and asymptomatic patients. Ann Surg.1985; 202: 59-63.

32) Charcot JM. Lecons sur les maladies du foi des voices biliares et veins faites à la Faculté de Médicine de Paris. Paris; 1877. 
33) Reynolds BM, Dargan EL. Acute obstructive colangitis; a distinct clinical sindrome. Ann Surg. 1959; 150: 299303.

34) Ferraina P, Oría A. Pancreatitis aguda. Cirugía de Michans. Argentina: El Ateneo; 2008. p. 651.

35) Wang GJ, Gao CF, Wei D, Wang C, Ding SQ. Acute pancreatitis: Etiology and common phatogenesis. World J Gastroenterol 2009; 15: 1427-30.

36) Opie EL. The etiology of acute hemorragic pancreatitis. Bull Johns Hopkins 1901; 12:182-8.

37) Acosta JM, Ledesma CL. Gallston migration as a cause of acute pancreatitis. N Engl J Med. 1974; 290:484-7.

38) Oría A, Frider B, Alvarez J, Chiappetta L, Souto N, Fontana JJ. Biliary and pancreatic obstruction during gallstone migration. Int J Pancreatol 1988; 3: 157-64.

39) Oría A, Alvarez J, Chiappetta L, Spina JC, Hernández N, Lovaldi M et al. Choledocholithiasis in acute gallstone pancreatitis. Incidence and clinical significance. Arch Surg. 1991; 126: 566-8.

40) Isaji S, Takada T, Kawarada Y, Hirata K, Mayumi T, Yoshida M et al. JPN Guidelines for the management of acute pancreatitis: surgical management. J Hepatobiliary Pancreat Surg. 2006; 13: 48-55.

41) Mirizzi PL. Sindrome du canal hepatique. J Int Chir. 1948;8:731-3.

42) Chiappeta Porras L, Canullán C, Nápoli E et al. Resultados en el tratamiento del Sindrome de Mirizzi por videolaparoscopía. Rev Argent Cirug. 2004; 87: 103-6.

43) Pekolj J, Quiñones E, Mazza O et al. Tratamiento laparoscópico de las fístulas biliodigestivas y el síndrome de Mirizzi tipo II. Rev Argent Cirug. 2006; 90: 142-51.

44) Mc Sherry CK, Ferstemberg H, Virshup M. The Mirizzi síndrome: sugested classification and surgical therapy. Surg Gastroenterol 1982; 1: 219-25.

45) Csendes A, Díaz JC, Burdiles P, Maluenda F, Nava O. Mirizzi síndrome and cholecystobiliary fístula: a unifiying classification. Br J Surg. 1989; 76: 1139-43.

46) Knol JA, Eckhauser FE. Fístulas biliares. Shackelford. Cirugía del Aparato digestivo. Zuidema-Yeo. 5a ed. Buenos Aires: Panamericana; 2005. p. 330-7.

47) Bortoff GA, Chen MY, Ott DJ, Wolfman NT, Routh WD. Gallbladder stones: imaging and intervention. Radiographics 2000; 20: 751-66.

48) Kondo S, Isayama H, Akahane M, Toda N, Sasahira N, Nakai Y et al.Detection of common bile duct stones: comparision between endoscopic ultrasonography, magnetic resonance cholangiography and helical-computed-tomographic cholangiography. Eur J Radiol. 2005; 54: 271-5.

49) Nathens AB, Curtis JR, Beale RJ, Cook DJ, Moreno RP, Romand JA, et al. Management of the critically ill patient with severe acute pancreatitis. Crit Care Med. 2004; 32: 2524-36.

50) Sugiyama M, Atomi Y. Endoscopic ultrasonography for diagnosing choledocholithiasis: a prospective comparative study with ultrasonography and computed tomography. Gastrointest Endosc. 1997; 45: 143-6.

51) Holzknecht N, Gauger J, Sackmann M, Thoeni RF, Schurig J, Holl J et al. Breath-hold MR cholangiography with snapshot techniques: prospective comparision with endoscopic retrograde cholangiography. Radiology. 1998; 206: 657-64.

52) Dahan P, Andant C, Lévy P, Amouyal P, Amouyal G, Dumont M et al. Prospective evaluation of endoscopic ultrasonography and microscopic examination of duodenal bile in the diagnosis of cholecystolithiasis in 45 patients with normal conventional ultrasonography. Gut. 1996; 38: 277-81.

53) Lévy $P$, Boruchowicz $A$, Hastier $P$, Pariente $A$, Thévenot T, Frossard JL et al. Diagnostic criteria in predicting a biliary origin of acute pancreatitis in the era of endoscopic ultrasound: multicentre prospective evaluation of 213 patients. Pancreatology. 2005; 5: 450-6.

54) Amouyal P, Amouyal G, Lévy P, Tuzet S, Palazzo L, Vilgrain V et al. Diagnosis of choledocholithiasis by endoscopic ultrasonography. Gastroenterology. 1994; 106: 1062-7. 
55) Sugiyama M, Atomi Y. Endoscopic ultrasonography for diagnosisng choledocholithiasis: a prospective comparative study with ultrasonography and computed tomography. Gastroentest Endosc. 1997; 45: 143-6.

56) Kohut M, Nowakowska-Duława E, Marek T, Kaczor R, Nowak A. Accuracy of linear endoscopic ultrasonography in the evaluation of patients with suspect ed common bile duct stones. Endoscopy. 2002; 34: 299-303.

57) Palazzo L. Ecoendoscopía biliar. En: Varas Lorenzo MJ. Ultrasonografía Endoscópica. Argentina: Panamericana; 2008. p. 171-204

58) Yang MH, Chen TH, Wang SE, Tsai YF, Su CH, Wu CW, et al. Biochemical predictors for abscence of common bile duct stones in patients undergoing laparoscopic cholecystectomy. Sug Endosc 2008; 22: 1620-4.

59) Portincasa P, Moschetta A, Puglisi F. Medical treatment of gallstone disease. En Borzellino G, Cordiano C. Biliary Lithiasis. Basic science, Current diagnosis and management. Italia: Springer-Verl; 2008. p. 152-4.

60) Carrilho-Ribeiro L, Carneiro de Moura M. Extracorporeal Shock Wave Treatment of Gallbladder Stones. En Borzellino G, Cordiano C. Biliary Lithiasis. Basic science, Current diagnosis and management. Ed. Springer-Verlag Italia. 2008: 480-5.

61) Gurusamy KS, Samraj K, Fusai G et al. Early versus delayed laparoscopic cholecystectomy for biliary colic. Cochrane Databases Syst Rev. 2008; 8: CD007196.

62) McSherry CK, Ferstenberg H, Calhoun WF, Lahman E, Virshup M. The natural history of diagnosed gallstonedisease in symptomatic and asymtomatic patients. Ann Surg. 1985; 202: 59-63

63) Keus F, de Jong JAF, Gooszen HG et al. Laparoscopic versus open cholecystectomy, laparoscopic versus small incisión cholecystectomy, small incisión versus open cholecystectomy for patients with symptomatic cholecystolithiasis. 2006. Cochrane Database of Systematic Review. Issue 4.Art №.:CD006231. DOI: 10.1002/14651858. CD006231.; CD006229. DOI: 10.1002/14651858. CD006229; CD004788. DOI: 10.1002/14651858. CD00478814.

64) Nuzzo G, Giuliante F, Giovannini I, Ardito F, D’Acapito F, Vellone M et al. Bile duct injury during laparoscopic cholecystectomy: results of an Italian national survery on 56.591cholecystectomy. Arch Surg 2005; 140 : 986-92.

65) Lowenfels AB, Lindström CG, Conway MJ, Hastings PR. Gallstones and risk of gallbladder cáncer. J Natl Cancer Inst 1985; 75: 77-80.

66) Ransohohoff DF, Gracie WA. Treatment of gallstones. Ann Intern Med 1993; 119: 606-19.

67) Pokorny WJ, Saleem M, O'Gorman RB, McGill CW, Harberg FJ. Cholelithiasis and cholecystitis in childhood. Am J Surg 1984; 148: 742-4.

68) Ashur H, Siegal B, Oland Y, Adam YG. Calcified gallbladder (porcelain gallbladder). Arch Surg 1978; 113: 594-6.

69) Stephen AE, Berger DL. Carcinoma in the porcelain gallbladder: a relationship revosoted. Surgery 2001; 129 : 699-703.

70) Escalona A, León F, Bellolio F, Pimentel F, Guajardo M, Gennero R et al. Pólipos vesiculares: correlación entre hallazgos ecográficos e histopatológicos. Rev. Méd Chile, 2006; 134: 1237-42.

71) Bonatsos G, Birbas K, Toutouzas K, Durakis N. Laparoscopic cholecystectomy in adults with sickle cell disease. Surg Endosc 2001; 15: 816-9.

72) Ware RE, Kinney TR, Casey JR, Pappas TN, Meyers WC. Laparoscopic cholecystectomy in youg patients with sickle hemoglobinopathies. J Pediatr 1992; 120: 58-61.

73) Kao LS, Kuhr CS, Flum DR. Should Cholecystectomy be performed for asyntomatic cholelithiasis in trasplant patients? J A Coll Surg 2003;197:302-12.

74) Graham SM, Flowers JL, Schweitzer E, Bartlett ST, Imbembo AL. The utility of prophylactic laparoscopic cholecystectomy in the transplant candidates. Am J Surg 1995; 169: 44-8.

75) Gurusamy KS, Samraj K.Cholecystectomy for patients with silent gallstones. Cochrane Database of Systematic Review 2007, Issue 1. Art. №.:CD006230. DOI: 10.1002/14651858.CD006230.pub2. 
76) Gutierrez I, Sanjuán V, Rebolledo, Barba C. Protocolo de manejo del paciente con colecistitis aguda. En: Gutiérrez I. Medicina de Urgencias. Principales problemas clínicos y su tratamiento basado en la evidencia. México: Panamericana; 2007. p.323-48.

77) Johansson M, Thune A, Blomqvist A, Nelvin L, Lundell L. Management of acute cholecystitis in the laparoscopic era: results of a prospective, randomized clinical trial. J Gastrointest. Surg 2003; 7: 642-5.

78) Yamashita Y, Takada T, Kawarada Y, Nimura Y, Hirota M, Miura F et al. Surgical treatment of patients with acute cholecystitis: Tokyo Guidelines. J Hepatobiliary Pancreat Surg 2007; 14: 91-7.

79) Macrì A, Scuderi G, Saladino E, Trimarchi G, Terranova M, Versaci A et al. Acute gallstone cholecystitis in the elderly: treatment with emergency ultrasonographic percutaneous cholecystectomy and interval laparoscopic cholecystectomy. Surg Endosc 2006; 20: 88-91.

80) Lai EC, Mok FP, Tan ES, Lo CM, Fan ST, You KT et al. Endoscopic biliary drainage for severe acute colangitis. N Engl J Med 1992; 326: 1582-6.

81) Adler DG, Baron TH, Davila RE, Egan J, Hirota WK, Leighton JA et al. ASGE guideline: the role of ERCP in diseases of the biliary tract and the pancreas. Gastrointest Endosc 2005; 62: 1-8.

82) Kimura Y, Takada T, Kawarada Y, Hirata K, Mayumi T, Yoshida M et al. JPN guidelines for the management of acute pancreatitis: treatment of gallstones-induced acute pancreatitis. J Hepatobiliary Pancreat Surg 2006; 13: 56-60.

83) Wilson CT, de Moya MA. Cholecistecomy for acute gallstone pancreatitis: early versus delayed approach. Scand J Surg 2010; 99: 81-5.

84) Heinrich S, Schäfer M, Rousson V, Clavien PA. Evidence-based treatment of acute pancreatitis: A look established paradigms. Ann Surg 2006; 243: 154-68.

85) Isaji S, Takada T, Kawarada Y, Hirata K, Mayumi T, Yoshida M et al. JPN guidelines for the management of acute pancreatitis: surgical management. J Hepatobiliary Pancreat Surg 2006; 13: 48-55.

86) Oría A, Cimmino D, Ocampo C, Silva W, Kohan G, Zandalazini H et al. Early endoscopic intervention versus early conservative management in patients with acute gallstone pancreatitis and biliopancreatic obstruction: $a$ randomized clinical trial. Ann Surg 2007; 245: 10-7.

87) Kok KY, Goh PY, Ngoi SS. Management of Mirizzi's síndrome in the laparoscopic era. Surg Endosc. 1998; 12:1242-4.

88) Gramática L (h), Moreno W, Palas Zúñiga C. Litiasis biliar complicada. En: Gramática L. ABC de la cirugía biliar. Ed: Ediciones Médicas del Sur. 2011; 3: 144-47. 


\title{
Capítulo 3
}

\section{CIRUGÍA LAPAROSCÓPICA DE LA VÍA BILIAR ACCESORIA. COLECISTECTOMÍA LAPAROSCÓPICA}

\author{
Dr. Andrés Salom
}

La colecistectomía laparoscópica implicó un cambio conceptual en la forma que se venía realizando la cirugía, dando lugar al desarrollo de la cirugía laparoscópica y los procedimientos mínimamente invasivos.

La visión directa que el cirujano tiene en la cirugía abierta, es remplazada por una imagen bidimensional y ampliada; la disección y las maniobras quirúrgicas son realizadas por instrumentos largos accionados desde afuera del abdomen con movimientos en espejo y se pierde el tacto directo, siendo remplazado por una nueva percepción táctil recibida a través de los instrumentos.

El principal beneficio para los pacientes es minimizar la agresión parietal al reemplazarse las incisiones amplias por pequeños abordajes, generalmente iguales o menores de un centímetro, producido por los trócares que labran trayectos a través de las paredes del abdomen, disociando los diferentes planos musculoaponeuróticos. Esto determina un menor daño tisular parietal y por consiguiente menos dolor postoperatorio, menor liberación de sustancias proinflamatorias, una recuperación física y laboral más rápida, así como una ventaja estética.

Estas razones han hecho que desde el año 1992, la colecistectomía laparoscópica sea considerada el "gold estándar" en el tratamiento de la litiasis vesicular 1,2.

Esto trajo aparejado que los cirujanos debieran adquirir un nuevo aprendizaje y entrenarse en forma diferente. Se tiene una mayor dependencia del correcto funcionamiento de los equipos y el material de laparoscopía, se introduce el neumoperitoneo que de por sí tiene sus complicaciones propias, se agrega la posibilidad de nuevas complicaciones por la utilización de los trócares, se requiere siempre de anestesia general para realizar las cirugías, surgen mayor número y lesiones más graves de la vía biliar con incremento de la morbilidad y aumento de la duración de las intervenciones, seguramente vinculado a la curva de aprendizaje. 


\section{Historia}

Paso más de un siglo antes de que cambiara en forma radical la manera de efectuar la colecistectomía, que realizó por primera vez en el año 1882 en el Hospital de Sán Lázaro en la ciudad de Berlín, Langenbuch ${ }^{3}$, y que por más de cien años fuera la operación tradicional para realizar el tratamiento de la litiasis vesicular.

También en Alemania, en la ciudad de Böblingen, fue un cirujano alemán, Erich Mühe, quien realiza la primera colecistectomía laparoscópica el 12 de septiembre de $1985^{4}$. El Dr. Mühe, cirujano general, graduado en la Universidad de Tubingen estaba familiarizado con los trabajos de un distinguido ginecólogo e ingeniero alemán, pionero en procedimientos laparoscópicos, el Dr. Kurt Semm, que hacía varios años urgía a los cirujanos para que adoptaran las técnicas laparoscópicas 5 . La operación se la practicó a una paciente de 41 años, portadora de una litiasis vesicular sintomática, utilizando un instrumento al que llamó Galloscope, por medio de una incisión umbilical y dos trócares adicionales suprapúbicos, duró cerca de dos horas y la paciente evolucionó bien. Entre ese momento y marzo de 1987, operó 94 pacientes con buenos resultados ${ }^{6}$.

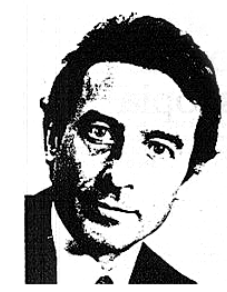

Figura 1. Dr. Mühe.

En Argentina, en la ciudad de Rosario, el Dr. Aldo Kleiman, mientras cursaba su último año de residente de cirugía general presenta su tesis para graduarse de cirujano, "Colecistectomía por laparoscopía. Modelo experimental en ovejas ", en octubre de 1985 en la Universidad de la Plata y en noviembre de 1986 presentó su trabajo: "Colecistectomía laparoscópica en ovejas", en el foro del Congreso Argentino de Cirugía ${ }^{7}$.

En Francia, en la ciudad de Lyon, en marzo de 1997, el Dr. Phillipe Mouret efectúa la primera colecistectomía laparoscópica; a quien erróneamente se le otorga el crédito de ser el autor en realizar esta cirugía por primera vez en el mundo.

El Dr. Francois Dubois, prestigioso cirujano francés que trabajaba en el Centre Medico-Chirurgical de la Porte de Choissy en París, acude a ver a Mouret para ver como realizaba la cirugía y realiza en abril de 1988 la primera colecistectomía laparoscópicå.
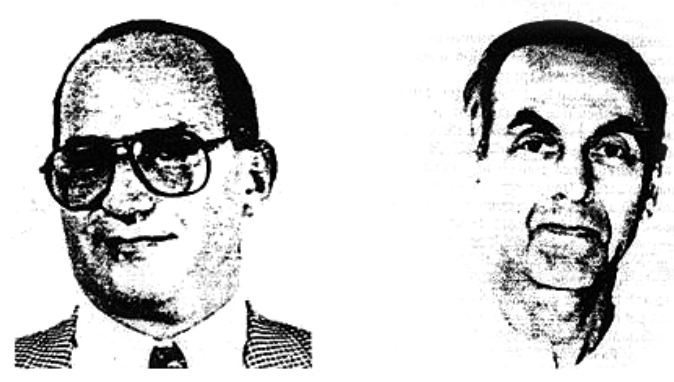

Figura 2. Dres Mouret y Doubois. 
Casi simultáneamente, otro cirujano francés, el Dr. Jacques Perissat, de Burdeos, efectúa la colecistectomía laparoscópica en el sur de Francia.

En Estados Unidos trabajaban sin conocer los proyectos de otros, los doctores William Saye y Mc Kernan en Georgia, y Reddick y Olsen en Tennessee, y efectuaron los primeros casos de colecistectomías laparoscópica en agosto y septiembre de 1988. Publican el primer trabajo de colecistectomía por laparoscopía en $1989^{9}$.

A partir de octubre de 1989 se produce la difusión masiva de esta técnica revolucionaria en cirugía de la vesícula, cuando se presentan dos videos de esta operación en el Congreso Anual del American College of Surgeons en Atlanta, Giorgia, y miles de cirujanos de todo el mundo pudieron ver el nacimiento de esta nueva técnica.

En América Latina los primeros cirujanos en realizar esta técnica fueron los Dres. Gutiérrez ${ }^{10}$ de México y Ayala y Souchón ${ }^{11}$ de Venezuela, en junio de 1990.

El primer curso formal de cirugía laparoscópica de la vesícula biliar para cirujanos generales en América Latina se realizá en el Hospital ABC de la ciudad de México en agosto de 1990, siendo el Dr. Jacobs, cirujano de origen cubano residente en Miami, profesor del curso.

De esta manera se inició la era de la cirugía laparoscópica de la vía biliar en Europa y América, revolucionando en un corto tiempo la práctica de la cirugía general en todo el mundo ${ }^{12}$.

En Uruguay las primeras colecistectomías laparoscópicas fueron realizadas a fines del año 1990, por el equipo de los Dres. Jorge Bermudez y Gustavo Veirano en el Hospital Británico.

En el año 1991, comenzaron a realizar esta técnica los equipos integrados por los Dres. Raúl Morelli y Luis Praderi Gambardella del Hospital Británico; Luis Praderi, Vartan Tchekmedyian, Héctor Geninazzi, Óscar Balboa, Ricardo Voelker, Pablo Matteucci y Luis Praderi Gambardella, en el Sanatorio Italiano; los Dres. José Pedro Perrier, Alberto Piñeyro y Miguel Fernández en el Hospital Central de las FF.AA y el equipo de los Dres. Fernando Delgado, Mario Hermida, Andrés Colet y colaboradores, en el Sanatorio Médica Uruguaya.

En el interior del país, los primeros cirujanos en realizar esta técnica, fueron los Dres. Conrado Bonilla en la ciudad de Maldonado y el Dr. Hugo Maglione en la ciudad de Carmelo.

También a partir del año 1991 se incorpora la enseñanza de la cirugía laparoscópica en los Servicios de la Facultad de Medicina: Clínicas Quirúrgicas A, B y F del Hospital de Clínicas, a cargo de los Profesores, Francisco Crestanello, Uruguay Larre Borges y Nisso Gateño; y posteriormente en la Clínica Quirúrgica 1 del Hospital Pasteur a cargo del Profesor Gonzalo Estapé, en la que tengo la oportunidad de comenzar a realizar mi aprendizaje en esta técnica.

\section{Indicaciones}

Las indicaciones para efectuar una colecistectomía laparoscópica son prácticamente las mismas que se aplican para indicar el procedimiento por cirugía abierta.

En las formas clínicas de litiasis vesicular sintomática, si bien las complicaciones son poco frecuentes, el tratamiento quirúrgico está universalmente aceptado, estando destinado a tratar los síntomas y evitar la aparición de complicaciones ${ }^{13}$.

La cirugía temprana, disminuye la morbilidad durante el período de tiempo preoperatorio para la operación de coordinación, la frecuencia de conversión y el tiempo operatorio y de internación ${ }^{14}$.

En los pacientes con litiasis vesicular asintomática se indica la cirugía con un criterio profiláctico, para evitar la aparición de síntomas y/o complicaciones. 
De acuerdo a la historia natural de la enfermedad, el riesgo de que el paciente se torne sintomático o tenga una complicación es bajo y la indicación de la colecistectomía tiene un riesgo estadísticamente similar para muchos autores, a adoptar una actitud expectante.

Se estima que aproximadamente el $10 \%$ de los pacientes asintomáticos tendrán síntomas en cinco años y el $20 \%$ a los veinte años ${ }^{15}$, presentándose las complicaciones generalmente en el grupo sintomático.

Con respecto a la posibilidad de desarrollar un cáncer de vesícula biliar, la incidencia de cáncer en pacientes con litiasis es de 1 en 10.000, comparado con 1 en 30.000 en pacientes sin litiasis ${ }^{16}$.

En la contraindicación para realizar la cirugía con un criterio profiláctico se invoca la morbimortalidad de la colecistectomía, siendo la morbilidad del 5 al $20 \%$ y la mortalidad del $0.09 \%$, con un riesgo de lesión de la vía biliar del 0.2 al $1.9 \%^{17}$.

Basados en estas observaciones, en la litiasis asintomática no hay pautas actuales que nos permitan dar como absoluta e indiscutible, la indicación de realizar su tratamiento quirúrgico.

La colecistectomía profiláctica estaría indicada en:

- pacientes obesos por la posibilidad de cirugía bariátrica y posible aparición de síntomas por la pérdida de peso ${ }^{18,19}$.

- en niños y pacientes jóvenes por la perspectiva de muchos años de vida con la aparición de síntomas y complicaciones ${ }^{20}$.

- en la vesícula en porcelana por tener un 7\% de posibilidades de desarrollar un cáncer ${ }^{21,22}$.

- en pólipos vesiculares mayores de un centímetro o de rápido crecimiento ${ }^{23}$.

- en anemia de células falciformes ${ }^{24,25}$.

- en pacientes en lista de espera para trasplante de órganos sólidos ${ }^{26,27}$.

Se debe tener en cuenta que no hay estudios randomizados que demuestren definitivamente los beneficios de la cirugía profiláctica en estos grupos de pacientes ${ }^{28}$.

El traumatismo quirúrgico en la colecistectomía laparoscópica es menor que en la abierta debido no sólo al abordaje, sino también a una disminución de las respuestas metabólicas e inflamatorias sistémicas. Esto sería un argumento a favor para indicar la colecistectomía profiláctica en pacientes con litiasis vesiculares asintomáticos para algunos autores, al reducirse la posibilidad de incidencia de complicaciones como son las colecistitis, litiasis coledocianas, colangitis y pancreatitis aguda ${ }^{29,30}$.

\section{Indicaciones de colecistectomía laparoscópica en la litiasis vesicular complicada}

El tratamiento de la colecistitis aguda es quirúrgico, existiendo la posibilidad de terapéuticas adicionales como son la decompresión percutánea (colecistostomía).

La colecistectomía laparoscópica ha sido aceptada por consenso como el procedimiento de elección para el tratamiento de la colecistitis aguda, si bien las dificultades de la cirugía, el porcentaje de conversión, las complicaciones y los riesgos de lesión de la vía biliar son mayores con respecto a la cirugía electiva ${ }^{31}$.

El tratamiento de la LVBP está destinado a extraer los cálculos de la vía biliar principal y realizar la colecistectomía. Esto puede realizarse por vía endoscópica, percutánea, laparoscópica y por cirugía abierta. 
Actualmente la tendencia de los principales centros de referencia es realizar el tratamiento por procedimientos mínimamente invasivos, ya sea por vía laparoscópica y endoscópica, sola o combinadas, como se verá más adelante.

En los pacientes con cuadros de colangitis aguda el tratamiento consiste en realizar una adecuada antibioticoterapia y el drenaje biliar.

El 80\% de los pacientes evolucionan favorablemente con el tratamiento médico, y el drenaje biliar se plantea por vía endoscópica; de forma electiva en las colangitis simples y urgente en pocas horas en las formas graves con sepsis.

La colecistectomía se puede realizar en segundo lugar en forma electiva y en forma ideal por abordaje laparoscópico.

En las formas leves y moderadas de pancreatitis aguda de etiología biliar, se realiza el tratamiento médico inicial que consiste en reposo digestivo, adecuada hidratación y analgesia; postergando el tratamiento quirúrgico los primeros días. Hay cierto consenso en aceptar la realización del tratamiento quirúrgico de la patología biliar, durante la internación, que consiste en la realización de la colecistectomía idealmente por laparoscopía con exploración radiológica de la VBP32,33,34. relativas.

Las contraindicaciones para realizar una colecistectomía laparoscópica pueden ser absolutas o

Las contraindicaciones absolutas son:

1) Alteraciones de la coagulación. Cuando existen estos trastornos, se contraindican tanto la cirugía laparoscópica como abierta. Cuando se corrigen estas alteraciones se puede realizar la cirugía laparoscópica, existiendo mayor porcentaje de conversión.

2) Intolerancia al neumoperitoneo. Como consecuencia de una insuficiencia cardíaca o respiratoria muy importante o inestabilidad hemodinámica.

Las contraindicaciones relativas están en relación directa con la experiencia del grupo quirúrgico y son cada día menos en la medida que se tiene más experiencia en la realización de esta técnica. Son:

1) Síndrome de Mirizzi y fístulas colecistoentéricas. Es muchas veces más seguro operar estos pacientes por cirugía abierta, si bien existen casos e informes que reportan su tratamiento por cirugía laparoscópica. Existe un mayor riesgo de lesionar la VBP, y el porcentaje de conversión es más elevado.

2) Cirugías previas del abdomen superior. Pueden condicionar la presencia de adherencias que dificulten el abordaje por laparoscopía. En muchas ocasiones es posible realizar la adhesiolisis y luego la colecistectomía laparoscópica. En casi todos los casos es posible comenzar por laparoscopía y convertir a cirugía abierta en la medida que sea necesario.

3) Cirrosis hepática. En estos pacientes la presencia de un hígado fibroso, inmóvil, friable y la circulación venosa por hipertensión portal hacen más dificultosa la cirugía.

4) Pancreatitis aguda. Los pacientes que presentaron un cuadro de pancreatitis aguda biliar pueden presentar elementos inflamatorios que dificulten la colecistectomía.

5) Colangitis aguda. En estos pacientes se puede realizar la extracción de los cálculos por vía endoscópica, para luego realizar la colecistectomía laparoscópica. Cuando no es posible efectuarse el tratamiento por vía endoscópica y/o no se cuenta con el instrumental ni con la experiencia en el tratamiento por laparoscopía de la litiasis coledociana, está indicada la vía abierta. 
6) Hernias o eventraciones grandes. Pueden crear dificultades por la insuflación de los sacos herniarios. Cuando el defecto parietal es muy importante y es necesaria la apertura de la cavidad abdominal puede ser más fácil realizar la colecistectomía por vía abierta.

\section{Consideraciones anátomo-quirúrgicas}

El preciso conocimiento de la anatomía de las vías biliares extrahepáticas y sus variaciones más frecuentes, es de fundamental importancia para realizar el adecuado abordaje, disección, identificación y maniobras quirúrgicas, para evitar lesiones y complicaciones.

Las variaciones anatómicas de los ductos biliares y arteriales son tan grandes que necesariamente la cirugía de las vías biliares debe realizarse con un elevado grado de cautela y minuciosidad en el reconocimiento de los diferentes elementos anatómicos, siendo la única regla la que indica: "no hay reglas".

El segmento extrahepático del conducto hepático derecho es corto, pero el izquierdo tiene un trayecto más largo y horizontal fuera del hígado ${ }^{35}$. De la confluencia de estos conductos se forma el conducto hepático común, que recibe al conducto cístico para formar el colédoco, que describiendo una curva de concavidad derecha transcurre por el páncreas y desemboca en el duodeno a través de la papila de Vater, rodeada del esfínter de Oddi. Estos conductos presentan numerosas variaciones como son: atresias, dilataciones congénitas, variaciones anatómicas con conductos aberrantes y accesorios de escasa frecuencia ${ }^{36}$.

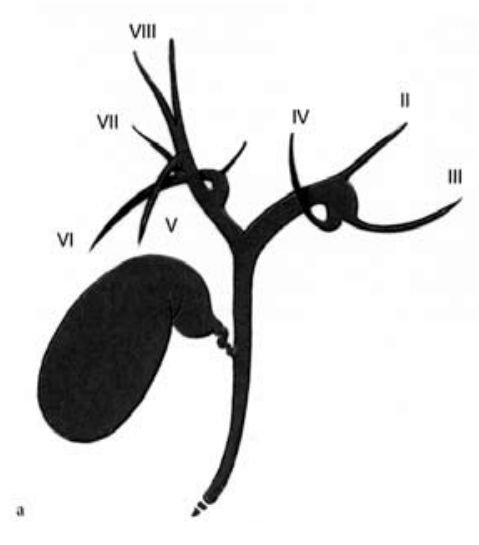

Figura 3. Anatomía de la vía biliar.

En el $25 \%$ de los casos se agrega a la unión de los conductos hepáticos derecho e izquierdo, un tercer conducto casi siempre procedente de segmentos posteriores ${ }^{37}$.

Debe destacarse la existencia de conductos accesorios o segmentarios que drenan un sector normal del hígado, pero que se unen al sistema biliar por fuera del parénquima hepático y que transcurren por lo general en el triángulo de Calot, pudiendo ser motivo de bilirragias y que en ausencia de un drenaje subhepático pueden producir como complicación un biloma o una peritonitis biliar localizada o generalizada.

La unión del conducto cístico con el hepático es variable en su disposición y localización. Puede formar un ángulo de 90 o o lo que es más frecuente adosarse paralelamente a la vía biliar principal, terminando en la mayoría de los casos en su vertiente externa, pero pudiéndolo hacer también sobre su lado interno, en la cara anterior o posterior. 

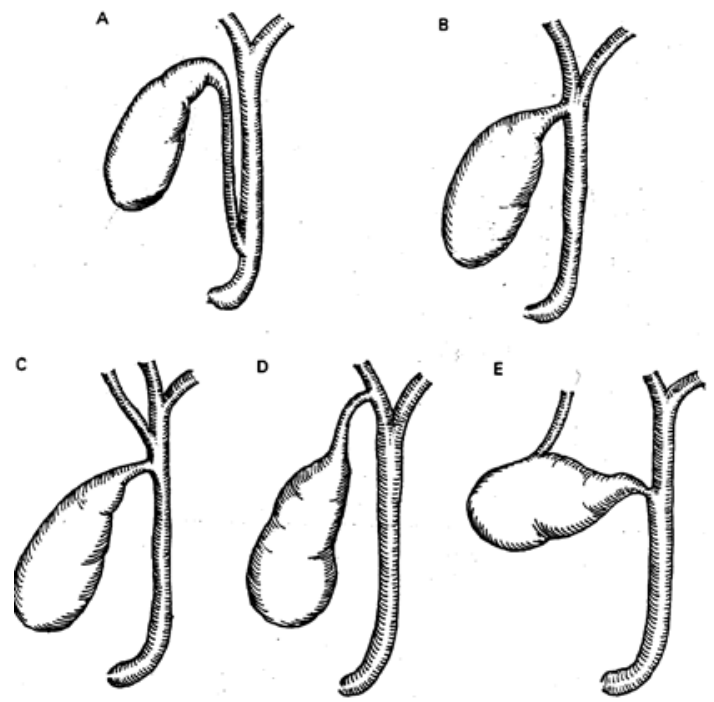

Figura 4. Variaciones anatómicas del conducto cístico.

La convergencia puede realizarse en forma alta en alrededor de la mitad de los casos, o puede ser baja, a nivel de la cara posterior de la primera porción del duodeno y de la cabeza del páncreas, por lo que la vía biliar en estos casos esta constituída por el hepático común.
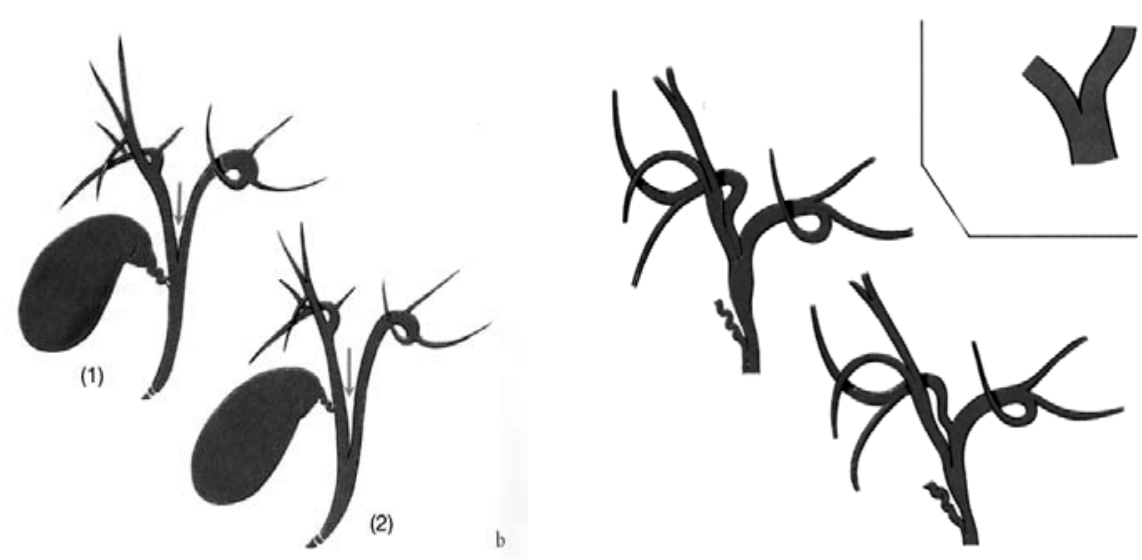

Figura 5. Variaciones anatómicas de la convergencia.

La vesícula biliar puede ser asiento de variaciones morfológicas hasta en el 33\% de los casos como ser: ausencia, bilobulada; y variaciones topográficas hasta en el 3.5\%, como ser: ubicada a la izquierda, intrahepática, móvil y duplicaciones ${ }^{38}$.

Resulta poco frecuente encontrar un patrón anatómico vascular constante. 


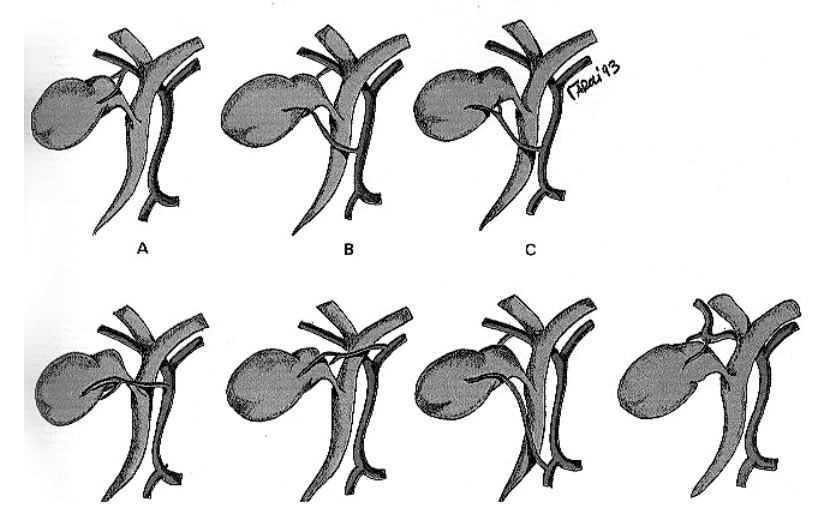

Figura 6. Variaciones anatómicas vasculares de la arteria hepática y cística.

(Tomado de Cirugía laparoscópica de Meinero, Melotti, Mouret).

La arteria hepatica común proviene en el $86 \%$ de los casos del tronco celíaco ${ }^{39}$, y con menos frecuencia de la arteria mesentérica superior, aorta o gástrica izquierda, observándose la disposición clásica en el $25 \%$ de los casos $^{37}$.

La arteria hepática derecha en un $13 \%$ de los casos se origina de la mesentérica superior y asciende en busca del hilio hepático generalmente por fuera de la VBP. El desconocimiento de esta variante puede condicionar la realización de una lesión vascular.

La rama derecha de la arteria hepática puede ser motivo de accidentes quirúrgicos en el curso de la colecistectomía al ponerse en contacto con la región infundíbulocística.

La arteria cística tiene un origen variado, y en el $72 \%$ de los casos la arteria cística se origina de la arteria hepática dentro del triángulo de Calot. En el resto de los casos puede originarse en la arteria mesentérica superior, gastroduodenal, o pancreatoduodenal postero-superior, y tener un recorrido por fuera del triángulo de Calot.

\section{Técnica quirúrgica}

\section{Colecistectomía Laparoscópica}

Generalmente se realizan dos técnicas: americana y francesa.

En la técnica francesa el cirujano se ubica entre las piernas del paciente. El primer ayudante que lleva la cámara se coloca a la derecha del paciente y el segundo a la izquierda. Este último debe exponer el pedículo hepático levantando con una pinza o un separador, el lóbulo izquierdo del hígado. El cirujano con su mano izquierda maneja el bacinete vesicular, para exponer el pedículo cístico y con su mano derecha maneja la tijera o el hook, para la disección del pedículo y realizar la colecistectomía. Se utilizan 4 trócares que se emplazan en forma romboidal; el primero de $10 \mathrm{~mm}$ para la introducción de la óptica, a nivel umbilical; el segundo de $10 \mathrm{~mm}$ a niel del hipocondrio izquierdo para la introducción de instrumentos que maneja el cirujano con su mano derecha; el tercer puerto de $5 \mathrm{~mm}$ a nivel del HD para la introducción de instrumentos que maneja el cirujano con su mano izquierda y un cuarto puerto de $5 \mathrm{~mm}$ para la introducción de un separador, una pinza o el aspirador que maneja el segundo ayudante. 


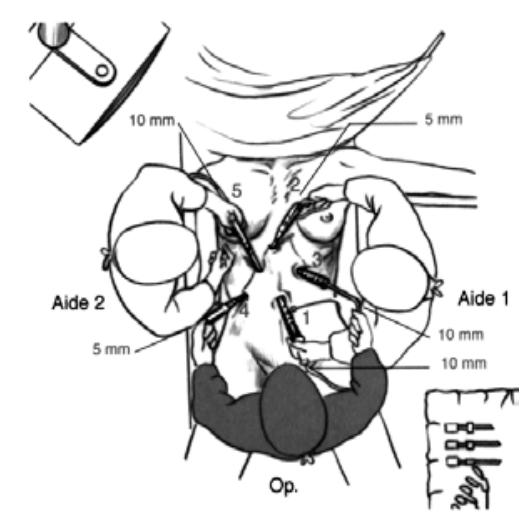

Figura 7. Técnica Francesa.

En la técnica americana el paciente se coloca en decúbito dorsal con los miembros inferiores juntos, ubicándose el monitor entre la cabeza y el hombro derecho. Se lo coloca en posición de Fowler, con rotación hacia la izquierda y anti-Trendelembur con elevación de la cabeza, para que se desplaze el colon, epiplón e intestino delgado del sitio de trabajo y facilitar la exposición del triángulo de Calot.

El cirujano se coloca a su izquierda, a la altura del hígado y el primer ayudante que maneja la cámara a la izquierda del cirujano. El segundo ayudante frente a él, del lado derecho del paciente y la instrumentista a su lado.

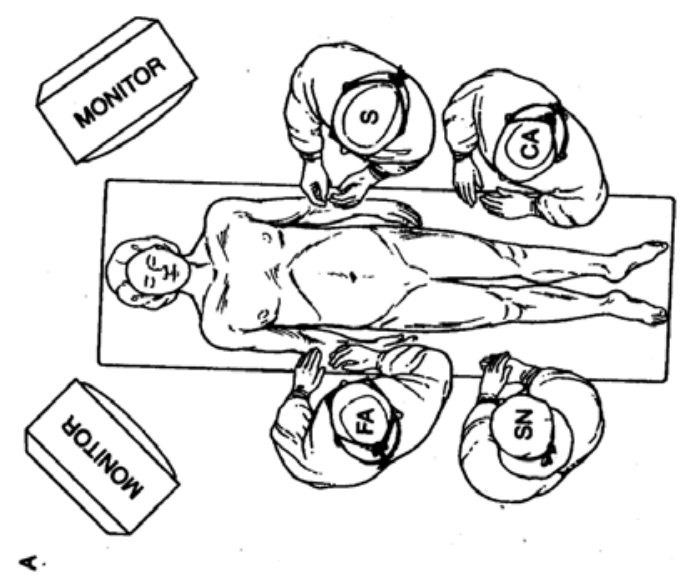

Figura 8. Técnica Americana. (Tomado de Katkhouda).

Se introducen 4 trócares. El primero de $10 \mathrm{~mm}$ para la introducción de la óptica que se coloca a nivel umbilical, pudiendo ser por encima o debajo de la cicatriz umbilical.

El segundo trócar de $10 \mathrm{~mm}$ para la mano derecha del cirujano se coloca a nivel de epigastrio, a la derecha del ligamento falciforme. Es importante emplazar este trócar en una posición alta, subxifoidea, para trabajar cómodo y lograr formar un ángulo de 90 으 con el tercer trócar de $5 \mathrm{~mm}$ para la mano izquierda del cirujano, que se emplaza en el HD, a nivel de la línea medio clavicular. 
Se coloca un cuarto trócar de $5 \mathrm{~mm}$ en el HD a nivel de la línea axilar anterior, subcostal. A través de él se introduce una pinza de prensión para sujetar la vesícula biliar desde el fondo y levantarla para exponer el triángulo de Calot, por parte del segundo ayudante.

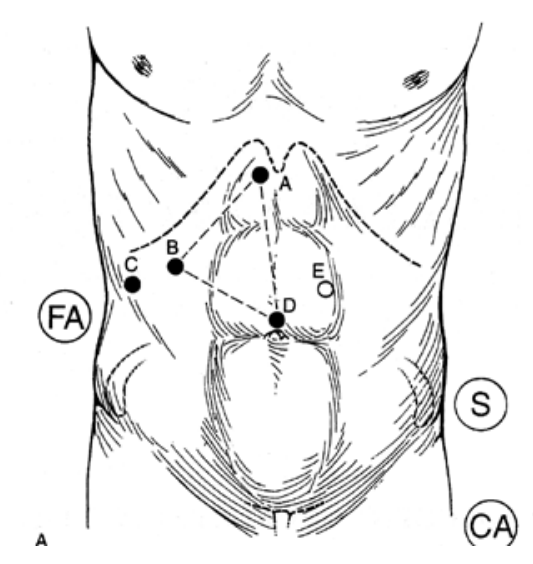

Figura 9. Técnica Americana. Colocación de los puertos. (Tomado de Katkhouda).

La ubicación precisa y la dirección de los puertos debe siempre ajustarse de acuerdo al biotipo del paciente y la anatomía de la vía biliar, una vez que se realizó la exploración de la cavidad abdominal y la vía biliar, de forma tal de trabajar creando ángulos de 90․ Este principio es muy importante, para lograr una adecuada y precisa técnica de forma de realizar movimientos cómodos. Es conveniente que exista una separación mayor de por lo menos $5 \mathrm{~cm}$ entre los puertos, para que no se produzcan interferencias entre los instrumentos.

No debe dudarse en la nueva colocación de los puertos cuando no quedan bien posicionados, dado que cuando queda mal planeada su dirección y ubicación, puede ser muy dificultosa la realización de la cirugía.

En algunos casos puede ser útil y necesaria la colocación de un quinto puerto de $5 \mathrm{~mm}$ en el hipocondrio izquierdo, para separar el lóbulo izquierdo del hígado o introducir el aspirador.

El ingreso a la cavidad abdominal y la realización del neumoperitoneo pueden realizarse en forma cerrada con la aguja de Veress o con la técnica abierta.

Con la técnica abierta se debe realizar una incisión en la línea media a nivel umbilical e utilizar el trócar de $10 \mathrm{~mm}$ de Hasson que posee un dispositivo que impide el escape de $\mathrm{CO} 2$.

En la técnica cerrada se introduce la aguja de Veress a ciegas al igual que el primer trócar umbilical.

Se realiza el neumopreritoneo, utilizando $\mathrm{CO} 2$ a una presión máxima de $15 \mathrm{~mm}$ de $\mathrm{Hg}$, pudiéndose trabajar generalmente de forma cómoda con una presión por encima de 10. El utilizar presiones de menos de $12 \mathrm{~mm} \mathrm{Hg}$ generalmente logra un mejor confort postoperatorio.

La insuflación inicial debe ser lenta, no mayor de 2.5 litros por minuto para permitir una adaptación gradual al neumoperitoneo.

En la técnica cerrada con la aguja de Veress el flujo está determinado por el calibre de esta, por lo que no se excede los 2.5 litros por minuto.

En la técnica abierta debe regularse el ritmo de insuflación del neumoperitoneo para evitar una insuflación muy rápida.

Una vez que se logra el neumoperitoneo, debe regularse el flujo de recuperación del mismo al máximo, para compenzar rápidamente las fugas y no perder cavidad. 

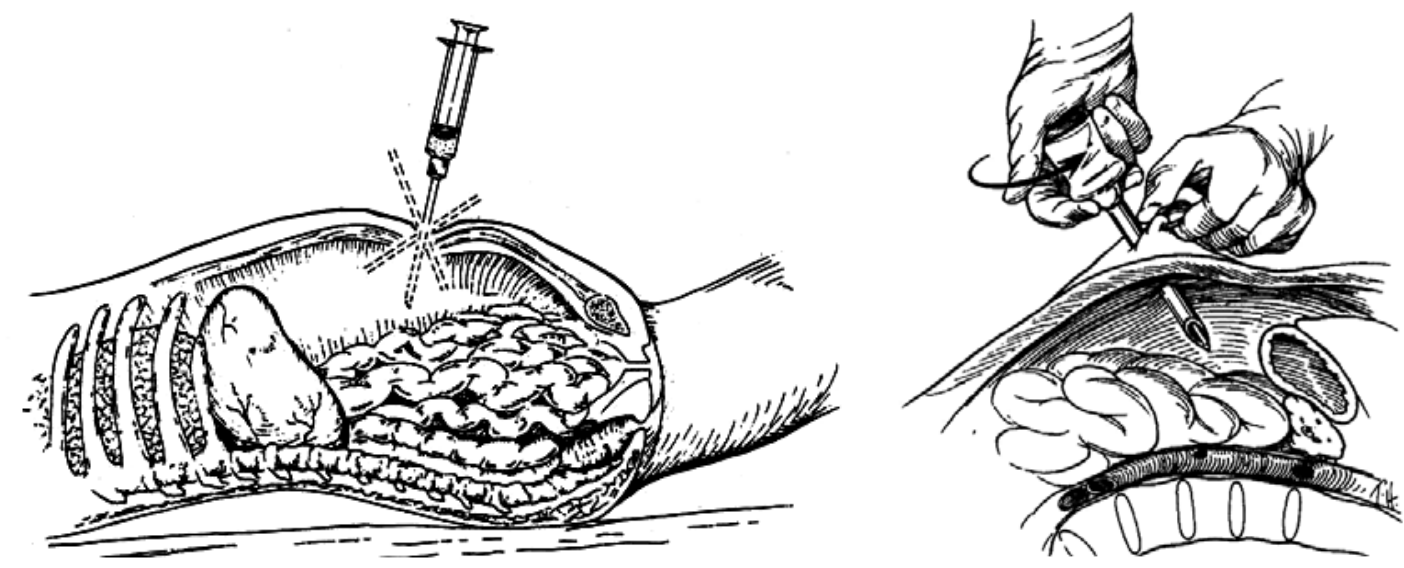

Figura 10. Realización del neumoperitoneo y colocación del primer trócar. (Tomado de Katkhouda).

Se realiza inicialmente una exploración visual completa de la cavidad abdominal buscando patologías concomitantes y eventualmente liberar adherencias. Utilizamos una óptica de 30 grados que nos permite excelentes ángulos de visión.

Si el estómago esta distendido puede dificultar la cirugía por lo que, se le puede pedir al anestesista que realice su degravitación con la colocación de una sonda nasogástrica la cual se retira al terminar la operación.

\section{Disección del triángulo de Calot}

Este tiempo inicial de la cirugía es de capital importancia para lograr realizar una adecuada disección e identificación de los elementos del pedículo cístico.

En muchos casos como maniobra inicial, es necesario seccionar el ligamento cisticoduodenal o cisticoduodenocólico de Angel y Sencert a nivel del borde libre del epiplón menor. Para esto es importante que el segundo ayudante levante la vesícula desde el fondo, sin realizar una tracción excesiva. El cirujano tracciona con una pinza de prensión el ligamento y lo desprende de la vesícula, soltando el duodeno. Luego tracciona desde el bacinete hacia afuera y abajo, de manera de abrir el triángulo de Calot, y con su mano derecha diseca los elementos del pedículo.

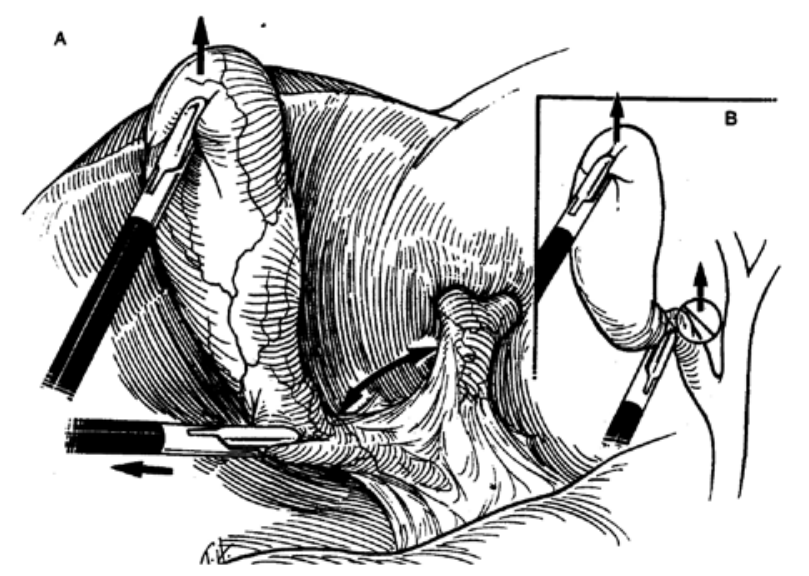

Figura 11. Disección del triángulo de Calot. (Tomado de Katkhouda). 
Seccionamos en primer lugar el peritoneo del lado derecho del pedículo cístico, exponiendo con una ligera tracción hacia el centro, el bacinete vesicular (maniobra de la bandera) y luego de su lado izquierdo, traccionando hacia abajo y afuera. Este paso lo consideramos de capital importancia para lograr el alargamiento del pedículo cístico y la disección de la unión cisticovesicular.
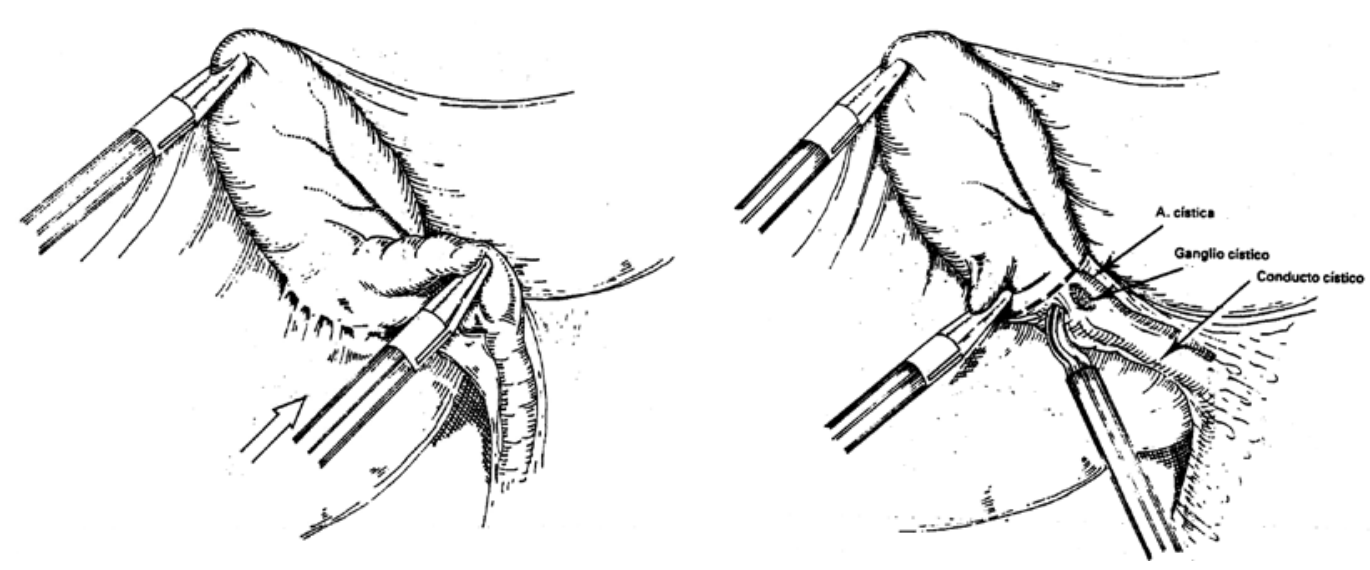

Figura 12. Sección del peritoneo y disección de la unión cístico-vesicular. (Tomado de Katkhouda).

Habitualmente realizamos la sección y disección del peritoneo y los elementos del pedículo con tijera con coagulación monopolar. Puede realizarse la disección con una pinza delicada de tipo Mariland o con el hook, sobre todo al inicio de la curva de aprendizaje, dado el mayor riesgo de producirse lesiones al utilizar la tijera.

Desde lo personal, no soy partidario de la técnica de disección por tracción y coagulación con pinza, dado que se desgarran los tejidos, produciéndose sangrados y existe más riesgo de lesiones térmicas por el uso de la coagulación.

Una vez que se identifican el conducto y la arteria cística, se realiza su clipado, primero proximal y luego distal. Habitualmente coloco 2 clip proximales por seguridad y uno distal a la sección para evitar el sangrado al realizar el corte, con lo que se ensucia el campo quirúrgico dificultándose la visión o se debe perder tiempo en aspirar y lavar. También es posible coagular el cabo distal con pinza.

En caso de realizar colangiografía, se realiza el clipado distal del conducto cístico, para luego realizar su sección con tijera para la introducción del catéter. Es conveniente clipar la arteria cística previa a la realización de la colangiografía para tener la certeza de que no se clipó ningún elemento de la vía biliar.

Sistemáticamente se coloca un clip, sólo proximal, a nivel del peritoneo del lecho vesicular a la altura del bacinete vesicular, a los efectos de clipar la rama arterial del lecho de la arteria cística, que a veces puede sangrar, o un canal aberrante no detectado.

El empleo de la coagulación monopolar debe manejarse con cautela porque la quemadura se puede extender a varios milímetros y si las vías biliares están cerca, pueden lesionarse y manifestarse a los pocos días como una fuga biliar o a las semanas o meses como un proceso cicatrizal con fibrosis y estenosis.

La colecistectomía la realizamos del cuello al fondo, seccionando el peritoneo entre la placa y la pared vesicular con coagulación. Debemos encontrar el plano adecuado mediante la realización de maniobras de tracción y contratracción en forma sincronizada con el segundo ayudante, a los efectos de que no se abra la vesícula y no se desgarre la placa vesicular. El hook es un instrumento adecuado para rea- 
lizar estas maniobras y descolgar la vesícula, si bien la tijera permite tener más precisión. En este tiempo no debemos apurarnos, dado que cuanto mejor sea realizado nos permitirá acortar los tiempos de hemostasis y lavado o el tener que extraer cálculos caídos a la cavidad peritoneal al romperse la vesícula.

Una vez que casi completamos la sección del peritoneo del lecho vesicular, es útil la maniobra de cambiar la toma del segundo ayudante, sosteniendo el peritoneo de la placa vesicular para completar la colecistectomía del fondo hacia el cuello.

Una vez suelta la vesícula procedemos a realizar la hemostasis del lecho vesicular.

Consideramos que hay que tener en cuenta estas tres premisas para evitar lesionar estructuras de la vía biliar:

1) Seccionar el peritoneo del pedículo cístico primero del lado derecho y luego del izquierdo con maniobras de tracción adecuadas y sin profundizarnos para no lesionar la arteria ni el conducto cístico.

2) Disecar e identificar en forma precisa la unión císticovesicular.

3) Siempre pegarnos a la vesícula biliar durante las maniobras de disección.

En nuestra experiencia cuando se identifica en forma correcta la unión cístico-vesicular con estas maniobras es muy poco frecuente que se produzcan lesiones de la vía biliar.

Cuando a pesar de realizar estas maniobras no logramos identificarla, es aconsejable soltar la vesícula desde el fondo, separándola de la placa, hasta encontrarnos con el conducto cístico, de afuera adentro.

\section{Extracción vesicular}

La extracción vesicular es un tiempo importante, dado que cuando no la hacemos correctamente puede producirse la rotura vesicular y la caída de bilis y cálculos al peritoneo y sangrados. Esto puede entorpecer y prolongar la cirugía, y producir contaminaciones de la cavidad peritoneal.

Extraemos la vesícula por el puerto de epigastrio.

La pinzamos con una pinza de agarre fuerte de $10 \mathrm{~mm}$, la exteriorizamos y vaciamos, aspirando su contenido y extrayendo los cálculos con una pinza de tipo Ferter.

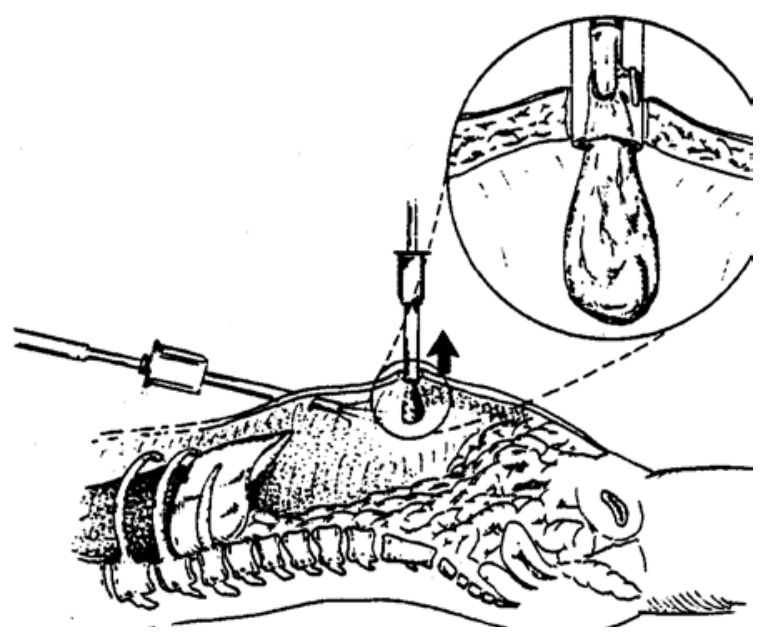

Figura 13. Extracción vesicular. (Tomado de Katkhouda). 
Cuando se rompe la vesícula, es de paredes friables como en la colecistitis aguda, está contaminada o si tenemos sospecha de que pueda ser tumoral debemos extraerla en bolsa o en un guante.

Puede ser necesario ampliar la incisión del puerto de epigastrio, en cuyo caso debemos cerrar la aponeurosis con uno o dos puntos de sutura, para evitar la aparición de eventraciones.

Luego recolocamos el puerto de epigastrio y procedemos a lavar, aspirar y explorar la zona operatoria. Para evitar la fuga de neumoperitoneo alrededor del trócar, pinzamos la piel de los bordes cerrando la incisión, con una pinza de campo.

El empleo de drenajes es selectivo.

Generalmente no dejamos drenaje, con excepción de los casos en que no estamos plenamente conformes con la hemostasis y la bilistasis. En estas situaciones dejamos un tubo de látex fino, fenestrado, que se exterioriza por el puerto lateral de $5 \mathrm{~mm}$.

Retiramos los trócares bajo visión a los efectos de despistar sangrados, fundamentalmente a nivel de epigastrio por la eventual lesión de la arteria epigástrica.

Lavamos los orificios de los puertos y cerramos la piel con puntos separados de nylon.

Es importante realizar la mayor evacuación posible del neumoperitoneo, a los efectos de lograr mejor confort postoperatorio y menos dolor, para lo cual dejamos algunos minutos el trócar umbilical y realizamos maniobras de presión del abdomen.

\section{Colecistectomía Laparoscópica con la utilización de tres puertos}

Es posible realizar la colecistectomía laparoscópica con la utilización de tres puertos.

Colocamos los puertos según la técnica americana, prescindiendo de la colocación del cuarto puerto de $5 \mathrm{~mm}$ a nivel del HD y por lo tanto del segundo ayudante.

El cirujano debe exponer el pédiculo cístico, levantando la vesícula biliar desde el bacinete con la pinza de prensión de $5 \mathrm{~mm}$ con su mano izquierda.

Una vez que se realiza la disección, identificación y el clipado del conducto cístico, se procede a realizar la colecistectomía del cuello al fondo.

Se ve dificultada la exposición del pedículo al no tener levantada la vesícula desde el fondo por parte del segundo ayudante, lo que implica una mayor exigencia técnica y habilidad en el manejo de la mano izquierda por parte del cirujano.

Las únicas ventajas de esta técnica son: evitar una incisión de $5 \mathrm{~mm}$ en el HD, evitar el desgarro hepático cuando se realiza una tracción excesiva del fondo vesicular por parte del segundo ayudante y lograr un mayor entrenamiento y destreza por parte de los cirujanos de su mano izquierda.

Por estos motivos, realizamos esta técnica sólo en los casos de colecistectomías muy fáciles, con vesículas de paredes finas, con mesos laxos y largos, pedículos de fácil disección y pacientes delgados.

No creemos indicada su realización en colecistectomías dificultosas, dado que las ventajas de no utilizar un puerto adicional de $5 \mathrm{~mm}$ son mínimas, y no debemos perder exposición y aumentar los riesgos de producir lesiones de la vía biliar u otras complicaciones. 


\section{Colecistectomía por "cirugía acuscópica"}

Se ha tratado de disminuir el trauma y la cicatriz, utilizando instrumental de menor diámetro, dando lugar a la denominada "cirugía acuscópica". Esta cirugía ha tenido un mejor resultado cosmético y menor dolor postoperatorio pero es más dificultosa y tiene un mayor índice de conversión ${ }^{40}$.

\section{Colecistectomía laparoscópica por un puerto}

Desde el año 1997 se comenzaron a realizar intentos de reducir el número de incisiones, utilizando un solo puerto, dando lugar a una nueva vía de abordaje que se llamó SILS (Single- Incision Laparoscopic Surgery), o sea cirugía laparoscópica por una incisión única.

Se desarrollaron trócares umbilicales especiales (Triport R, SILS port, X-Conel), e instrumentos adaptados para poder subsanar el problema de triangulación que implica el ingreso de las ópticas y las pinzas por el mismo sitio $^{41}$.

Es un método que recién comienza a generalizarse y deberá demostrar que es mejor y más eficaz que la colecistectomía laparocópica con 4 trócares, que actualmente es el gold standard.

Ya existe un trabajo randomizado que compara los resultados del SILS con la colecistectomía laparoscópica con 4 trócares y que concluye que esta técnica requiere más tiempo operatorio y ha tenido más complicaciones, sin agregar beneficios significativos en lo que respecta a la satisfacción del paciente, dolor postoperatorio, calidad de vida y resultados cosméticos ${ }^{42}$.

Nos parece que el hecho de tener que realizar una incisión de por lo menos $2 \mathrm{~cm}$ a nivel umbilical le agrega morbilidad al procedimiento, por ser una zona potencial de desarrollo de eventraciones postoperatorias, fundamentalmente en pacientes obesos.

\section{Cirugía endoscópica a través de orificios naturales (NOTES)}

En el año 2004 se abordó por primera vez la cavidad peritoneal en cerdos a través del estómago con instrumental endoscópico ${ }^{43}$, dando lugar al comienzo de la cirugía endoscópica a través de orificios naturales; conocida por su sigla NOTES en inglés: Natural Orifice Translumenal Endoscopic Surgery.

Al poco tiempo se realizó la primera colecistectomía por esta vía en animales ${ }^{44}$, seguida de una técnica híbrida en humanos, con apoyo de instrumental colocado transparietalmente.

En el año 2007, con el título de "Proyecto Anubis", se realizó la primera colecistectomía en humanos usando un abordaje transvaginal ${ }^{45}$.

Teniendo en cuenta el potencial valor de estas técnicas, la SAGES (Society of American Gastrointestinal and Endoscopic Surgeons) y la ASGE (American Society for Gastrointestinal Endoscopy) fijaron las normativas y centraron los datos mundiales de los grupos que trabajan en este nuevo campo de la cirugía, creando el NOSCAR (Natural Orifice Surgery Consortium for Assesment and Research) ${ }^{46}$.

La ventaja de esta vía de abordaje es minimizar el traumatismo parietal, no generando cicatrizes ni dolor.

Se accede a la cavidad abdominal por vía transgástrica o transvaginal.

El cierre del órgano por el que se accedió al abdomen y la aparición de nuevos tipos de complicaciones como ser perforación de esófago, dehiscencia de los cierres viscerales, lesión de la vejiga, disconfort sexual, etc, son los puntos débiles de la técnica ${ }^{47}$.

Las limitaciones de estos procedimientos es que requieren de un instrumental específico y sofisticado, nuevos endoscopios distintos de los convencionales, que permitan transmitir una imagen deta- 
llada, adecuada iluminación, tener tres canales de trabajo con posibilidad de triangulación con los instrumentos, con gran capacidad de maniobrabilidad en el extremo, que permita la irrigación y realización del neumoperitoneo y de diámetro acotado ${ }^{48}$.

Existen comercialmente las plataformas AnubisR de Storz, el TransportTM de USGI Medical y el "R" Scope de Olympus.

Hay aparatos para la sutura endoluminal como el g-Prox de USGI Medical.

Con el tiempo se evaluarán si el desarrollo de estos nuevos procedimientos y sus costos elevados justifican su realización y determinan un real beneficio para el paciente.

\section{Colangiografía}

La realización de la colangiografía intraoperatoria fue un aporte revolucionario para la cirugía biliar, dado que permitió realizar el diagnóstico de litiasis de la VBP en el intraoperatorio y actuar en consecuencia, y tener un mapeo de la vía biliar.

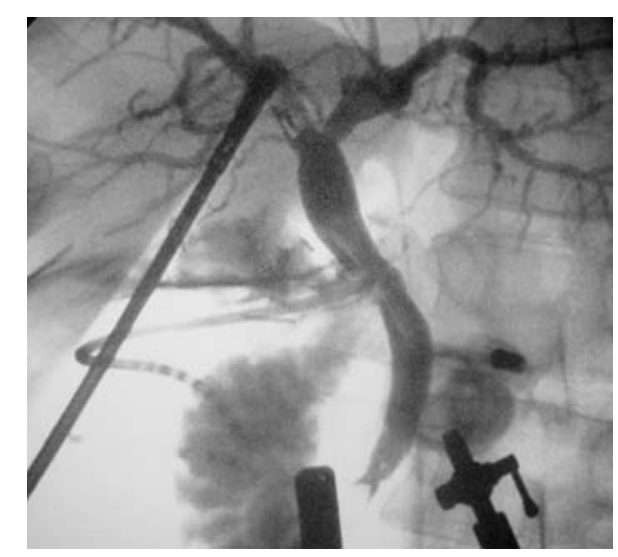

Foto 1. Colangiografía.

La primera colangiografía intraoperatoria en el mundo fue realizada por el Pofesor Pablo Mirizzi en el Hospital Nacional de Clínicas de Córdoba, en Argentina, el 16 de junio de $1931^{49}$.

Se ha discutido mucho con respecto a si es un procedimiento que deba realizarse de rutina o selectivamente.

Las razones para realizar la colangiografía en forma sistemática son: existencia de litiasis coledociana insospechada, determinación de la anatomía de la vía biliar, detección temprana de lesiones de la vía biliar y fugas biliares ${ }^{50}$, para adquirir destreza en la manipulación de la vía biliar ${ }^{51}$ y el valor médico legal al tener el registro gráfico de la vía biliar ${ }^{52}$.

Las razones para realizarla con un criterio selectivo son: la presencia de falsas imágenes ${ }^{53}$, realizándose una exploración biliar o papilotomía endoscópica innecesaria; la muy baja sensibilidad para poder detectar una lesión biliar menor ${ }^{54}$, o un conducto aberrante o accesorio ${ }^{55}$; morbilidad del procedimiento sobre todo cuando la vía biliar es muy fina; reacciones alérgicas al contraste iodado ${ }^{56}$ y pérdida de tiempo quirúrgico y prolongación de la cirugía de manera innecesaria ${ }^{57}$.

Nosotros la realizamos en forma selectiva. 
Cuando el paciente no tiene elementos clínicos, de laboratorio ni ecográficos de sospecha de litiasis coledociana, el conducto cístico es de pequeño calibre y la anatomía de la unión cístico vesicular y el conducto hepatocolédoco es normal y no existen dudas, no realizamos el estudio colangiográfico.

Las razones para adoptar esta conducta son: se prolonga el tiempo operatorio en forma innecesaria; se agrega morbilidad a la cirugía por la posibilidad de lesionar la VB en el intento de cateterizar una vía biliar muy fina; exposición a radiaciones; y considero que la posibilidad de detectar una litiasis de la VBP cuando el cístico es filiforme es prácticamente nula. En el caso excepcional de que exista una muy pequeña litiasis o barro biliar, lo más probable es que migrara espontáneamente al duodeno, a través de la papila.

Frente a la menor duda con respecto a la anatomía de la vía biliar, presencia de bilirragias, cístico de calibre aumentado o sospecha de litiasis de la VBP, siempre la realizamos.

De todos modos consideramos que para hacer una colecistectomía laparoscópica es imprescindible tener la posibilidad de realizar la colangiografía, para lo cual debemos contar con un arco en C y el técnico radiólogo en sala de operaciones. El cirujano debe saber y estar entrenado en la realización de la técnica, pero preferimos que los residentes y cirujanos en formación se entrenen en realizarla, cuando realmente se debe hacer, para no generar morbilidad.

La realizamos por vía transcística y generalmente utilizando la técnica de tipo Seldinger.
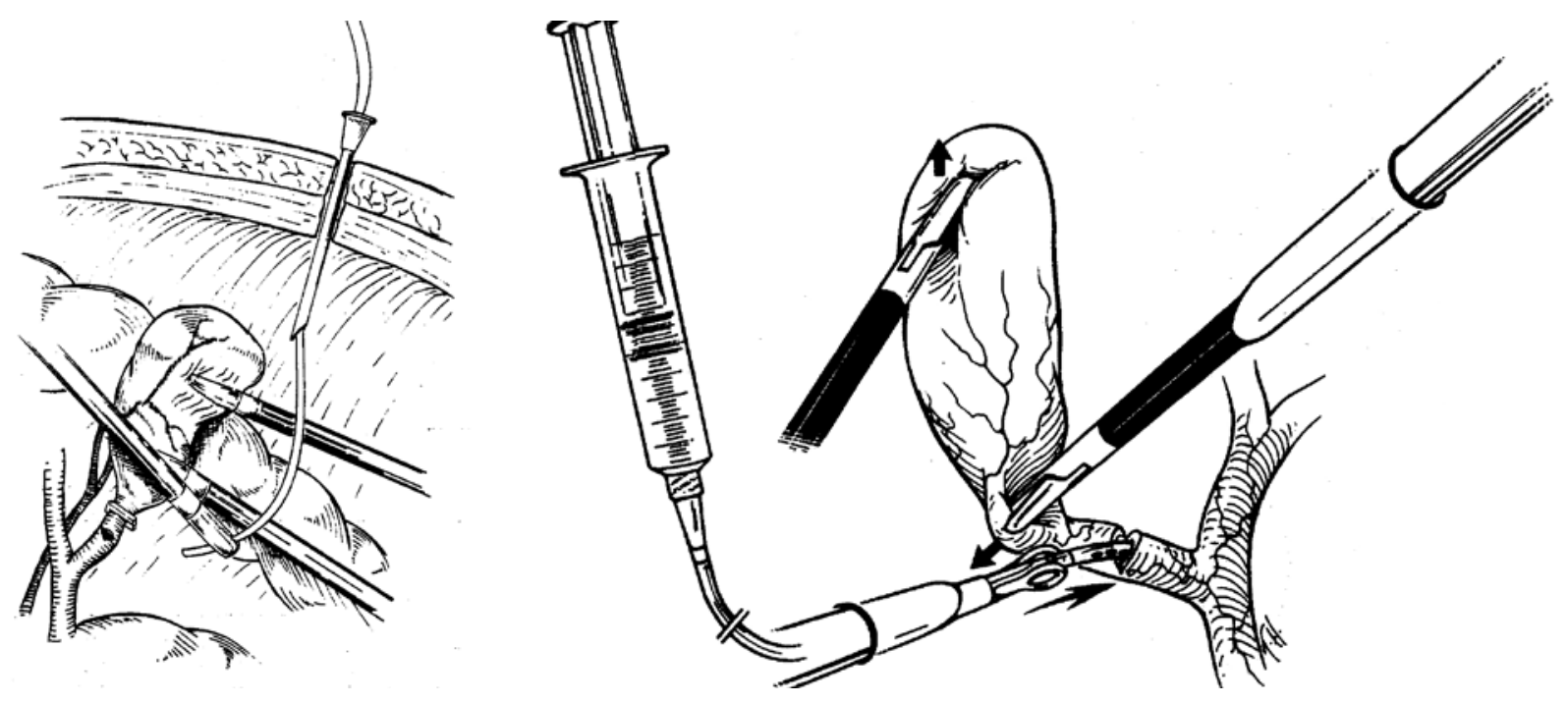

Figura 14. Colangiografía transcística. (Tomado de Katkhouda).

Dicho procedimiento consiste en puncionar con un abocat a nivel de hipocondrio derecho o epigastrio, e introducir una guía de plástico con la punta flexible. Luego retiramos el abocat e introducimos el catéter utilizando a la cuerda como guía.

Seccionamos el conducto cístico luego de cliparlo en la unión con la vesícula y lo cateterizamos, dejando a la guía dentro del catéter, la cual sobresale ligeramente del mismo para luego colocar un clip y retirarla progresivamente de manera de no colapsar el catéter.

Aspiramos e inyectamos suero fisiológico para probar la permeabilidad del catéter. Lo ideal es que venga bilis al aspirar, lo que nos da la certeza de que estamos dentro de la vía biliar.

La ventaja de esta técnica es que el cirujano maneja el catéter para cateterizar el conducto cístico con su mano derecha, y con su mano izquierda el bacinete. Es importante alinearlo con el cístico lo que se logra elevando el bacinete. Muchas veces es necesario vencer la resistencia de alguna válvula para poder 
cateterizarlo. Una maniobra útil y a veces necesaria es exprimir el conducto cístico desde el colédoco, para extraer algún cálculo que pueda estarlo obstruyendo.

Luego realizamos la colangiografía mediante la inyección de contraste diluído al 50\%, muy lentamente y a baja presión para evitar el pasaje al conducto de Wirsung, bajo visión con el arco en C.

Se observa el llenado paulatino de los conductos, la indemnidad y anatomía de los mismos, la ausencia o presencia de algún cálculo, la ausencia de pérdida de contraste y su pasaje al duodeno.

También es posible realizar la colangiografía utilizando la pinza de Olsen y distintos tipos de instrumentos y catéteres que existen en el mercado, que se introducen desde los trócares laterales del HD.

En caso de no poder cateterizar el conducto cístico, se puede recurrir a la punción de la vesícula o de la vía biliar principal. En este último caso se debe usar una aguja de pequeño calibre y dejar un drenaje peritoneal subhepático, por la posibilidad de bilirragia.

\section{Resultados y complicaciones}

La colecistectomía laparoscópica como ya se ha hecho referencia en el capítulo 2, es de las cirugías abdominales realizadas con mayor frecuencia, por lo que si bien las complicaciones son estadísticamente bajas, el gran volumen de pacientes que se operan, las convierten en cotidianas.

Esta técnica tiene además de los mismos riesgos que la cirugía abierta en cuanto a las posibles lesiones del pedículo y órganos y estructuras vecinas, los propios del método laparoscópico, como son las complicaciones vinculadas a la realización del neumoperitoneo, a la colocación de los trócares y a la técnica laparoscópica.

La morbilidad global de la colecistectomía es del 5 al $20 \%$ y la mortalidad de $0.09 \%{ }^{58}$.

La lesión de la vía biliar es de las complicaciones más graves, y ocurre del 0.2 al $1.9 \%{ }^{59}$. Esta constituye un riesgo inherente de esta técnica quirúrgica, por lo que no debe considerarse una "mala praxis" y este concepto debe ser trasladado al paciente en el consentimiento informado ${ }^{60}$.

Según la literatura mundial hay lesiones muy graves, incluso con mortalidad, como ser la perforación de una víscera hueca y lesiones vasculares de la vena porta, aorta o sus ramas, pero que son excepcionales ${ }^{61,62}$.

\section{Complicaciones vinculadas a la realización del neumoperitoneo y a la colocación de los trócares}

Estas complicaciones son patrimonio de la cirugía laparoscópica y están relacionadas a la colocación de la aguja de Veress y de los trócares ${ }^{63}$.

La incidencia de perforación del intestino provocadas por la aguja de Veress para la realización del neumoperitoneo es del 0.1 al $0.3 \%{ }^{64,65}$.

Estas lesiones suelen ser pequeñas y generalmente se cierran con rapidez $z^{66}$. Cuando se detectan deben tratarse con la colocación de puntos de sutura, de elección bajo visión laparoscópica o mediante la evisceración del sector intestinal afectado a través de la ampliación de alguna de las heridas de los puertos ${ }^{67}$. El principal riesgo de estas lesiones es que pueda manifestarse en forma tardía una lesión intestinal inadvertida y producir como consecuencia una peritonitis aguda.

Las lesiones vasculares de los vasos retroperitoneales por lesión con la aguja de Veress o el primer trócar que se introduce a ciegas, constituyen las complicaciones más letales, poco frecuentes ( 0.1 a $0.4 \%$ ), pero con una mortalidad cercana al $10 \%{ }^{68}$. 
El tratamiento de estas lesiones, implican la conversión a técnica abierta en forma inmediata.

Para reducir estos riesgos, Fitzgibbons desarrolló la técnica de laparoscopía a cielo abierto con el trócar de Hasson ${ }^{69}$. Esta técnica es más segura de utilizar en pacientes con cirugías previas, sobre todo del abdomen superior, por la posibilidad de adherencias de vísceras a la pared abdominal.

Pueden ocurrir sangrados a nivel de los sitios de introducción de los puertos, fundamentalmente a nivel de epigastrio por lesiones de la arteria epigástrica o sus ramas ${ }^{70,71}$.

Estos sangrados pueden ser controlados al efectuar compresión con la colocación de los trócares, debiendo controlar siempre su detención al terminar la cirugía y el retiro de los mismos. Puede llegar a ser necesaria la colocación de puntos de sutura.

Otra causa de hemorragia puede ser la laceración del ligamento redondo, que puede ser solucionada con coagulación o mediante una ligadura.

Las complicaciones vinculadas a la realización del neumoperitoneo son la disminución del retorno venoso, la disección gaseosa del epiplón, el escroto y retroperitoneo, el enfisema cervical y mediastínico y el neumotórax a tensión. Generalmente son debidos a una posición incorrecta de la aguja de insuflación y a la presencia de una presión intra-abdominal elevada, mayor de $15 \mathrm{mmHg}$.

El enfisema subcutáneo y la disección gaseosa del mediastino pueden producir una hipercapnia importante, sobre todo en pacientes con patología respiratoria. Esto puede desencadenar una acidosis severa y/o arritmias cardíacas que pueden ser fatales para el paciente. Para evitar estas complicaciones es imprescindible el monitoreo del CO2 mediante la capnografía.

La complicación más grave es la embolia gaseosa. Ésta es excepcional, se presenta en menos del $0.01 \%$ de los pacientes y es debida generalmente a la introducción de la aguja de Veress o de alguno de los trócares directamente en la luz de un vaso sanguíneo mayor durante la administración del gas ${ }^{65}$.

\section{Complicaciones hemorrágicas}

Las hemorragias intaoperatorias se producen en general por una lesión de la arteria cística, del lecho hepático o excepcionalmente un gran vaso como la vena porta o la arteria hepática.

El confundir la arteria cística anterior con el conducto cístico es la causa más frecuente del sangrado. Esto debe controlarse con el pinzado transitorio del vaso y la colocación de clips. Puede requerir de la colocación de un quinto puerto para introducir el aspirador. No deben colocarse clips a ciegas, dado que estos pueden provocar lesiones accidentales de los conductos biliares, la arteria hepática o sus ramas. De no poderse lograr la hemostasis en forma segura debe evaluarse la necesidad de conversión ${ }^{72}$.

Otras causas de hemorragia son las laceraciones hepáticas por tracción excesiva de la vesícula biliar desde el fondo; la rotura de la placa vesicular durante la colecistectomía o en el pinzado del lecho hepático para exposición. En situaciones poco frecuentes puede producirse lesión de una de las ramas de origen de la vena suprahepática media.

La lesión de la arteria hepática, sobre todo su rama derecha puede ocurrir por confundirla con la arteria cística, dado que en un $15 \%$ de los casos la arteria hepática transcurre por delante del conducto hepático ${ }^{73}$.

La lesión accidental de la vena porta debe ser reparada inmediatamente, dado que la oclusión completa y súbita de este vaso conduce a una complicación mortal.

Frente a la presencia de graves complicaciones hemorrágicas algunos autores aconsejan realizar la conversión y procedimientos de taponaje abdominal o packing ${ }^{74,75,76}$. 
Cuando la hemorragia es de la profundidad del surco transverso y se aproxima a la confluencia de los hepáticos, la incidencia de lesiones vasculares es para Koffon, de acuerdo a la clasificación de Bismuth del $71 \%$ para el grado IV, $63 \%$ para el grado III y $33 \%$ para el tipo II $^{77}$.

\section{Bilirragias y lesiones de la vía biliar}

La presencia de una bilirragia intraoperatoria es un elemento que debe preocupar al cirujano y se debe siempre tratar de determinar su causa ${ }^{78}$. Ésta puede ser debida a filtraciones del muñón cístico, canales aberrantes del lecho hepático o una lección accidental de la vía biliar principal. Esta última puede ser una complicación grave de la cirugía laparoscópica de la vía biliar, por lo que siempre debe diagnosticarse y descartarse.

Si bien las lesiones quirúrgicas de la vía biliar (LQVB) son poco frecuentes, en la colecistectomía a cielo abierto ocurren en un 0.1 a $0.2 \%$, pero esta cifra ha aumentado con la aparición de la cirugía laparoscópica hasta cifras de un 0.2 a un $3 \% 79,80,81,82,83,84,85,86,87,88$.

La mayoría de estas lesiones se producen por lo general como consecuencia de confundir el conducto cístico con el colédoco ${ }^{89,90}$. Esto determina muchas veces que se realice la sección o resección de la vía biliar principal.

Para que esto no ocurra es imprescindible realizar la correcta disección e identificación de la unión cístico-vesicular.

La aplicación en forma indiscriminada de clips o la cauterización excesiva y a ciegas para controlar una hemorragia es otro de los mecanismos frecuentes que pueden llevar a lesionar la VBP.

Cuando se produce una bilirragia intraoperatoria y no es clara la anatomía de la vía biliar es imprescindible la realización de la colangiografía para poder detectar la causa de la misma, definir la anatomía de la vía biliar y descartar una eventual lesión de la vía biliar. En la mayoría de los casos la lesión ya se produjo, pero es de capital importancia para hacer el diagnóstico inmediatamente y realizar su reparación.

El diagnóstico temprano de una LQVB es uno de los factores más importantes para disminuir la morbilidad asociada a su tratamiento.

Solamente del 8 al 13\% se diagnostican durante la cirugía en el momento que se producen ${ }^{91}$.

Algunos elementos que nos deben hacer sospecharla son la presencia de bilis en forma inexplicable en el campo operatorio, vascularización pericística abundante, una arteria cística de muy grueso calibre y la necesidad de colocación de muchos clips para tratar el pedículo. Frente a esta situación es obligatoria la realización de una colangiografía intraoperatoria para diagnosticar la presencia y el tipo de lesión y la anatomía de la vía biliar.

En el postoperatorio debe sospecharse una LQVB cuando la evolución no es la habitual: persistencia del dolor, distensión abdominal, nauseas, vómitos o fiebre.

El 70 a $80 \%$ de las LQVB se manifiestan como fístulas biliares, con coleperitoneo generalmente sin ictericia.

La presencia de una colección abdominal o una bilirragia nos obliga a plantear su presencia, hasta que se demuestre lo contrario.

Frente a la presencia de una lesión, se deberán realizar una secuencia de estudios (ECO, TAC, CER, $\mathrm{CTPH}$, Colangioresonancia), que dependen de la clínica del paciente, la experiencia de los profesionales actuantes y las posibilidades técnicas de la institución ${ }^{92}$.

Es muy importante poder contar con la videograbación de la cirugía para poder comprender el mecanismo de la lesión. 
La sospecha de una lesión vascular, generalmente de la arteria hepática justifica la realización de un estudio Eco Doppler del pedículo hepático y eventualmente una arteriografía selectiva hepática y mesentérica con retorno venoso.

El tratamiento debe ser encarado por un equipo multidisciplinario con experiencia en cirugía hepatobiliar.

La localización y la naturaleza de lesión, conjuntamente con el estado general del paciente, determinarán la necesidad de recurrir a procedimientos diagnósticos e intervencionistas endoscópicos y percutáneos radiológicos.

Por intermedio de estos procedimientos se pueden en algunas situaciones lograr definir y diagnosticar el tipo de lesión, definir la anatomía, drenar colecciones (bilomas, abscesos), reducir o suprimir filtraciones biliares derivando la bilis hacia la luz intestinal (stens biliares) o hacia el exterior (stens nasobiliares), dilatar estenosis y eliminar cálculos. rapéutico.

La relaparoscopía tiene un rol importante en algunas situaciones con un criterio diagnóstico y te-

La reparación quirúrgica de una LQVB debe ser correctamente planificada y realizada por un equipo de cirujanos especializados en cirugía hepatobiliar.

El objetivo de la reparación es evitar las complicaciones y o secuelas a corto y largo plazo como son: fístulas biliares, colecciones y abscesos intraabdominales e intrahepáticos, colangitis, estenosis biliares o anastomóticas y la cirrosis biliar secundaria.

Un tercio aproximadamente de las lesiones se diagnostican durante la cirugía laparoscópica.

Lo ideal es reparar la lesión en el momento para lo cual es conveniente en la mayoría de los casos convertir a cirugía abierta ${ }^{93,94}$.

Sin embargo la presencia de una importante alteración de los tejidos locales (inflamación aguda, vía biliar muy fina) o una imposibilidad técnica de definir la lesión o inexperiencia del equipo actuante pueden condicionar la decisión de postergar la solución definitiva.

El manejo terapéutico de las LQVB depende de los siguientes factores: estado general del paciente, tiempo que transcurre entre la lesión y el diagnóstico, tipo, extensión y nivel de lesión, existencia de lesiones asociadas y de la experiencia del equipo quirúrgico actuante.

Es conveniente dejar un drenaje subhepático, dado que la mayoría de estas filtraciones biliares remiten en forma espontánea si el drenaje es adecuado y está bien posicionado y no existe obstrucción del colédoco distal.

Destacamos, al igual que lo dicen otros autores, el valor diagnóstico y terapéutico de dejar un drenaje peritoneal subhepático en cirugía biliar, para detectar y evitar complicaciones, frente a estas situaciones de bilirragias intraoperatorias, sobre todo en colecistectomías dificultosas ${ }^{95}$.

\section{Ruptura vesicular y caída de los cálculos al peritoneo.}

La perforación de la vesícula durante la colecistectomía se observa de acuerdo a la literatura entre el 13 al $40 \%$ de los $\operatorname{casos}^{96}$.

La caída de bilis al peritoneo con posterior aspirado y lavado, no produce mayores consecuencias, pero los cálculos deben ser extraídos, porque pueden ser el foco de una probable infección o comportarse como un cuerpo extraño de recorrido y comportamiento incierto ${ }^{97,98,99}$.

Cuando se derramen múltiples cálculos es más práctico introducir una bolsa para su extracción, a los efectos de acortar la cirugía ${ }^{100}$. 


\section{Conversión}

El porcentaje de conversión a nivel de la literatura mundial es de alrededor del $10 \%^{101}$

Las causas más frecuentes de conversión son:

- No reconocimiento de la anatomía biliar luego de un plazo razonable de disección;

- Presencia de una friabilidad extrema de los tejidos;

- Sospecha de que se trate de un carcinoma vesicular;

- Hemorragias difíciles de controlar a nivel del pedículo hepático o del lecho vesicular;

- Lesión de la vía biliar.

Son predictores de conversión: pacientes de más de 60 años, sexo masculino; peso mayor de 65 $\mathrm{kg}$, colecistitis; antecedentes de cirugías del abdomen superior; diabéticos mal controlados y cirujanos con poca experiencia ${ }^{102}$.

La conversión no debe considerarse como un fracaso; es una posibilidad terapéutica que debe manejarse y es importante realizarla a tiempo, antes de que se produzcan lesiones. Es muy importante en este aspecto la experiencia que tiene el equipo quirúrgico tratante y no empecinarse en continuar la cirugía por laparoscopía ${ }^{103}$.

\section{Complicaciones postoperatorias}

\section{Bilirragia}

La bilirragia se puede manifestar en el postoperatorio inmediato y ser fácilmente evidenciada si el paciente tiene un drenaje subhepático de la cavidad abdominal.

Desde el punto de vista terapéutico, en los pacientes con drenajes con bajo gasto, buen estado general y sin colecciones asociadas, la conducta debe ser expectante, pues la evolución en la mayoría de los casos es al cierre espontáneo y al cese del gasto.

Cuando el gasto es alto y no baja debe pensarse en la existencia de una causa más importante, como es una lesión de la vía biliar o una obstrucción y puede ser necesaria la realización de una colangiografía endoscópica retrógrada por vía endoscópica y/ colangioresonancia con un criterio diagnóstico y terapéutico en el caso de la primera.

En la mayoría de los casos el paciente no queda con drenaje y es dado de alta a las 24 horas, por lo que consulta a los días con un coleperitoneo que se manifiesta clínicamente por dolor abdominal, distensión, fiebre y leucocitosis elevada.

Se deben realizar estudios imagenológicos como la ecografía y la TAC.

Cuando la bilirragia está localizada dando origen a la formación de un biloma, el drenaje percutáneo guiado por imágenes, es por lo general suficiente para la solución de esta complicación sobre todo si no hay hipertensión biliar.

Cuando el paciente presenta signos de peritonitis biliar generalizada y se encuentra estable, somos partidarios de realizar una relaparoscopía con exploración abdominal, tratando de determinar la zona de la fuga biliar y su causa, con lavado de la cavidad abdominal. 
Cuando la causa es la salida de los clips del conducto cístico, es posible su recolocación y posterior tratamiento de la cavidad peritoneal, mediante aspiración y lavado.

Cuando se detecta una bilirragia por la presencia de un canalículo aberrante es posible intentar realizar su clipado y dejar un drenaje subhepático.

Cuando sospechamos la existencia de una lesión ó una obstrucción de la vía biliar principal creemos indicada la realización de una colangiografía endoscópica retrógrada. Ésta se realiza con un criterio diagnóstico y terapéutico. Si existe una obstrucción litiásica de la VBP, se realiza la papilotomía con extracción del cálculo, para luego proceder a realizar la relaparoscopía. El otro estudio que nos permite realizar el diagnóstico es la colangioresonancia.

Cuando se diagnostica una lesión importante de la VBP debemos planificar su reparación por cirugía abierta en nuestra experiencia.

Si el paciente presenta un mal estado general puede indicarse una relaparoscopía con tratamiento de la peritonitis biliar con lavado y drenaje de la cavidad peritoneal, para diferirse la reparación definitiva de la VBP a una mejor oportunidad y con un paciente en mejores condiciones.

\section{Colecciones abdominales}

La formación de abscesos intra-abdominales puede ser secundaria a una colección hemática o de bilis infectada, o en algunos casos por cálculos derramados y dejados en el peritoneo, situación muy poco frecuente ${ }^{104}$.

Sin embargo es frecuente observar colecciones pequeñas a nivel del lecho vesicular en estudios ecográficos. Cuando la colección es pequeña, se puede observar al paciente; generalmente no requieren ser drenadas y evolucionan favorablemente con el tratamiento médico.

Cuando son más grandes y el paciente tiene síntomas como dolor abdominal y fiebre pueden ser drenadas, de elección por punción percutánea, dejando eventualmente un drenaje.

Para evitar esta complicación es conveniente dejar un drenaje peritoneal subhepático, en las colecistectomías laparoscópicas dificultosas, en las cuales no podemos realizar una perfecta hemostasis o bilistasis.

\section{Complicaciones parietales:}

\section{Equímosis y hematomas}

Es frecuente observar equimosis y pequeños hematomas a nivel de los puertos, fundamentalmente a nivel umbilical y epigastrio; que generalmente no requieren de ningún tratamiento.

El riesgo para la formación de hematomas se ve aumentado en pacientes con alteraciones de la coagulación, por ingesta de aspirina o uso de anticoagulantes o cuando se realizó una disección excesiva del tejido subcutáneo.

Es generalmente aceptado que deben ser evacuados los hematomas importantes observados dentro de las primeras 48 horas de la cirugía, 


\section{Infección}

La infección de las heridas es muy poco frecuente y generalmente no son un problema importante, dado que las incisiones de los puertos son pequeñas y cicatrizan rápidamente.

La herida que puede infectarse más frecuentemente es la del puerto de epigastrio, dado que por ahí se extirpa la vesícula. Para evitar esta complicación debe extraerse en una bolsa las vesículas con colecistitis evolucionadas y lavarse las heridas con suero fisiológico ${ }^{105,106}$.

\section{Eventraciones}

La incidencia de eventraciones a nivel de los puertos es sumamente baja, siendo del 0.1 al $0.5 \%$ de los casos.

Pueden producirse eventraciones a nivel de los puertos de $10 \mathrm{~mm}$, umbilical y epigastrio.

Para evitar esta complicación, se debe cerrar con puntos de sutura el plano musculo facial a nivel de epigastrio, sobre todo cuando se tiene que ampliar la incisión para extraerse la vesícula.

\section{Litiasis residual}

Definimos a la litiasis residual como la presencia de cálculos en la vía biliar principal luego de la colecistectomía.

La frecuencia de litiasis residual en la colecistectomía laparoscópica es variable según las diferentes estadísticas, pero generalmente puede ocurrir del 2 al $5 \%$ de los pacientes y puede requerir para su tratamiento de una papilotomía endoscópica o una reintervención ${ }^{107}$.

Está vinculada a la realización de la colangiografía intraoperatoria, que puede indicada en forma sistemática o selectiva; hecho que todavía no ha sido resuelto a nivel de la bibliografía mundial ${ }^{108,109,110}$.

Nosotros, como ya fue mencionado, realizamos la colangiografía en forma selectiva.

Cuando el paciente presenta estas características que se detallan: no tiene elementos clínico de laboratorio ni ecográficos, no existe sospecha de litiasis coledociana, el conducto cístico es de pequeño calibre, la anatomía de la unión cístico vesicular se identifica corretamnete y el conducto hepatocolédoco es normal, entonces no realizamos el estudio colangiográfico.

Las razones para adoptar esta conducta son porque consideramos que la posibilidad de detectar una litiasis de la VBP es nula, nos prolonga el tiempo operatorio y agrega morbilidad a la cirugía (lesiones de la VB, exposición a radiaciones).

La litiasis persistente la definimos como la presencia de cálculos en la VBP luego de la cirugía; debido a la ausencia de exploración radiológica, su no detección en la misma, o por razones técnicas que nos imposibilitaron su extracción.

\section{Situaciones especiales:}

\section{Colecistectomía laparoscópica en la colecistitis aguda}

La colecistectomía laparoscópica $(\mathrm{CL})$ ha sido aceptada por consenso como el procedimiento de elección para el tratamiento de la colecistitis aguda $(\mathrm{CA})^{111}$. 
El tratamiento de la CA es de resolución fundamentalmente quirúrgica, mediante la colecistectomía; pudiéndose realizar en casos puntuales la decompresión vesicular, por vía percutánea o quirúrgica (colecistostomía).

Los pacientes portadores de una CA, pueden presentar un amplio espectro clínico de la enfermedad, desde formas leves y autolimitadas, hasta otras formas graves, con riesgo vital.

A partir del año 2006, las CA se clasifican, de acuerdo a su gravedad en tres grados o categorías: grado I o leve, grado II o moderada, y grado III o grave ${ }^{112}$.

En el grado I no hay disfunciones orgánicas, siendo la colecistectomía un procedimiento seguro. En el grado II, existe un mayor compromiso locoregional y la colecistectomía temprana es más dificultosa ${ }^{113,114}$. En el grado III, hay un compromiso multiorgánico que determinan que los pacientes requieran su internación en CTI, debiéndose realizar en muchos casos el drenaje percutáneo o quirúrgico de la vesícula biliar en forma urgente.

La guía de Tokio, concluye que en las formas leves y moderadas, está indicada la colecistectomía temprana con resultados seguros y efectivos ${ }^{111}$.

En las formas moderadas, si el proceso inflamatorio es severo, se recomienda evaluar el drenaje percutáneo o quirúrgico y diferir la cirugía.

En las formas graves, se sugiere realizar la descompresión percutánea y decidir la conducta quirúrgica de acuerdo a la evolución del paciente.

En la colecistitis aguda se producen alteraciones inflamatorias que distorsionan la anatomía ductal y vascular, aumentando la friabilidad tisular.

Esto hace que el tratamiento quirúrgico por laparoscopía sea más difícil y tenga potencialmente más complicaciones que la cirugía abierta.

Estas intervenciones exigen una mayor experiencia y capacidad técnica en cirugía laparoscópica.

En los años 90, se consideraba una contraindicación al abordaje por laparoscopía, debido a los elevados índices de conversión, tiempos operatorios muy prolongados y mayores estadías hospitalarias ${ }^{115}$.

La experiencia del cirujano y del equipo quirúrgico es un factor determinante de la seguridad de la intervención quirúrgica por laparoscopía.

Los casos de conversión a cirugía abierta son mayores (20 a 30\%), pero en el $80 \%$ de los casos el tratamiento es exitoso ${ }^{116}$.

La cirugía mínimamente invasiva tiene numerosas ventajas respecto a la cirugía abierta tradicional. A pesar de que los tiempos quirúrgicos pueden ser mayores, los pacientes tienen menor dolor postoperatorio, se recuperan más rápidamente y disminuyen la posibilidad de complicaciones a nivel de las heridas (hematomas, supuración y dehiscencias), y evolutivas como consecuencia de las mismas, como son las eventraciones, el dolor abdominal crónico y las oclusiones intestinales por formación de adherencias.

Una considerable cantidad de pacientes operados por laparoscopía con cuadros de colecistitis aguda han mostrado buenos resultados, con baja morbilidad y mortalidad ${ }^{117,118,119,120,121}$.

Con respecto a la oportunidad, la mayoría de los pacientes se benefician de un tratamiento médico inicial, una correcta valoración preoperatoria y un tratamiento quirúrgico precoz en las primeras 48 horas $^{122,123,124}$.

La colecistectomía laparoscópica temprana, dentro de las primeras 96 horas de comenzado el cuadro es la mejor opción según la mayoría de las series publicadas. Los índices de conversión, la morbilidad postoperatoria y la duración de la hospitalización disminuyen, si la cirugía se realiza en forma temprana. 
El tratamiento quirúrgico precoz es el mejor, salvo en situaciones particulares como ser: pacientes graves en los que se puede realizar el drenaje vesicular por punción percutánea; coledocolitiasis asociada o pancreatitis aguda.

En algunas situaciones excepcionales la colecistectomía puede ser diferida.

En los casos de evolución subaguda (más de 20 días), cuando la operación no se realizó por diferentes motivos, es conveniente, cuando es posible y no hay complicaciones (perforación vesicular) y la evolución es favorable; esperar a la remisión completa del cuadro con tratamiento médico y vigilancia y diferir la cirugía en algunas semanas o meses, hasta que el proceso inflamatorio aguda haya cesado ${ }^{125}$.

Cuando existe un procedimiento inflamatorio subagudo, las alteraciones anatómicas y la friabilidad del pedículo pueden ser muy importantes, con lo que aumenta la posibilidad de lesionar la vía biliar principal.

Un estudio de meta-análisis de Papi y colaboradores ${ }^{116}$ mostró, que no existe diferencia significativa en términos de morbilidad y mortalidad entre la intervención temprana y la electiva, pero si una disminución en los índices de conversión, una menor incidencia de complicaciones postoperatorias y un menor período de internación a favor de la cirugía temprana.

En la modalidad diferida se observó un aumento de los costos y del período de internación, y debe ser tenido en cuenta que alrededor de un 20 a un $30 \%$ de los pacientes que esperaban la cirugía, presentaron una complicación que requirió una operación de urgencia ${ }^{125}$; siendo la tasa de conversión a cirugía abierta en la CL diferida mayor al $30 \%{ }^{126}$.

Los pacientes diabéticos o inmunocomprometidos tiene mayor riesgo de padecer formas graves, perforadas, gangrenosas, enfisematosas ${ }^{127,128}$. En ellos se indica la cirugía en forma temprana, y de acuerdo al caso puede ser necesaria la realización de un procedimiento de descompresión percutánea.

El tratamiento por laparoscopía puede ser intentado de realizarse, en la mayoría de los casos.

El cirujano debe tener experiencia en la realización de colecistectomía laparoscópica de coordinación, especialmente teniendo en cuenta que esta cirugía es realizada frecuentemente por residentes en formación.

\section{Con respecto a algunos aspectos de la técnica quirúrgica:}

Es muy importante el realizar la decompresión vesicular por punción con abocat en forma percutánea a través del fondo, para facilitar la prensión y movilización vesicular.

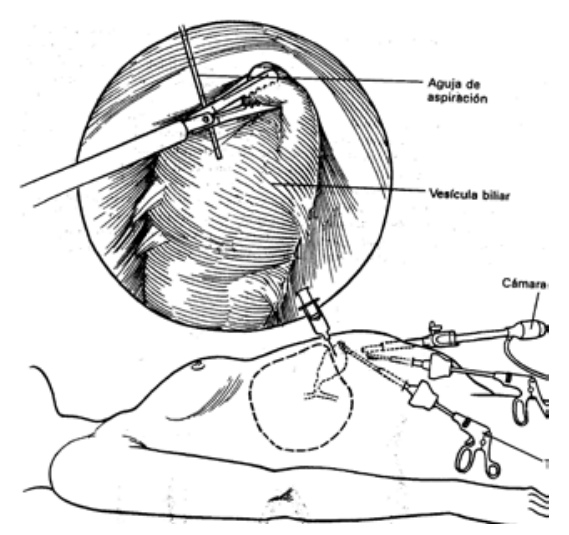

Figura 15. Punción y degravitación vesicular percutánea. (Tomado de Katkhouda). 
Se debe realizar una disección muy prolija y delicada de todas las adherencias perivesiculares y del pedículo hepático, para evitar el sangrado, que obstaculiza la visión y aumenta la posibilidad de realizar lesiones de la vía biliar, el duodeno y el colon derecho.

Es muy útil, segura y recomendable la realización de la hidrodisección con la utilización del aspirador lavador y la utilización de instrumentos romos (pinzas de disección de tipo Maryland).

La colangiografía es más riesgosa y de más difícil realización dada la friabilidad del conducto cístico. La indicamos cuando: hay elementos clínicos, ecográficos o de laboratorio de sospecha de litiasis coledociana; cuando el conducto cístico esta dilatado; si hay dudas en la anatomía de la vía biliar; o si se produce una bilirragia.

La colecistectomía generalmente es laboriosa y sangrante a pesar de haberse clipado la arteria cística. Es frecuente que se abra la vesícula con pérdida de cálculos o se lesione el lecho vesicular.

Para extraer la vesícula generalmente es conveniente introducirla en una bolsa o guante como utilizamos nosotros, a los efectos de evitar la rotura y pérdida de cálculos, y contaminación del trayecto parietal.

También es frecuente tener que agrandar la incisión de epigastrio, por lo que en estos casos debe cerrarse con puntos de sutura.

Se debe realizar una prolija limpieza de la cavidad peritoneal con aspiración y lavado con suero fisiológico, y en algunas situaciones es conveniente dejar un drenaje peritoneal subhepático.

Puede estar indicada la conversión a cirugía abierta cuando es imprescindible su realización, sobre todo cuando se sospecha una posible lesión de la vía biliar principal.

La conversión a cirugía abierta es más frecuente como ya se expresó (10 a 30\%).

Las causas más frecuentes de conversión son: el no reconocimiento de la anatomía biliar luego de un plazo razonable de disección; la existencia de una friabilidad extrema de los tejidos; la sospecha de que se trate de un carcinoma vesicular; hemorragias difíciles de controlar a nivel del pedículo hepático o del lecho vesicular, y una lesión de la vía biliar.

La conversión no debe considerarse como un fracaso, es una posibilidad terapéutica que debe manejarse, y es importante realizarla a tiempo, antes de que se produzcan lesiones. Es muy importante en este aspecto la experiencia que tiene el equipo quirúrgico tratante y debe ser la expresión cabal de la capacidad crítica, de análisis y prudencia del equipo quirúrgico.

Citamos dos frases del libro de Mosche Schein de cirugía abdominal de urgencia: "si después de 60 minutos de una cirugía laparoscópia se dan cuenta que no están llegando a ninguna parte, es el momento de bajar el pulgar indicando el vamos para una laparotomía"; "cuando la situación anatómica es compleja; la regla del hombre sabio es: vaya del fondo hacia abajo, y permanezca cerca de la vesícula"129.

Se consideran factores de riesgo para la conversión: la edad mayor de 65 años, leucocitosis superior a $13.000 \mathrm{~mm}^{3}$, y las colecistitis gangrenosas ${ }^{130}$.

La tasa de conversión para CA complejas es de hasta el $48 \%$, en comparación al $4.5 \%$ en los casos de CA leves.

Si las dificultades en la disección e identificación de las estructuras del pedículo son muy grandes, debe evaluarse la posibilidad de realizar operaciones en menos, como una colecistostomía o resección parcial de la vesícula y colocación de una sonda de Pezzer, para evitar una lesión de la vía biliar principal o de la arteria hepática o la vena porta.

En algunos casos en los que la vesícula esta incrustada en la placa vesicular y el parénquima hepático, no existiendo un plano anatómico claro, es aconsejable realizar la operación de Pribran ${ }^{131,132,133}$. En esta técnica se reseca el cuerpo y fondo de la vesícula libre, dejando el sector de la pared, adherido a la 
placa y continuando la disección a nivel del triángulo de Calot, donde la existencia de un meso, facilita la identificación de los elementos canaliculares.

Las complicaciones más frecuentes son a nivel de las heridas: hematomas e infección (0.3 a 1\%), eventraciones ( 0.3 a $0.5 \%$ ), lesiones por trócar ( 0.1 a $0.3 \%$ ), hemorragias $(0.1$ a $4 \%$ ), lesiones de vía biliar, peritonitis biliar, biloma y litiasis persistente o residual.

\section{Colecistostomía percutánea}

Consiste en descomprimir la vesícula biliar por punción percutánea guiada por ecografía, por vía transhepática y a través del fondo vesicular.

Esta técnica está indicada en las siguientes situaciones:

- Pacientes con un riesgo quirúrgico muy elevado por la presencia de comorbilidades, en los que el tratamiento quirúrgico convencional tiene una tasa de morbilidad cercana al $65 \%$ y mortalidad del $35 \%{ }^{134,135,136}$. Posee como ventaja la posibilidad de poder realizarse con anestesia local y lograr el alivio del dolor y el control de la sepsis en las primeras 24-48 horas ${ }^{137}$. Es prácticamente realizable en casi el $100 \%$ de los casos, y tiene índices de morbilidad y mortalidad bajos, del $10 \mathrm{y}$ $2 \%$ respectivamente ${ }^{138}$. Permite la realización de estudios radiológicos (colangiografía) y permite el diagnóstico y tratamiento de la litiasis de la VBP.

- Colecistitis alitiásicas en pacientes graves.

- CA en pacientes ancianos y en estado crítico sin respuesta al tratamiento médico conservador ${ }^{139,140}$.

Las principales complicaciones de esta técnica son:

- salida del catéter, CA recurrente en el $25 \%$ de los $\operatorname{casos}^{141}$

- reacciones vagales, peritonitis biliar

- perforación intestinal

- sepsis

- neumotórax

\section{Colecistectomía laparoscópica en pacientes con fístulas biliares internas}

Los pacientes con síndrome de Mirizzi son los más complejos de resolver, dada las alteraciones anatómicas que determinan en la vía biliar, siendo la incidencia de este síndrome del 0.1 al $0.7 \%{ }^{142,143}$.

El tratamiento por laparoscopía es posible, sin embargo estos pacientes deben ser operados por cirujanos muy entrenados y con mucha experiencia en cirugía biliar laparoscópica y con una adecuada infraestructura.

Las tasas de conversión son elevadas, del 30 al $60 \%{ }^{144}$.

Se debe tener espacial precaución de no lesionar la VBP, para lo cual puede llegar a ser necesario realizar, en los casos que existe un pedículo congelado, con alteraciones inflamatorias que hagan muy difícil identificar con claridad la VBP, colecistostomías con extracción de los cálculos, dejando una sonda Petzer, o colecistectomías parciales tipo Pribran. 
La conversión a cirugía abierta debe estar siempre presente y no debemos empecinarnos en continuar la cirugía por laparoscopía, cuando la situación anatómica es muy compleja, existe riesgo elevado de lesionar la VBP y/o se prolonga en forma desmedida la operación.

Es muy importante realizar una colangiografía intraoperatoria transcística o por punción, para definir la anatomía de la vía biliar y descartar la presencia de una litiasis coledociana, la cual deberá ser extraída.

Puede ser necesaria la realización de una biopsia extemporánea para descartar la presencia de una patología tumoral maligna.

El tratamiento de los síndrome de Mirizzi tipo II, va desde la colocación de un tubo de Kehr en la zona de la fístula con o sin rafia de la pared de la vía biliar, hasta los procedimientos de derivación biliar con la realización de una hepaticoyeyunoanastomosis latero-lateral o termino-lateral, de elección esta última para algunos autores ${ }^{145}$.

Cuando existe una fístula colecistoduodenal, es posible realizar la colecistectomía, la exploración radilológica de la VBP y luego proceder al cierre del orificio duodenal con puntos por laparoscopía, como lo hemos realizado en alguna ocasión y con buenos resultados.

\section{Colecistectomía laparoscópica en pacientes obesos}

Actualmente es aceptado que la obesidad es un factor de riesgo para el desarrollo de la litiasis biliar, independientemente de la edad y el sexo, y que aproximadamente el $20 \%$ de los pacientes obesos presentan cálculos vesiculares ${ }^{146}$.

La sensibiliad de la ecografía abdominal para detectar litiasis en pacientes obesos, se ve disminuida, llegando en algunos casos solo a un $65 \%{ }^{147}$. Esto es debido al gran espesor de la pared abdominal y la cantidad de tejido adiposo dentro de la cavidad, que dificultan el registro de las imágenes del ultrasonido.

En el inicio de la cirugía laparoscópica, la obesidad era considerada una contraindicación relativa para el abordaje mini invasivo, debido a las dificultades que se podían presentar para la realización de la colecistectomía.

Al adquirir mayor experiencia en la realización de la técnica, sumado a la mejora del instrumental y equipos de visión e iluminación, la colecistectomía laparoscópica se ha transformado en el método de elección para el tratamiento de la litiasis vesicular en obesos.

Se considera una técnica segura y eficaz; siendo estos pacientes los más beneficiados, dado que la cirugía abierta tiene mayor morbilidad por las incisiones. Estos pacientes tienen una disminución de la estadía hospitalaria y un más rápido reintegro a sus actividades habituales ${ }^{148,149}$.

Los pacientes comienzan a deambular precozmente, pero igualmente deben tomarse las medidas necesarias para prevenir las trombosis venosas y el TEP.

\section{Técnica quirúrgica}

Generalmente no se requiere de instrumental especial con respecto al resto de las colecistectomías en pacientes delgados, pero sí, de la realización de algunos detalles de técnica quirúrgica.

Los pacientes deben ser muy bien fijados a la mesa de operaciones, para poderlos colocar en una posición de anti-Trendelunbur acentuado y lateral izquierda, a los efectos de que las vísceras del piso inframesocólico caigan a la pelvis. 
Es muy importante la utilización de una óptica de 30 으, a los efectos de poder tener una correcta visualización del pedículo hepático, sorteando con la visión angulada de la óptica, el epliplón y el gastroduodeno.

Generalmente no se requieren de agujas de Veress, trócares e instrumentos especiales, más largos.

El emplazamiento de los puertos, es similar; pudiéndose colocar el trócar umbilical en una posición más alta, para estar más próximos con la cámara a la zona operatoria, en pacientes muy grandes.
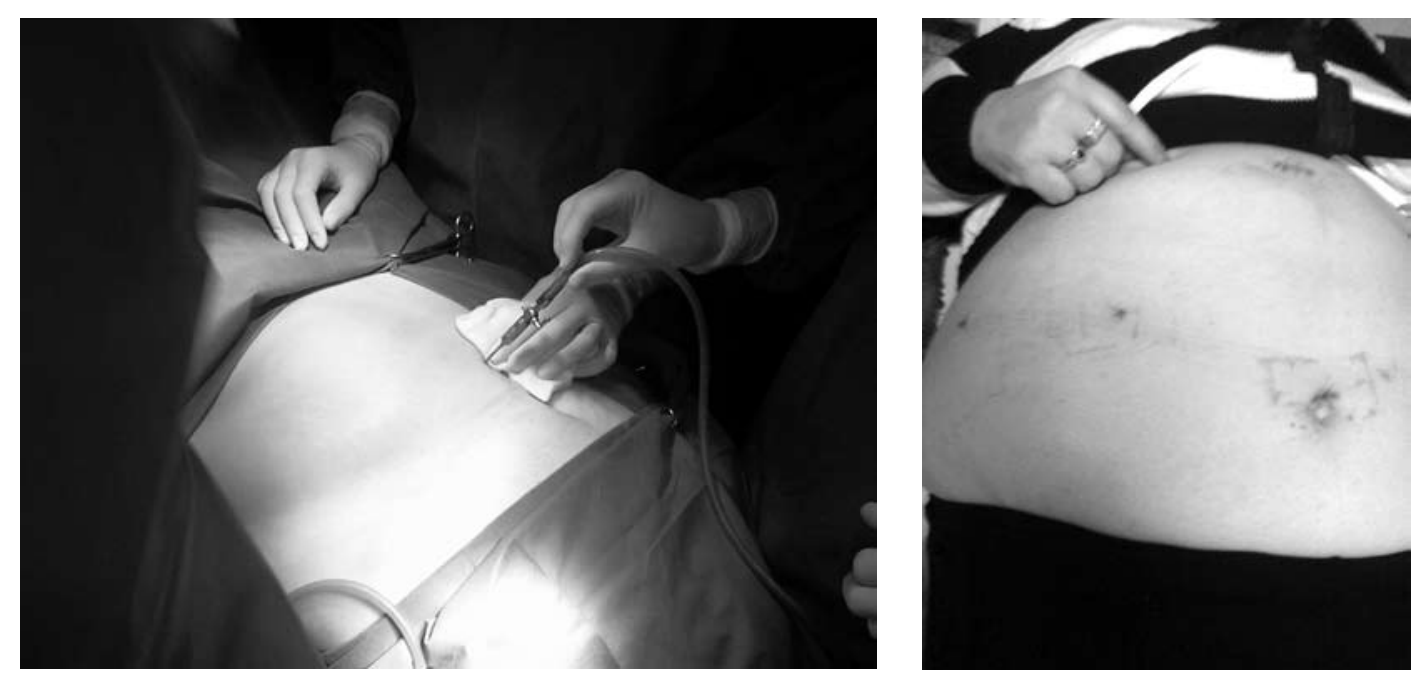

Figura 2. Colecistectomía laparoscópica en paciente obesa.

Generalmente la exposición es más dificultosa y debemos ser muy cuidadosos con la prensión y tracciones realizadas con los instrumentos, dada la mayor fragilidad de los tejidos, sobre todo el hígado por la esteatosis que frecuentemente se asocia.

La identificación del pedículo suele ser más dificultosa por la infiltración grasa y la colecistectomía es más laboriosa.

La extracción vesicular también es más dificultosa, debido al mayor espesor de la pared.

Si bien esta técnica es más difícil y es conveniente que sea realizada por cirujanos entrenados y con experiencia, los beneficios para el paciente son mayores y en nuestra experiencia personal es más sencilla y rápida que la cirugía abierta.

Con respecto a la conducta de realizar la colecistectomía laparoscópica en el curso de la cirugía bariátrica, es motivo de debate.

Algunos autores, recomiendan realizar la colecistectomía rutinaria con fines profilácticos, durante la realización de los procedimientos convencionales de cirugía bariátrica, por la posibilidad elevada de desarrollar cálculos en el postoperatorio ${ }^{150}$.

Otros consideran que no está indicada la colecistectomía en pacientes alitiásicos ni asintomáticos, dado el bajo índice de necesidad de colecistectomías después de la cirugía bariátrica. Además se incrementa el tiempo quirúrgico y la aparición de posibles complicaciones ${ }^{151}$.

Existe un acuerdo casi generalizado, en que la colecistectomía debe asociarse al bypass gástrico laparoscópico en la litiasis vesicular sintomática, a pesar de los mayores tiempos quirúrgicos y del mayor porcentaje de complicaciones ${ }^{152}$. 


\section{Colecistectomía laparoscópica en pacientes con cirugías previas por laparotomía}

En los pacientes con laparotomías, no existe una contraindicación absoluta para la realización de la colecistectomía laparoscópica.

La formación de adherencias es muy variable de un paciente a otro y es imposible de valorar en el preoperatorio.

Las cirugías previas del abdomen superior por incisiones medianas o transversas, generalmente determinan la formación de adherencias del epiplón mayor a la cicatriz operatoria, por lo que se debe realizar la adhesiolisis por laparoscoía para poder llegar a la vía biliar. Pueden también adherirse asas delgadas y el colon transverso.

Las incisiones del abdomen inferior también pueden producir adherencias, como ser las incisiones de Mc Burney, medianas infraumbilicales y de Phannestiel; pero generalmente dejan libre al sector superior del abdomen y no dificultan la realización de la colecistectomía.

La videolaparoscopía se puede realizar en casi todos los casos, como procedimiento inicial.

En los períodos iniciales de la cirugía laparoscópica, los porcentajes de conversión eran de hasta un $50 \%{ }^{153,154}$; siendo actualmente de aproximadamente el $10 \%{ }^{155,156}$.

Los pacientes con gastrectomías oncológicas y linfadenectomías de los grupos ganglionares D2 suelen tener adherencias firmes, por lo que es frecuentemente necesario convertir a cirugía abierta ${ }^{157}$.

El neumoperitoneo, puede realizarse por entrada abierta, bajo visión directa y con control digital.

Otra forma de realizarlo, es mediante la introducción de la aguja de Veress, por un acceso alejado de las incisiones previas y luego introducir el primer trócar con la óptica, bajo visión, con la utilización de un trocar en espiral de tipo Taernamian.

Existen trócares especiales, transparentes y huecos, que pueden ser introducidos con la óptica en su interior y permiten ir visualizando al atravesarse, los diferentes planos parietales.

Algunos autores aconsejan para evitar la lesión de vísceras huecas, realizar una ecografía parietal, con alto índice de positividad y sin ninguna complicación ${ }^{158}$.

Resulta difícil diseñar estudios que puedan determinar diferencias significativas entre las técnicas de acceso mencionadas, dado que la tasa de complicaciones es muy baja y que, por lo tanto, el número de pacientes necesario sería, también muy grande.

Los cirujanos deben tomar decisiones sobre la técnica de acceso más apropiada, en función de sus propias habilidades y entrenamiento, del equipo y el instrumental disponible y de su experiencia.

\section{Colecistectomía laparoscópica en pacientes embarazadas}

La litiasis biliar en la paciente embarazada es la patología quirúrgica no ginecológica más frecuente. Tiene una incidencia del 2 al 14\% aproximadamente ${ }^{159,160}$.

Constituye una entidad clínica, que plantea muchos problemas materno- fetales, especialmente desde el punto de vista terapéutico.

Tiene una morbi-mortalidad para la madre y para el feto, que se incrementa durante todo el embarazo ${ }^{161,162}$. 
En la litiasis vesicular asintomática, no existe una indicación formal para realizar la cirugía profiláctica en las mujeres con deseos de embarazarse, dado que las posibilidades de hacerse sintomáticas son bajas y sobre todo en un período relativamente corto, como es el embarazo ${ }^{163}$.

En las pacientes con litiasis vesicular sintomática y deseos de embarazarse, es apropiado proponerles la realización del tratamiento definitivo de la litiasis, mediante la colecistectomía laparoscópica.

Existe consenso en la literatura, que toda patología de tratamiento quirúrgico, de ser posible, deberá postergarse hasta después del parto para su tratamiento definitivo y que todos aquellos cuadros de litiasis biliar complicada que puedan comprometer el estado materno-fetal, deberán ser resueltos de inmediato $^{164,165}$.

En la litiasis vesicular sintomática, durante el embarazo, deberá en la medida de lo posible realizarse tratamiento médico y postergar la cirugía para luego del parto.

En los cuadros agudos de colecistitis, durante el embarazo, se puede plantear el tratamiento médico. Si éste no es eficaz, deberá evaluarse de acuerdo a parámetros clínicos y de laboratorio la necesidad de cirugía y en los casos graves, la decompresión vesicular percutánea o quirúrgica.

Sobre todo los casos complejos, deben ser manejados y resueltos por equipos multidisciplinarios integrados por obstetras, cirujanos, endoscopistas y radiólogos.

Si bien, no hay un consenso en cuanto a la vía de abordaje, hay muchos trabajos que demuestran que la cirugía laparoscópica no tiene contraindicaciones y puede ser utilizada con seguridad y tiene excelentes resultados ${ }^{166,167,168,169,170}$.

Se recomienda que la presión intra abdominal de neumoperitoneo, sea lo más baja posible y no supere los $10 \mathrm{~mm} \mathrm{Hg}^{171,172}$.

Es conveniente la colocación de una sonda naso gástrica, previo a la inducción anestésica para evitar el reflujo gastroduodenal y riesgo de aspiración, debido al cambio fisiológico que se genera en el esfínter esofágico inferior ${ }^{173,174}$.

El útero aumentado de tamaño, dificulta la realización de la cirugía, la creación del neumoperitoneo y el ingreso de los trócares; por lo que es conveniente utilizar la técnica abierta ${ }^{175,176,177,178}$.

Con respecto a la oportunidad, es conveniente en la medida de lo posible, realizar la cirugía en el segundo trimestre, debido al menor porcentaje de abortos (6\%) en relación al primero (15\%) y de partos prematuros ${ }^{169,170}$.

\section{Colecistectomía laparoscópica en pacientes con una hepatoptía crónica}

La colecistectomía laparoscópica en pacientes con una hepatopatía crónica (cirrosis), puede ser más complicada, debido a la mayor fragilidad del hígado, a la presencia de una hipertensión portal con el desarrollo de circulación colateral y riesgo aumentado de sangrado y a alteraciones de la coagulación.

Al principio se consideraba una contraindicación de la colecistectomía laparoscópica, pero al adquirirse mayor experiencia en esta técnica, es posible su realización.

Algunos autores, como Yehn, muestran en un trabajo de 226 pacientes operados Child A y B, comparado con 4.030 no cirróticos: igual tiempo operatorio, igual porcentaje de conversión (4.4\%), igual morbilidad y tiempo de internación, mayor sangrado intraoperatorio ( $54 \mathrm{vs} 30 \mathrm{ml}$ ), y mayor tasa de mortalidad $(0.88 \% \text { vs } 0.01 \%)^{179}$.

Con respecto a algunos detalles de la técnica quirúrgica: 
- Se debe realizar una suave tracción del fondo vesicular por parte del segundo ayudante para no producir desgarros y laceraciones hepáticas, dada la mayor fragilidad del hígado.

- Puede ser muy laboriosa y sangrante la disección del conducto cístico, por la presencia de gruesas venas pericísticas, es conveniente realizar una colangiografía intraoperatoria para descartar la presencia de una litiasis de la vía biliar principal, dado el antecedente frecuente de episodios de ictericia.

- La colecistectomía debe realizarse en forma muy meticulosa, a través del plano adecuado y sin desgarrar la placa vesicular para evitar la presencia de complicaciones hemorrágicas.

- Puede ser necesaria la colocación de un quinto puerto para la introducción del aspirador, a los efectos de mantener el campo exangüe y facilitar la disección.

- Es conveniente cerrar con puntos los puertos de $10 \mathrm{~mm}$, para evitar la fuga de ascitis.

\section{Bibliografía}

1) Gallstones and laparoscopic cholecystectomy. NIH Consens Statement 1992; 10: 1-28.

2) Sain AH. Laparoscopic cholecystectomy is the current "gold standard" for the treatment of gallstone disease. Ann Surg. 1996; 224: 689-90.

3) Langenbuch C. Elin fall von extirpation de gallenblase wegen chronischer cholelithiasis. Heilung Berl Klin Wsch. 1882; 19: 725.

4) Mühe E. Die erste cholecystecktomie durch das laparoskop. Langenbecks. Arch Klin Chir 1986; 369: 804.

5) Semm K. Die endoskopic intra abdominelle naht. Geburtsh u Frauenheilk 1982; 42: 56-7.

6) Mühe E. Laparoskopiche cholezystektomie-spätergebnisse. Langenbecks Arch Chir Suppl (Kongrebericht) 1991; 188: 416-23.

7) Kleiman A. Colecistectomía Laparoscópica en ovejas. Rev Arg de Cir 1987; 52: 317-9.

8) Dubois F, Berthelot G, Leverth H. Cholecystectomie par celioscopie. Presse Med 1989; 18:980-2.

9) Reddick EF, Olsen DO. Laparoscopic laser cholecystectomy: a comparison with mini-lap cholecystectomy. Surg Endosc. 1989; 3: 131-3.

10) Gutiérrez RL, Grau Cobos LM, Rojas NA y col. Colecistectomía por laparoscopía. Informe del primer caso realizado en México. Endoscopía 1990; 3: 99-102.

11) Ayala LA, Soucchon E, Belloso R y col. La colecistectomía por videolaparoscopía. Cirugía de acceso mínimo. Trib Méd 1991; 60: 89-96.

12) Cervates J. Historia de la colecistectomía por laparoscopía. En: Cervantes J, Patiño JF. Cirugía laparoscópica y toracoscópica. España: Graw-Hill Interamenricana; 1997. 8: 45-50.

13) Mc Sherry CK, Ferstenberg H, Calhoun WF, Lahman E, Virshup M. The natural history of diagnosed gallstone disease in symptomatic and asymtomatic patients. Ann Surg. 1985; 202:59-63.

14) Gurusamy KS, Samraj K, Fusai G et al. Early versus delayed laparoscopic cholecystectomy for biliary colic. Cochrane Databases Syst Rev. 2008; 8: CD007196.

15) National Institutes of Health Consensus Development Conference Statement: gallstones and laparoscopic cholecystectomy. September 14-16, 1992. J Laparoendosc Surg 1993; 3: 77-90.

16) Lowenfels $A B$, Lindstrom CG, Conway MJ, Hastings PR. Gallstones and risk of gallbladder cáncer. J Natl Cancer Inst. 1985; 75: 77-80.

17) Nuzzo G, Giuliante F, Giovannini I, Ardito F, D'Acapito F, Vellone M, et al. Bile duct injury during laparoscopic cholecystectomy: results of an Italian national survery on 56.591 cholecystectomy. Arch Surg. 2005; 140: 986-92. 
18) Amaral JF, Thompson WR. Gallbladder disease in the morbidly obese. Am J Surg. 1985; 149: 551-7.

19) Shiffman ML, Sugerman HJ, Kellum JH, Brewer WH, Moore EW. Gallstones in patients with morbid obesity. Int J Obes Relat Metab Disord. 1993; 17: 153-8

20) Pokorny WJ, Saleem M, O’Gorman RB, Mc Gill C, Harberg F. Cholelithiasis and cholecystitis in childhood. Am J Surg. 1984; 148: 742-4.

21) Ashur H, Siegal B, Oland Y, Adam Yl. Calcified gallbladder (porcelain gallbladder). Arch Surg. 1978; 113: 594-6.

22) Stephen AE, Berger DL. Carcinoma in the porcelain gallbladder: a relationship revosoted. Surgery. 2001; 129: 699-703.

23) Escalona A, León F, Bellolio F, Pimentel F, Guajardo M, Gennero R, et al. Pólipos vesiculares: correlación entre hallazgos ecográficos e histopatológicos. Rev. Méd Chile. 2006; 134: 1237-42.

24) Bonatsos G, Birbas K, Toutouzas K, Durakis N. Laparoscopic cholecystectomy in adults with sickle cell disease. Surg Endosc. 2001; 15: 816-9.

25) Ware RE, Kinney TR, Casey JR, Pappas T, Meyers W. Laparoscopic cholecystectomy in youg patients with sickle hemoglobinopathies. J Pediatr. 1992; 120: 58-61.

26) Kao LS, Kuhr CS, Flum DR. Should Cholecystectomy Be Performed for Asyntomatic Cholelithiasis in Trasplant Patients? J A Coll Surg. 2003; 197: 302-12.

27) Graham SM, Flowers JL, Schweitzer E, Bartlett ST, Imbembo AL. The utility of prophylactic laparoscopic cholecystectomy in the transplant candidates. Am J Surg. 1995; 169: 44-8.

28) Gurusamy KS, Samraj K.Cholecystectomy for patients with silent gallstones. Cochrane Database of Systematic Review 2007, Issue 1. Art. №.:CD006230. DOI: 10.1002/14651858.CD006230.pub2.

29) Cuschieri A. Whiter minimal acces surgery: tribulations and expectations. Am J Surg 1995; 169: 9

30) Patiño JF. Conveniencia de la colecistectomía laparoscópica en el paciente con litiasis asintomática. Cir Cirujanos (México) 1996; 64: 29.

31) Yamashita Y, Takada T, Kawarada Y, Nimura Y, Hirota M, Miura F et al. Surgical treatment of patients with acute cholecystitis: Tokyo Guidelines. J Hepatobiliary Pancreat Surg. 2007; 14:91-7.

32) Kimura Y, Takada T, Kawarada Y, Hirata K, Mayumi T, Yoshida M, et al. JPN guidelines for the management of acute pancreatitis: treatment of gallstones-induced acute pancreatitis. J Hepatobiliary Pancreat Surg. 2006; 13: 56-60.

33) Wilson CT, de Moya MA. Cholecistecomy for acute gallstone pancreatitis: early versus delayed approach. Scand J Surg. 2010; 99: 81-5.

34) Heinrich S, Schäfer M, Rousson V, Clavien PA. Evidence-based treatment of acute pancreatitis: A look established paradigms. Ann Surg. 2006; 243: 154-68.

35) Smadja C, Blumgarth LH. Vías biliares y exposición quirúrgica del pedículo biliar. En: Cirugía del Hígado y de las vías biliares. Buenos Aires: Médica Panamericana; 1990. P. 12-27.

36) Gramática L, Senzín M. Anatomía Quirúrgica. En: Cirugía de las vías biliares y bazo. Indicaciones y técnicas. Córdoba: Universidad Nacional de Córdoba; 1990. p. 35-42.

37) Gramatica L - Sezin M - Aranega Cl - Olivares PE. Consideraciones anatómicas sobre la placa hiliar y su relación con la cirugía de los conductos hepáticos. Rev Esp Enferm Apar Dig. 1975; 45:613-24

38) Senecail B, Texier F, Kergastel I, Patin-Philippe L. Anatomic variability and congenital anomalies of the gallbladder: ultrasonographic study of 1823 patients. Morphologie 2000; 84: 35-9.

39) Van Damme JP. Behavioral anatomy of the abdominal arteries. Surg Clin North Am. 1993; 73: 699-725.

40) Sajid MS, Khan MA, Ray K, Cheek E, Baig MK. Needlescopic versus laparoscopic cholecystectomy: a metaanálysis. ANZ J Surg 2009; 79: 437-42. 
41) Chamberlain RS, Sakpal SV. A Comprehensive Review of Single-Incision Laparoscopic Surgery and Natural Orifice Transluminal endoscopic Surgery Techniques for Cholecystectomy. J Gastrointest Surg. 2009; 13: 173340.

42) Ma J, Cassera MA, Spaun GO, Hammill CW, Hansen PD, Aliabadi-Wahle S. Randomized Control Trial Comparing Single-Port Laparoscopic Cholecystectomy and Fourd Port Laparoscopic Cholecystectomy. Ann Surg. 2011; 254: 22-7.

43) Dallemagne B, Marescaux J. Notes: past, present and future. Asian J Endosc Surg. 2010; 3: 115-21.

44) Park PO, Bergström M, Ikeda K, Fritscher-Ravens A, Swain P. Experimental studies of transgastric gallbladder surgery: cholecystectomy and cholecystogastric anastomosis. Gastrointest Endosc. 2005; 61: 601-6.

45) Marescaux J, Dallemagne B, Perretta S, Wattiez A, Mutter D, Coumaros D. Surgery without scars: report of transluminal cholecystomy in a human being. Arch Surg. 2007; 142: 823-6

46) SAGES ASGE ASGE/SAGES working group on natural orifice translumenal endoscopic surgery white paper October 2005. Gastrointest Endosc. 2005; 63: 199-203.

47) Salinas G, Saavedra L, Agurto H, Quispe R, Ramírez E, Grande J, et al. Early experience in human hybrid transgastric and transvaginal endoscopic cholecystectomy. Surg Endosc. 2010;24:1092-8

48) Bardaro SJ, Swanström L. Development of advenced endoscopes for Natural Orifice Transluminal Endoscopic Surgery. Minim Invasive Ther Allied Technol. 2006; 15: 378-83.

49) Mirizzi PL. Fisiopatología del hepatocolédoco. Colangiografía operatoria. Buenos Aires: El Ateneo; 1939.

50) Mac Fadyen BV. Intraoperative cholangiography: past, present, and future. Surg Endosc. 2006; 20(Supl 2): 43640.

51) Soper NJ, Brunt LM. The case for routine operative cholangiography during laparoscopic cholecystectomy. Surg Clin North Am. 1994; 74: 953-9.

52) Mc Lean TR. Risk management observations from litigation involving laparoscopic cholecystectomy. Arch Surg. 2006; 141: 643-8.

53) Way LW, Stewart L, Gantert W, Liu K, Lee CM, Whang K et al. Causes and prevention of laparoscopic bile duct injuries: analysis of 252 cases from a human factors and cognitive psychology perspective. Ann Surg. 2003; 237: 460-9.

54) Metcalfe MS, Ong T, Bruening MH, Iswariah H, Wemyss-Holden SA, Maddern GJ. Is laparoscopic intraoperative cholangiogram a matter of routine? Am J Surg. 2004; 187: 475-81.

55) Wright KD, Wellwood JM. Bile duct injury during laparoscopic cholecystectomy witthout operative cholangiography. Br J Surg. 1998; 85: 191-4.

56) Moskovitz AH, Bush WH Jr, Horvat KD. Anaphylactoid reaction to intraoperative cholangiogram. Report of a case, review of literatura, and guidelines for prevention. Surg Endosc. 2001; 15: 1227.

57) Massarweh NN, Flum DR. Role intraoperative cholangiography in avoiding bile duct injury. J Am Coll Surg. 2007; 204: 656-64.

58) Keus F, de Jong JA, Gooszen HG, van Laarhoven CJ. Laparoscopic versus open cholecystectomy for patients with symptomatic cholecystolithiasis. Cochrane Database Syst Rev. 2006; 18: CD006231.

59) Nuzzo G, Giuliante F, Giovannini I, Ardito F, D’Acapito F, Vellone M, et al. Bile duct injury during laparoscopic cholecystectomy: results of an Italian national survery on 56.591 cholecystectomies. Arch Surg. 2005; 140: 986-92.

60) Fischer JE. Is damage to the common bile duct during laparoscopic cholecystectomy an inherent risk of the operation? Am J Surg. 2009; 197: 829-32

61) Ponsky JL.: Pitfalls in laparoscopic Cholecystectomy. Prob. Gen. Surg. 1991; 8: 321-8. Gouma DJ: Complicated Laparoscopic Cholecystectomy. Dig. Surg. 2002; 19: 114-6. 
62) Schäfer M, Lauper M, Krähenbühl L. Trocar and Veress needle injuries during laparoscopy. Surg Endosc. 2001; 15: 275-80.

63) Deziel DJ, Millikan KW, Economou SG, Doolas A, Ko ST, Airan MC. Complications of laparoscopic cholecystectomy: a National Survery of 4292 Hospitals and an analysis of 77.604 Cases. Am J Surg. 1993; 165: 9-14.

64) Lee VS, Chari RS, Cucchiaro G, Meyers WC. Complications of laparoscopic cholecystectomy. Am J Surg. 1993; 165: 527-32.

65) Deyo GA. Complications of laparoscopic cholecystectomy. Surg Laparosc. Endosc. 1992; 2: 41-8.

66) Bida B, Manger T. The iatrogenic small bowel perforation as a complication of laparoscopic cholecystectomy. Zentralbl Chir 2002; 127: 554-8.

67) Polychronidis A, Tsaroucha AK, Karayiannakis AJ, Perente S, Efstathiou E, Simopoulos C. Delayed perforation of the large bowel due to termal injury during laparoscopic cholecystectomy. J Int Med Res. 2005; 33: 360-3..

68) Chandio A, Timmons S, Majeed A, Twomey A, Aftab F. Factors influencing the successful completion of laparoscopic cholecystectomy. JSLS. 2009; 13: 581-6.

69) Fitzgibbons RJ, Annibali R, Litke BS. Gallblader and gallstone removal, open versus closed laparoscopy and neumoperitoneum. Am J Surg. 1993; 165: 497-504

70) Lightdale C. Indications, contraindications, and complications of laparoscopy. In: Sivak M. Ed Gastroenterologic Endoscopy. Philadelphia: WB Saunders; 1987: 1039.

71) Antsaklis GI, Karanikas ID, Sakellaridis TE, Alexiou CP, Konstantinidou E, Economou N. Subcapsular hematoma of the liver: a rare complication of the laparoscopic cholecystectomy. Minerva Chir. 2009; 64: 322-3.

72) Alexander HC. Two unusual hemorragic complications during laparoscopic cholecystectomy. Surg Laparosc Endosc. 1993; 3: 346-8.

73) Feliciano DV. Surgery of liver trauma. Surg Clin North Am. 1989; 69: 273-84.

74) Sharp KW, Locicero RJ. Abdominal packing for surgically uncontrollable hemorrhage. Ann Surg. 1992; 215 : 467-75.

75) Shen GK, Rappaport W. Control of nonhepatic intraabdominal hemorrahage with temporary paccking. Surg Gyneco Obstet. 1992; 174: 411-3.

76) Ercan M, Bostanci EB, Ozer I, Ulas M, Ozogul YB, Teke Z, et al. Postoperative hemorrhagic complicationts after elective laparoscopic cholecystectomy in patients receiving long-term anticoagulant therapy. Langenbecks. Arch Surg. 2010; 395: 247-53.

77) Koffron A, Ferrario M, Parsons W, Nemcek A, Saker M, Abecassis M. Failed primary managements of iatrogenic biliary injuries: incidente and significance of concomitant hepatic arterial disruption. Surgery. 2001; 130: 728-31.

78) Quinn SF, Sangster W, Standage B, Schuman E, Gross G. Biliary complications related to laparoscopic cholecystctomies: Radiologic diagnosis and management. Surg Laparosc Endosc. 1992; 2: 279-86.

79) Valdivieso López A, Gastaca Mateo M y Ortiz de Urbina. Lesiones iatrogénicas de la vía biliar. En: Casanova D, Fernandez-Cruz, Pardo F. Cirugía Biliopancreática. España: Arán; 2009; p 64-79.

80) Archer SB, Brown DW, Smith CD, Branum GD, Hunter JG. Bile duct injury during laparoscopic cholecystectomy: result of national survery. Ann Surg. 2001; 234: 549-58.

81) Manson J. Bile duct injury in the era of laparoscopic cholecystectomy. Br J Surg. 2006; 93: 640-1

82) Deziel DJ, Millikan KW, Economou SG, Doolas A, Ko ST, Airan MC. Complications of laparoscopic cholecystectomy: a national survery of 4292 hospitals and a analysis of 77604 cases. Am J Surg. 1993; 165: 9-14.

83) Melton GB, Lillemoe KD, Cameron JL, Sauter PA, Coleman J, Yeo CJ. Major bile duct injuries associated with laparoscopic cholecystectomy: effect of surgical repair on quality of life. Ann Surg. 2002;235:888-95.

84) Chapman WC, Abecassis M, Jarnagin W, Mulvihill S, Strasberg SM. Bili duct injuries12 years after de introduction of laparoscopic cholecystectomy. J Gastrointest Surg. 2003; 7: 412-6. 
85) Rosen M, Brody F, Ponsky J. Predictive factors for conversión of laparoscopic cholecystecomy. Am J Surg. 2002; 184: 254-8

86) Strasberg SM, Hertl M, Soper NJ. An Analysis of the problem of biliary injury during laparoscopic cholecystectomy. Am J Coll Surg. 1995; 180: 101-25.

87) Scott T, Zucker K, Bailey R. Laparoscopic cholecystectomy: a review of 12.397 patients. Surg Laparosc Endosc. 1992; 2: 191-8.

88) Ahmad F, Saunders RN, Lloyd GM, Lloyd DM, Robertson GS. An algorithm for the management of bile leak following laparoscopic cholecystectomy. Ann R Coll Surg Engl. 2007; 89: 51-6.

89) Davidoff AM, Pappas TN, Murray EA, Hilleren DJ, Johnson RD, Baker ME, et al. Mechanisms of mayor biliary injury during laparoscopic cholecystectomy. Ann Surg. 1992; 215: 196-202.

90) Salom A. Complicaciones biliares de la cirugía laparoscópica de la vía biliar. (en prensa).Trabajo presentado en la Sociedad de Cirugía del Uruguay en agosto de 2011.

91) De Santibañes E, Pekolj J, Stork G. Lesiones quirúrgicas de la vía biliar y sus consecuencias. Enfoque en el nuevo milenio. En: Perera S, García H. Cirugía de Urgencia. Buenos Aires: Panamericana; 2007. p. 605-31.

92) Casavilla F, Gasali F, Uchiumi L. Qué hacer y qué no hacer ante una lesión quirúrgica de la vía biliar. En: Perera S, García H. Cirugía de Urgencia. Buenos Aires: Panamericana; 2007. p. 573-9.

93) Angrisani L. Laparotomic conversion during videolaparoscopic cholecistectomy. Chirurgia. 1999; 12(5): 31926.

94) Azagra JS, De Simona P, Goergen M. Is there a place for laparoscopy in management of postcholecystectomy biliary injuries? World J Surg. 2001; 25: 1331-4.

95) Lada E, Ávila JA. Complicaciones más frecuentes de la cirugía biliar. En: Gramática L. ABC de la cirugía biliar. Buenos Aires: Médicas del Sur; 2011. p.399-416.

96) Catarci M, Zaraca F, Scaccia M, Carboni M. Lost intraperitoneal stones after laparoscopic choleccystecomy: harmless séquela or reason for re-operation? Surg Laparosc Endosc. 1993; 3: 318-22.

97) Sooper N, Dunnegan D. Does intraoperative gallbladerperforations influence the early outcome of laparoscopic cholecystectpmy? Surg Laparosc. Endosc. 1991; 1: 156-61.

98) Phillips E, Daykhovsky L, Carroll B, Gershman A, Grundfest WS. Laparoscopy cholecystectomy: instrumentation and technique. J Laparoendosc Surg. 1990; 1: 3-15.

99) Bouasker I, Zoghlami A, El Ouaer MA, Khalfallah M, Samaali I, Dziri C. Parietal abscess revealing calculation forget eight years after laparoscopic cholecystectomy. Tunis Med. 2010; 88: 277-9.

100) Cullis SN, Jeffery PC, McLauchlan G, Bornman PC. Intraperitoneal abscess after laparoscopic cholecystectomy. Surg Laparosc Endosc. 1992; 2: 337-8

101) Mc Lean TR. Risk management observations from litigation involving laparoscopic cholecystectomy. Arch Surg. 2006; 141: 643-8.

102) Ibrahim S, Hean TK, Ho LS, et al. Risk factors for conversión to open surgery in patients undergoing laparoscopic cholecystectomy. World J Surg. 2006; 30: 1698-704.

103) Mc Aneny D. Open Cholecystectomy. Surg Clin N Am. 2008; 88: 1273-94.

104) Brueggemeyer MT, Saba AK, Thibodeaux LC. Abscess formation following spilled gallstones during laparoscopic cholecystectomy. JSLS. 1997; 1: 145-52.

105) Uludag M, Yetkin G, Citgez B. The role of prophylactic antibiotics in elective laparoscopic cholecystectomy. JSLS. 2009; 13: 337-41.

106) Yildiz B, Abbasoglu O, Tirnaksiz B, Hamaloglu E, Ozdemir A, Sayek I. Determinants of postoperative infection after laparoscopic cholecystectomy. Hepatogastroenterology. 2009; 56: 589-92. 
107) Sciumè C, Geraci G, Pisello F, Facella T, Li Volsi F, Modica G. Common bile duct stones in cholecystectomized patients. En: Borzellino G, Cordiano C. Biliary litiasis. Current diagnosis and management. Heidelberg: Springer-Verlag; 2008. p. 365-79.

108) Shively EH, Wieman TJ, Adams AL, Romines RB, Garrison RN. Operative cholangiography. Am J Surg. 1990; 159: 380-4.

109) Horwood J, Akbar F, Davis K, Morgan R. Prospective evaluation of a selective approach to cholangiography for suspected common bile duct stones. Ann R Coll Surg. Engl. 2010; 92: 206-10.

110) Khan MN, Nordon I, Ghauri AS, Ranaboldo C, Carty N. Urgent cholecystectomy for acute cholecystitis in a district general hospital-is it feasible? Ann R Coll Surg Engl. 2009; 91: 30-4.

111) Yamashita Y, Takada T, Kawarada Y, Nimura Y, Hirota M, Miura F, et al. Surgical treatment of patients with acute cholecystitis: Tokyo Guidelines. J Hepatobiliary Pancreat Surg. 2007; 14: 91-7.

112) Hirota M, Takada T, Kawarada Y, Nimura Y, Miura F, Hirata K, et al. Diagnostic criteria and severity assessment of acute cholecystitis: Tokyo Guidelines. Hepatobiliary Pancreat Surg. 2007; 14: 78-82.

113) Brodsky A, Matter I, Sabo E, Cohen A, Abrahamson J, Eldar S. Laparoscopic cholecystectomy for acute cholecystectomy: can the need for conversión and the probability of complications be predicted? A prospective study. Surg Endosc. 2000; 14: 755-60.

114) Merriam LT, Kanaan SA, Dawes LG, Angelos P, Prystowsky JB, Rege RV, et al. Gangrenous cholecystitis: analysis of risk factors and experience with laparoscopic cholecystectomy. Surgery. 1999; 126: 680-5.

115) Breitenstein S, Kraus A, Clavien PA. Acute and chronic cholecystitis. En: Clavien PA, Baillie J. Diseases of the Gallbladder and Bile Ducts: diagnosis and treatment. 2a. ed. Oxford: Blackwell Publishing; 2006. p.229-38.

116) Papi C, Catarci M, D’Ambrosio L, Gili L, Koch M, Grassi GB, et al. Timing of cholecystectomy for acute calculous cholecystectomy for acute cholecystitis: a meta-analysis. Am J Gastroenterol. 2004; 99: 147-55.

117) Chandler CF, Lane JS, Ferguson P, Thompson JE, Ashley SW. Prospective evaluation of early versus delaved laparoscopic cholecystéctomy for treatment of acute cholecystitis. Am Surg. 2000; 66: 896-900.

118) Johansson M, Thune A, Blomqvist A, Nelvin L, Lundell L. Management of acute cholecystectomy in the laparoscopic era: result of a prospective, randomized clinical trial. J Gastrointest Surg. 2003; 7: 642-5.

119) Lai PB, Kwong KH, Leung KL, Kwok SP, Chan AC, Chung SC, et al. Randomized trial of early versus delayed laparoscopic cholecystectomy for acute cholecystitis. Br J Surg. 1998; 85: 764-7.

120) Lo CM, Liu CL, Fan ST, Lai EC, Wong J. Prospective randomized study of early versus delayed laparoscopic cholecystectomy for acute cholecystitis. Ann Surg. 1998; 227: 461-7.

121) Salom A. Tratamiento de la colecistitis aguda por cirugía laparoscópica (en prensa). Presentado en la Sociedad de Cirugía del Uruguay mayo de 2010

122) Sharp KA. Acute cholecystitis. Surg Clin North Am 1988; 68:269-79.

123) Eldar S, Eitan A, Bickel A, et al. The impact of patient delay and Bickel A, Rappaport A, Kanievski V. Laparoscopic management of acute cholecystitis. Sur Endosc. 1996; 10: 1045-9.

124) Bickel A, Rappaport A, Kanievski V, Vaksman I, Haj M, Geron N, et al. Laparoscopic management of acute cholecystitis. Sur Endosc. 1996; 10: 1045-9.

125) Gurusamy KS, Samraj K. Early versus delayed laparoscopic cholecystectomy for acute cholecystiyis. Cochrane Databases Syst Rev. 2006; 18: CD005440.

126) Kum CK, Goh PM, Isaac JR, Tekant Y, Ngoi SS. Laparoscopic cholecystectomy for acute cholecystitis. Br J Surg. 1994; 81: 1651-4.

127) Garcia-Sancho Tellez L, Rodriguez-Montes JA, Fernandez de Lis S, Garcia-Sancho Martin L. Acute emphysematous cholecystitis. Reporta f twenty cases. Hepatogastroenterology. 1999; 46: 2144-8.

128) NIH Consensus conference Gallstones and laparoscopic cholecystectomy. JAMA. 1993; 269: 1018-24.

129) Mosche Schein. Cirugía abdominal de urgencia. Madrid: Mediterraneo; 2001. p. 117-26. 
130) Eldar S, Sabo E, Nash E, Abrahamson J, Matter I. Laparoscopic versus open cholecystectomy in acute cholecystitis. Surg Laparosc Endosc. 1997; 7: 407-14.

131) Pribran BO: Mukoklase und drainägelose gallenchirugie. Zentralblatt Chirurgie. 1928; 13: 773-81.

132) Gramática L, Sezin M. Cirugía de las vías biliares, páncreas y bazo: Indicaciones y técnicas. Córdoba: Universidad Nacional de Córdoba; 1990.

133) Gramática L, Mdalel O, Dutari Ch, Gramática HL, Juárez N. Valor de la técnica de Pribran en el tratamiento Video-laparoscópico de la colecistitis aguda evolucionada. Rev Argent Cirug. 1996; 70: 201-3.

134) Picklemann J, Gonzalez RP. The improving results of cholecystectomy. Arch Surg. 1986; 121: 930-4.

135) Frazze RC, Nagorney DM, Mucha P Jr. Acute acalculous cholecystitis. Mayo Clin Proc. 1989; 64: 163-7.

136) Miura F, Takada T, Kawarada Y, Nimura Y, Wada K, Hirota M, Nagino M, et al. Flowcharts for the diagnosis and treatment of acute colangitis and cholecystitis: Tokyo Guidelines. J Hepatobiliary Pancreat Surg. 2007; 14: 27-34.

137) Macrì A, Scuderi G, Saladino E, Trimarchi G, Terranova M, Versaci A et al. Acute gallstone cholecystitis in the elderly: treatment with emergency ultrasonographic percutaneous cholecystectomy and interval laparoscopic cholecystectomy. Surg Endosc. 2006; 20: 88-91.

138) Famulari C, Macri A, Galipo S, Terranova M, Freni O, Cuzzocrea D. The role of ulrasonographic percutaneous cholecystectostomy in the treatment of acute cholecystectitis. Hepatogastroenterology. 1996; 43: 538-41.

139) Griniatsos J, Petrou A, Pappas P, Revenas K, Karavokyros I, Michail OP, et al. Percutaneous cholecystostomy without interval cholecystectomy as definitive Treatment of acute cholecystectitis in elderly and critically III patients. South Med J. 2008; 101: 586-90

140) Ito K, Fujita N, Noda Y, Kobayashi G, Kimura K, Sugawara T, et al. Percutaneous cholecystectomy versus gallbladder aspiration for acute cholecystitis: a prospective randomized controlled trial. AJR Am J Roentgenol. 2004; 183: 193-6

141) Van Steenbergen W, Ponette E, Marchal G, Pelemans W, Aerts R, Fevery J, et al. Percutaneous transhepatic cholecystectomy for acute complicated cholecystitis in elderly patients. Am J Gastroenterol. 1990; 85: 1363-9.

142) Pekolj J, Quiñones E, Mazza O, Arbués G, Santibañez E. Tratamiento laparoscópico de las fístulas biliodigestivas y del síndrome de Mirizzi tipo II. Rev Argent Cirug. 2006; 90: 142-51.

143) Kok KY, Goh PY, Ngoi SS. Management of Mirizzi's síndrome in the laparoscopic era. Surg Endosc.1998; 12: 1242-4.

144) Chiappetta Porras L, Canullan C, Nápoli E, Roff H, Hernández N, Uva P, et al. Resultados en el tratamiento del Sindrome de Mirizzi por videolaparoscopía. Rev Argent Cirug. 2004; 87: 103-6.

145) Gramática L (h), Moreno W, Palas Zúñiga C. Litiasis biliar complicada. En: Gramática L. ABC de la cirugía biliar. Buenos Aires: Médicas del Sur; 2011. p.144-7.

146) Iglezias Brandao de Olivera C, Adami Chaim E, da Silva BB. Impact of rapid weight reduction on risk of cholelithiasis after bariatric surgery. Obes Surg. 2003; 13: 625-8.

147) Amaral JF, Thomson WR. Gallbladder disease in the morbidly obese. Am J Surg. 1985; 149: 551-7.

148) Sidhu RS, Raj PK, Treat RC, Scarcipino MA, Tarr SM.. Obesity as a factor in laparoscopic cholecystectomy. Surg Endosc. 2007; 21: 774-6.

149) Simopoulos C, Polychronidis A, Botaitis S, Perente S, Pitiakoudis M. Laparoscopic cholecystectomy in obese patients. Obes Surg. 2005; 15: 243-6.

150) Sugerman HJ, Brewer WH, Shiffman ML, Brolin RE, Fobi MA, Linner JH, et al. A multicenter, placebo controlled randomized, doublé blind, prospective trial of prphylactic ursodiol for the prevention of gallstone formation following gastric bypass induced rapid weight loss. Am J Surg. 1995; 169: 91-6.

151) Gramática $L(h)$, Arias A. La litiasis biliar en circunstancias especiales. En: Gramática L. ABC de la cirugía biliar. Buenos Aires: Médicas del Sur; 2011. p. 382-97. 
152) Mason E, Renquist KE. Gallbladder management in obesity surgery. Obes Surg. 2002; 12:222-9.

153) Yu SC, Chen SC, Wang SM, Wei TC. Is previous abdominal surgery a contraindication to laparoscopic cholecystectomy. J Laparoendosc Surg. 1994; 4: 31-5.

154) Miller K, Hölbling N, Hutter J, Junger W, Moritz E, Speil T. Laparoscopic cholecystectomy for patients who had previous abdominal surgery. Surg Endosc. 1993;7: 400-3.

155) Kwon AH, Inui H, Imamura A, Kaibori M, Kamiyama Y. Laparoscopic cholecystectomy and choledocotomy in patients with a previous gastrectomy. J Am Coll Surg. 2001; 193: 614-9.

156) Karayiannakis AJ, Polychronidis A, Perente $S$, Botaitis S, Simopoulos C. Laparoscopic cholecystectomy in patients with previous upper or lower abdominal surgery. Surg Endosc. 2004; 18: 97-101.

157) Gramática $L(h)$, Arias $A$. La litiasis biliar en circunstancias especiales. La litiasis biliar y la cirugía gástrica. En: Gramática L. ABC de la cirugía biliar. Buenos Aires: Médicas del Sur; 2011. p. 370-3.

158) Borsellino G, de Mazzoni G, Ricci F. Detection of abdominal adhesions in laparoscopic surgery. A controlled study of 130 cases. Surg Laparos Endosc. 1998; 8: 273-6.

159) Alba-Quintanilla F, Posadas-Robledo FJ. Evaluación ultrasónica de la vesícula durante el embarazo. Ginecol Obstet Mex. 1997; 65:39-42.

160) Al-Hashem $\mathrm{H}$, Muralidharan $\mathrm{V}$, Cohen $\mathrm{H}$, Jamidar PA. Biliary disease in pregnancy with an emphasis on the role of ERCP. J Clin Gastroenterol. 2009; 43: 58-62.

161) Swisher SG, Schmit PJ, Hunt KK, Hiyama DT, Bennion RS, Swisher EM, et al. Biliary disease during pregnancy. Am J Surg. 1994; 168: 576-9.

162) Sungler $P$, Heinerman PM, Steiner H, Waclawiczek HW, Holzinger J, Mayer F, et al. Laparoscopic cholecystectomy for gallstones complications during pregnancy. Surg Endosc. 2000; 14: 267-71.

163) Gramática $L(h)$, Arias $A$. La litiasis biliar en circunstancias especiales. La litiasis biliar en la embarazada. En: Gramática L. ABC de la cirugía biliar. Buenos Aires: Médicas del Sur; 2011. p. 365-9.

164) Stepp K, Falcone T. Laparoscopy in the second trimester of pregnancy. Obstet Gynecol Clin North Am. 2004; 31: 485-96.

165) Bisharah M, Tulandi T. Laparoscopic surgery in pregnancy. Clin Obstet Gyneccol. 2003; 46: 92-7.

166) SAGES guidelines for laparoscopic surgery during pregnancy [en línea]. 2011 [Acceso 30 julio 2012]. [aprox. 8 p.]. URL: www.sages.org/sg_pub23.html.

167) Holthausen UH, Metter L, Troid H. Pregnancy: a contraindication? World J Surg. 1999; 23: 856-62.

168) Eichenberg BJ, Vanderlinden J, Miguel C, Bianchi C, Robles A, McLarty R, et al. Laparoscopic cholecystectomy in the third trimester of pregnancy. Am Surg. 1996; 62: 874-7.

169) Daradkeh S, Sumrein I, Daoud F, Zaidin K, Abu-Khalaf M. Management of gallbladder stones during pregnancy: conservative treatment or laparoscopic cholecystectomy? Hepatogastroenterology. 1999; 46: 3074-6.

170) Wu JM, Chen KH, Lin HF, Tseng LM, Tseng SH, Huang SH. Laparoscopic appendectomy in pregnancy. J Laparoendosc Adv Surg Tech A. 2005; 15: 447-50.

171) Neudecker J, Sauerland S, Neugebauer E, Bergamaschi R, Bonjer HJ, Cuschieri A. The European Association for Endoscopic Surgery clinical practice guideline on the pneumoperitoneum for laparoscopic surgery. Surg Endosc. 2002; 16: 1121-43.

172) Sungler P, Heinerman PM, Steiner H, Waclawiczek HW, Holzinger J, Mayer F, et al. Laparoscopic cholecystectomy and interventional endoscopy for gallstone complications during pregnancy. Surg Endosc. 2000; 14: 267-71.

173) Stepp K, Falcone T. Laparoscopy in the second trimester of pregnancy. Obstet Gynecol Clin Norrth Am. 2004; 31: 485-96.

174) Morrell DG, Mullins JR, Harrison PB. Laparoscopic cholecystectomy during pregnancy in synmptomatic patients. Surgery. 1992; 112: 856-9. 
175) Martin IG, Dexter SPL, Mc Mahon MJ. Laparoscopic cholecystectomy in pregnancy. Surg Endosc. 1996; 10: 508-10.

176) Robertson KW, Stewart IS, Imrie CW. Severe acute pancreatitis and pregnancy. Pancreatology. 2006; 6: 30915.

177) Hasson HM. A modified instrument and method or laparoscopy. Am J Obstet Gynecol. 1971; 110: 886-7.

178) Chapron C, Cravello L, Chopin N, Kreiker G, Blanc B, Dubuisson JB. Complications during set-up procedures for laparoscopy in ginecology: open laparoscopy does not reduce the risk of mayor complications. Acta Obstet Gynecol Scand. 2003; 82: 1125-9.

179) Yehn CN, Chen MF, Jan YY. Laparoscopic cholecystectomy in 226 cirrhotic patients. Experience of a single center in Taiwan. Surg Endosc 2002; 16: 1583-7. 


\title{
Capítulo 4
}

\section{CIRUGÍA LAPAROSCÓPICA DE LA VÍA BILIAR PRINCIPAL}

\author{
Dr. Andrés Salom
}

\section{Introducción}

Actualmente el tratamiento de la litiasis de la vía biliar principal (VBP) se puede efectuar por laparotomía como tradicionalmente fue realizado durante muchos años, por cirugía laparoscópica o por vía endoscópica.

En 1987 se comienza a difundir la cirugía laparoscópica de la vía biliar, cuando en Francia, primero Mouret y luego Dubois, realizan las primeras colecistectomías laparoscópicas, transformandose rápidamente en la vía de elección para el tratamiento de la litiasis de la vesícula biliar ${ }^{1,2}$.

A pesar de que en 1991 se realizaron las primeras coledocotomías por laparoscopía por cirujanos de los EEUU (Petelin y Franklin) ${ }^{3,4}$, la cirugía laparoscópica de la vía biliar principal no tuvo la misma difusión que la cirugía de la vía biliar accesoria.

Esto se puede explicar ya que se trataba del inicio de la experiencia en la cirugía laparoscópica y resultaba más fácil realizar la extracción de la litiasis coledociana en el preoperatorio por vía endoscópica, mediante la realización de la colangiografía endoscópica retrógrada (CER) y eventual papilotomía, seguida de la colecistectomía laparoscópica.

La conducta más aceptada hasta hace poco tiempo en cirugía laparoscópica era intentar diagnosticar y resolver la posible litiasis de la VBP en el preoperatorio con la CER y eventual papilotomía, ${ }^{5,7}$.

Con el desarrollo de la cirugía laparoscópica durante estos años, se ha adquirido en el momento actual una experiencia importante en el manejo y tratamiento por video-cirugía de la litiasis de la VBP8.

El tratamiento por cirugía laparoscópica permite actualmente efectuar casi todos las maniobras que se realizan por laparotomía para el tratamiento de la litiasis biliar, con las ventajas que proporciona esta forma de cirugía mínimamente invasiva.

Esta nueva forma de abordaje al respetar la integridad de la pared abdominal, permite que el paciente tenga una recuperación más rápida, menor dolor, mejor confort posoperatorio y menor morbilidad vinculada a la herida operatoria., ${ }^{90,11,12}$ 
La tendencia actual, cuando se diagnostica o existe la sospecha de litiasis coledociana, y el paciente no tiene un cuadro de colangitis, es efectuar el tratamiento integral y en una sola etapa de la litiasis vesicular y coledociana. Con esto se evita la realización de muchos estudios de CER innecesarios, dado el elevado porcentaje de migración espontánea de los cálculos al duodeno y la morbimortalidad de la CER y la papilotomía ${ }^{13,14,15,16,17,18,19}$.

La vía endoscópica transpapilar tiene indicaciones precisas, a saber:

- Pacientes colecistectomizados con una litiasis residual.

- En los cuadros de colangitis graves y pancreatitis aguda con obstrucción biliar, en los cuales la prioridad es desobstruir la vía biliar y la mortalidad de la cirugía es muy elevada.

- Pacientes añosos o con muy mal estado general, con afecciones cardiovasculares severas, en los cuales se intenta evitar o acortar la cirugía.

El equipo médico que trata estos pacientes debe estar integrado por cirujanos con experiencia en cirugía laparoscópica y abierta, endoscopistas y radiólogos intervencionistas, de manera de poder recurrir e utilizar las diferentes modalidades de tratamiento de acuerdo a la situación clínica particular que presenta el paciente, como ser: características de la litiasis biliar (número, tamaño y tipo de cálculos), anatomía de la vía biliar (fina, dilatada), repercusión de la enfermedad y estado biológico del paciente, y a la experiencia e infraestructura con que cuenta el equipo quirúrgico actuante ${ }^{20}$.

\section{Reseña histórica}

Es conveniente recordar algunos hechos históricos, que nos permiten apreciar la verdadera dimensión de los adelantos, que tecnología mediante, la cirugía de la litiasis de la vía biliar ha tenido en los últimos dos siglos.

Carl Langenbuch, Profesor de cirugía en Berlín y padre de la colecistectomía, fue quien ideó la cirugía de la litiasis coledociana a través de la coledocotomía, pero no la realizó.

En Alemania, Kümmel en 1884 y Riedel en 1888 realizaron las primeras coledocotomías, pero con malos resultados.

Fue un año más tarde, en 1889, que en Inglaterra Knowsley Thornton realizó la primera coledocotomía para extraer cálculos coledocianos con sobrevida del paciente.

Ludwing Curvoisier, cirujano suizo, operó poco después otro caso con sobrevida.

El gran problema de esta cirugía en esos años, lo constituía el pasaje de la bilis al peritoneo luego de la apertura coledociana.

De ahí que en 1892, Yversen, realizó la cirugía del colédoco en dos tiempos, abordando el órgano en una primera intervención para colocar mechas hasta la piel y abriéndole para extraer los cálculos en una segunda intervención.

Los verdaderos drenajes de la vía biliar principal comenzaron con Hans Kehr, cirujano alemán que en 1895 drenó por primera vez el colédoco con un tubo de goma extraído a través del muñón y que llamó "Hepaticus Drainage".

En 1912 el mismo autor describió un tubo en T con una rama corta en media caña que evita el deslizamiento y salida del drenaje. 


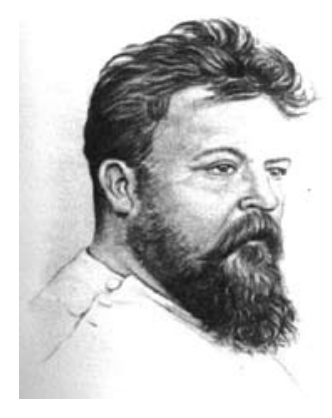

Figura 1. Hans Kehr.

Desde ese momento hasta nuestros días se coloca el tubo de Kehr, hace ya cien años.

Fue posiblemente, este cirujano alemán nacido en 1862 la figura más descollante en la historia de la cirugía biliar, al decir de Raúl Praderi21.

En 1962, Mazzariello y Mondet en Argentina introducen la técnica de extracción incruenta de cálculos a través del trayecto de los drenajes biliares, constituyéndose en una muy buena opción muchas veces para el tratamiento de la litiasis residual del colédoco 22 .

En 1975, gastroenterólogos de Alemania y Japón realizan las primeras papilotomías endoscópicas para la extracción de cálculos coledocianos ${ }^{23,24}$.

En 1987 se comienza a difundir la cirugía laparoscópica, cuando en Francia, primero Mouret y luego Dubois realizan las primeras colecistectomías laparoscópicas, transformándose rápidamente en la vía de elección para el tratamiento de la litiasis de la vesícula biliar ${ }^{1,2}$.

En 1991 se realizan las primeras coledocotomías por laparoscopía por cirujanos de los EEUU, los Dres. Petelin y Franklin ${ }^{3,4}$.

\section{Táctica y técnica quirúrgica}

La resolución terapéutica de la litiasis de la VBP, es un tema complejo que todavía presenta controversias en cuanto al mejor tratamiento.

Una vez diagnosticada la situación ( 5 a $20 \%$ de la litiasis vesicular ${ }^{25}$ ), se debe tratar al paciente, dada la imposibilidad de poder predecir que cálculos van a migrar espontáneamente y cuáles van a producir síntomas o complicaciones, como pueden ser: dolor abdominal (46\%), ictericia obstructiva (33\%), pancreatitis $(14 \%)$ y colangitis $(0.7 \%)^{26}$.

El mejor tratamiento, a los efectos de tener la más baja morbilidad y mortalidad, depende básicamente de la infraestructura, y de los recursos terapéuticos y técnicos con que cuente cada centro asistencial, donde van a ser tratados estos pacientes.

La opción quirúrgica ideal, es la de tratar estos pacientes en un solo tiempo, como se preconizaba clásicamente; si bien esto depende de la situación clínica particular de cada caso y de la infraestructura y experiencia del equipo multidisciplinario tratante.

Las opciones terapéuticas con las que contamos actualmente son:

- Abordaje por vía endoscópica

- Por laparoscopía (sola o combinada con la anterior)

- Por vía percutánea trans-hepática bajo radiología 
- Por cirugía abierta.

La vía endoscópica es el abordaje de elección en los pacientes colecistectomizados.

En los pacientes no colecistectomizados, la situación puede ser resuelta de diferentes formas, que depende de cada caso.

En los casos de litiasis de la VBP no complicados y en pacientes con un riesgo quirúrgico aceptable, pueden tratarse inicialmente y en un tiempo por laparoscopía.

Se tienen resultados muy buenos, con baja morbiliad y mortalidad, siempre y cuando el equipo quirúrgico tenga experiencia y la infraestructura adecuada (sondas Dormia con canal operador, arco en C, catéteres de angioplastia, coledocoscopio, etc) $19,27,28,29,30,31,32,33,34,35,36$.

En los pacientes con litiasis de la VBP complicada con colangitis, y elevado riesgo quirúrgico por patologías asociadas o añosos, la vía endoscópica con papilotomía y extracción de los cálculos, permite resolver la mayoría de los casos y con menor morbimortalidad. Disponiendo de endoscopistas con destreza y experiencia, esta opción terapéutica es muy valiosa. Luego se realiza la colecistectomía, de elección por vía laparoscópica.

Una situación particular, menos frecuente, son los pacientes con litiasis coledociana y VBP no dilatada en los estudios de imagen (ecografía o colangioresonancia). En éstos, la opción de la vía endoscópica es válida, dado los riesgos (morbilidad) y dificultades técnicas que genera el intentar manipular una vía biliar fina.

Otra situación puntual es el paciente con colangitis sin remisión, en la cual se sospecha la presencia de un cálculo enclavado en la papila. En estos casos la vía endoscópica es más adecuada y tiene menor morbilidad y mortalidad que la cirugía en un tiempo.

Trabajos controlados y randomizados demuestran que la terapéutica endoscópica es más segura que la cirugía, por presentar una menor morbimortalidad ${ }^{37,38}$.

Para asegurarnos la descompresión biliar, debe dejarse un drenaje nasobiliar o un stent.

Para la colocación de estos sistemas de drenaje, no siempre es necesaria la realización de una esfinterotomía, con lo que se disminuye el riesgo de hemorragia y perforación.

Si se inyectó contraste y el drenaje de la vía biliar no fue correcto, será necesario repetir el procedimiento por vía percutánea.

La respuesta de los pacientes con colangitis aguda al drenaje biliar endoscópico, generalmente es rápido, lográndose la mejoría en 24 horas $^{39}$.

Se debe tener en cuenta, la respuesta inflamatoria que generan en la vía biliar, los procedimientos por vía endoscópica (colangiografía, papilotomías, pasaje de sondas Dormia, extracción de cálculos), haciendo muchas veces muy dificultosa la colecistectomía.

En cuanto a la oportunidad de la misma, lo ideal es luego de las primeras 24 horas de realizado el procedimiento endoscópico, a los efectos de descartar la presencia de complicaciones del mismo, y antes del alta del paciente.

Dado que el 35 al $80 \%$ de los cálculos migran espontáneamente al duodeno ${ }^{40}$, es conveniente diferir la cirugía en 24 a 48 horas $^{41}$.

Una opción interesante es realizar la extracción de los cálculos, en forma combinada con el endoscopista, en forma intra-operatoria. Esta técnica se llama de encuentro o "rendez vous" por los franceses. Algunos autores encuentran hasta un $3 \%$ de litiasis coledociana no sospechada en los estudios radioló- 
gicos colangiográficos realizados en forma sistemática ${ }^{42}$. De esta forma se pueden evitar reoperaciones y resolver el problema en un solo acto y con una sola anestesia, antes o durante la colecistectomía ${ }^{43,44}$.

Se debe contar con endoscopistas con experiencia y con la posibilidad de estar en el block quirúrgico durante la cirugía.

Las ventajas de realizar la extracción por vía endoscópica intraoperatoria son:

- Se realiza el tratamiento completo de la litiasis de la VBP en un tiempo y en el mismo acto anestésico.

- Se puede cateterizar la papila mediante pasaje de una guía transcística cuando no se logra visualizar por vía endoscópica.

- Se evita en muchos casos la realización de una coledocotomía y sus eventuales consecuencias (necesidad de conversión, alargar la cirugía, uso de drenajes biliares externos, riesgos de estenosis de la VB, etc).

La principal desventaja de este abordaje endoscópico peroperatorio, es la insuflación del intestino delgado que puede dificultar la colecistectomía. Es recomendable completar la liberación de la vesícula biliar antes del procedimiento endoscópico, o en su defecto clampear un asa yeyunal proximal, impidiendo el pasaje del aire ${ }^{45,46}$.

La cirugía abierta sigue teniendo un lugar, aunque cada vez es más pequeño.

Algunas de las indicaciones, a nuestro entender serían:

- Sl el centro asistencial no cuenta con el material, la infraestructura y la experiencia suficiente del equipo quirúrgico en cirugía laparoscópica, es mejor opción realizar la cirugía abierta y en un tiempo.

- Si no contamos con endoscopistas con experiencia y/o frente al hallazgo de cálculos grandes que no podemos extraer, es mejor opción convertir a cirugía abierta y resolver la situación en un tiempo.

- Debemos tener presente que la morbimortalidad de la vía endoscópica, sumada a la de la colecistectomía, supera la incidencia de complicaciones y mortalidad que tiene un cirujano experimentado para resolver el problema de la vía biliar accesoria y principal, en un solo tiempo, ya sea por abordaje laparoscópico o convencional ${ }^{47}$.

- Cuando la situación anatómica es muy compleja por las alteraciones inflamatorias del pedículo hepático y/o panlitiasis, es conveniente convertir a cirugía abierta y resolver la situación en un tiempo. No creemos que sea conveniente embarcarse en cirugías laparoscópicas muy prolongadas y con mayor riesgo de lesionar la VBP.

\section{Cirugía laparoscópica}

Utilizamos la técnica Americana. Es fundamental que todos los integrantes del equipo (cirujano y dos ayudantes), tengan experiencia en cirugía laparoscópica, dado que se trata de cirugías más complejas, que requieren de destrezas y habilidades de todos los cirujanos del equipo para la realización de la cámara y manejo de las sondas Dormia, catéteres, etc. 


\section{Vía transcística}

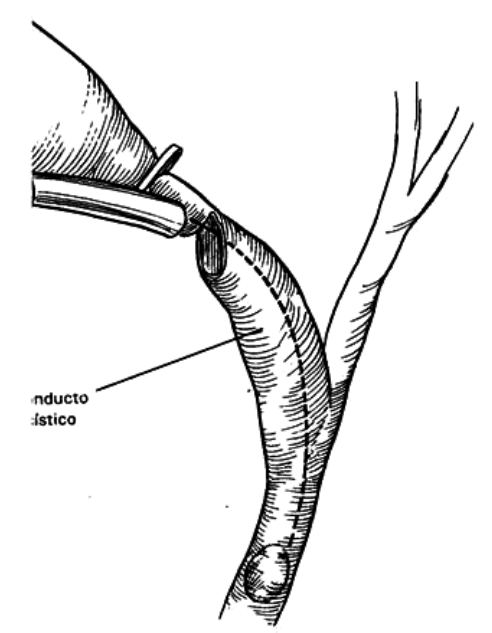

Figura 2. Vía transcística

La vía transcística está indicada cuando el paciente presenta un conducto cístico con una anatomía adecuada; grueso (mayor de $3 \mathrm{~mm}$ ), con una terminación corta y a la derecha de la vía biliar principal y generalmente no más de 3 cálculos. Esto último es relativo, dado que en una oportunidad le extrajimos por vía transcística a una paciente joven, 18 litos.

Las contraindicaciones para la utilización de esta vía son: una anatomía inadecuada del conducto cístico (largo, terminación baja y a la izquierda de la vía biliar), litiasis primitiva, panlitiasis y litiasis intrahepática.

Se debe contar además con todo el instrumental adecuado como ser: arco en $\mathrm{C}$ de última generación; canastillas Dormia con canal operador para la inyección de contraste de manera de guiarnos en la extracción de los cálculos; catéteres dilatadores de angioplastia; y un coledocoscopio fibróptico flexible de $3 \mathrm{~mm}$ con canal operador con monitor accesorio.

Las sondas Dormia que se deben utilizar dependen del tamaño de los cálculos. Cuando son grandes es adecuado utilizar una sonda de 4 filamentos, pero para la captura de los cálculos más pequeños se requieren de 5 o 6 filamentos.

La técnica que utilizamos y que nos resulta más eficaz para la extracción de los cálculos, es mediante la utilización de una sonda Dormia con canal para la inyección de contraste y bajo radioscopía amplificada con un arco en $\mathrm{C}$.

Se coloca la sonda Dormia a través de la pared abdominal por una cánula de Teflon no14, emplazada a nivel del epigastrio.

La introducimos en el conducto cístico y la hacemos avanzar hasta la papila, sin franquear ésta, controlando su progresión en el amplificador, bajo visión. En este momento se abre la cestilla, se atrapan los cálculos y se la retira progresivamente. Generalmente son necesarias varias tentativas para tener éxito con la maniobra y retirar todos los cálculos. 

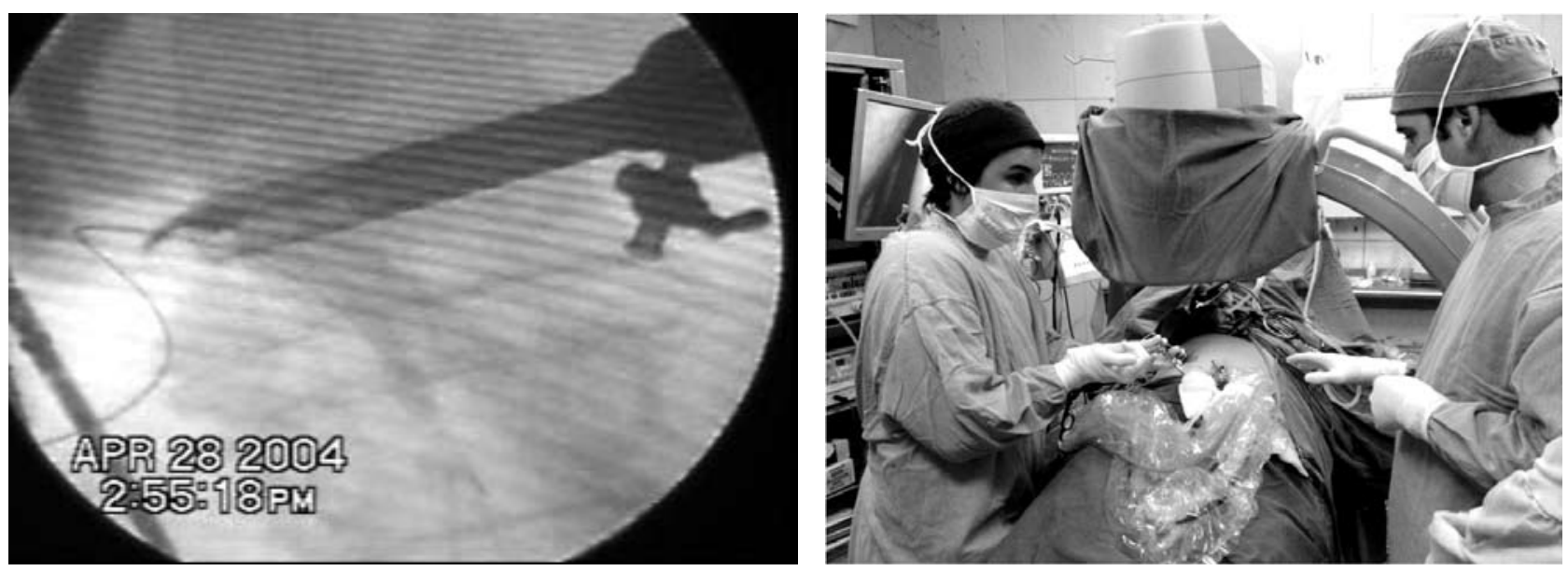

Foto 1. Extracción de litiasis bajo radioscopía con arco en C y sondas Dormia con canal operador.

Tenemos una excelente experiencia en la utilización de esta técnica, coincidente con otros autores $^{14,19,30}$.

La principal ventaja de este abordaje, es que se respeta la vía biliar principal, disminuyéndose la posibilidad de lesionarla, y cuando tenemos la certeza de que no hay más litiasis, es posible ligar el conducto cístico y no dejar drenaje de la vía biliar.

Ante la menor duda preferimos dejar un drenaje transcístico, con una sonda Nelaton de goma, que fijamos con un punto intracorpóreo y nos permite realizar una descompresión de la vía biliar y principalmente realizar un estudio radiológico postoperatorio.

En caso de litiasis residual, este drenaje facilita la extracción a través de una papilotomía endoscópica postoperatoria ${ }^{48}$, o puede permitir su extracción por vía incruenta por el método de Mazzariello ${ }^{49}$.

Frente a la situación particular de encontrar en la colangiografía intraoperatoria, cálculos muy pequeños a nivel del colédoco distal, en vías biliares muy finas y con císticos finos o espiralados que no permiten operar a través de ellos, es más seguro clipar el conducto cístico o dejar un drenaje transcístico, para realizar la extracción de los mismos en el postoperatorio por vía endoscópica.

En estos casos, se puede plantear su extracción por vía endoscópica intraoperatoria, si contamos con el técnico en sala de operaciones (rendez-vous).

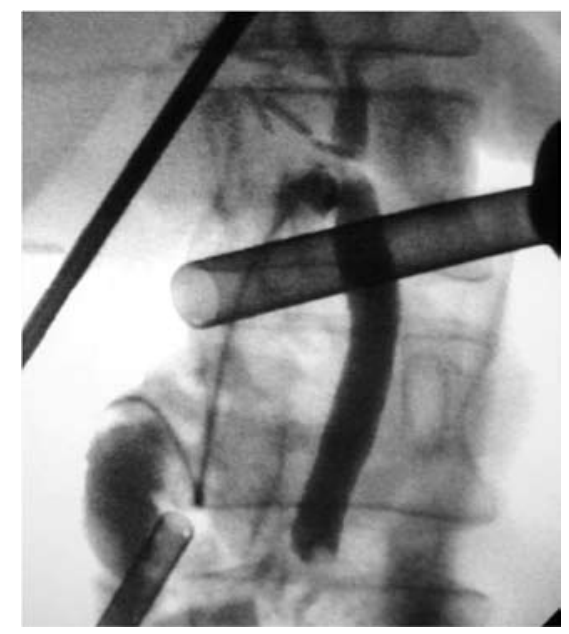

Foto 2. Litiasis coledociana distal en vía biliar fina con cístico espiralado. 
Otra opción, impulsada en nuestro medio por el Dr. Hugo Maglione, es el tratamiento de la litiasis coledociana por vía transcística de elección, o por coledocotomía laparoscópica, con la utilización de un catéter de angioplastia, utilizado por los cirujanos vasculares para dilatar estenosis. En este caso se dilata la papila y luego se hace progresar los cálculos al duodeno por lavado de arrastre, y luego se procede a clipar o ligar el conducto cístico. Este procedimiento solo requiere de los catéteres, del $\operatorname{arco}$ en $\mathrm{C}$, y es sencillo de realizar ${ }^{50}$.

Esta papiloesfinteroplastia anterógrada, tiene la ventaja de que la función esfinteriana se recupera parcial o totalmente entre los 20 a 40 días posteriores a la dilatación de la papila, ya que ésta no se daña ni se ve afectada en su función.

Otras ventajas, comparándola con la esfinterotomía endoscópica, son el no tener las complicaciones de ésta: hemorragia, perforación, pancreatitis, pérdida de la función esfinteriana, contaminación del árbol biliar con colangitis recidivante, aumento de la incidencia de colangiocarcinomas y estenosis papilar.

\section{Coledocotomía laparocópica}

El tratamiento por coledocotomía lo realizamos frente a la presencia de colédocos dilatados, generalmente con varios cálculos o de gran tamaño y cuando no están dadas las condiciones para intentar la vía transcística o ésta fracasa.

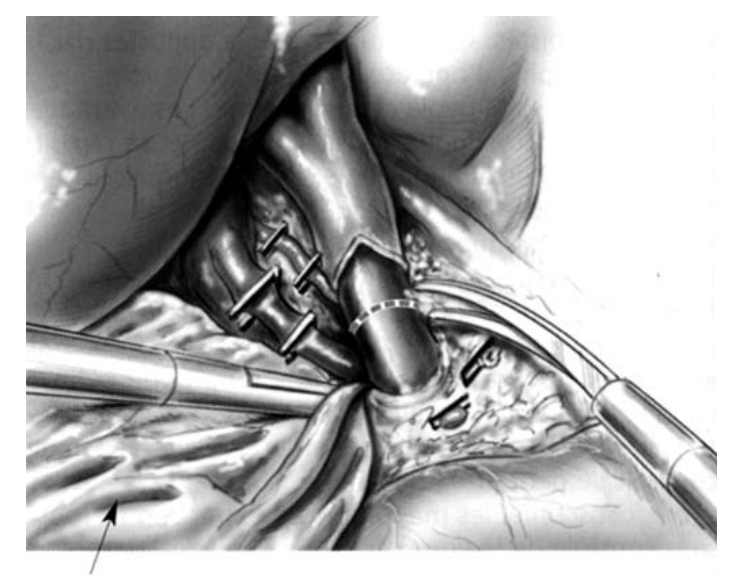

Figura 3. Coledocotomía laparoscópica.

Se realiza una coledocotomía generalmente vertical, o transversal cuando el colédoco está muy dilatado, con tijera y lo más pequeña posible.

La extracción de los cálculos, generalmente es más sencilla que por vía transcística.

Muchas veces se evacuan espontáneamente al abrir el colédoco.

Los cálculos que son de fácil acceso o visibles a través de la coledocotomía se extraen con pinzas. Los cálculos no evacuados con estas maniobras, se extraen con sondas Dormia manipuladas bajo control radiológico o endoscópico como en la vía transcística, o por arrastre con lavado con suero fisiológico. 

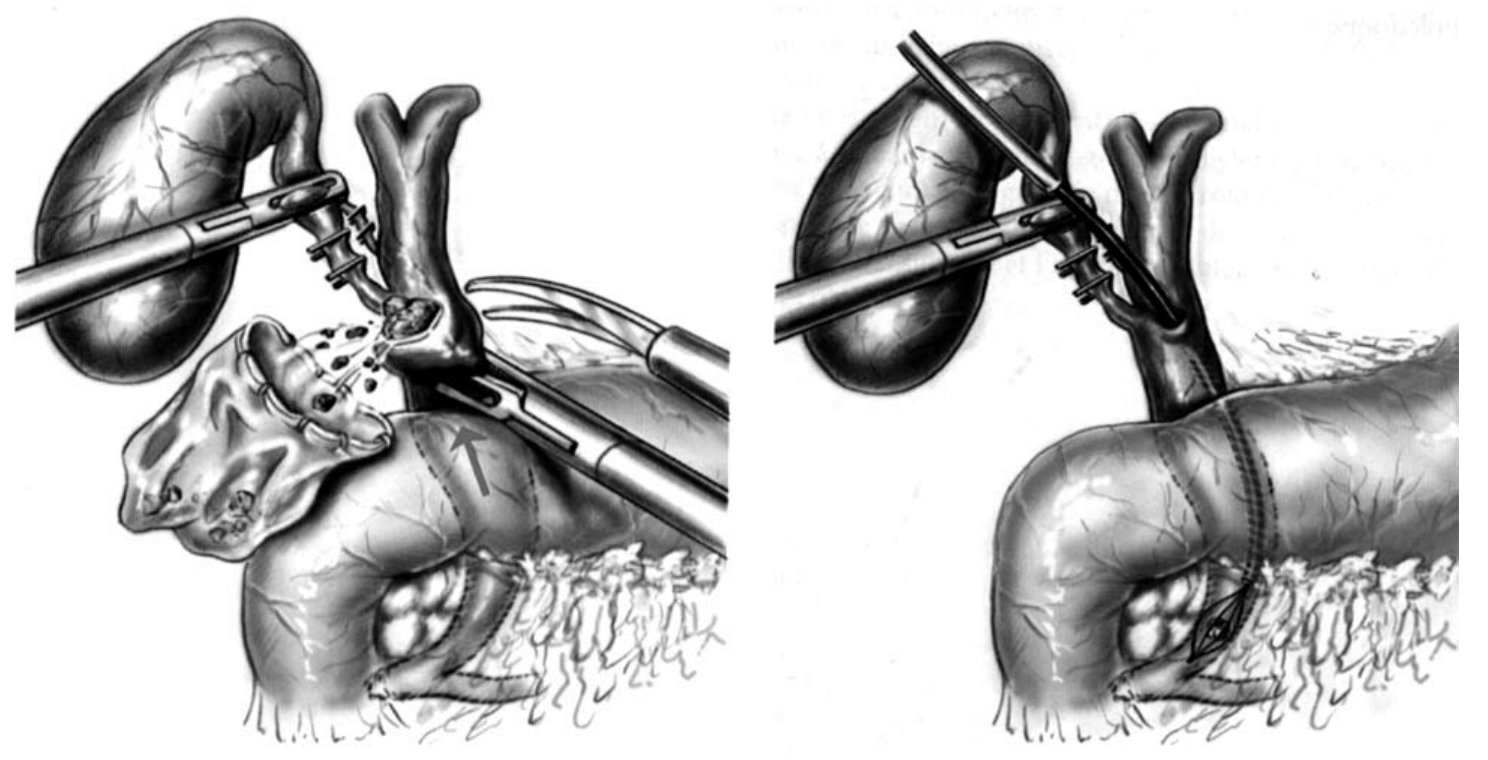

Figura 4. Extracción de litiasis coledociana por coledocotomía.

Cuando hay menos de 3 cálculos, el calibre del colédoco es inferior a $12 \mathrm{~mm}$, la pared coledociana es sana, el control endoscópico es plenamente satisfactorio y la permeabilidad del esfinter de Oddi es correcta, es teóricamente posible realizar un cierre primario sin drenaje del colédoco.

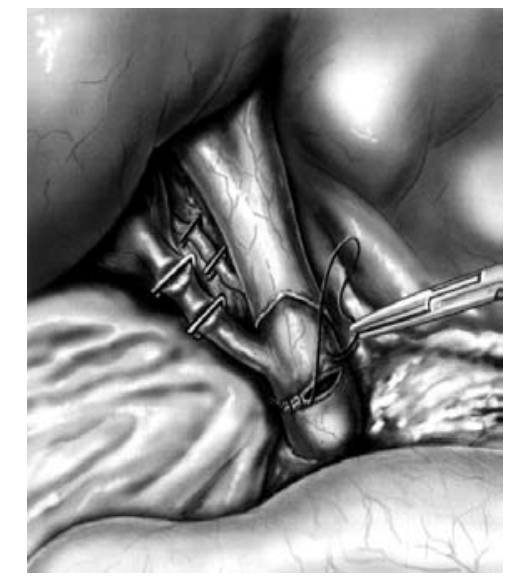

Figura 5. Coledocorrafia laparoscópica.

No tenemos experiencia con la realización de la coledocorrafia ideal, si bien es preconizada por algunos autores ${ }^{51}$.

Una opción intermedia es realizar un cierre primario del colédoco dejando un drenaje externo por vía trancística, a los efectos de evitar que la hipertensión biliar secundaria a la manipulación de la papila, origine una fuga biliar a nivel de la sutura. Otras ventajas son que permite realizar un control radiológico postoperatorio y eventualmente realizar la extracción de una litiasis residual por el trayecto del drenaje ${ }^{52}$.

En nuestra opinión, cuando se practica una coledocotomía, el cierre se debe hacer sobre un tubo de Kehr con puntos separados de material de sutura reabsorbible 4.0 o 5.0. Se deben colocar tubos de 
Kehr con brazos cortos y del mayor calibre posible, para permitir la extracción transfistular por el método de Mazzariello, frente a la presencia de litiasis residual ${ }^{52,53}$.

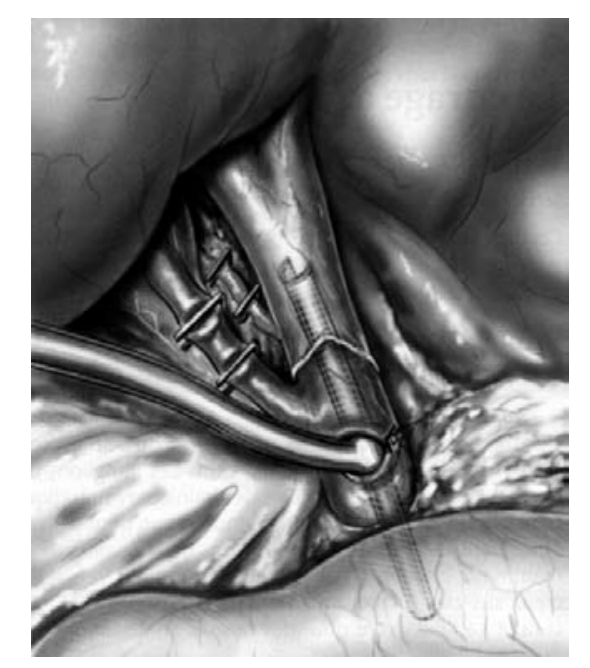

Figura 6. Colocación de un drenaje de Kehr.

Se deja un drenaje sub-hepático, para evitar la formación de colecciones y mediatizar posibles fugas de bilis.

\section{Derivaciones biliodigestivas}

La realización de una derivación biliodigestiva, mediante la confección de una anastomosis de la VBP con el duodeno (hepato o coledocoduodeno anastomosis), o con el yeyuno, es un procedimiento de mayor complejidad y se requiere de mucha experiencia en cirugía laparoscópica avanzada.

Rothlin y colaboradores realizaron por primera vez una hepatoyeyunoanastomosis laparoscópica, en un paciente con un cáncer de páncreas y con un criterio paliativo ${ }^{54}$.

En pacientes con patología litiásica generalmente se indica esta técnica cuando: el colédoco tiene un calibre mayor de $2 \mathrm{~cm}$, hay una panlitiasis, o hay una estenosis por una enfermedad de la papila.

Otra ventaja que tiene la realización de procedimientos de derivación biliodigestiva, es el de no requerir la colocación de drenajes biliares externos.

Se realiza una derivación biliodigestiva, de preferencia mediante la confección de una coledocodudenostomía laterolateral ${ }^{55,56,57}$.

Desde lo personal no tenemos experiencia en la realización de coledocoduodenostomías por laparoscopía, y en los casos en que hemos participado la evolución no fue buena por la aparición de estenosis y bilirragias.

Hemos realizado este procedimiento por cirugía abierta en pacientes con: litiasis coledocianas voluminosas, imposibles de extraerse por vía endoscópica y con megacolédocos con panlitiasis.

En un caso se trataba de una paciente añosa, colecistectomizada, en la cual fracasó la vía endoscópica, dada la presencia de un voluminoso divertículo duodenal. 
Las principal ventaja de realizar este procedimiento cuando se realiza por laparoscopía, son las de evitar la realización de una incisión, con todos los beneficios en cuanto al dolor, la recuperación y evitar las complicaciones de la herida.

La principal desventaja del abordaje por laparoscopía, es el mayor tiempo operatorio y complejidad de la cirugía, teniendo en cuanta que generalmente se trata de pacientes añosos y con una situación locorregional compleja, debido a las alteraciones inflamatorias de la vía biliar (Sind de Mirrizzi, adherencias, etc).

Cuschieri clasificó las intervenciones quirúrgicas por laparoscopía en tres grupos, no incluyendo en ninguno de ellos a las anastomosis biliodigestivas ${ }^{58}$.

En las guías para la aplicación de laparoscopía en cirugía biliar, la SAGES, solo incluye un ítem final, donde concluyen que las anastomosis bilio-digestivas, están restringidas sólo para ser realizadas por cirujanos con gran experiencia en cirugía laparoscópica y con habilidades destacables en técnicas de sutura ${ }^{59}$.

\section{Complicaciones}

Dentro de las complicaciones posibles de estas cirugías, están además de las vinculadas al abordaje laparoscópico (capítulo 3), las derivadas del abordaje de la vía biliar principal. Éstas pueden ser:

- Sección del conducto cístico.

- Lesiones de la VBP (perforación instrumental de la VBP, lesiones de los conductos hepáticos, estenosis por quemaduras).

- Bilirragias

- Bilomas.

- Salida de los drenajes biliares con o sin peritonitis biliar.

- Lesiones vasculares de la arteria hepática o la vena porta.

\section{Bibliografía}

1) Dubois F, Icard P, Berthelot G, Levard H. Coelioscopic Cholecistectomy. Preliminary report of 36 cases. Ann Surg. 1990: 211(1): 60-2.

2) Dubois F, Berthelot G, Levard H. Cholécistectomie sous Celioscopie. 330 cas. Chirugie 1990; 116: 248-50.

3) Petelin JB. Five years with laparoscopic biliary tract surgery, the role of laparoscopic common bile duct exploration. Scientific Session in Sayes Congress, Orlando. 1995; p 173.

4) Franklin ME, Pharand D, Rosenthal D. Laparoscopic common bile duct exploration. Surg Laparosc Endosc. 1994; 4: $119-24$.

5) Morelli R. Litiasis de la vía biliar principal en cirugía laparoscópica. Cir Uruguay. 1998; 68: $19-24$.

6) Mc Fadyen B, Passi R. The role of endoscopic retrograde cholanpancreatography in the era of laparoscopic cholecystectomy. Laparoscopic biliary tract surgery. Seminars in laparoscopic Surgery. Cuschieri A, Mac Fayden B. W. B. Saunders Company. 1997, vol 4, 1: 18-23.

7) Toouli J. Peroperative Endoscopic Sphinterotomy. Bile duct calculi. Seminars in Laparoscopic Surgery. Cuscheri A, Mac Fayden B. 1995, vol 2, 2: 128-31.

8) Berthou J, Drouard F, Passone-Szerzyna. Tratamiento laparoscópico de la litiasis de la vía biliar principal. Enciclopedia Médico-Quirúrgica. 2002, 40-952: 1-15. 
9) Berthou J, Drouard F, Charbonneau Ph, Moussalier K. Evaluation of laparoscopic management of common bile duct stones in 220 patients. Surg Endosc. 1998; 12: 16-22.

10) Keeling N, Menzies D, Motson R. Laparoscopic exploration of the common bile duct. Beyond the learning curve. Surg Endosc. 1999; 13: 109-12.

11) Paganini A, Lezoche E. Follow up of 161 unselected consecutive patients treated laparoscopically for common bile duct stones. Surg Endosc. 1998; 12: 23-9.

12) Pekolj J, Sendín R, De Santibañes E. Tratamiento de la litiasis coledociana por vía transcística laparoscópica. Utilización y efectividad. Rev Argent Cirug 1997; 72: 146-158.

13) Praderi Gambardella L, Geninazzi H, Tchekmedyian V, Balboa O, Matteucci P, Voelker R, Praderi L. Exploración y tratamiento de la litiasis de la vía biliar principal en cirugía laparoscópica. Cir Uruguay. 1995; 65: 153-8.

14) Tranter S, Thompson M. Comparison of endoscopic sphincterotomy and laparoscopic exploration of the common bile duct. Br J Surg. 2002; 89: 1495-504.

15) Thompson M, Tranter S. All-comers policy for laparoscopic exploration of the common bile duct. Br J Surg. 2002; 89: 1608-12.

16) Urbach $D$, Khajanchee $Y$, Jobe $B$, Standage $B$, Hansen $P$, Swanstrom L. Cost-effective management of common bile duct stones. A decision analysis of the use of endoscopic retrograde cholangiopancreatography (ERCP), intraoperative colangiography, and laparoscopic bile duct exploration. Surg Endosc. 2001; 15: 4-13.

17) Paganini A, Feliciotti F, Guerrieri M, Tamburini A, Campagnacci R, Lezoche E. Laparoscopic cholecystectomy and common bile duct exploration are safe for older patients. Surg Endosc. 2002; 16: 1302-8.

18) Riciardi R, Islam S, Canete J, Arcand P, Stoker M. Effectiveness and long-term results of laparoscopic common bile duct exploration. Surg Endosc. 2003; 17: 19-22.

19) Salom A, Estapé Viana G, Müller A, Peyroulou A. Tratamiento por cirugía laparoscópica de la litiasis coledociana. Actas del 75을 Congreso Argentino de Cirugía; 2004: Buenos Aires, Argentina.

20) Salom A, Estapé Viana G, Acevedo C, Harguindeguy M, Etlin A et al. Tratamiento de la litiasis coledociana. Cir Uruguay. 2004; 74: 46-57.

21) Praderi R. Historia de la Cirugía de la litiasis coledociana. Cien años de Cirugía Biliar. Cir Uruguay. 1982; 52: $1-18$.

22) Mazzariello R. A fourteen-year experience with nonoperative instrument extraction of retained bile duct stones. World J Surg. 1978; 2: 447-55.

23) Classen M, Demling L. Endoscopische Sphinckterotomie der Papilla Vateri. Dtsch Med Wochenschr. 1974; 99:496-7.

24) Kawai K, Akasaka Y, Murakama M, Tada M, Kholi Y, Nakajima M. Endoscopic sphincterotomy of the ampulla of Vater. Gastrointest Endosc. 1974; 20: 148-51.

25) Williams EJ, Green J, Beckingham I, Parks R, Martin D, Lombard M, et al. Guidelines on the management of common bile duct stones (CBDS). Gut. 2008; 57: 1004-21.

26) Collins C, Maguire D, Ireland A, Fitzgerald E, O'Sullivan G. A prospective Study of Common Bile Duct Calculi in Patients Undergoing Laparoscopic Cholecystectomy. Natural History of Choledocholitihiasis revisited. Ann Surg. 2004; 239: 28-33.

27) Paganini AM, Guerrieri M, Sarnari J, De Sanctics A, D’Ambrosio G, Lezoche G, et al. Thirteen years experience with laparoscopic transcystic common bile duct exploration for stones. Surg Endoc. 2007; 21: 34-40.

28) Chiappeta-Porras LT, Nápoli ED, Canullán CM, Roff H, Quesada B, Hernández N, et al. Single-stage management of common duct stones by video-assisted laparoscopy. Analysis of 10 years experience. Cir Esp. 2007; 82: 231-4.

29) Chiappetta Porras LT, Nápoli ED, Canullán CM, Quesada B, Petracchi J, Oría A. Laparoscopic bile duct reexploration for retained duct stones. J Gastrointest Surg. 2008; 12: 1518-20. 
30) Pekolj J, Sendín R, Aldet A et al. Tratamiento de la litiasis coledociana por vía transcística Laparoscópica: utilización y efectividad del método. Rev Argent Cir. 1997; 72: 146-58

31) Pekolj J, Santibañes E, Sívori J et al. Tratamiento de la litiasis coledociana por vía transcística durante la colecistectomía Laparoscópica. Rev Argent Cir. 1995; 69: 10-7.

32) Petelin JB, Pruett CS. Common bile duct stones. In: Cameron JL, editor. Current surgical therapy. 8yh edition. Philadelphia: Elsevier Mosby. 2004: 392-9.

33) Petelin JB. Laparoscopic common bile duct exploration. Surg Endosc. 2003; 17: 1705-15.

34) Tinoco R, Tinoco A, El-Kadre L, Peres L, Sueth D. Laparoscopic Common Bile Duct Exploration. Ann of Surg. 2008; 247: 674-9.

35) Tekin A, Ogetman Z. Laparoscopic Exploration of the Common Bile Duct with a Rigid Scope in Patients with Problematic Choledocholithiasis. World J Surg. 2010; 34: 1894-9.

36) Shively EH, Richardson M, Romines R, Englund G, Watkins J. Laparoscopic Common Duct Exploration in 90-Bed Rural Hospital. Am Surg. 2010; 76: 626-9.

37) Lai EC, Mok FP, Tan ES, Lo C, Fan S, You K, et al. Endoscopic biliary drainage for severe acute colangitis. N Engl J Med. 1992; 326: 1582-6.

38) Adler DG, Baron TH, Davila RE, Egan J, Hirota WK, Leighton JA, et al. ASGE guideline: the role of ERCP in diseases of the biliary tract and the pancreas. Gastrointest Endosc. 2005; 62: 1-8.

39) Leung JW, Chung SC, Sung JJ, Banez VP, Li AK. Urgent endoscopic drainage for acute suppurative colangitis. Lancet. 1989; 1: 1307-9

40) Tranter SE, Thompson MH. Spontaneous passage of bile duct stones: frequency of occurrence and relation to clinical presentation. Ann R Coll Surg Engl. 2003; 85: 174-7

41) Acevedo C, Teixeira M. Cirugía en diferido de la litiasis coledociana: menor porcentaje de intervención sobre la vía biliar. Cir Esp 2006; 6(79): 361-4.

42) Matteucci P, Barreiro C, Del Campo A, Consoni C. Litiasis coledociana insospechada. Cir. Uruguay. 1994; 64(3): 217-8.

43) Moroni J, Haurie JP, Judchak I, Fuster S. Single-stage laparoscopic and endoscopic treatment for choledocholithiasis: a novel approach. J Laparoendosc Adv Surg Tech A. 1999; 9: 69-74.

44) Muniz N, Bonilla F, Brito Noelia, Sanguinetti M, Robaina R. Tratamiento quirúrgico, endoscópico y combinado de la litiasis coledociana en el Hospital de Clínicas. Clínica Quirúrgica ??]B?? Hospital de Clínicas, Montevideo, Uruguay. Presentado en el Congreso Uruguayo de Cirugía en noviembre de 2011.

45) Pineda L, Arbeláez V, Gómez M, Daza J, Siado A, Nel Aponte P et al. Estudio comparativo entre la papilotomía endoscópica intraoperatoria y papilotomía endoscópica convencional para el tratamiento de la colédocolitiasis. Rev. Col. Gastroenterol. 2007; 22(4): 272-82.

46) Kroh M, Chand B. Choledocholithiasis, Endospcopic Retrograde Cholangiopancreato-graphy and Laparoscopic Common bile Duct Exploration. Surg Clin N Am. 2008; 88: 1019-31.

47) Gramática $L(h)$, Moreno W, Palas Zuñiga. Litiasis biliar complicada. Litiasis de la vía biliar principal. En: Gramática L. ABC de la cirugía biliar. Ed: Ediciones Médicas del Sur. 2011; 3: 106-20.

48) Piazze A, Ruocco A. Tratamiento de la litiasis residual del colédoco con drenaje biliar externo por papilotomía endoscópica guiada. Cir Uruguay 1996; 66: 99-103.

49) Mazzariello R. A fourteen-year experience with nonoperative instrument extraction of retained bile duct stones. World J Surg. 1978; 2: 447-55.

50) Maglione H, Pignanessi D, Cerruti R, Díaz F. Papiloesfinteroplastia anterógrada con balón para el tratamiento laparoscópico de la litiasis coledociana.Trabajo presentado en la Sociedad de Cirugía del Uruguay el 18 de agosto de 2010. 
51) Pekolj J, Arbues G, Mazza O, Aldet A, Mc Lean I, Sívori J, De Santibañes E. Cierre primario del colédoco: una vieja técnica a utilizar en una época nueva?. Rev Argen Cirug. 1998; 6: 239-47.

52) Mazzariello R. Litiasis de la vía biliar principal. Tratamiento incruento. Relato LII Congreso Argentino de Cirugía. 1969: 157-72.

53) Mazzariello R. Extracción de grandes cálculos por vía transparietohepática. Rev Argent Cirug. 1988; 56: 241.

54) Rothlin M, Schob O, Weber M. Laparoscopic gastro and hepatojejustomy for palliation of pancreatic cáncer. A case controlled study. Surg Endosc. 1999; 13: 1065-9.

55) Edye M. Laparoscopic choledochoduodenostomy. In: Ballantyne G. Atlas of laparoscopic surgery. Philadelphia, Pennsylvania, U.S.A. W.B. Saunders Company. 2000; 7: 81-97.

56) Farello GA, Cerofolini A, Bergamaschi G, Rebonato M. Anastomosis Biliointestinal. In: Meinero M, Melotti G, Mouret Ph. Cirugía Laparoscópica. Buenos Aires. Argentina. Edit Med Panamericana S.A. 1996; 7: $230-8$.

57) Pereira-Lima L, Domene C. Anastomosis coledocoduodenal por laparoscopía. In: Cervantes J, Patiño JF. Cirugía Laparoscópica y toracoscópica. México. Mc Graw-Hill Interamericana. 1997; 20:132-7.

58) Cuschieri A. La cirugía laparoscópica en Europa: ¿hacia dónde vamos? Cir. Esp. 2006; 79: 10-21.

59) SAGES. Guidelines for the clinical application of laparoscopic biliary tract surgery. SAGES. Guidelines. Committee. October. 2002. 


\title{
Capítulo 5
}

\section{TRATAMIENTO ENDOSCÓPICO DE LA LTIASIS DE LA VÍA BILIAR PRINCIPAL.}

\author{
Dr. Álvaro Piazze
}

Próximamente, en el año 2014 se cumplirán 40 años desde el inicio del abordaje endoscópico de la vía biliar a través de la papila de Vater, con criterio diagnóstico primero (colangiografia endoscópica retrógrada, CER) y luego terapéutico (papilotomia, extracción de cálculos, dilatación de estenosis, colocación de prótesis plásticas, drenajes nasobiliares, prótesis autoexpandibles) para gran variedad de patologías benignas y malignas que afectan la vía biliar principal (VBP) en forma primaria o secundaria.

Al inicio del desarrollo de la técnica, y mientras se ganaba en experiencia, el cirujano solo la indicaba para el caso de litiasis residual en pacientes de alto riesgo quirúrgico y añosos, en el entendido que la papilotomía endoscópica realizada a pacientes jóvenes, podía derivar en complicaciones a futuro (estenosis papilar, colangitis a repetición por reflujo, cáncer de la VBP), y las inmediatas vinculadas al procedimiento (pancreatitis, perforación, sangrado) por lo que en otras circunstancias clínicas, el paciente era reoperado.

La difusión universal de la técnica, la búsqueda de la excelencia para optimizar los resultados (éxito), minimizando las complicaciones (número y gravedad) por todo el equipo actuante (endoscopista, asistente), el mejoramiento de los endoscopios y accesorios (papilótomos, guías, Dormias, balones extractores, drenajes nasobiliares, prótesis), la realización de los procedimientos bajo sedoanalgesia, equipos de radioscopia mejorados (mejor definición de imágenes, amplificación, últimamente digitalización) y el creciente aumento de la indicación por ser tan prevalente la patología, ha determinado un cambio muy significativo en los conceptos del cirujano a la hora de indicar el tratamiento endoscópico de la litiasis en la VBP.

Es así que se abren varios escenarios en el paciente portador de litiasis vesicular que será intervenido, ante la duda razonable o presencia confirmada de litiasis de la VBP.

La sospecha de litiasis en la VBP puede ser clínica (colangitis, pancreatitis biliar), humoral (alteración del funcional y enzimograma hepático con ascenso de bilirubina total a expensas de la bilirrubina directa, aumento de las enzimas fosfatasa alcalina y gamaglutamiltransferasa), o imagenológico (dilatación de ductos biliares en la ecografía o tomografía axial computada). La confirmación es por la visualización de una o varias imágenes sugestivas de cálculo(s) en estudios de imagen (ecografía, TAC, colangioresonancia, ecoendoscopia). 
La indicación sistemática de CER en el preoperatorio de toda colecistectomía laparoscópica, (conducta aceptada al inicio de los 90, cuando recién se iba adquiriendo experiencia en la cirugía laparoscópica de la vesícula), se dejó de lado posteriormente al comprobarse su inutilidad en la gran mayoría de pacientes (ausencia de cálculos en la VBP), a la vez que se exponía a los pacientes a los riesgos (complicaciones) de la CER y aumentando los costos asistenciales.

Un primer escenario es la CER y eventual papilotomia con extracción de cálculos en el preoperatorio, procediendo posteriormente a la colecistectomía (sea abierta o más frecuentemente y de preferencia laparoscópica), más aún cuando la vía biliar no aparece dilatada en los estudios imagenológicos previos. En el mejor de los casos, con éxito terapéutico y sin aparición de complicaciones, la cirugía a realizar será exclusivamente la colecistectomía por la vía elegida. La colangiografía intraoperatoria (muchas veces no se hace si existió una CER previa que resolvió la VBP) evidenciará la ausencia de cálculos residuales y un rápido pasaje del contraste hacia el duodeno a expensas de la papilotomía realizada. Especial cuidado deberá tenerse por la posible presencia de aerobilia (por la papilotomia que permite el paso del aire presente en el duodeno) para no confundir las imágenes con cálculos. Igual cuidado debe tenerse al inyectar el contraste, de no asociar el envío de aire por la tubuladura, dando lugar a burbujas que pueden confundir con la presencia de cálculos. Cuánto más distante en el tiempo se realice la colecistectomía respecto al tratamiento endoscópico de la litiasis de la VBP, más indicación de colangiografía intraoperatoria, habida cuenta de la posible migración a la VBP de nuevos cálculos procedentes de la vesícula. Situación que se verá favorecida en casos de cístico ancho, ambiente común colecistocoledociano o cálculos pequeños/medianos que pueden desplazarse más fácilmente.

La mejor oportunidad para realizar la colecistectomía, de elección por laparoscopía, es 24 horas luego del procedimiento endoscópico, teniendo en cuenta la posibilidad de que existan complicaciones inmediatas relacionadas (pancreatitis, colangitis, hemorragias, perforación) en ese lapso; por la respuesta inflamatoria que se produce en muchos casos por la manipulación endoscópica de la vía biliar (referida por algunos cirujanos al momento de la exploración varios días después) y por la posibilidad de nuevas migraciones litiásicas con el pasar de los días, que obligue al tratamiento quirúrgico de la litiasis de la VBP o en su defecto o fracaso, a otra sesión de tratamiento endoscópico en el postoperatorio.

Existe la probabilidad, que la CER fracase, no sea posible técnicamente, en el preoperatorio (casos de situación anatómica adversa insuperable, tamaño y número de cálculos, asociación de cálculos con estenosis biliar, falta de experiencia del profesional). En tal caso, el cirujano sabe de antemano que deberá resolver la situación integralmente (coledocolitotomía) al momento de la colecistectomía (abierta o laparoscópica).

Un subcapítulo lo representa el tratamiento en forma combinada con el endoscopista, por la técnica llamada de encuentro o "rendez vous" por los franceses, en el intraoperatorio, escenario que se trata a continuación: CER y papilotomia intraoperatoria.

Esta situación es posible en forma programada, o sea coordinada previamente, ya que exige que el endoscopista especializado, su asistente también especializado, el equipamiento endoscópico y accesorios necesarios, estén presentes durante el desarrollo de la colecistectomía, habitualmente laparoscópica. Si no es una práctica difundida en cada lugar en que se practica una colecistectomía, es por la falta de endoscopistas capacitados en la técnica y de equipamiento específico. Por otra parte la posibilidad de una litiasis insospechada durante una colecistectomía es de bajo porcentaje, y en ellos muchas veces puede resolverse quirúrgicamente en el mismo acto. Elementos de radioprotección son imprescindibles en el área (chalecos plomados, protector de cuello, lentes plomados) para todos los involucrados expuestos a radiaciones ionizantes.

Si no fue coordinada la presencia del endoscopista entrenado en vías biliares en sala de operaciones, y surge la indicación para su presencia en carácter urgente, es posible que esté realizando simultáneamente su trabajo endoscópico a otros pacientes en un área alejada del quirófano y en tal caso deberá abandonar el mismo, hacer el traslado del equipamiento referido junto a un ayudante de en- 
doscopia a su vez entrenado en CER (situación que no es la predominante). Por eso surge la necesidad de tener todo coordinado, con presencia "stand by" del equipo endoscópico integralmente, material y humano, de ser posible. Otra situación es que ante la convocatoria urgente del endoscopista, éste no se encuentre en la Institución, por ejemplo desempeñándose en otra consulta alejada, haciendo imposible la concurrencia en tiempo y forma.

Curiosamente, han pasado décadas en que el cirujano invierte tiempo en capacitarse intelectualmente y adquiriendo destrezas manuales en diferentes clínicas quirúrgicas, buscando el perfeccionamiento técnico, pericia, para solucionar la patología litiásica de la VBP (sea por vía abierta o laparoscópica), ofreciendo lo mejor de si en el cuidado de su paciente. Pero frente al hallazgo de cálculos en la VBP y de no poder extraer los mismos por vía laparoscópica convierte a cirugía abierta en algunos casos, o deja un drenaje trancístico o cierra el cístico y deriva al paciente al endoscopista, confiando a él la solución definitiva, con las eventualidades que veremos en el próximo escenario de CER en el postoperatorio.

En cambio, algunos centros quirúrgicos que realizan CER intraoperatorias cada vez que se necesitan, cuentan con cirujanos e instrumentistas en sala de operaciones, entrenados en endoscopia de vías biliares y por cierto con el equipamiento y accesorios específicos.

La realidad (y experiencia personal) demuestra que es más fácil entrenarse como cirujano de vías biliares que como endoscopista especializado en vías biliares, y el número de unos (mayor cantidad) y otros (pocos) explican en parte las dificultades relatadas.

Cuando irrumpió el abordaje endoscópico de la vía biliar hace 40 años, quienes habían iniciado la práctica de la endoscopia digestiva diagnóstica primero, luego incorporando terapéuticas, eran los servicios de Gastroenterologia, por lo que al tener la práctica básica, restaba incorporar la tecnología (duodenoscopio y accesorios) para iniciarse en las maniobras con la anuencia de los cirujanos referentes de los pacientes. Y así ha continuado en la mayor parte de los países, salvo excepciones, en que algunos cirujanos decidieron formarse por iniciativa personal en endoscopia digestiva, en lugares o programas de formación ajenos a su Clínica quirúrgica o al programa de formación del Residente de Cirugía que ofrece el Departamento de Cirugía. En esos casos fue o es necesario vincularse individualmente con un Maestro experiente en la técnica, por el lapso prudencial de tiempo de dedicación al aprendizaje de todo lo que refiere a la endoscopia: preparación, premedicación, indicación, contraindicaciones, consentimiento, alternativas terapéuticas, oportunidad, prevención de complicaciones, diagnóstico precoz de ellas y su manejo, conocimiento y cuidados del instrumental endoscópico y accesorios, más allá de los pasos técnicos precisos para llevar adelante la más exigente de las técnicas endoscópicas.

Del punto de vista técnico, la realización de una CER intraoperatoria, requiere de las mismas exigencias que su realización en el pre o postoperatorio. Con el paciente en decúbito dorsal e intubado, puede ser más dificultoso el avance del duodenoscopio, que al ser de visión lateral se pasa a ciegas, por lo que la evaluación de las resistencias al deslizamiento por la buco e hipofaringe hasta pasar el esfinter esofágico superior debe realizarse con extremo cuidado. Una vez superado el pasaje faringoesofágico la llegada a la segunda porción del duodeno no ofrece dificultades. Para el reconocimiento y cateterismo de la papila de Vater, se procede como habitualmente. En el caso que no se logre pasar el duodenoscopio por la bucofaringe hacia el esófago con el paciente en decúbito dorsal, hay que lateralizarlo hacia la izquierda (decúbito lateral izquierdo) procediendo como se hace habitualmente la técnica.

Es conveniente que la mesa de operaciones sea radiolúcida en su máxima extensión para conseguir en distintas posiciones del paciente una radioscopia efectiva con el arco en $\mathrm{C}$, y no limitado a un espacio radiolúcido restringido (romboidal) de algunas mesas. Previsión necesaria antes de pasar al paciente para la cirugía.

Una vez frente a la papila de Vater se procede al cateterismo selectivo de la vía biliar, utilizando o no una guía hidrofilica 0.035 inch por dentro del papilótomo, comprobar la posición inyectando contraste (colangiografía), identificar los cálculos, número, tamaño, posición, realizar la papilotomia, ingresar con 
la cestilla Dormia o con el balón extractor, repitiendo las maniobras como sean necesarias hasta dejar libre de cálculos la vía biliar.

Existe la posibilidad de simplificar las maniobras de ingreso selectivo a la vía biliar, si el cirujano logra pasar una guía transcistica larga $(450 \mathrm{cms}$ para los papilótomos estándar o más corta para la nueva línea de accesorios que viajan a lo largo de una guía que a poco de ingresar por el extremo del accesorio recorren solamente unos $\mathrm{cm}$ y salen por otro orificio lateral) hacia el duodeno, ésta es extraída por el endoscopista con un lazo o pinza, y una vez fuera del endoscopio, se enhebra la guía al papilotomo, cuyo deslizamiento será entonces guiado directo hacia el interior de la vía biliar, haciendo un solo intento de ingreso, certero. A continuación se realiza la papilotomia guiada y demás maniobras ya referidas.

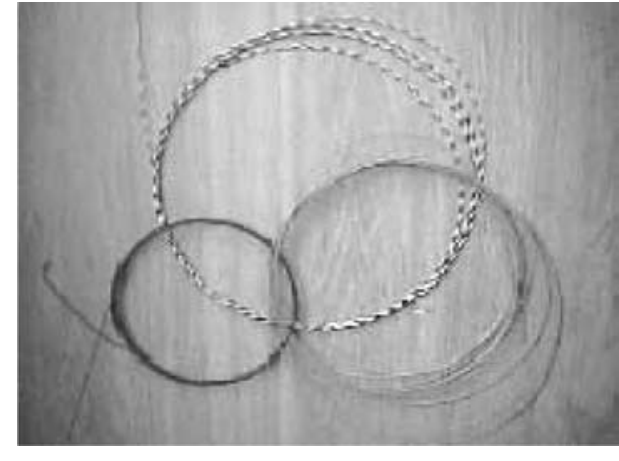

Guías hidrofílicas 0.035 inch punta recta

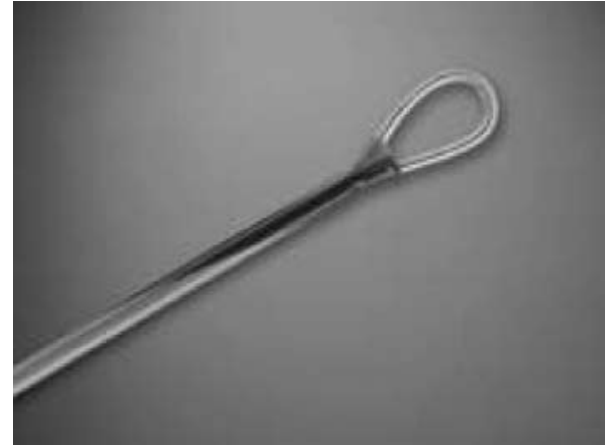

guía con ojal en su extremo

Existe una nueva guía hidrofílica en cuyo extremo tiene un pequeño ojal de 4 por $2 \mathrm{~mm}$, de $480 \mathrm{~cm}$ de largo y 0.035 inch de calibre. Si se utiliza por el cirujano, avanzándola por vía transcística, al llegar al duodeno, el endoscopista debe pasar el extremo de la guía que está utilizando dentro del papilótomo, al interior del ojal, de forma tal que el cirujano al retraer la guía transcistica hacia el interior de la vía biliar, arrastra la guía del papilótomo con éste montado en ella, ingresando de primera al interior de la vía biliar. A la inversa es válido, una guía que termina en punta es pasada por el cirujano por vía transcistica al duodeno, y la guía con el ojal en el extremo es la empleada por el endoscopista en el interior del papilótomo, de tal forma que logrando enhebrar la guía transpapilar en el ojal de su guía, solamente hay que empujar o deslizar la guía y el papilotomo hacia el interior de la vía biliar.

Estas maniobras buscan minimizar el traumatismo a la papila de Vater provocado por reiterados intentos de ingreso a la vía biliar. De esta manera se evita todo cateterismo no deseado del Wirsung, con el objetivo de disminuir los riesgos de una pancreatitis secundaria a la CER y papilotomia por un lado, y también evitar hacer un precorte o infundibulotomia de la papila de Vater, maniobra realizada cuando no es posible ingresar a la vía biliar por el ostium papilar. Esta última maniobra se acompaña de mayor porcentaje de complicaciones especialmente si no se tiene suficiente experiencia.

Esta técnica llamada de encuentro o "rendez vous" es de gran ayuda cuando existen dificultades anatómicas sea para el acceso a la papila de Vater en pacientes operados del tracto digestivo superior (gastrectomías, como veremos más adelante) o cuya papila de Vater o más precisamente el ostium, se encuentra oculto en relación a la presencia de un divertículo duodenal, u ofreciendo una dirección para acceder a ella demasiado oblicua o tangencial no corregible pese a realizar todas las variaciones técnicas disponibles, situaciones que pudieron ser las responsables de fracasos técnicos de la CER en el preoperatorio.

Hay que considerar el aumento del costo, ya que una guía simple cuesta 100 dólares y la con ojal algo superior. No obstante el costo sanitario de una pancreatitis postprocedimiento que logre evitarse es muy superior en todo aspecto. 
Una de las dificultades técnicas para el cirujano responsable de la colecistectomía y que sigue a la CER intraoperatoria, es la sobredistensión del intestino delgado por el aire insuflado durante el procedimiento endoscópico, tanto más aire cuanto más prolongada o difícil haya sido (de ahí que cuanto más facilidades ofrezca la técnica de "rendez vous", menor duración de la CER, menor insuflación). Por ello es conveniente, antes de proceder a la CER, tener disecado el pedículo cístico y clipada la arteria cística, para facilitar la colecistectomía, como recomendación.

El escenario ideal es lograr la solución integral de la patología litiasica de la vía biliar accesoria y de la VBP, en un mismo acto quirúrgico, sea la colecistectomía abierta o laparoscópica con coledocolitotomía transcística o con coledocotomía y drenaje biliar externo, trancístico o Kehr. Pero si no se pudo resolver la litiasis de la VBP por dificultades técnicas o debió acortarse la cirugía por algún problema anestesiológico o aún creyendo haber extraído todos los cálculos, puede suceder que en el postoperatorio, la realización de una colangiografia por el drenaje arroje la persistencia de cálculos. También está el caso que el cirujano finaliza la colecistectomía clipando o ligando el cístico de haber interpretado la colangiografia intraoperatoria como normal, o también confiando en la eliminación espontánea de microcálculos vistos en la colangiografía intraoperatoria en que se demuestra buen pasaje del contraste hacia el duodeno. $O$ mismo toma esa decisión de clipar o ligar el cístico sabiendo de la existencia de cálculos en la VBP, confiando finalmente en la solución por CER y papilotomia en el postoperatorio. Está también aquella situación en que no se hizo una colangiografía intraoperatoria pero en el postoperatorio el paciente presenta un cuadro clínico compatible con obstrucción de la VBP.

Aquí estamos frente al escenario de intentar resolver la situación de litiasis en la VBP con una CER con papilotomia en el postoperatorio, para la cual existen varias alternativas que dependerán si el paciente quedó o no con drenaje biliar externo.

Referente a la colocación de un drenaje biliar externo, remarcamos la importancia de que el cirujano coloque de forma adecuada el drenaje transcístico o el Kehr, con un trayecto directo y corto hasta la pared abdominal, sin bucles, del mayor calibre posible y correctamente fijada para que no se salga al manipularse. En el caso de la sonda Nelaton de goma, es necesario seccionar su punta para facilitar el pasaje de una guía para el caso de ser necesario su utilización, sea para facilitar el cateterismo de la vía biliar o realizar otras maniobras como papiloesfinteroplastia con balón anterógrado, como se explica en el siguiente capítulo.

En este punto, desarrollaremos la CER con papilotomia en el postoperatorio. La misma puede hacerse en cualquier momento luego de la cirugía e implica los pasos técnicos referidos anteriormente. Siempre que el paciente tenga un drenaje biliar externo (transcístico, Kehr), situación recomendada, existe la opción de una técnica que combine maniobras por el drenaje como fueron referidas en la CER intraoperatoria ("rendez vous"), situación particularmente necesaria para tener éxito en situaciones anatómicas desfavorables, disminuyendo los casos de fracasos, variables con la experiencia del endoscopista actuante. Ante el fracaso de la CER, hay que saber bien el motivo, ya que hay veces que en un segundo intento se logra el éxito, o el paciente deberá ser derivado a un centro de mayor experiencia en endoscopia de vías biliares. Otra opción es la reintervención quirúrgica, por cierto no deseada por el paciente ni el cirujano, pero puede ser el único recurso.

Otra opción, el tratamiento de la litiasis de la VBP por vía percutánea transfistular o por vía transparietohepática (pacientes con o sin drenaje biliar externo), se tratan en el siguiente capítulo. 


\section{Consideraciones técnicas generales de la CER en el manejo de litiasis de la VBP y soluciones para casos especiales}

La CER ha perdido terreno en los últimos años como técnica diagnóstica, por su morbimortalidad, a favor de técnicas no invasivas o menos riesgosas como ecografía, tomografía, colangioresonancia e incluso ecoendoscopia.

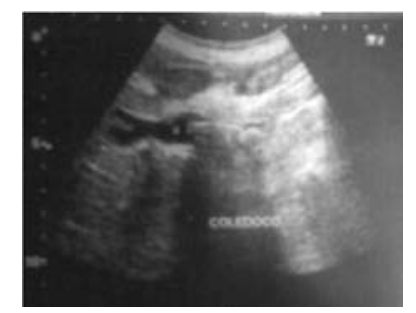

Ecografía evicencia cálculos en la VBP

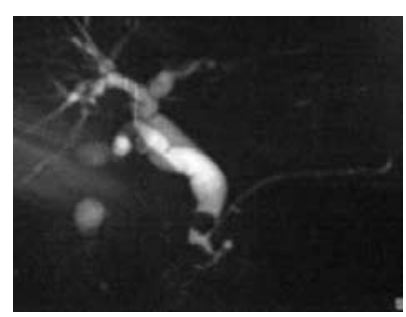

Colangioresonancias: 2 cálculos en la VBP

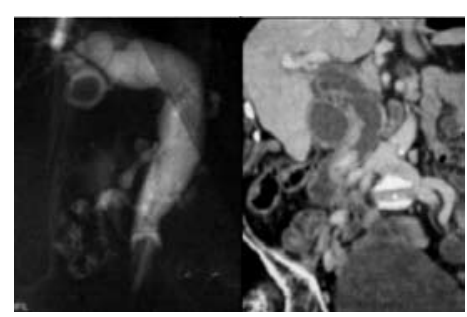

cálculos impactados

El rol actual es terapéutico, configurando una cirugía endoscópica dirigida a solucionar la litiasis de la VBP.

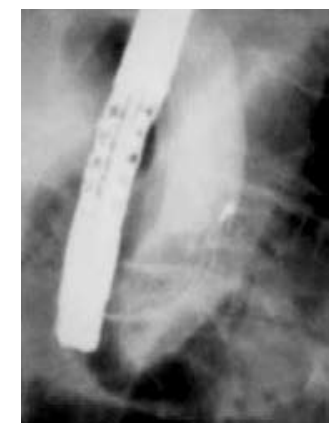

caso de la colangioresonancia Dormia atrapando el cálculo

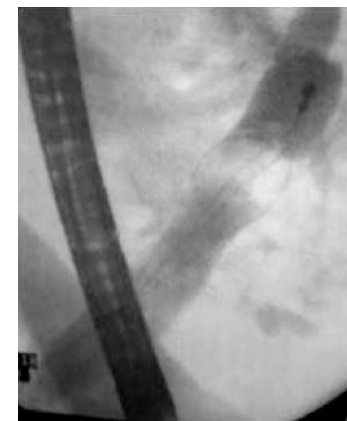

CER con papilotomia y extracción de cálculo con Dormia

Se diferencia de la cirugía abierta o laparoscópica para el tratamiento de la litiasis de la VBP, solamente por la vía de acceso (oral) y por el empleo de un duodenoscopio (instrumento) y accesorios similares a los empleados en cirugía abierta o laparoscópica para resolver la misma patología (Dormias, balones, guías), pero más largos para conducirlos por el canal operador del duodendoscopio que mide $140 \mathrm{~cm}$ y que se realiza la más de la veces con sedoanalgesia, aunque hay situaciones que requieren de intubación orotraqueal y anestesia general.

Cirugia endoscópica minimamente invasiva en lo que hace al concepto de abordaje, pero con morbimortalidad aún en manos expertas.

La tasa de éxito ronda el 70 - 95\%, considerando estudios multicéntricos con endoscopistas de experiencia dispar en CER en cada centro. En el capítulo de casuística endoscópica, publicamos nuestros resultados, en la población atendida durante un año (abril 2011-marzo 2012) para el presente Relato Oficial del 63‥ Congreso Uruguayo de Cirugia.

Existen situaciones en que resulta imposible la solución endoscópica, sea por inaccesibilidad a la papila de Vater, o por particularidades de la enfermedad litiásica de la VBP. No obstante ello, en centros que disponen de todos los recursos tecnológicos: variedad de endoscopios (mother and baby scope, 
Spy-Glass, y endoscopio de visión frontal ultrafino que pueden ingresar a la vía biliar por la papilotomia), enteroscopios, coledocoscopios, ecoendoscopios, para conducir guías para litotricia electrohidráulica o litotricia con laser, la posibilidad de combinar técnicas transparietohepáticas y endoscópicas ("rendez vous"), disponer de litotricia extracorpórea, y también combinar técnicas laparoscópicas y endoscópicas, pueden alcanzar casi el $100 \%$ de solución de las litiasis de la VBP. Los casos más complejos, pueden requerir de varias sesiones. Cuentan con personal multidisciplinario capacitado. La sumatoria y combinación de técnicas, aunque de mini-invasividad, conlleva un incremento de costos y morbimortalidad específica de cada una de las técnicas que corresponda.

No es esa la situación en nuestro país ni en la mayor parte de países de la región, quedando reducido a centros excepcionales que están a la vanguardia del desarrollo tecnológico con la capacitación o entrenamiento de los especialistas en consonancia.

La CER es una técnica quirúrgica endoscópica y radiológica, por lo que debe contarse con una cama radiolúcida, equipo de radioscopia con amplificador de imagen y técnico radiólogo encargado de su manipulación. Debería poder registrarse algún documento de la técnica realizada, sea radiografía, foto papel o video, más allá que habitualmente la radioscopia (siempre que sea de buena calidad) permite hacer el diagnóstico y sirve de apoyo para la terapéutica a realizar. De esta infraestructura se dispone en salas de radiología o salas de operaciones (arco en C).

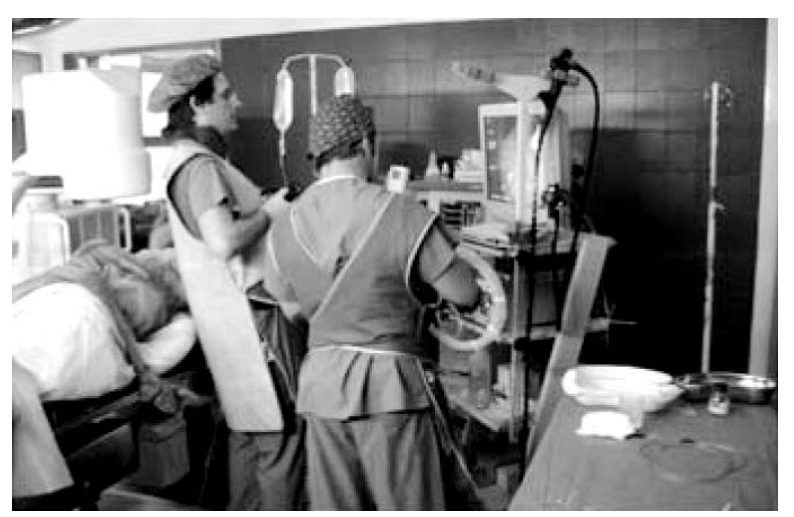

CER tiempo endoscópico

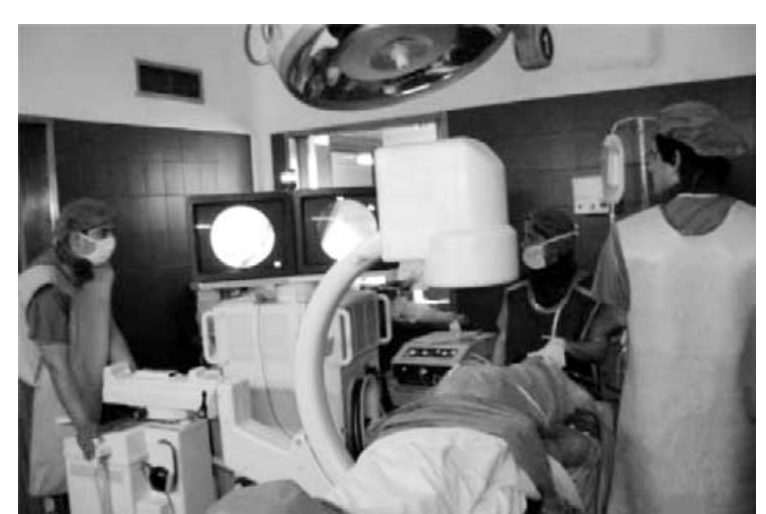

CER tiempo radiológico

Del punto de vista endoscópico se puede realizar con equipos portátiles: fuente de luz y un duodenoscopio de fibra óptica, por el que solo observa el endoscopista por la óptica el tiempo endoscópico, salvo que se adapte un dispositivo para trasmitir la imagen a un monitor. En tal caso el ayudante y el endoscopista pueden observar el tiempo endoscópico en el monitor. El problema es la disminución progresiva de la calidad de imagen cada vez que se interpone un adaptador para trasmitir la misma, por lo que es una tecnología que se va dejando de lado con la aparición de nueva y mejor tecnología. La versatilidad de los equipos portátiles hace posible su transporte permitiendo la realización de la CER en cualquier institución que cuente con los requerimientos radiológicos necesarios. El empleo de videoendoscopios electrónicos, montados en un carro o torre con ruedas, que constan de un procesador de imagen, fuente de luz y monitor (de preferencia de alta definición) permiten una mejor definición de imagen. La posibilidad de trasmitir la imagen desde el monitor, con un cable, hacia otros monitores estratégicamente colocados en la sala, permite el seguimiento de la técnica con el menor esfuerzo postural al equipo actuante, conservando la misma calidad de imagen, a diferencia de la tecnología anterior. Esta tecnología moderna es la preferida en centros de referencia o de gran volumen de pacientes. También en consultorios de menor volumen de pacientes biliares, pero que ya utilizan esa tecnología para la realización de videogastroscopias y videocolonoscopias. Incorporando un videoduodenoscopio (y todos los accesorios para vía biliar) adaptable al procesador, pueden llevarla a cabo, como en toda técnica, de contar con el entrenamiento 
adecuado. El carro es trasladable desde el consultorio de endoscopia hacia la sala de radiología o a la sala de operaciones, salvo que el consultorio de endoscopia ya cuente con el equipamiento radiológico imprescindible incorporado para realizar también las CER.

Desde agosto del 2012, disponemos de un carro de transporte birodado plegable diseñado por nuestro equipo de trabajo, que nos permite trasladar un videoprocesador compacto con la fuente de luz incorporada, proyectando la imagen a una laptop también ensamblada en el carro. Es decir que los procedimientos endoscópicos que hemos venido realizando en múltiples instituciones y hospitales, trasladando equipos de fibra portátiles, en los últimos 20 años, que solo permiten observar por la óptica al endoscopista, ahora los realizamos con un sistema de videoendoscopia electrónica digital, observando en un monitor de laptop el procedimiento, junto al asistente y demás personas presentes alrededor de la intervención. De suma utilidad para quienes están aprendiendo endoscopia, ya sea en la etapa inicial de observación (pueden apreciar el total de los procedimientos) o en la de realización de las técnicas con tutoría, pudiendo ser supervisados en todo momento mientras están realizando las mismas. Por otra parte es posible grabar directamente al disco duro y editar.
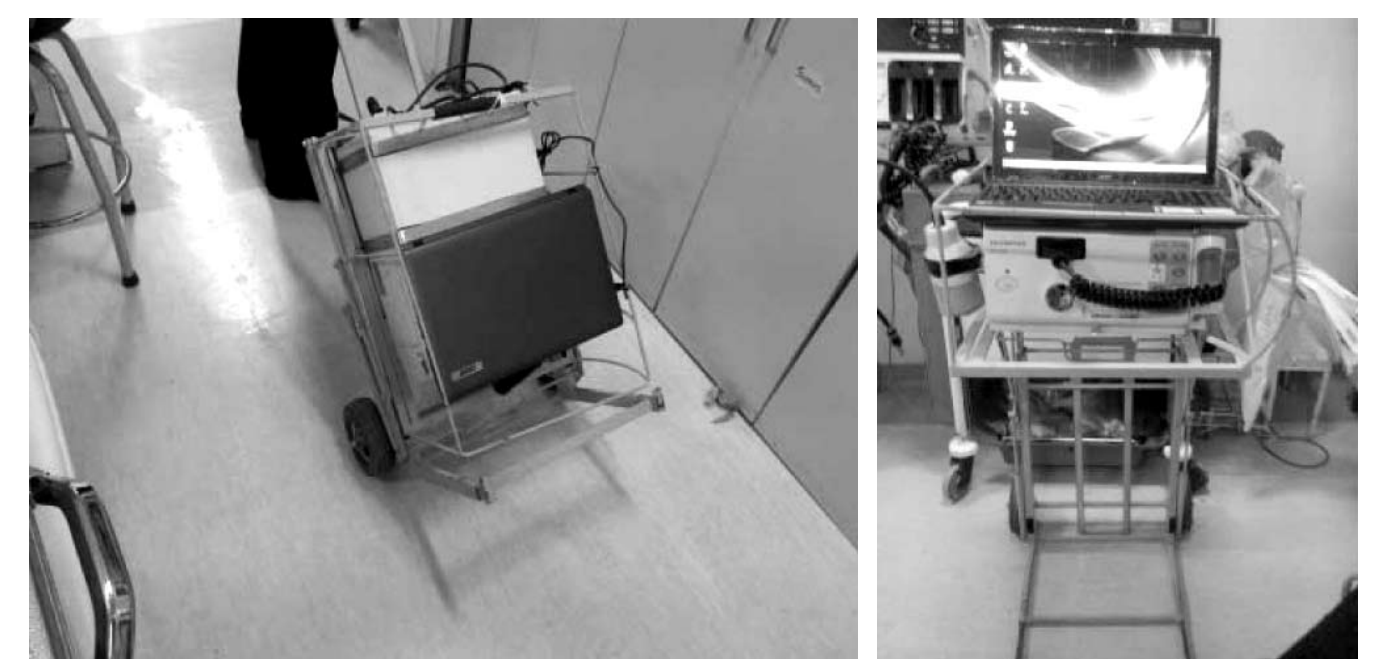

Debe haber como mínimo un aspirador para conectarlo al endoscopio y de ser requerido por el anestesista compartirlo, o mejor si hay otro aspirador disponible para él.

La sedoanalgesia o anestesia general dependerá del estado clínico de cada paciente y las preferencias del anestesista actuante. La realización de procedimientos cada vez más complejos y prolongados, con reiteración de maniobras para resolver los casos, amerita la presencia de un anestesista para mantener al paciente en posición, monitorizado, con correcta oxigenación (catéter nasal o intubación orotraqueal), oxímetro de pulso. No obstante puede realizarse una ligera sedoanalgesia ante ausencia de anestesista, por parte del endoscopista actuante, sin dejar de cuidar los mismos parámetros que vigila el anestesista y contar con todas las medidas necesarias para una reanimación ante un efecto farmacológico adverso.

Para la papilotomia se requiere de un bisturí eléctrico, que disponga de corriente de corte y posibilidad de mezcla (blend). En los últimos años, hubo una recomendación de realizar la papilotomia con corriente de corte puro por acompañarse de menor probabilidad de pancreatitis secundaria al procedimiento (a expensas de mayor posibilidad de sangrado), complicación que puede resultar grave, incluso mortal. Un meta-análisis del 2006 demostró que no había diferencias significativas en la aparición de pancreatitis secundaria a la papilotomia, según se use corte puro o blend. 
El paciente debe estar con ayuno de 8 horas y disponer de un estudio de crasis sanguínea normal. Cualquier alteración de la coagulación deberá ser corregida previamente por hemoterapeuta, sea la necesidad de vitamina $\mathrm{K}$, plasma fresco o reposición de plaquetas, según el caso.

El paciente y de ser posible un familiar directo que le acompañe (imprescindible en caso de menores de 18 años) debe leer cuidadosamente el consentimiento informado específico de la CER, que contiene información sobre la indicación, alternativas terapéuticas, beneficios, potenciales complicaciones, mención de porcentajes globales de las complicaciones y su gravedad, otorgando el mismo con su firma. Debe tener la posibilidad de hacer todas las preguntas o aclarar dudas tanto con el cirujano referente como con el endoscopista, antes de la intervención. Cuando el paciente no está en condiciones intelectuales o motrices de leer, comprender y firmar, un familiar directo, mayor de edad, deberá dar el consentimiento de igual forma. A continuación se expone el Consentimiento para CER de la Sociedad Uruguaya de Endoscopia Digestiva (S.U.E.D.)

\title{
Consentimiento informado de Colangiopancreatografía Endoscópica Retrograda Diagnostica y Terapéutica
}

\section{Información para los pacientes}

\author{
¿QUÉ ES LA COLANGIOGRAFíA ENDOSCÓPICA?
}

A usted se le ha solicitado un examen que consiste en estudiar los conductos biliares y pancreáticos, así como su terminación a nivel de una estructura llamada Papila de Vater en el duodeno. Para ello se utiliza un endoscopio flexible que se introduce por la boca avanzándose hasta el duodeno, segmento que le sigue al estómago. Es un examen combinado endoscópico y radiológico, obteniéndose radiografías de los conductos, al ser éstos rellenados por líquido de contraste yodado.

\section{PREPARACIÓN REQUERIDA}

Deberá estar con 8 horas de ayuno, se le colocará una vía venosa para pasar suero y medicamentos según necesidad (sedantes del tipo midazolam u otros, analgésicos, antiespasmódicos, antibióticos). Debe informar si es alérgico (a) al yodo o medicamentos. También si toma aspirina, antiagregantes plaquetarios o anticoagulantes. El estudio de la coagulación de la sangre (crasis sanguínea) debe ser normal. Si no lo fuera, se deberá corregir con vitamina $\mathrm{K}$ y/o plasma fresco.

\section{¿EN QUE CONSISTE EL ESTUDIO?}

Previo a la introducción del endoscopio por la boca, se le aplicará un anestésico en forma de spray en la garganta y se le colocará un protector dental de plástico (mordillo), que usted mantendrá sujeto con los dientes. Para el examen, usted estará acostado(a) sobre su lado izquierdo, realizándose el mismo en sala de radiología o en block quirúrgico, según cada caso. En algunas circunstancias puede requerirse de un anestesista. Usted puede que ya esté internado(a) o puede concurrir en forma ambulatoria.

\section{DESPUÉS DEL ESTUDIO}

Luego del examen quedará unas horas en observación, pudiendo regresar a su sala de internación o a su domicilio, según considere el especialista actuante y en relación con el medio familiar. 


\section{BENEFICIOS Y RIESGOS}

A través del examen se busca esclarecer que tipo de enfermedad está afectando los conductos biliopancreáticos o descartar la misma, de resultar su examen normal. Asimismo se pueden realizar intervenciones terapéuticas con la finalidad de extraer cálculos (papilotomía y extracción de cálculos) o de colocar prótesis (tubos plásticos o metálicos) para desobstruir los conductos, según cual sea la obstrucción. Estos tratamientos simplifican otras cirugías o mismo pueden hacer innecesarias las mismas, según el caso. Los riesgos pueden ser por los medicamentos utilizados, inflamación del páncreas (pancreatitis), sangrado y/o perforación si hubo necesidad de corte y colangitis (infección de los conductos biliares).

Globalmente consideradas, la incidencia de complicaciones es baja (menos del $10 \%$ ). El riesgo de vida puede variar del 0,1 al $1 \%$. En algunas circunstancias puede requerirse de operaciones, ya sea porque no se pudo resolver su caso con esta técnica o ante alguna complicación derivada de la misma. Pueden verse complicaciones relacionadas con la sedación, sobretodo en pacientes con factores de riesgo, como enfermedades previas y edad avanzada. Si se realiza medicación intravenosa, puede presentar moretones en la zona de punción. Las complicaciones infecciosas son raras.

En caso de presentar DOLOR INTENSO ó SANGRADO INTENSO concurra al Servicio de Emergencia de la Institución Médica que corresponda, con el informe de la endoscopía.

Consentimiento $\mathrm{N}^{\circ}$ :

\section{CONSENTIMIENTO INFORMADO POR PARTE DEL PACIENTE}

\section{PARA ENDOSCOPÍA DIGESTIVA}

He leído cuidadosamente y con tiempo suficiente el formulario de información que se me proporcionó y entiendo todos los puntos. Se me ha ampliado la información y se me ha respondido a mi entera satisfacción todas las preguntas que he formulado. Doy mi consentimiento en forma voluntaria y libre para realizarme el estudio. Si el médico endoscopista considera que es necesario realizar biopsias, realizar tratamiento para detener el sangrado de alguna lesión sangrante, dilatar zonas estrechas, colocar prótesis, extraer cálculos o cuerpos extraños y cortar o coagular con electrobisturí, también doy mi consentimiento en forma voluntaria.

Por otra parte doy mi consentimiento para realizarme premedicación, sedación vía oral (comprimidos), sedación intravenosa o anestesia general.

Se me ha entregado una copia de este formulario de consentimiento.

Firma del paciente.

Aclaración

Fecha .

Firma del testigo.

Aclaración

Fecha

Firma del médico que pide el consentimiento

Aclaración

Fecha 
A lo largo de los años hemos experimentado la errónea percepción de maniobra mínima y sin riesgos sobre la intervención a la que van a exponerse, que traen pacientes y familiares por la información (o interpretación de la misma) recibida de su médico/cirujano, gastroenterólogo referente, al ser consultados previo a la intervención. Tan es así, que algunos pacientes leen el consentimiento y al explicarle el alcance de las posibles complicaciones, renuncian a ser tratados en ese momento, regresando a su sala de internación. Por lo general vuelven con el consentimiento informado firmado para la siguiente coordinación, más tranquilos y confiados porque pudieron meditar, sacarse dudas al volver a compartir información con el médico referente. Expresiones como las que siguen " A mi me dijeron que era un estudio por la boca, me sacaban los cálculos y al otro día me voy de alta", o "con un pequeño cortecito me solucionan el problema" o "la cirugía salió bien, ahora va a ir a que le hagan un estudio ambulatorio para sacar las piedritas que quedaron" y así una variedad de expresiones que traducen el sentir del paciente sobre su actual situación. Como que la intervención (CER) fuera algo mágico, efectivo y seguro 100\%. Ahora, ¿cómo es posible entonces que luego de la papilotomia, el paciente pueda estar 30 días en el CTI por una pancreatitis grave, operado varias veces, o sangre con tal magnitud, que no se controle por endoscopia (inyección de vasoconstrictor, esclerosante, electrocoagulación, clips), y deba ser sometido a una laparotomía, duodenotomia y papiloesfinteroplastia hemostática si no se contó con el tratamiento vascular intervencionista (embolización) o fallezca por derivaciones de una perforación? Tal gravedad será difícil de entender y menos aceptar por el paciente y familiares, por la idea de "simplicidad" y de "sin riesgos o inocuo" que traían previo a la intervención. Cirugía endoscópica mini-invasiva sobre la VBP no es equivalente a complicaciones mínimas.

Felizmente las complicaciones graves suceden en baja proporción. La mayor parte de las veces son de grado leve y se controlan con tratamiento conservador o mini-invasivo, pero el peor de los escenarios debe ser tenido en cuenta, para casos excepcionales que siempre aparecen y no precisamente por impericia, imprudencia o negligencia. Excepciones que pasan a aumentar porcentualmente cuando algunos de esos tres elementos aislados o combinados están involucrados.

Igualmente surge de las alternativas diagnósticas redactadas en el consentimiento $o$ ante la información brindada por el especialista al paciente (especialmente en casos de dudosa indicación de la CER), de que la colangioresonancia (CRM) puede ofrecer la misma información diagnóstica que se busca, pero sin los riesgos de una CER. Algunos pacientes optan por tramitar la autorización de esta técnica menos invasiva del punto de vista diagnóstico. Posiblemente la CRM obtenga imágenes que permiten descartar un factor obstructivo evitando así los riesgos de una CER que finalmente no estaba indicada. Todos los expertos en CER coinciden en que la mejor manera de disminuir las complicaciones de la técnica, es evitar la realización de la misma cuando no está indicada. Vale decir que las complicaciones (si llegan a aparecer) deben ser consecuencia de la cirugía endoscópica o terapéutica, no del empleo de la CER con fines diagnósticos.

Otra situación es el caso de crear una expectativa desmedida de posible etiología litiásica (benigna, alta probabilidad de solución por vía endoscópica o eventualmente quirúrgica) como causa obstructiva frente a un paciente añoso con una ictericia fría progresiva, con prurito y hasta repercusión general, por más que los estudios imagenológicos previos a la CER no lograron definir la etiología. Hasta demostración de lo contrario corresponde a una obstrucción neoplásica, siendo la excepción un comportamiento seudoneoplásico de una litiasis biliar. Hemos asistido al impacto negativo del grupo familiar cuando damos la información del hallazgo de una obstrucción neoplásica, muchas veces de difícil solución aún paliativa. "Nadie nos dijo esa posibilidad", "el Dr. en todo momento nos habló de un estudio por la boca y que le sacarían una piedra". Seguramente nunca estuvo en el ánimo del colega referente llegar a ese estado de situación de la expectativa del paciente y del grupo familiar, pero es evidente que en algunas oportunidades falla la comunicación 


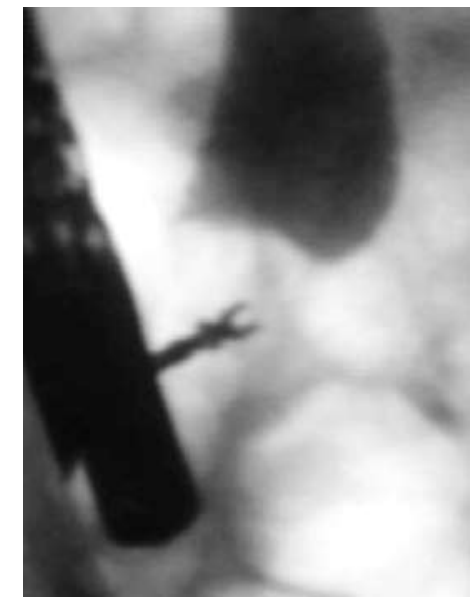

Biopsias de tumor de colédoco distal enviado para extraer litiasis que no tenia

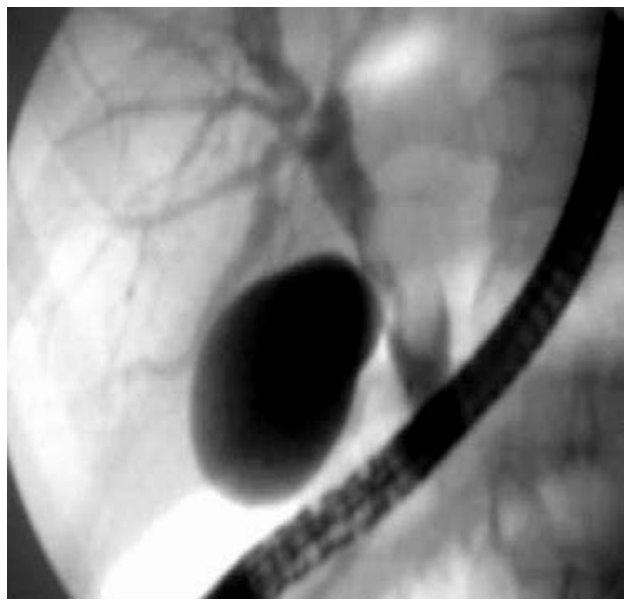

CER que muestra ocupación de la VBP fija al explorar con dormía (se trataba de tumor papilar de la VB que se resecó)

La situación inversa, también la describimos: con planteo de ictericia fría por neoplasma de vesícula (paredes engrosadas y posible infiltración del hígado) en paciente añoso, con vía biliar distal no dilatada y dilatación de la vía biliar proximal, nos solicitaron el drenaje biliar transparietohepático paliativo. La etiología de la obstrucción era litiásica y se operó de coordinación: colecistectomía y coledocolitotomia, extrayéndose el drenaje biliar externo.

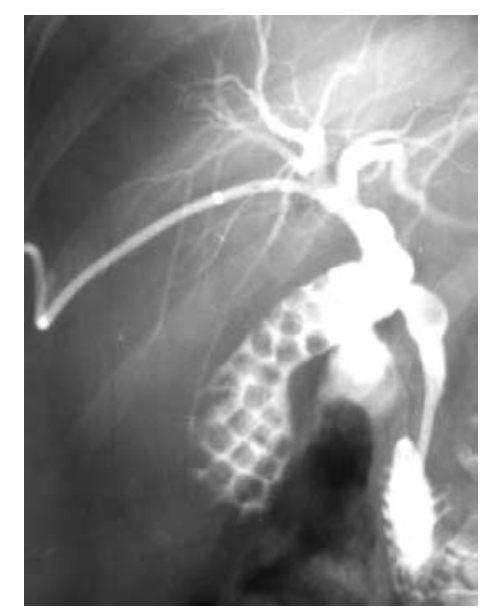

El paciente debe concurrir con una vía venosa periférica, de preferencia en el antebrazo derecho, habida cuenta que el paciente es colocado en decúbito lateral izquierdo y la compresión postural en la raíz del miembro superior izquierdo puede bloquear el pasaje del suero y la medicación empleada.

Aquellos pacientes que se coordinaron en forma ambulatoria y concurren desde su domicilio, se les coloca la vía venosa periférica momentos antes de la intervención.

Es importante mantener una hidratación parenteral adecuada, por las horas de ayuno previo al procedimiento y las horas siguientes al mismo ya que continuará con él. Una correcta hidratación y perfusión del páncreas, es necesaria para disminuir la isquemia y así mitigar la gravedad de la pancreatitis, cuando ella se desencadena. 
Se utiliza antibioticoterapia profiláctica, dirigida hacia los gérmenes enterales involucrados en las colangitis. Ampicilina sulbactam intravenoso, previo al procedimiento, salvo que ya estuviera con un plan previo, por ejemplo instaurado al ingreso del paciente.

Puede prescindirse de antibioticoterapia en pacientes asintomáticos en la medida que la vía biliar quede expedita luego de la CER y papilotomia con extracción de todos los cálculos. Es el caso del hallazgo de litiasis de la VBP en algún estudio imagenológico, pero sin obstrucción biliar manifiesta ni infección clínica.

La papila de Vater, por lo general está situada en la cara interna de la segunda porción del duodeno, a una distancia variable de la rodilla inferior (más o menos proximal a ella) siendo más rara la ubicación en la misma rodilla inferior, tercer o cuarta porción.

Puede identificarse fácilmente como protrusión que representa, a veces cubierta por algún pliegue mucoso redundante que cae sobre la misma, obligando a replegarlo con el papilótomo para identificar el ostium, o puede estar en relación a la presencia de un divertículo duodenal, sea yuxtadiverticular, en alguno de los bordes (anterior, posterior), en el piso o fondo de mismo, ofreciendo cada situación una dificultad diferente para su canulación.

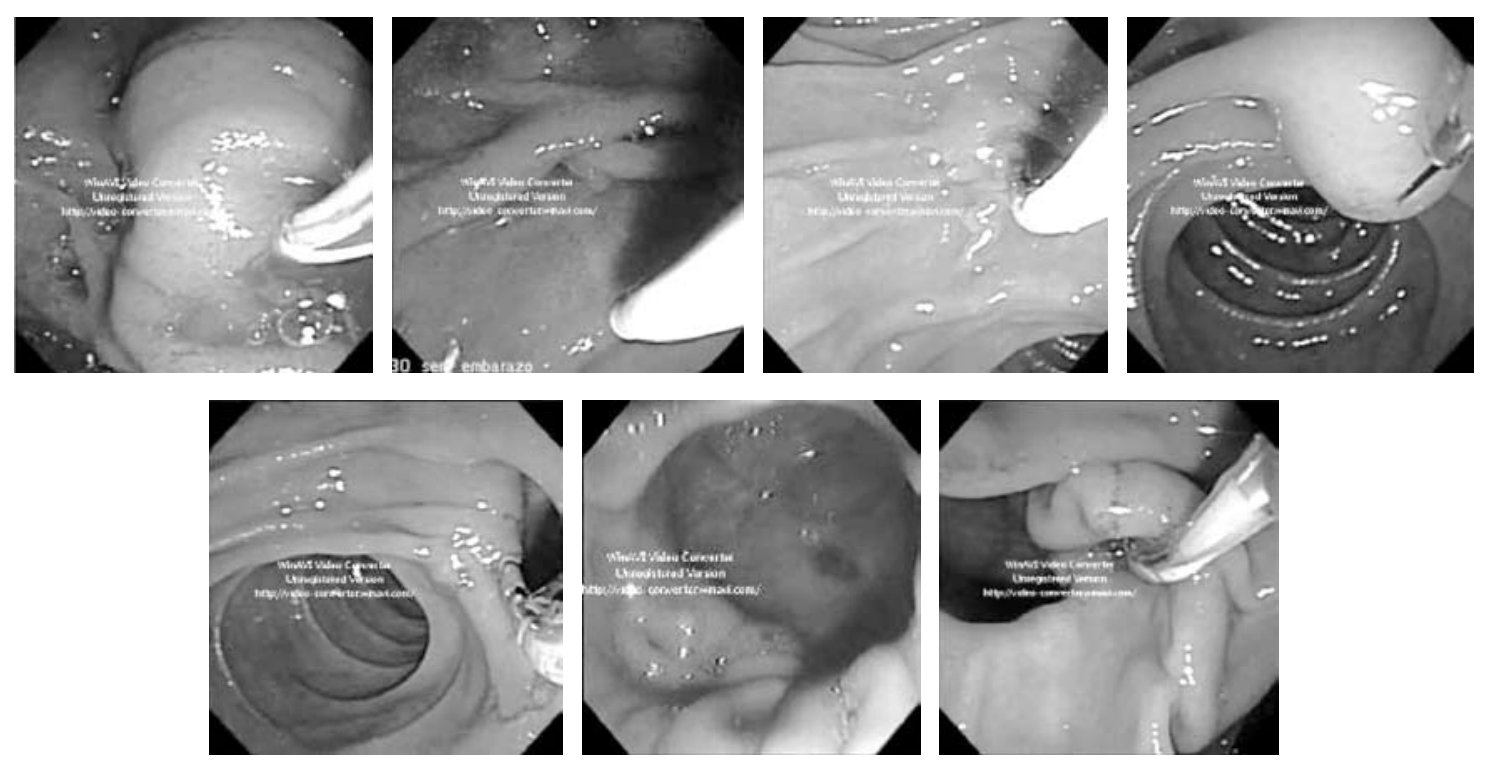

Secuencia superior: diferentes papilas de Vater, en cara interna de 2a.porción duodenal, normales las dos centrales, protruidas las otras; secuencia inferior: en borde posterior de divertículo, en el piso de amplio divertículo con restos de alimentos, en el borde anterior de divertículo duodenal

La orientación que ostenta la papila de Vater, particularmente el ostium, cuando está detrás del borde de un divertículo, puede hacer imposible su cateterismo, a pesar de ensayar cambios posturales al paciente (decúbito lateral izquierdo, decúbito dorsal o ventral), cambios posicionales al extremo del duodenoscopio con los comandos respectivos (up/down, derecha/izquierda), ensayando las posiciones corta (endoscopio estirado) o por la vía larga (formando un bucle en el estómago) y variando los catéteres, con y sin guía de por medio. En el mejor de los casos, puede presentar un infundíbulo prominente que permita acertar un precorte con el papilótomo tipo cuchillo, hacia la hora 11-12, para acceder a la vía biliar. En cambio, si la papila es pequeña, esta maniobra se transforma en extremadamente peligrosa, con 
alto riesgo de complicaciones mayores (perforación, sangrado) aparte de fracasar en el intento. Se transformaría en un paciente no resuelto de su patología inicial y además complicado, lo que puede derivar en una cirugía compleja de necesidad si el tratamiento conservador, o las medidas endoscópicas ensayadas en el mismo momento (inyección de adrenalina diluida, clips, electrocoagulación) no tienen éxito. Laparotomia, duodenotomia y papiloesfinteroplastia, para lograr la hemostasis de un vaso sangrante o cierre de una perforación además de la exploración del colédoco y drenaje biliar, puede ser la solución de salvataje, con morbimortalidad propia.

Hay papilas de Vater intradiverticulares o en sus bordes, con el ostium orientado de forma tal que todo intento de canulación fracasa, en los cuales ensayando la inyección submucosa de suero lateralmente a la papila, para lograr un desplazamiento corrector de la posición de la papila y su ostium, permite a veces alcanzar el éxito.

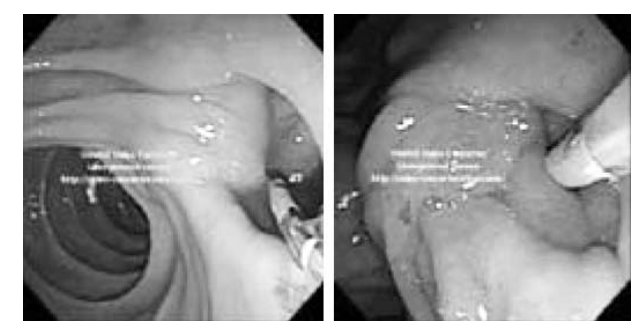

Papila con ostium inaccesible (borde posterior de divertículo), inyección de suero fisiológico en el fondo del divertículo para desplazar la papila y el ostium

La mayoría de situaciones, se resuelven con la papilotomia estándar (ingreso con papilótomo estándar) y extracción con Dormia. Cuando no se puede ingresar por el ostium al interior de la vía biliar, y en cambio se repiten ingresos al Wirsung, realizamos precortes de la papila dirigiendo el mismo a la hora 11-12, para acceder selectivamente a la vía biliar, e interrumpir maniobras sobre el Wirsung, que pueden precipitar una pancreatitis.

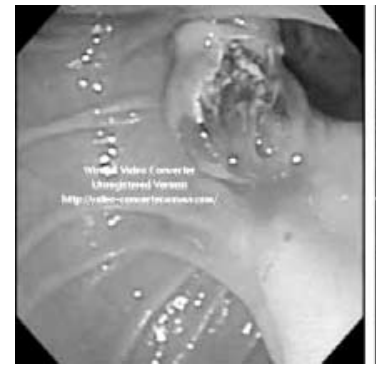

Papilotomia

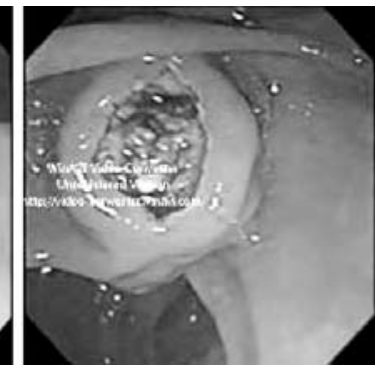

precorte

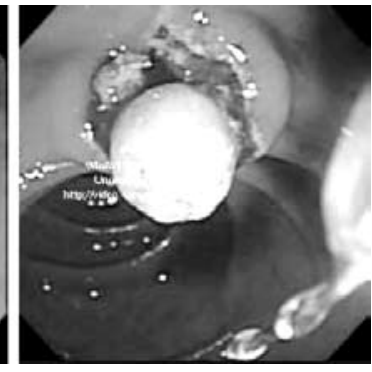

cálculo impactado: precorte y salida espontánea 


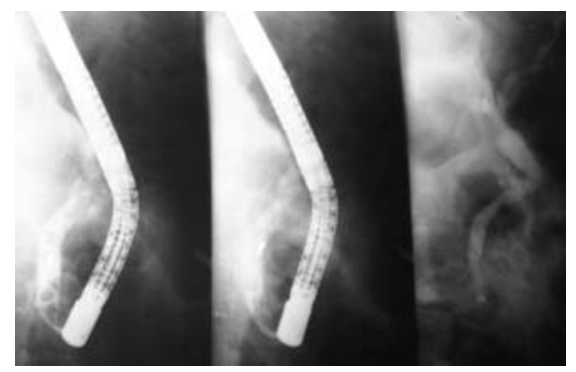

Cálculos múltiples, luego de la papilotomia, se extraen con Dormia, la vía biliar queda sin cálculos

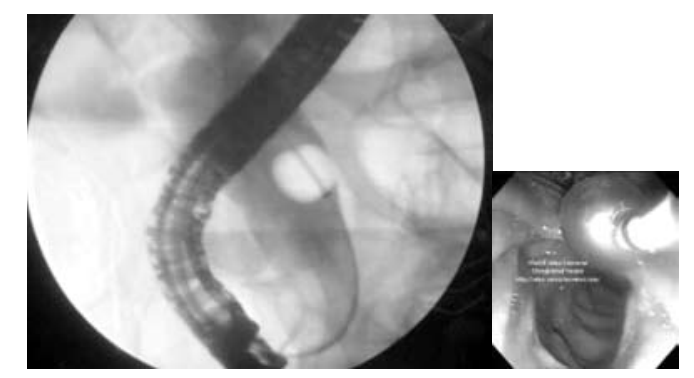

Barrido de la vía biliar con balón extractor (se rellena con aire)

En situaciones en que la papilotomía no puede ser de amplitud suficiente para extraer uno o más cálculos grandes, la asociación de una papiloesfinteroplastia y dilatación del colédoco distal con un balón de altas presiones de calibre adecuado al diámetro de la vía biliar y/o cálculo (10 a $12 \mathrm{~mm}, 12$ a $15 \mathrm{~mm}$, 15 a $18 \mathrm{~mm}$ ) permitirá extraer los mismos, disminuyendo la necesidad de litotricia mecánica y acortando el tiempo de la intervención. Los balones miden $5.5 \mathrm{~cm}$ de largo, y se deslizan sobre una guía hidrofílica. El control de la dilatación se hace observando por endoscopia, pero especialmente por radioscopia, hasta objetivar la desaparición de la cintura o muesca en el contorno del balón al que se va rellenando con contraste hidrosoluble diluido. Puede conectarse el balón a un manómetro siguiendo el incremento de presión hasta alcanzar el máximo recomendado por el fabricante. La extracción del o los cálculos una vez retirado el balón, se realiza con Dormia y/o balón extractor con mayor facilidad.

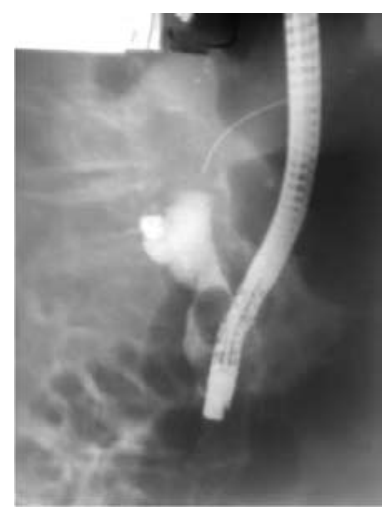

Cálculo grande

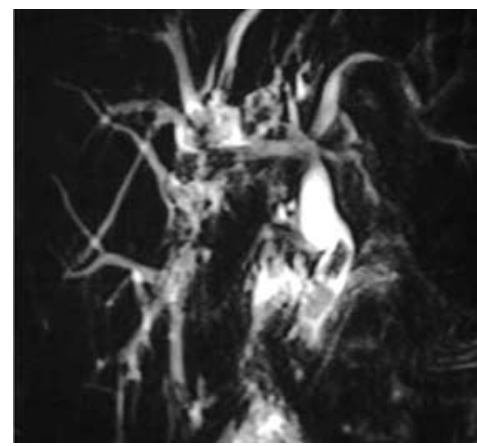

Colangioresonancia

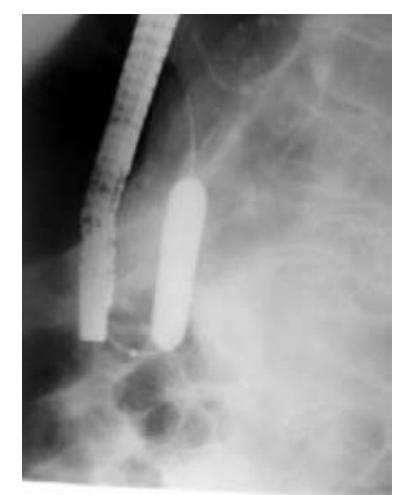

papiloesfinteroplastia con balón

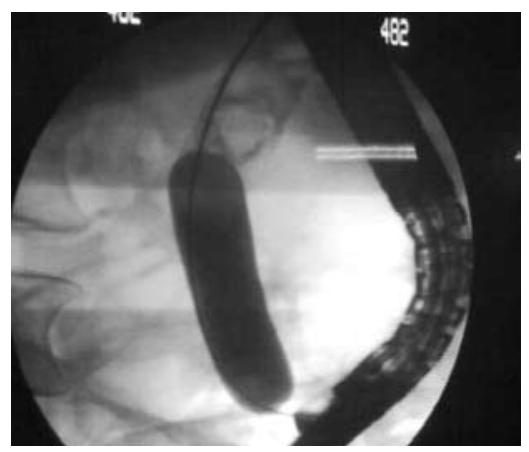

papiloesfinteroplastia con balón en Rx

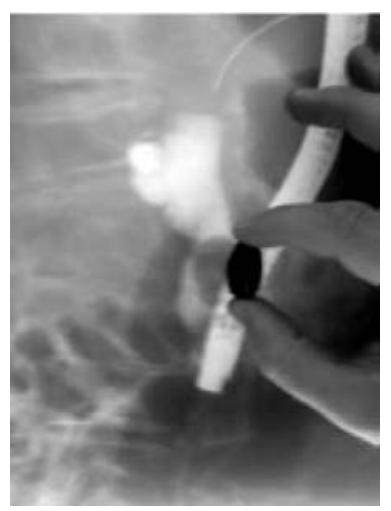

cálculo fuera del paciente

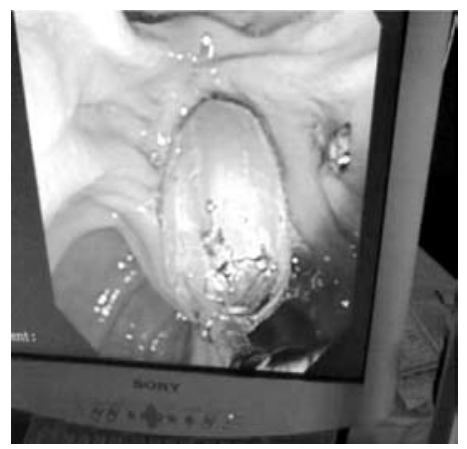

papiloesfinteroplastia con balón 


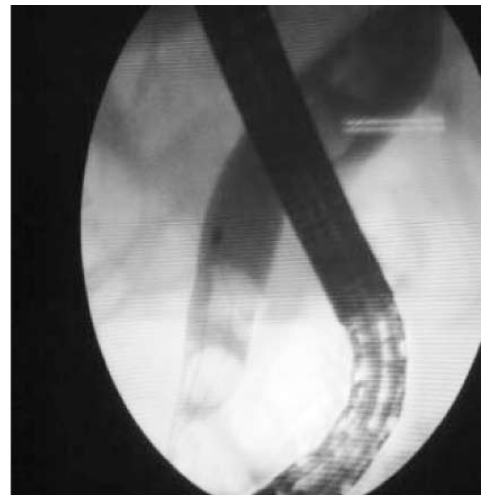

Extracción con Dormia

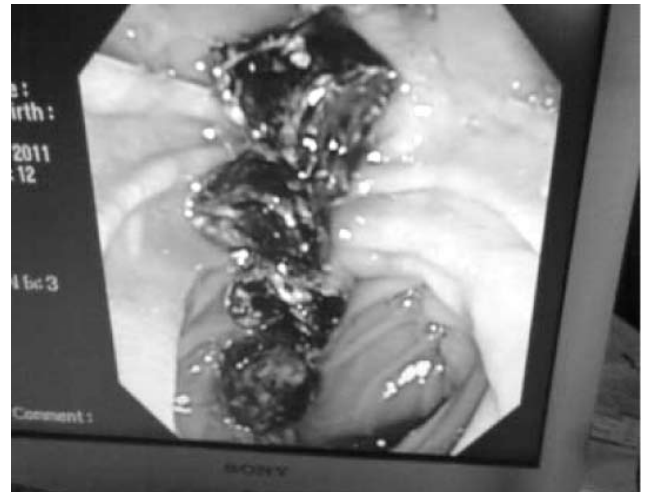

cálculos extraídos en la luz duodenal

Los cálculos muy grandes, que son extraídos enteros hacia la luz del duodeno, sin fragmentarse, pueden determinar un ileo biliar al migrar a segmentos de luz más estrecha del intestino delgado o válvula ileocecal. En tal sentido, para prevenir el ileo biliar, existen varias opciones. Una de ellas es extraer el cálculo, atrapado con la Dormia, fuera del paciente arrastrándolo junto al retiro del duodenoscopio.
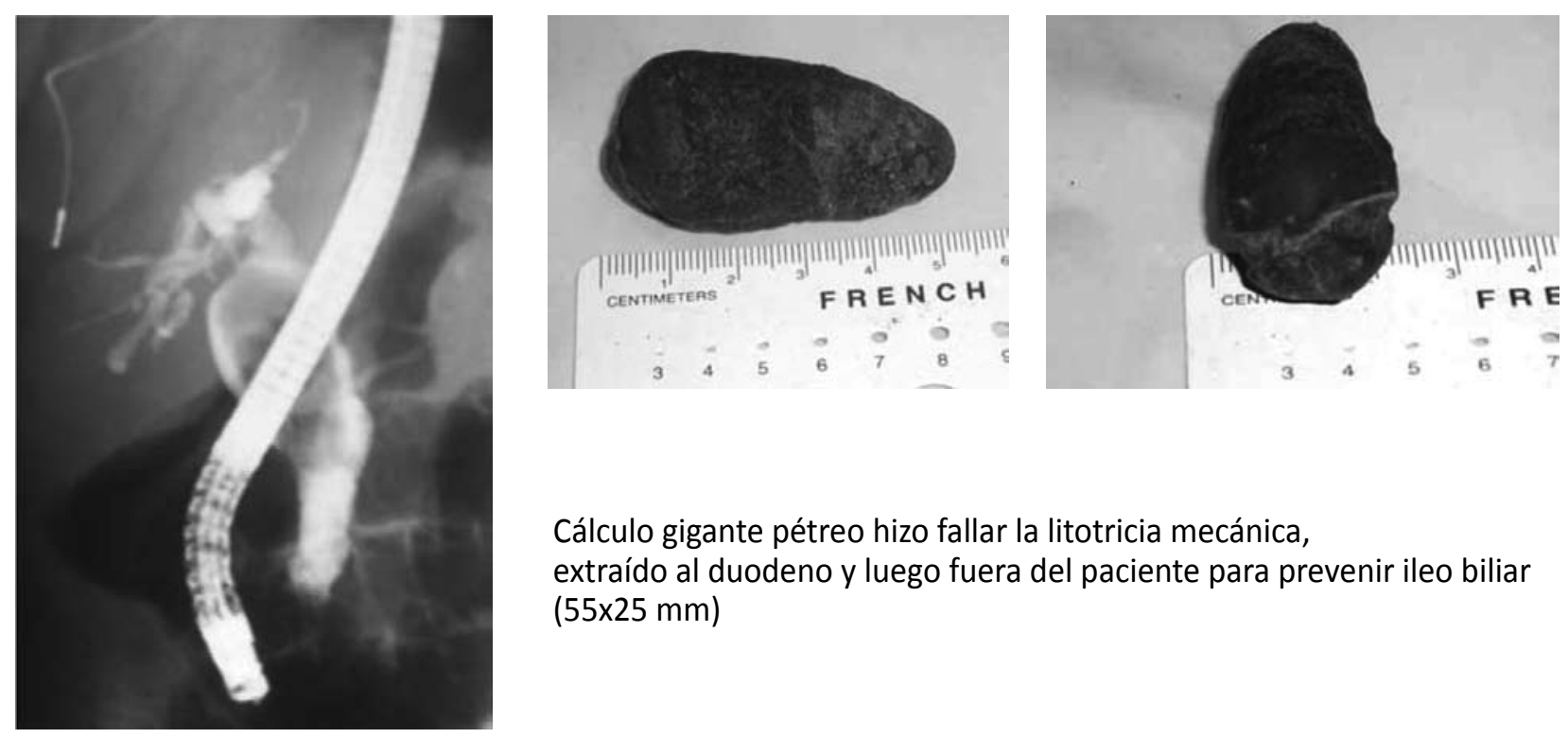

Cálculo gigante pétreo hizo fallar la litotricia mecánica, extraído al duodeno y luego fuera del paciente para prevenir ileo biliar $(55 \times 25 \mathrm{~mm})$

Otra opción es fragmentarlo, haciendo la litotricia, con alguna de las dos técnicas más empleadas. Una de ellas es utilizar el litotriptor de Soehendra, que consiste en un tubo flexible de acero, que se desliza por el alambre de la Dormia con la técnica Seldinger. Para ello es necesario cortar con tijera la Dormia (vaina plástica y cable de metal) separádola del comando, retirar el duodenoscopio y la vaina plástica de la Dormia, quedando el cálculo atrapado en el interior de la vía biliar con los alambres del canasto, hacia donde debemos hacer progresar el litotriptor enhebrado en la guía metálica de la Dormia que quedó saliendo por la boca. Para hacer contacto con el cálculo el extremo del tubo de acero se hace progresar por la boca, esófago, estómago, duodeno e ingresa por la papila abierta por la papilotomía con o sin papiloesfinteroplastia con balón (siguiendo el alambre de la Dormia). Es el momento de hacer 
una tracción enérgica del alambre de la Dormia hacia afuera, sea con la mano o empleando un sistema de rotación con poleas, que hará converger los alambres de la Dormia que rodean el cálculo logrando la fragmentación del mismo. Finalizada esta maniobra se retira el litotriptor y la Dormia, se reintroduce el duodenoscopio, y con nuevas Dormias o con balón extractor se extraen uno a uno los fragmentos, abandonados en el duodeno. Al ser más pequeños, no existe el riesgo de ileo biliar.

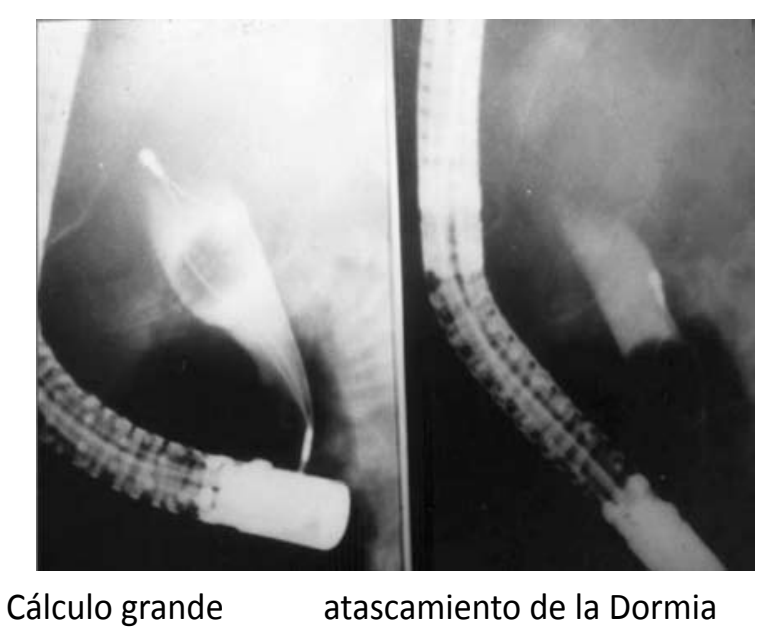

Cálculo grande atascamiento de la Dormia

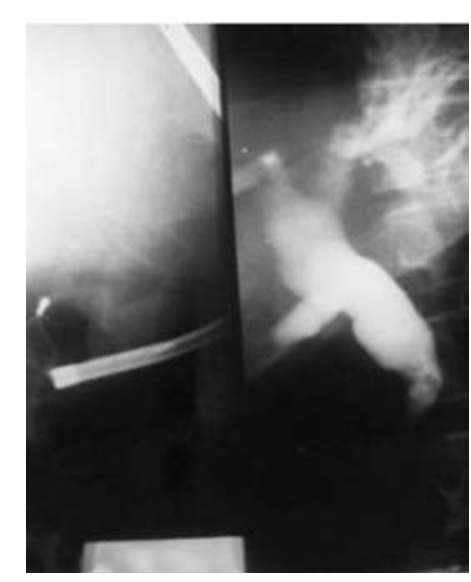

litotriptor de Soehendra VB sin cálculos en contacto con el cálculo

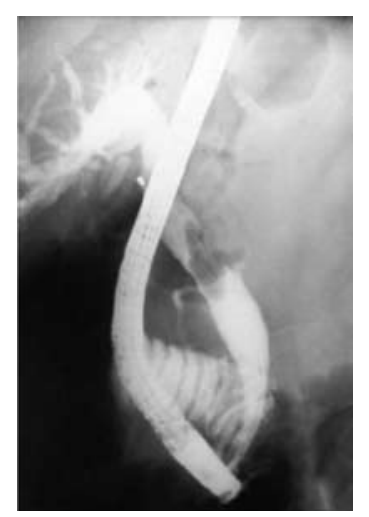

Otro cálculo grande

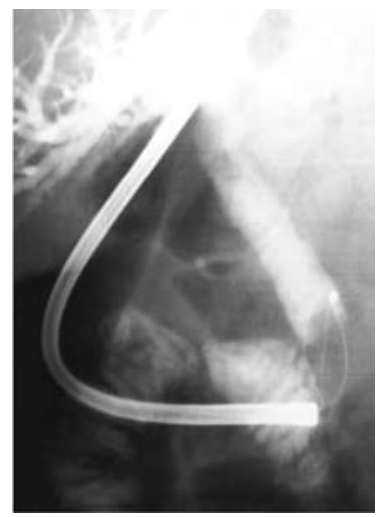

litotriptor en contacto con cálculo sujetado por la Dormia

Puede suceder que fracase la litotricia, frente a un cálculo de consistencia pétrea. En tal caso lo que se rompe es alguno de los alambres de la Dormia, por lo que el cálculo queda nuevamente libre en su posición. Esta litotricia descripta, puede ser una necesidad, si el cálculo quedó firmemente engarzado en la cestilla, pero por su dimensión no sale por la papila, y tampoco puede liberarse de la Dormia a pesar de los movimientos de apertura y cierre que hagamos con el comando de la Dormia, o los intentos de empujarla en sentido ascendente hacia la vía biliar proximal para lograr liberarla del cálculo. Si esta circunstancia acontece por encima de una estenosis biliar no dilatada, frente a un cálculo duro que no se logró fragmentar con la tracción enérgica, puede determinar que debamos cortar la Dormia como se estableció anteriormente, para poder extraer el duodenoscopio y enviar a cirugía el paciente, con el alambre de la Dormia, que inicialmente salía por la boca, pero que por intermedio de una sonda introducida por la narina y extraída fuera de a boca, nos permite arrastrar el alambre por el interior de la sonda, que al retirarla fuera de la narina, hace que el alambre de la Dormia emerja por ella. En la cirugía, al realizar la coledolitotomia ya se extrae con la Dormia que le sujetaba. En algún paciente que 
el atascamiento del cálculo grande en la Dormia se da en la papilotomia, y observando que hay todavía espacio para ampliarla hacia su límite máximo superior (pliegue transversal) hemos resuelto la situación, seccionando la Dormia, extrayendo el duodenoscopio, dejando el alambre de la misma saliendo por la boca. En paralelo reintroducimos el duodenoscopio hasta llegar a la papila con el cálculo impactado, y cortando con el papilótomo de precorte algunos milímetros más, sobre el mismo cálculo, se alcanzó el éxito, permitiendo su salida.

La otra manera de hacer litotricia, es empleando una Dormia litotriptora, que ya tiene incorporada una vaina metálica que se avanza una vez que el cálculo fue atrapado en el interior de la cestilla. Esta Dormia, más gruesa y rígida, requiere de un canal operador de $4.2 \mathrm{~mm}$ en el duodenoscopio. Esta Dormia tiene un canal accesorio fino durante un corto trayecto de su extremo, que le permite ser deslizada sobre una guía hidrofílica, alojada previamente en el interior de la vía biliar. La ventaja que ofrece es que una vez fragmentado el cálculo, con la misma Dormia se van extrayendo los fragmentos. Otra ventaja es que cuando existe más de un cálculo grande para hacer litotricia, puede repetirse la maniobra con la misma Dormia. Todas las maniobras se realizan con el duodenoscopio en posición, observando en radioscopia la apertura, captura del cálculo y litotricia. La desventaja es su mayor costo, compensado por las virtudes ya referidas.

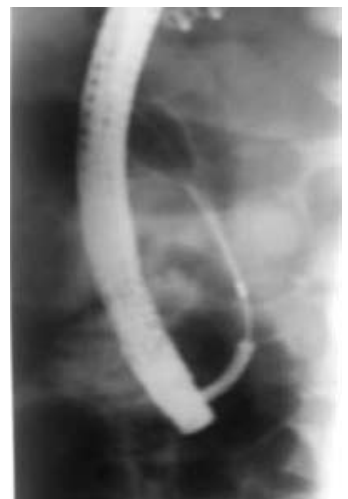

Dormia litotriptora
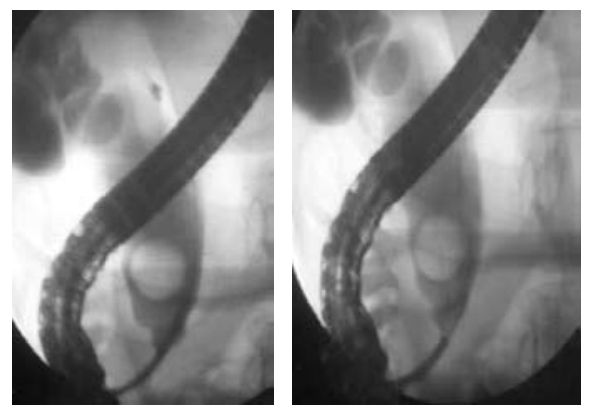

Dormia litotriptora fractura cálculo grande, facilitando extracción en fragmentos

En cambio, para las Dormias comunes, alcanza un canal operador de $2.8 \mathrm{~mm}$, con la diferencia que el avance del litotriptor de Soehendra requiere la extracción del duodenoscopio y se realiza sobre el alambre de la Dormia, guiado por radioscopia. Esta Dormia queda inutilizada, y toda nueva maniobra de extracción de fragmentos o nueva litotricia requiere el empleo de nuevas Dormias, que si bien son más económicas por unidad, al necesitar más de una el costo total es aproximado al costo de la Dormia litotriptora.

Pueden fracasar estas litotricias, existiendo otras, también intracorpóreas como las dos anteriores. Una es el empleo de energía electrohidráulica, trasladada desde un generador por guías que se ponen en contacto bajo visión directa del cálculo. Para ello se requiere de endoscopios ultrafinos que ingresan a la VBP por la papilotomia y fragmentan los cálculos de manera semejante a la técnica empleada por los urólogos. La otra litotricia intracorpórea muy similar, pero empleando la energía de la luz láser, conducida también por guías especiales.

Es un equipamiento muy costoso, reservado para centros especiales.

Cuando los cálculos no pueden extraerse, la intervención endoscópica debe asegurar el drenaje biliar. La imposibilidad de extraer los cálculos puede ser por sus características (tamaño: casos de $30 \mathrm{~mm}$ 
o mayores, número: múltiples encajados unos a otros sin espacio para maniobrar o desplegar los accesorios para extraerlos, consistencia: pétrea, rompiendo los alambres de la Dormia al realizar la litotricia, topografía: alojados encima de estenosis biliares, o intrahepáticos de acceso imposible), fracaso de las maniobras para atraparlos con Dormias comunes o litotriptoras o balones, o inestabilidad del paciente que obliga a una intervención rápida para asegurar el drenaje biliar exclusivamente, dejando para una segunda sesión, con el paciente estable, la resolución definitiva de extracción de cálculos. Esta última circunstancia puede ser el recurso frente a un trastorno de la crasis no corregible que contraindique la papilotomia, pero si se logra ingresar una guía hidrofilica por el ostium papilar, en dirección de la vía biliar, puede ascenderse una prótesis plástica o un drenaje nasobiliar, bajo control radioscópico. Una vez mejorada la situación clínica, se recoordina al paciente para completar el tratamiento.
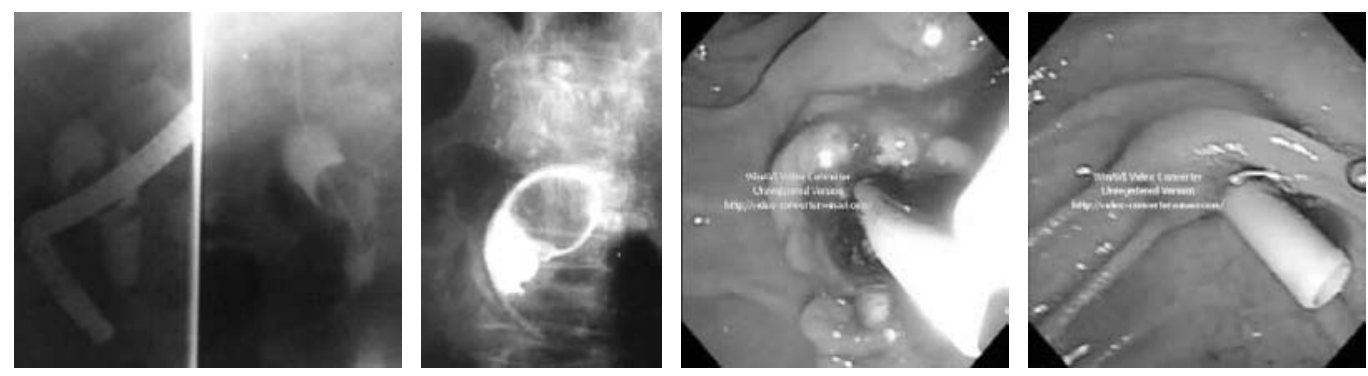

Cálculos grandes: drenaje biliar interno con prótesis plásticas con papilotomia y en este caso sin papilotomia (crasis alterada)

La litotricia extracorpórea, ampliamente utilizada para fragmentar cálculos en la esfera nefrourológica, empleando ondas de choque por ultrasonido, también puede utilizarse para fragmentar y/o desestructurar un cálculo grande de la VBP. Para ello, el dejar un drenaje nasobiliar puede permitir contrastar la vía biliar, objetivar el cálculo en radioscopia al inyectar contraste y acertar los disparos en el objetivo. Con equipos modernos de excelente definición ecográfica, pueden identificarlo sin necesidad del contraste. Si su uso, para casos especiales, no es difundido, tiene relación al elevado costo. Una vez fragmentado el o los cálculos, una nueva sesión de CER con extracción de los fragmentos, finalizará el tratamiento definitivo de la litiasis de la VBP. Hemos tenido algún caso en que los especialistas en la técnica informaron que falló pues se seguía observando el cálculo del mismo tamaño, sin embargo, en una nueva sesión de CER pudo extraerse el cálculo al poder fragmentarse más fácilmente. Eso se debe a que la litotricia extracorpórea fracturó la estructura interna del cálculo, sin modificar sus dimensiones, pero haciéndolo más blando.

\section{CER en pacientes operados del tracto digestivo superior}

En el caso de una gastrectomía parcial distal con reconstrucción tipo Billroth I, el acceso al duodeno y la papila de Vater no ofrece dificultad alguna, al mantenerse la continuidad anatómica esófagoestómago-duodeno, como en un paciente no gastrectomizado.

Cuando existe una gastrectomía parcial distal o subtotal con reconstrucción tipo Billroth II o gastroyeyunostomia, es imprescindible reconocer el asa aferente, remontar la misma hasta encontrar la papila de Vater, desde una dirección distal a proximal. Habitualmente la confección de la anastomosis hace que el asa aferente esté a la derecha o sobre la curvatura menor. Puede ayudar al reconocimiento la salida de bilis por su estoma o la dirección del peristaltismo hacia la propia anastomosis. Al alcanzar la papila 
de Vater con el duodenoscopio (visión lateral) se observará en posición inversa a la situación anatómica normal, de tal manera que la papilotomia debe realizarse hacia la hora 5 en vez de hacia la hora 11.

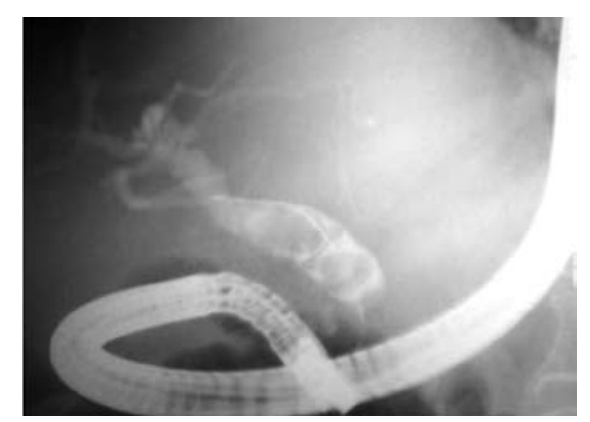

Billroth II, duodenoscopio recorre asa aferente CER: litiasis grandes

Si se emplea un gastroscopio (visión frontal) la progresión será más fácil, pero al carecer de elevador, que permite orientar o angular los accesorios a la salida del canal operador, la técnica puede ofrecer dificultades adicionales. Con el equipo de visión frontal, arribando de distal a proximal, la papila de Vater se observará en su posición normal y la papilotomia en dirección a la vía biliar o el precorte para ingresar a la misma deberá hacerse hora 11.

En el caso de una gastroyeyunostomia como derivación interna, sin resección, como tratamiento de una estenosis gastroduodenal, si bien la anatomía o continuidad gastroduodenal transpilórica está conservada, hay que evaluar si el pasaje permite el ingreso del duodenoscopio hasta alcanzar la 2a porción del duodeno y la papila de Vater o no. Todo dependerá de la causa, por ejemplo una estenosis cicatrizal por ulcus péptico, puede dilatarse con balón sobre guía y posteriormente pasar el duodenoscopio.

Caso contrario, si el pasaje está impedido, hay que recorrer el asa aferente como se estableció anteriormente y alcanzar la papila de Vater, la cuál muchas veces es irreconocible, por infiltración, en caso que la causa de la estenosis gastroduodenal que motivó la gastroyeyunostomía, sea por un tumor de páncreas, duodeno o mismo de papila, haciendo imposible el acceso a la vía biliar por este medio. En esta situación existen las alternativas transparietohepática o por acceso transgástrico a la vía biliar intrahepática guiado por ecoendoscopia.

En situaciones de gastrectomía total con reconstrucción esofagoyeyunal, de Roux en " $Y$ ", el acceso al duodeno y papila de Vater, impone un extenso recorrido, del asa, hasta alcanzar la anastomosis al pie, ingresar por la misma en dirección ascendente por el yeyuno proximal, 4a Ningún equipo estándar (duodenoscopio, gastroscopio) puede llegar, por lo cual debe ensayarse con un colonoscopio pediátrico largo, un enteroscopio, sin o con doble o balón único. Hay reportes de éxito, pero siempre el porcentaje es menor que en situaciones anatómicas normales o favorables.

En caso de duodenopancreatectomia con doble derivación: gastroyeyuno y hepaticoyeyunostomias, el recorrido es similar con los mismos instrumentos hasta alcanzar la hepaticoyeyunostomia, siendo también el porcentaje de éxito menor.

La hepaticoyeyunostomía se reconoce por la confluencia de pliegues hacia un punto (en caso de estenosis), donde puede reconocerse restos de hilos de sutura, muchas veces rodeados o con adherencia de barro biliar. El ingreso de una guía hidrofilica montada en un catéter o el mismo papilótomo, dará acceso al interior de la vía biliar, permitiendo la inyección de contraste para el diagnóstico primero y continuar con el tratamiento: dilatación con balón de la estenosis hasta un calibre semejante al de la vía biliar y extracción de cálculos y/o barro biliar con Dormia y balón extractor. 
Cuando se confecciona una hepaticoyeyunostomia, dejando el asa aferente corta, alojada en el tejido celular subcutáneo (técnica de Barker modificada), previendo posibles estenosis a tratar por endoscopia, el acceso es fácil haciendo una descubierta del extremo del asa, ingresando por ella con un gastroscopio o duodenoscopio. A escasos $10 \circ 15 \mathrm{~cm}$, en general se descubre la anastomosis y se procede de igual forma que anteriormente. En esta situación se precisa de un ayudante que mantenga el endoscopio en posición a nivel de la descubierta en la piel y con gasa o compresa comprimir alrededor del endoscopio para evitar la fuga del aire insuflado al interior del intestino, lo que permite mantener una adecuada distancia focal para la intervención. Caso contrario, la luz del intestino se colapsa por falta de aire y no es posible trabajar, por visión nula o casi nula, al contactar la mucosa con la óptica.

Bajo esta circunstancia, es necesario recordar que la longitud de la vía biliar está restringida a su segmento más proximal, que puede comprender el hepático común o la misma confluencia de los hepáticos o mismo hepaticoyeyunostomías derecha e izquierda independientes, de ahí la importancia de conocer el protocolo operatorio. No será lo mismo dilatar una hepaticoyeyunostomia con el hepático común (anastomosis única) permitiendo explorar luego la vía biliar proximal en forma íntegra a su través, que abordar en forma independiente cada una de las anastomosis, procediendo luego a la exploración individual de cada vía biliar intrahepática derecha e izquierda. Por otro lado, se hace referencia a la longitud de la vía biliar, pues la profundidad en que se introducirá una guía hidrofílica al árbol biliar es sustancialmente menor que a través de la papila de Vater normal. Lo mismo sucede con los balones de dilatación, generalmente son suficientes los de $3 \mathrm{~cm}$ de largo y en cuanto al calibre, deberán ajustarse al de la vía biliar a tratar, conceptualmente de menor diámetro que la vía biliar extrahepática en términos generales. Es necesario por ello y para poder resolver (o intentar) toda la variedad de situaciones en patología biliar, contar con un stock de accesorios variados (guías, balones de dilatación, balones extractores, Dormias, prótesis, etc).

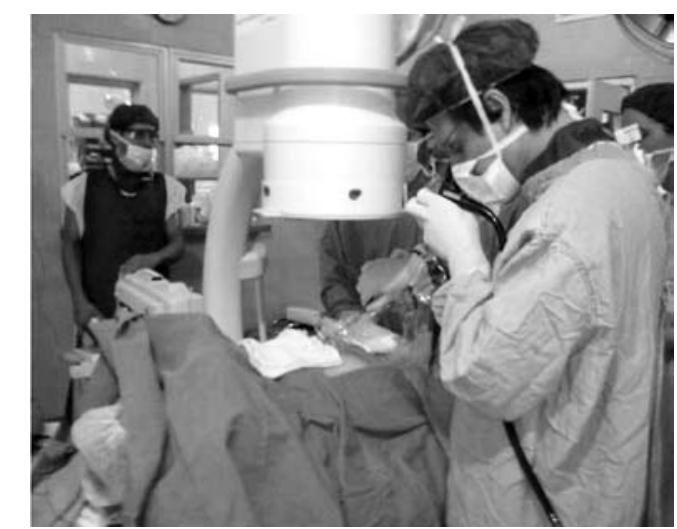

Ingreso percutáneo al asa aferente de hepaticoyeyunostomia

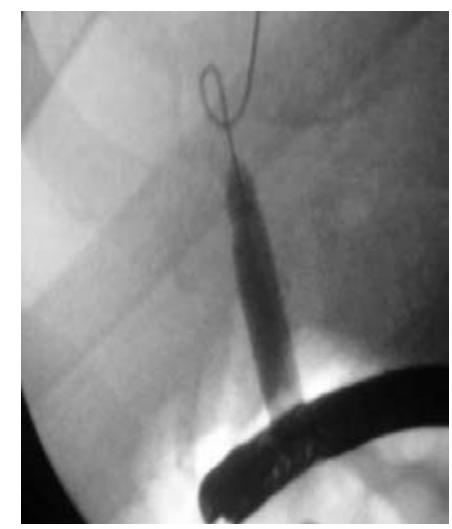

dilatación con balón

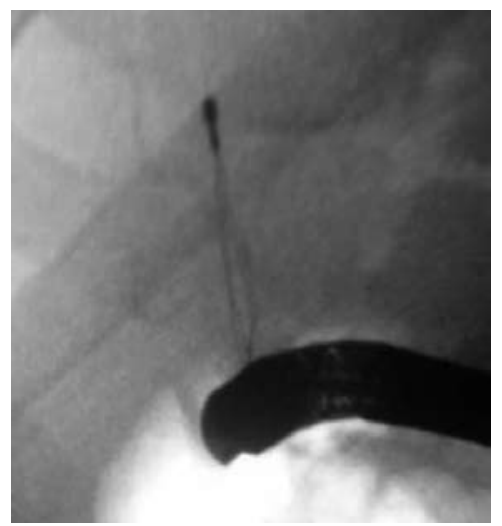

exploración con Dormia de la VB

La litiasis intrahepática desarrollada por encima de estenosis de una hepaticoyeyunostomia puede afectar diferentes conductos, ser en forma de barro amorfo o litiasis de mayor consistencia, con formas y tamaños variados, usualmente blandos y fragmentables. No siempre se logra acceder desde el yeyuno hacia todos y cada uno de los canalículos biliares comprometidos. El cambio de posición al endoscopio y al paciente, el cambio de endoscopio (visión lateral y frontal), los lavados de arrastre con suero suelen ayudar. Disponer de un endoscopio ultrafino que pueda introducirse al árbol biliar para una colangioscopia directa, procediendo a una limpieza dirigida pasando accesorios especiales (más finos) por su canal operador permitirá una solución óptima. 
Debe tenerse precaución con la insuflación excesiva de aire ambiental, por casos de embolia gaseosa; en el interior de la vía biliar la instilación de suero es suficiente y en los últimos años se está recomendando emplear el insuflador de $\mathrm{CO} 2$, por su fácil difusión y eliminación.

Cuando el asa aferente no se dejó subcutánea, sino que abandonada en el interior del abdomen, puede hacerse una minilaparotomia (cirugía abierta) para acceder a ella o al asa eferente, realizar una apertura (enterotomía) la cuál permite el ingreso del endoscopio, para remontar el intestino hasta alcanzar la anastomosis y actuar de similar forma que la descripción anterior.

El abordaje quirúrgico del asa puede ser también laparoscópico, combinado con endoscopia para proceder de igual forma.

Estos accesos por vía endoscópica exclusiva o asociadas a cirugía abierta o laparoscópica, son alternativas menos invasivas que un nuevo abordaje quirúrgico de la anastomosis biliodigestiva con exploración de la vía biliar intrahepática y reconfección de la anastomosis.

Otra derivación biliodigestiva es la_coledocoduodenostomía laterolateral. Puede sufrir de estenosis, estasis biliar, formación de cálculos o barro biliar, por encima de la misma (intrahepático) o distal a la anastomosis, en el colédoco configurando en este caso el síndrome de resumidero. En este caso puede juntarse restos de alimentos. Con el endoscopio de visión frontal (gastroscopio) o el de visión lateral (duodenoscopio) es posible identificar la anastomosis, evaluar su calibre, observar más allá de ella, explorar con Dormia o balón para extraer cálculos o barro y de estimar su necesidad, previamente dilatarla con un balón de altas presiones. El contenido del colédoco puede extraerse por la anastomosis o abordando la papila de Vater, realizando la papilotomia y extracción del contenido del colédoco, en caso de pacientes sintomáticos.

\section{Litiasis de VBP asociadas a estenosis biliares}

Dos situaciones que comportan sutura de ductos biliares entre si, tal el caso de la reparación de una sección de la vía biliar durante la colecistectomía y reparada con anastomosis terminoterminal, sobre un tubo de Kehr tutor y la otra situación es el caso del transplante hepático con reconstrucción biliobiliar, con o sin tutor. En ambas situaciones, la posibilidad de una estenosis anastomótica tiempo después de retirar el tutor en el caso del Kehr, (ya que el tutor dejado en el transplante generalmente migra espontáneamente), precipitará la aparición de sintomatología de una obstrucción biliar. Es común la asociación con litiasis por encima de la obstrucción como consecuencia de la estasis mantenida. El tratamiento endoscópico implica solucionar primero la estenosis procediendo a la papilotomia, dilatación de la estenosis con balón de altas presiones sobre una guía hidrofílica que previamente superó el obstáculo e ingresó a la vía biliar proximal. Son balones de $3 \mathrm{~cm}$ de largo que se centrarán en la estenosis bajo radioscopia y de calibres variables $(4,6,8,10 \mathrm{~mm})$. Posteriormente se extraen los cálculos con cestilla Dormia o con balón extractor procediendo de la manera habitual. Cuando además existen cálculos por debajo de la estenosis, su extracción será lo primero, antes de la dilatación de la estenosis. El evitar la recidiva de la estenosis colocando varias prótesis tutoras entre 6 a 12 meses para estabilizar el calibre a un diámetro adecuado y la indicación de ácido ursodesoxicólico, son medidas complementarias para disminuir el riesgo de formación de nuevos cálculos. 


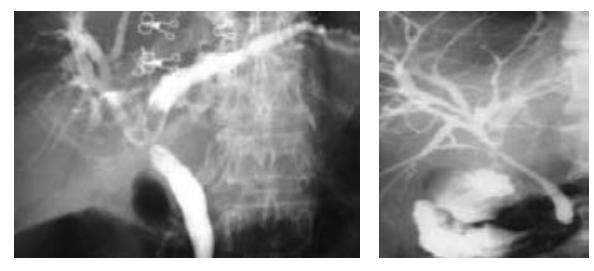

Estenosis postquirúrgicas y litiasis intrahepática bilateral en un caso y del izquierdo en el otro, en pacientes jóvenes, resueltos por hepaticoyeyunostomias

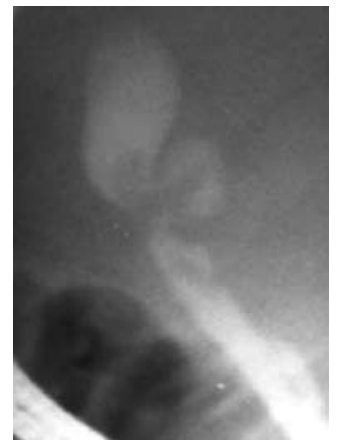

Estenosis anastomosis biliar y litiasis en transplante hepático

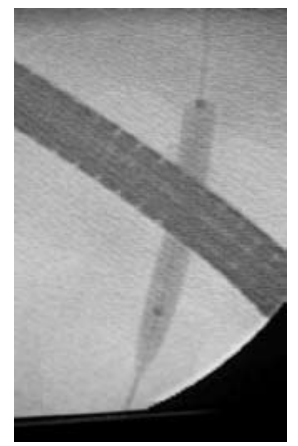

dilatación con balón

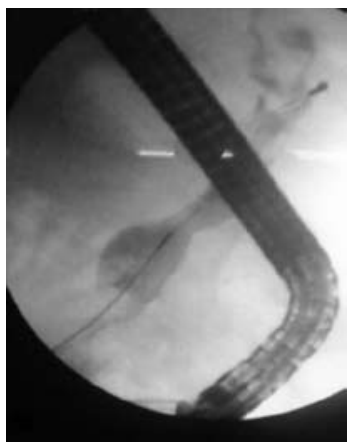

exploración con Dormia

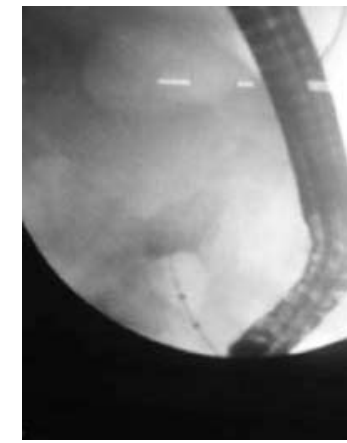

exploración con balón extractor

Otras enfermedades de la vía biliar, como colangitis esclerosante y la colangiopatía de la hipertensión portal, también pueden asociar estenosis y litiasis. Son estenosis cuya dilatación con balón puede acarrear riesgo de hemobilia, al estar fusionada o integrada la pared de la vía biliar con vasos sanguíneos colaterales del pedículo hepático. Hay que estar preparados para esta contingencia y disponer de material adecuado para su tratamiento. 


\title{
Capítulo 6
}

\section{TRATAMIENTO PERCUTÁNEO DE LA LITIASIS BILIAR}

\author{
Dr. Álvaro Piazze
}

\section{Tratamiento percutáneo de la litiasis de la vía biliar extra e intrahepática}

El tratamiento percutáneo puede ofrecerse a 2 grupos de pacientes: a) aquellos que tienen un drenaje biliar externo, sea una coledocostomia directa por un tubo de Kehr o indirecta por una sonda Nelaton transcística y b) quienes no cuentan con ese abordaje a la vía biliar pero puede accederse a ella por vía transparietohepática.

En el primer grupo, transcurridas 6 semanas de permanencia del Kehr o la sonda Nelaton transcística, se considera "maduro" el trayecto a su alrededor, conformado por tejido inflamatorio que ha reaccionado en respuesta al material extraño. Es decir que puede extraerse el drenaje biliar externo y con instrumentos apropiados explorar por vía transfistular percutánea, el interior de la vía biliar. En este caso, lo primero a realizar es una colangiografia puncionando el drenaje e inyectando contraste a baja presión observando en radioscopía, teniendo la precaución de no inyectar aire (burbujas, que confunden con imágenes de cálculos). La colangiografía permite conocer si persiste(n) él o los cálculos, su tamaño, topografía, recorrido del trayecto y anatomía del árbol biliar.

Las recomendaciones de quienes crearon y desarrollaron esta técnica hace más de 40 años, siguen teniendo vigencia, vale decir, que el trayecto entre el colédoco y la piel sea el más corto, grueso y directo posible, por contrabertura, para facilitar las maniobras de extracción incruenta o técnica Mazzariello (cirujano argentino).

El abandono del drenaje una vez sujetado a la salida de la vía biliar, alojándolo en el interior de la cavidad abdominal, al comenzar el cierre de la laparotomía, sin prestar atención en todo momento a su posición y trayecto, determina en algunos casos que forme bucles más o menos largos, a veces con ángulos muy agudos, acentuados, que harán fracasar la técnica de extracción incruenta transfistular. El trayecto se romperá (y se pierde) con los accesorios que se estén empleando, en dichos ángulos agudos, creando falsas rutas con fugas de contraste hacia la cavidad peritoneal. En cierta manera el cirujano actuante debe tener en mente que puede haber quedado algún cálculo a pesar de la exploración exhaustiva realizada y el caso de su paciente no estará resuelto hasta tanto una colangiografia postoperatoria descarte su presencia. Pero de corroborarse la persistencia de litiasis, aún quedarán pendientes interven- 
ciones (CER con papilotomía en cualquier momento luego de la cirugía, analizada en el capítulo anterior, o extracción incruenta transfistular una vez madurado el trayecto) a realizar en el paciente para finalizar el tratamiento iniciado con la cirugía, abierta o laparoscópica. Cuanto mejor posicionado el drenaje, más fácil el acceso a la vía biliar, a través de maniobras que puede ser necesario repetir en la misma sesión hasta lograr el éxito (dejar expedita la vía biliar) o en más de una.

\section{Accesorios o instrumental empleado}

a) Contraste hidrosoluble, que se diluye al $50 \%$ con suero fisiológico, para evitar falsos negativos, provocado por el contraste puro, cuya densidad impide ver cálculos, especialmente los más pequeños y en vías biliares dilatadas.

b) Guias hidrofílicas, cuyo extremo es atraumático, las mismas que se emplean en endoscopia digestiva biliar (largas) o específicas para intervencionismo percutáneo (cortas), de.035 inch de calibre, o más rígidas del tipo Amplatz. Deslizadas por el trayecto hacia la vía biliar primero y superando la papila de Vater hacia el duodeno, permiten mantener el acceso en caso de tener que recolocar un drenaje transitorio, si no fue posible finalizar la extracción y hay que reconstruir el trayecto alrededor de una nueva sonda para otra sesión o también empleadas como tutoras para pasar dilatadores (bujías) de calibre creciente para dilatar un trayecto de inicio muy fino si el drenaje biliar empleado por el cirujano así lo fue.

c) Catéteres plásticos, de punta recta y de punta curva, utilizados para conducir la guía y/o para inyectar contraste, el que sale por orificios accesorios (multifenestrado) vecinos al extremo distal.

d) Cestillas Dormias variadas, en sus dimensiones de apertura y en número de alambres que conforman la cestilla o canastilla y de estructuras variadas en cuanto a la rigidez o maleabilidad del material. Cuando son nuevas, y el extremo es rectilíneo, es necesario curvarlo dándole forma friccionando el mismo entre el pulgar e índice, para adaptarla al trayecto fistuloso, muchas veces sinuoso, o para superar ángulos al ingresar a la vía biliar y poder explorarla en sentido proximal y distal según necesidad, objetivo difícil de lograr si no pueden curvarse los extremos o no le llega al extremo, las maniobras de rotación ejercidas desde afuera. El Dr.Mazzariello disponía de una Dormia artesanal a la que llegaba un hilo a su extremo, para angularlo ejerciendo desde afuera tracción del hilo que estaba atado a un anillo o aro, empleándola para situaciones anatómicas desfavorables. Las Dormias tienen un canal accesorio por el que se instila contraste y permite hacer colangiografias tantas veces como se requiera. Ello, junto a la radioscopia dinámica, permite que bajo visión directa en la pantalla de radioscopia, la maniobra se ejerza con la mayor precisión (no a ciegas). Existen Dormias que tienen la posibilidad de avanzar sobre una guía. Son especialmente útiles para dirigirlas a posiciones intrahepáticas selectivas, cuando por si solas no pudieron ser dirigidas específicamente, pero si se logró conducir una guía a dicho lugar. A su vez, la Dormia litotriptora también puede deslizarse sobre la guía hasta hacer contacto y atrapar el cálculo, para su fragmentación.

e) Pinzas Mazzariello, curvas, de metal, articuladas, que tienen la peculiaridad de una apertura pequeña en su extremo distal con la que se atrapa el cálculo, en relación a una apertura mayor por su comando proximal accionado fuera del paciente. Hay que disponer de un juego de pinzas, pues cada una tiene una curvatura fija, y es necesario disponer para curvaturas variables que tienen los trayectos fistulosos, eligiendo aquella que más se adapte. Son tanto más efectivas cuanto más corto, rectilíneo y ancho sea el trayecto, por lo que fracasa el uso cuando los trayectos son largos, sinuosos, finos y con ángulos, a los cuales suele romper generando una falsa ruta. Una vez en el interior de la vía biliar, se abren frente al cálculo, procediendo a su extracción si es pequeño o fragmentándolo al pinzarlo varias veces si es grande, ya que el espacio a tran- 
sitar por el trayecto no admite un diamétro que sume el del cálculo más las ramas abiertas de la pinza. Una vez fragmentado, se repiten las maniobras de ingreso-extracción, hasta constatar por una colangiografia de salida que no quedó ningún cálculo residual.

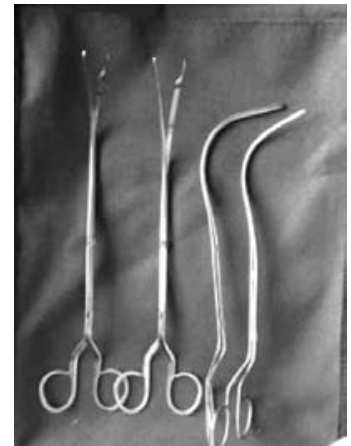

Juego de pinzas

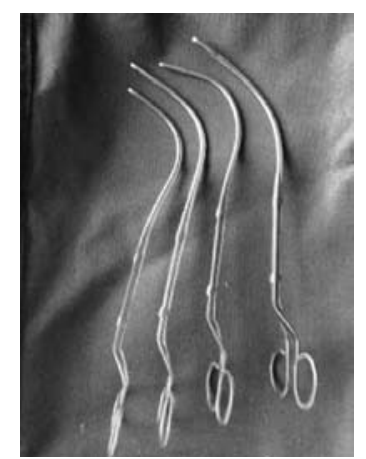

curvaturas variadas

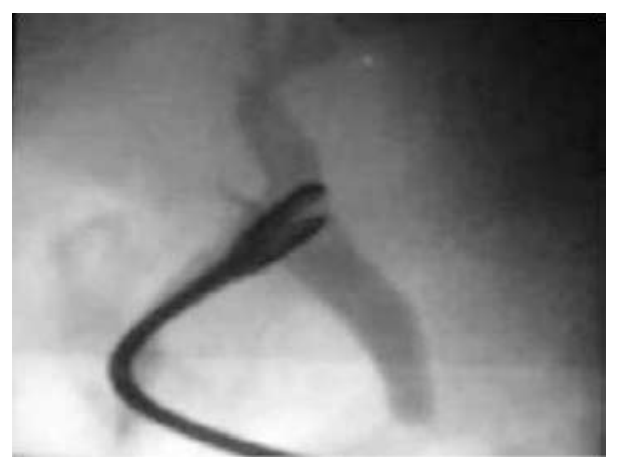

f) Balones extractores de cálculos, avanzados sobre una guía. Sirven para atraer cálculos, por ejemplo de un ducto intrahepático, hacia una posición más favorable para luego ser atrapados por una Dormia o pinza, que por si solas no se pudieron avanzar hasta la posición intrahepática del cálculo. En la medida que si se pudo pasar una guía al ducto que interesa, hacia allí se envía el balón. Raramente un cálculo arrastrado por el balón ingresará al trayecto fistuloso para completar su extracción.

g) Balones de dilatación, que resisten altas presiones y permiten una papiloesfinteroplastia, con la finalidad de lograr evacuar posteriormente hacia distal (duodeno)los cálculos a expensas de una amplia apertura lograda en la terminación del colédoco y del aparato esfinteriano (esfínter de Oddi). Se emplean deslizándolos sobre una guía, que previamente se logró hacer transitar por el colédoco hacia el duodeno. El relleno del balón y su apertura se controla por radioscopia. Al ser rellenados con contraste diluído, se aprecia bien su posición, centrada en la papila, y dilatando hasta que desaparece la cintura o muesca en el contorno del balón. Hay de calibres variados y fijos $(6,8,10,12 \mathrm{~mm})$ o de calibres crecientes de acuerdo a la presión que se ejerce en su llenado, por ejemplo de 10 a $12 \mathrm{~mm}$, de 12 a $15 \mathrm{~mm}$, de 15 a $18 \mathrm{~mm}$, variando la elección de acuerdo al calibre de la vía biliar y el diámetro de los cálculos a tratar.

h) Sondas Nelaton de goma y sondas Bequille, de diferentes calibre para dejar la más gruesa posible en relación al trayecto, con intención de reconstruir y mantener el acceso a la vía biliar para otra sesión días después.

i) Jeringas

j) Agujas

k) Recipiente para contraste

l) Agujas montadas curvas para fijar sondas a la piel

m) Porta aguja o pinza

n) Bolsas colectoras para permitir drenaje libre a través de la sonda que oficie de drenaje biliar externo

o) Solución desinfectante

p) Campo fenestrado o juego de campos estériles 
q) Gasas

r) Cortantes (hoja de bisturí, tijera)

s) Coledocoscopio y fuente de luz. Disponer de él es de gran utilidad para casos especiales. Puede deslizarse sobre una guía, siempre y cuando el trayecto haya sido dilatado hasta el calibre del endoscopio. Permite una visión directa y desplegar por su canal operador, accesorios como Dormias, pinzas de biopsias.

\section{Técnica}

La técnica es ambulatoria (salvo aparición de alguna complicación durante el procedimiento). El paciente concurre con 6 horas de ayuno. Debe despojarse de la ropa de la cintura para arriba en caso de hacerse en sala de radiología con amplificador de imágenes o estar vestido con ropa de block quirúrgico si se realizará en sala de operaciones, con arco en $\mathrm{C}$.

Generalmente se hace sin anestesia. En casos complejos y prolongados es preferible colocar una vía venosa periférica para administrar sedoanalgesia.

No es obligatoria la administración de antibióticos en casos sencillos, en cambio administramos en forma profiláctica ampicilina sulbactam para casos de cálculos múltiples o grandes que hay que fragmentar y que obligan a realizar reiteradas exploraciones e incluso rehacer el trayecto con una sonda para otras sesiones posteriores.

La posición del paciente es en decúbito dorsal.

Se prepara el área de trabajo con solución antiséptica y campos estériles.

Previamente se estudian las radiografías (colangiografia) con las que concurre el paciente y que motivaron la solicitud de la extracción incruenta y se comparan con los hallazgos de la colangiografia hecha como primer maniobra. La realizamos inyectando por el tubo de drenaje, suavemente, contraste diluido al 50\% teniendo precaución de eliminar las burbujas de aire de la jeringa para evitar falsos positivos. Antes de inyectar contraste se aspira hasta que llega bilis a la jeringa. Puede acontecer que en el tiempo transcurrido desde que se diagnosticó una litiasis residual hasta que se coordinó su extracción, el cálculo haya migrado espontáneamente. En tal caso la colangiografia dará normal, con relleno de todo el árbol biliar y pasaje del contraste hacia el duodeno. Es conveniente (de ser posible técnicamente) extraer radiografías en distintas posiciones de manera de documentar el hallazgo, sean impresiones en acetato, en papel, CD,DVD, pendrive, o fotos digitales, según facilidades del equipo de radioscopia.

Aún frente a este hallazgo, tenemos por conducta extraer el drenaje biliar, previa liberación del o los puntos de amarre, y hacer una exploración con Dormia, asegurando la ausencia de cálculos que pudieran pasar desapercibidos. Finalizada la exploración el paciente queda sin drenaje biliar y se le coloca una curación plana en el orificio. Se le advierte que mojará las gasas por un par de días hasta que finalmente se cierre el trayecto, por el solo hecho de no tener el drenaje. Puede higienizarse normalmente y es suficiente con cambiar las gasas mojadas de bilis por unas secas.

Cuando se identifica la litiasis residual, es necesario evaluar el calibre del trayecto (directamente relacionado al drenaje biliar colocado), la dirección, longitud y angulaciones (dificultades) a recorrer, comparándolo con el diámetro de los cálculos. Si el trayecto es fino en relación a los cálculos, la primer maniobra será pasar una guía por el drenaje, hacia el interior de la vía biliar y duodeno, como tutora de dilatadores de trayecto, tantos como sean necesarios para hacer congruente el calibre del trayecto con el de los cálculos. Logrado el objetivo, se pasa una Dormia o pinza Mazzariello para extraer el (los) cálculo(s), todas las veces que sean necesarias hasta dejar libre la vía biliar. La Dormia se desliza cerrada suavemente por el trayecto ya contrastado y siempre bajo control radioscópico, hasta ingresar a la vía biliar en la dirección necesaria (proximal, distal) sobrepasando el cálculo o por lo menos posicionarla a la 
altura del mismo, para abrirla y tratar de que el cálculo se aloje dentro de los alambres. Obtenido el objetivo se procede a la tracción de la Dormia (abierta) y se recorre el trayecto en sentido inverso hasta que sale completamente al exterior con el cálculo retenido. Estas maniobras se repiten tantas veces como cálculos hay que extraer. Hay cálculos que se fragmentan al ingresar al trayecto, por lo que con los fragmentos hay que obrar de igual forma. Nunca se realizan maniobras a ciegas, siempre bajo radioscopia.

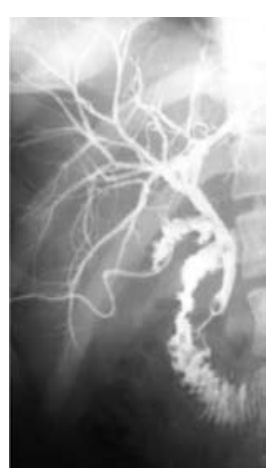

Litiasis residual

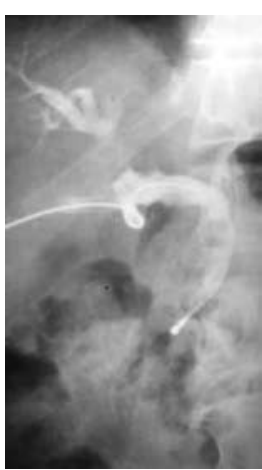

Dormia hacia el colédoco distal
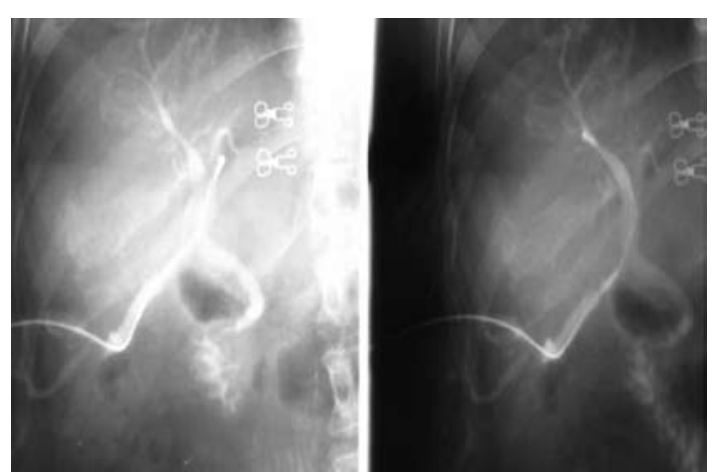

Dormia hacia el hepático izquierdo y derecho

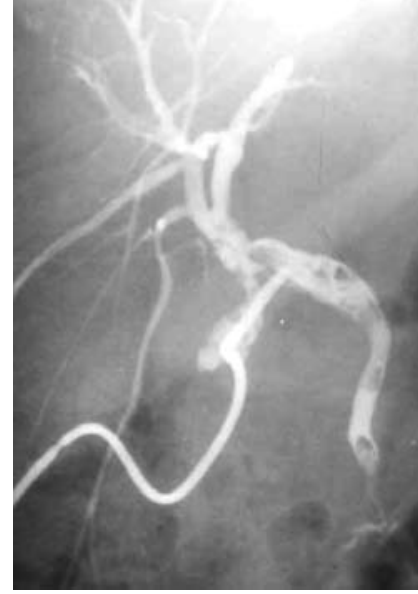

Litiasis residual múltiple

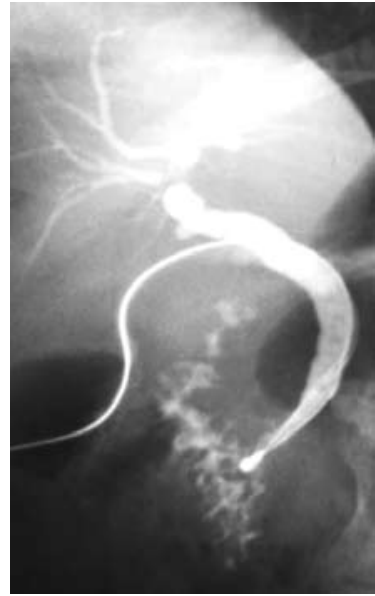

extracción con Dormia

En el caso de usar las pinzas rígidas Mazzariello, los desplazamientos y giros deberán realizarse con el cuidado y amplitud necesarios, guiados por radioscopia. Una vez ingresada a la vía biliar, se realiza la apertura para fijar el cálculo y extraerlo entero o realizar sucesivas maniobras de apertura y cierre sobre el cálculo si el objetivo es fragmentarlo. Los fragmentos podrán extraerse con la misma pinza o con Dormias, combinando instrumentos con el objetivo de alcanzar el éxito 


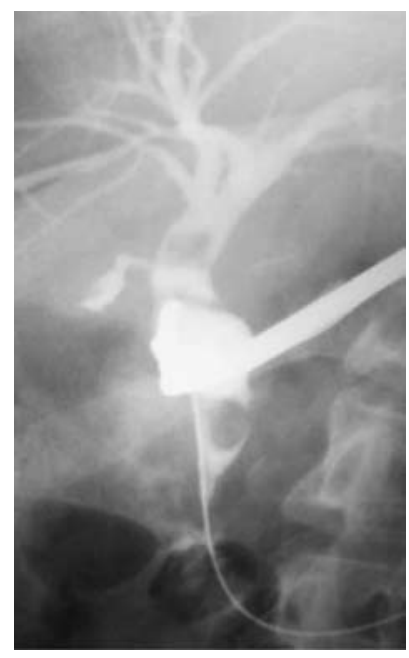

pinza Mazzariello atrapando un cálculo, guía pasando por la papila hacia el duodeno

En casos de empedrados hepatocoledocianos, las maniobras de extracción transfistular pueden resultar insuficientes. En tal caso preferimos realizar la papiloesfinteroplastia con balón, empleando un balón de diámetro creciente avanzado con la técnica Seldinger sobre una guía hidrofílica que transcurre por el trayecto, colédoco, papila de Vater y duodeno. En cuanto al diámetro a elegir, estará relacionado al diámetro de los cálculos y de la vía biliar. La dilatación alcanza a ampliar el diámetro del colédoco terminal, no solo de la papila de Vater. Los balones miden $5.5 \mathrm{~cm}$ de largo y deben posicionarse bien centrados en la papila de Vater, sobrando balón hacia el duodeno y hacia la vía biliar. Como la dilatación se realiza bajo radioscopia, la cintura o muesca en el contorno del balón es fácilmente apreciable, finalizando la maniobra cuando la misma desaparece una vez alcanzada la presión de llenado que recomienda el fabricante. El balón se vacia aspirando el contenido, y se extrae dejando la guía en posición. Es común apreciar escasa sangre recubriendo la superficie del balón, en relación a la maniobra realizada, sin tener mayor significado. Una vez dilatado el colédoco terminal y la papila, el pasaje de los cálculos está facilitado. Basta reintroducir una Dormia, pinza o mismo empujar los cálculos con una guía metálica de punta curva del tipo Amplatz, y hacer lavados con suero para arrastre hacia el duodeno.
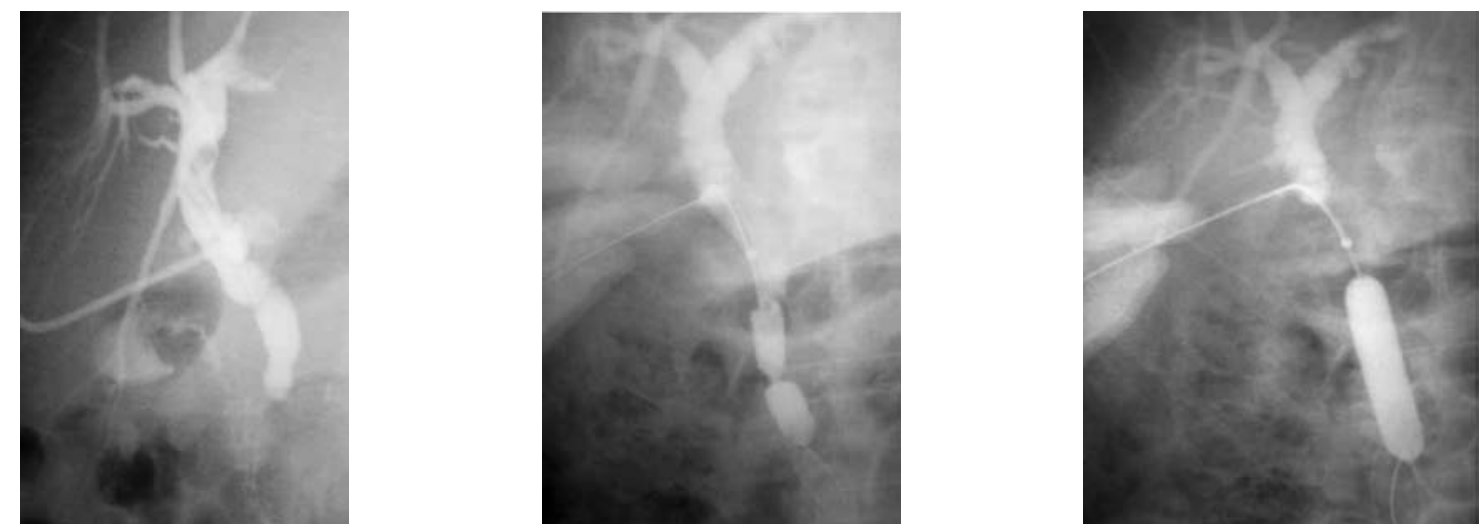

Caso: litiasis residual en un paciente con CER fallida en el preoperatorio, resuelta por vía incruenta previa papiloesfinteroplastia con balón de 10 a $12 \mathrm{~mm}$ de calibre. En la foto del medio se aprecia la cintura o escotadura a la altura del esfínter de Oddi, desaparecida al aumentar la presión de llenado del balón. 
De no lograr el objetivo en esta primer sesión, dejamos colocado un drenaje biliar grueso por una semana a 10 días, para que se restablezca la pared del trayecto y explorar en una nueva sesión de extracción. El mantener una guía en posición asegura la posibilidad de dejar colocado un drenaje biliar luego de las maniobras de extracción y así recuperar el trayecto.

Puede suceder que el trayecto se rompa y no pueda recuperarse el acceso a la vía biliar. Mientras se hubiere alcanzado el éxito y la vía biliar esté libre, generalmente la evolución será favorable. Si mantiene algún grado de obstrucción, la fuga de bilis hacia el peritoneo puede determinar biliperitoneo y peritonitis si no se actúa a tiempo (CER con papilotomia endoscópica y extracción de cálculos, reintervención quirúrgica, toilette peritoneal, recolocación de drenaje biliar, drenaje percutaneo)

Alcanzado el éxito del tratamiento, el paciente puede retomar la ingesta inmediatamente de finalizadas las maniobras.

Se indican analgésicos menores si presenta algún malestar.

Toda instrumentación que pase por el esfínter de Oddi, puede precipitar la aparición de una pancreatitis aguda. En tal caso la intensidad del cuadro clínico ameritará la internación y los cuidados inherentes a la misma, que escapan al objetivo del capítulo.

Contar con un endoscopio fino, capaz de deslizarse por el trayecto, puede permitir la visión directa de la vía biliar, de su contenido y realizar una serie de maniobras precisas, por ejemplo desplegar una cestilla Dormia sobre un cálculo, siempre que pueda pasar por su canal operador. La flexibilidad del extremo del endoscopio puede colaborar en alcanzar sectores de la vía biliar inaccesibles con otros instrumentos. Igualmente útil será si puede pasar una guía para litotricia electrohidráulica o por láser. Fragmentado el cálculo grande, se procede a la extracción de los fragmentos con la técnica descrita anteriormente.

No es conveniente insuflar aire dentro de la vía biliar por el riesgo de embolia gaseosa. Por ello, se conecta al canal operador una tubuladura que sale de un sachet de suero fisiológico colgado en un soporte de suero. La visión dentro de la vía biliar se hace bajo goteo continuo de suero.

La efectividad del tratamiento dependerá de las características del trayecto, el número, tamaño y topografía de los cálculos, el instrumental y experiencia del operador.

En última instancia y como recurso complementario de técnicas mini-invasivas, el acceso percutáneo es parte del "rendez vous" facilitando el abordaje endoscópico peroral de la vía biliar, técnicas desarrolladas en el capítulo anterior.

\section{Tratamiento transparietohepático de la litiasis de la VBP}

Este tratamiento puede hacerse en forma exclusiva e integral o como apoyo al tratamiento endoscópico transpapilar peroral, CER con papilotomia (rendez vous) en situaciones especiales.

Hay regiones o ciudades en que se conjugan dos circunstancias: por un lado hay profesionales cirujanos o radiólogos intervencionistas con experiencia en el abordaje de la vía biliar por vía transfistular (cuando existe drenaje biliar externo) y por vía transparietohepática cuando no lo tiene el paciente, y por otro carecen de endoscopista experto en vías biliares. Para que el paciente acceda a una CER con papilotomia y extracción de cálculos, deben ser trasladados largas distancias. Tal es el caso del grupo de Jujuy, extremo norte argentino, quienes tienen esa particularidad, por lo que algunos casos de litiasis de la vía biliar principal sin drenaje biliar externo, los trataron accediendo a la vía biliar por vía transparietohepática.

En su reciente publicación exponen casuística y resultados (Antegrade papillary balloon dilation for extrahepatic bile duct stone clearance: lessons learned from treating 300 patients. Szulman C., Giménez M., Sierre S. J. Vasc Interv Radiol. 2011 Mar;22(3): 346-53. Epub 2011 Feb 1) 
Por otra parte, otra es la situación de la técnica combinada con endoscopia (rendez vous) en que alcanza con lograr pasar una guía por vía transparietohepática al interior de la vía biliar y por ella llegar al duodeno en casos de anatomía conservada, o al yeyuno en casos de hepaticoyeyunostomias. El endoscopista puede atrapar la guía, y proceder con una serie de maniobras que le permiten ingresar a la vía biliar, hacer la papilotomia, dilatar una anastomosis y extraer los cálculos con accesorios variados (Dormia, balón extractor).

El acceso transparietohepático requiere de material específico: agujas Chiba, guías finas 0.018 inch que pasan por dentro de la aguja Chiba, introductor D'Agostino, guías 0.035 inch de punta recta y de punta curva, hidrofílicas y metálicas tipo Amplatz, set de bujias dilatadoras, drenajes biliares externointerno y drenajes multipropósito de calibres variados $(8.5,10.2,12$ french), balones de dilatación para papiloesfinteroplastia de diámetros variados, Dormias.

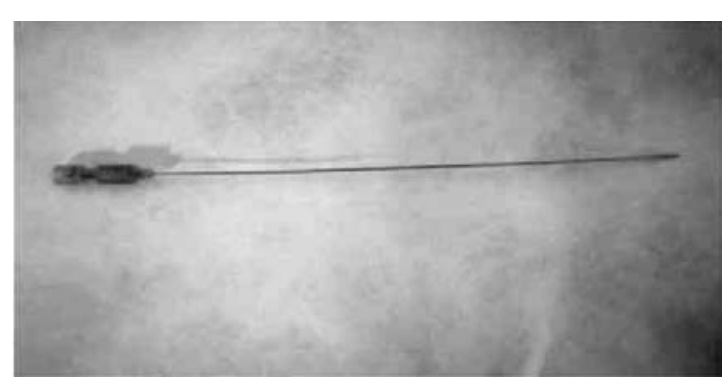

Aguja Chiba

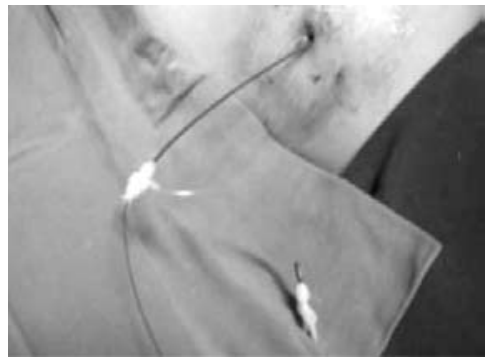

introductor DÁgostino

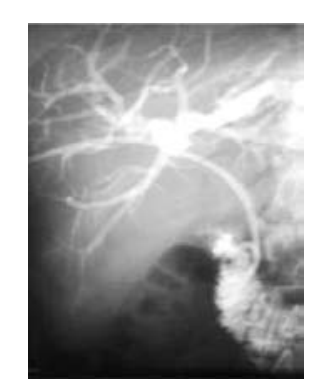

drenaje biliar externo interno

Se necesita radioscopia con amplificador de imágenes, por lo que puede hacerse en sala de radiología o en sala de operaciones con un arco en $\mathrm{C}$.

Material estéril, condiciones de asepsia quirúrgica, sobretúnica y guantes estériles, gorro, tapaboca, campos estériles, desinfectante de piel, material blanco, jeringas, hojas de bisturí, caja de pequeña cirugía, contraste hidrosoluble, suero fisiológico, anestésico local.
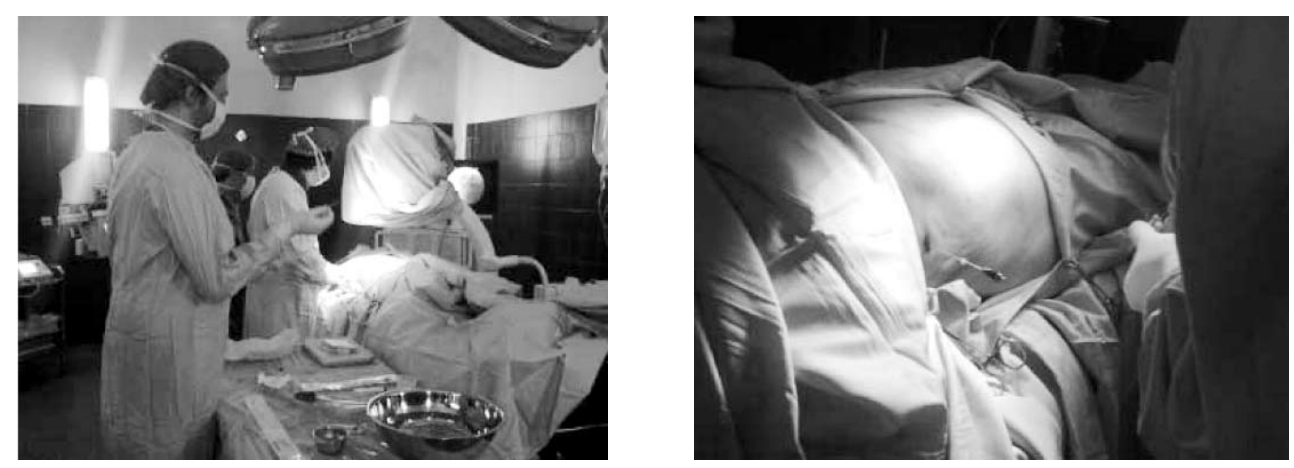

Habitualmente se hace con sedoanalgesia a cargo de anestesista.

El espacio intercostal elegido en la línea medioaxilar derecha, generalmente entre el 70 o 9으, previa comprobación en radioscopia que la proyección que llevará la aguja Chiba hacia el hígado, respeta el 
fondo de saco pleural y base del pulmón derecho por arriba y el ángulo derecho o hepático del colon por abajo.

El sitio elegido debe respetar los vasos intercostales por lo que la aguja penetrará rente al borde superior de la costilla inferior. Previo a ello se hace un habón con anestesia local y se infiltra el trayecto también con anestesia, seguido por una pequeña incisión en la piel con la punta de la hoja de bisturí.

La dirección de ingreso de la aguja Chiba (15 cm de largo) es ascendente siguiendo el plano de la cama en la proyección del hombro izquierdo. Se retira el mandril y se comienza a inyectar suavemente contraste diluido al medio, con una jeringa de $10 \mathrm{ml}$, adaptada por un conector al extremo de la aguja Chiba. Debe evitarse la formación de "manchas de contraste" por inyecciones parenquimatosas que de repetirse y no prosperar correctamente la técnica van obstaculizando la visión. El contraste inyectado puede desvanecerse o "lavarse" en sentido ascendente y rápido por estar dentro de un vaso sanguíneo, o más lentamente y por capilares más finos de ser un ducto linfático. El ingreso a la vía biliar se reconoce por el relleno progresivo de un ducto biliar que va dando paso progresivamente al relleno de todo el árbol biliar como lo conocemos, permitiendo objetivar la o las imágenes radiolúcidas de cálculos a tratar.

Siendo una posición favorable (trayecto) de ingreso, dejando fija la aguja Chiba, se pasa la guía de titanio de.018 por dentro de la aguja, teniendo el cuidado de manipularla para que se dirija hacia la vía biliar contrastada. Pasa con frecuencia que al salir del extremo de la aguja Chiba sigue directo penetrando el parénquima, en vez de flexionarse y deslizarse al interior de la vía biliar. Si se falla, hay que hacer pequeños deslizamientos de la aguja hasta intentar alcanzar el objetivo. Logrado éste, se deja la guía y se extrae la aguja, manteniendo en posición la guía. Se enhebra el introductor D'Agostino en la guía, deslizándolo hasta el interior de la vía biliar, En este momento se retira la guía fina y se intercambia por otra más gruesa, por ejemplo una hidrofílica de 0.035 que pasará por el interior del introductor. Una vez bien posicionada esta guía, se retira el introductor. En este momento, el procedimiento puede finalizar si dicha guía pasó hacia el duodeno o yeyuno como parte de una técnica combinada con el endoscopista, quién se encargará de realizar las maniobras necesarias para ingresar a la vía biliar, gracias a esta guía anterógrada, o continúa, como veremos a continuación para hacer el tratamiento de la litiasis por esta vía.

En esta última situación clínica, se pondera el tratamiento percutáneo transparietohepático, a cambio de reoperar al paciente, que en la mayor parte de lugares será por cirugía convencional.

Sobre la guía 0.035 inch se dilata el trayecto transparietohepático, con bujías de calibre creciente hasta el diámetro inmediato superior que el del drenaje que quedará colocado, por ejemplo hasta 11 french si el drenaje es 10.2 o hasta 9 french si será un drenaje 8.5 french, de forma tal que deslice sin dificultad, siempre sobre la guía que permanece en posición. En pacientes cursando una colangitis, cuánto más grave con más razón, alcanza en primera instancia lograr el drenaje biliar externo o externo interno, que se deja conectado a una bolsa colectora. Se fija con un punto a la piel. Luego del tratamiento antibiótico sumado a la descompresión biliar alcanzada, el paciente mejorará en los siguientes días, dando tiempo a madurar el trayecto alrededor del drenaje. En una segunda sesión, en primer lugar se hace una colangiografía por el drenaje a baja presión con contraste diluido para ver si persisten los cálculos, la ubicación, número, tamaño. En segundo lugar, se pasa una guía hidrofílica por el drenaje, dejándola en el duodeno y retirando el drenaje. Seguidamente se avanza con la técnica Seldinger, un balón de dilatación de altas presiones por la guía, centrándolo en la papila de Vater y procediendo a su dilatación hasta el diámetro elegido $(10,12,15,18 \mathrm{~mm}$ de acuerdo al tamaño de los cálculos). Logrado el objetivo, se retira el balón previo vaciado y se procede con una Dormia a atrapar desde el cálculo más distal y conducirlo sin resistencia hacia el duodeno, liberarlo, atraer la Dormia vacía hacia el interior del colédoco, repitiendo la maniobra tantas veces sea necesario. También es práctico y efectivo pasar en paralelo por el trayecto una guía metálica más firme de punta curva, que logra flexionarse en el interior de la vía biliar y por su convexidad va empujando los cálculos hacia el duodeno, no precisamente de a uno, muchas veces pasan columnas de cálculos a favor de la falta de resistencia del aparato esfinteriano y del calibre alcanzado de la terminación del colédoco con la papiloesfinteroplastia. 
Finalizada la maniobra es aconsejable dejar colocado nuevamente el drenaje biliar, como seguridad, para una definitiva colangiografia de control, alejada del procedimiento, cuidando de no inyectar aire (falsos positivos). De no haber más cálculos, se extrae el drenaje, dando por concluido el tratamiento. Si quedó alguno no percibido en la sesión anterior, se procederá según las referencias técnicas anteriores.

\section{Extracción de cálculos retenidos en la vesícula por el trayecto de colecistostomia}

De igual forma que es necesario aguardar un plazo para la maduración del trayecto de un drenaje biliar externo para la extracción de litiasis de la VBP, sucede lo mismo con el tubo (Pezzer) de la colecistostomia si fue quirúrgica, o del drenaje multipropósito si fue realizada por vía percutánea. Es más fácil explorar el trayecto que deja una gruesa sonda Pezzer, que el de un drenaje percutáneo fino. En este último caso hay que dilatar el trayecto, sobre una guía, pasando las bujías correspondientes de calibre creciente, bajo control radioscópico.

Una vez logrado al acceso directo a la vesícula sea con cestillas Dormias, a través de las cuales es posible inyectar contraste para identificar la posición del o los cálculos, se procede a la apertura y arrastre de los mismos, o en caso de utilizar las pinzas Mazzariello, se van atrapando de a uno y extrayendo enteros si son relativamente pequeños o medianos y pasan por el trayecto, o deben fragmentarse con litotricia realizada con la misma pinza sin son más grandes o con una Dormia y el litotriptor de Soehendra o una Dormia litotriptora.

Disponer de un fibrocoledocoscopio o endoscopio fino que pueda ingresar por el trayecto al interior de la vesícula y bajo visión directa del cálculo proceder al despliegue de una Dormia para atraparlo, facilita la tarea. La exploración por endoscopia se hace instilando agua y no insuflando aire. Por el endoscopio es posible pasar guías especiales para litotricia electrohidráulica o por láser, en centros que disponen de la tecnología.

Precaución debe tenerse por la posible migración de pequeños cálculos o fragmentos por el cístico en dirección de la VBP. Para ello hay autores (comunicación personal del Dr. D'Agostino) que recomiendan colocar una guía transcística hacia la VBP, y por ella avanzan e inflan un balón en el bacinete para evitar migraciones. 


\title{
Capítulo 7
}

\section{CASUÍSTICA \\ Cirugías laparoscópicas de la vía biliar}

\author{
Dr. Andrés Salom
}

La serie comprende 1494 pacientes operados por cirugía laparoscópica entre marzo de 1996 y junio de 2012 en los Hospitales: Pasteur, Clínicas, Central de las FF.AA y en los Sanatorios: Asociación Española y Casa de Galicia de la ciudad de Montevideo.

Los pacientes incluidos en esta serie, fueron operados personalmente, $y$ en algunos casos por residentes en formación bajo mi tutoría.

Las edades oscilaron entre los 17 y 89 años, con un promedio de 41 años; 926 (62\%) de sexo femenino y 568 (38\%) de sexo masculino

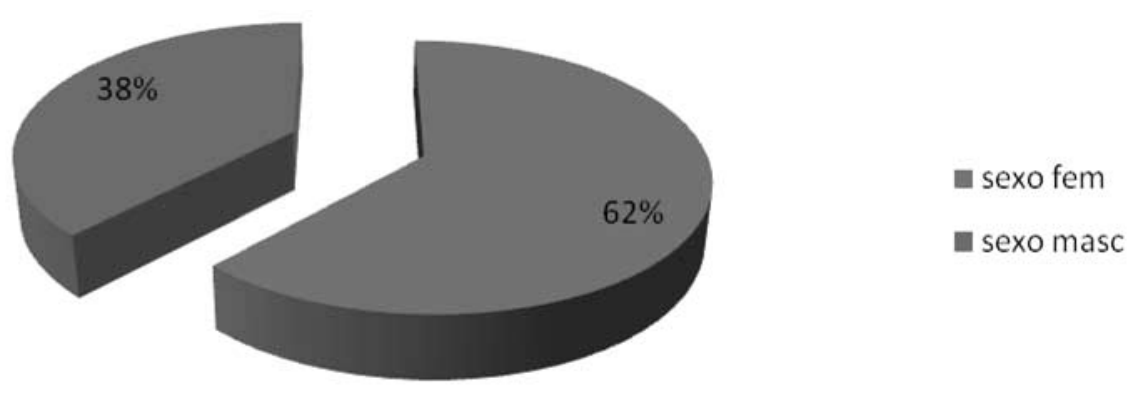

Gráfica 1. Cirugías distribuidas por sexo.

Se realizaron 1391 (93\%) colecistectomías y 103 (7\%) cirugías laparoscópicas de la vía biliar principal (VBP). 


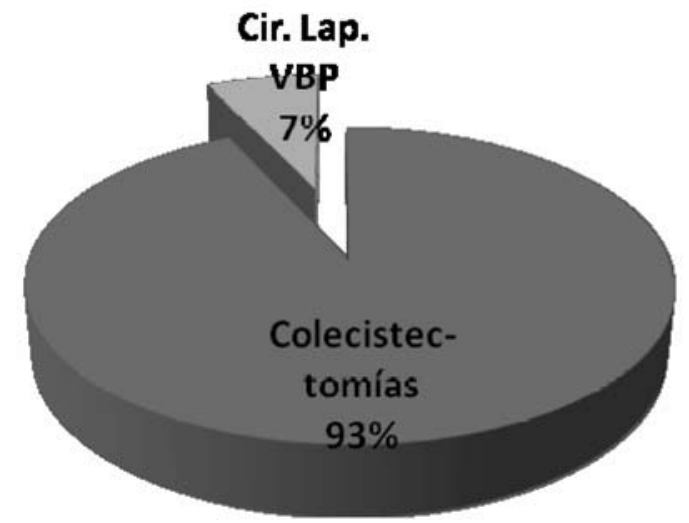

Gráfica 2. Clasificación de las cirugías laparoscópicas de la vía biliar realizadas.

La técnica utilizada fue la Americana, en 1421 casos (95.1\%); en 21 casos la técnica Francesa (1.4 \%) y en 52 casos la técnica con 3 trócares (3.5\%). Esta última técnica, fue utilizada en pacientes con litiasis vesicular, operados de coordinación y en casos de fácil realización.

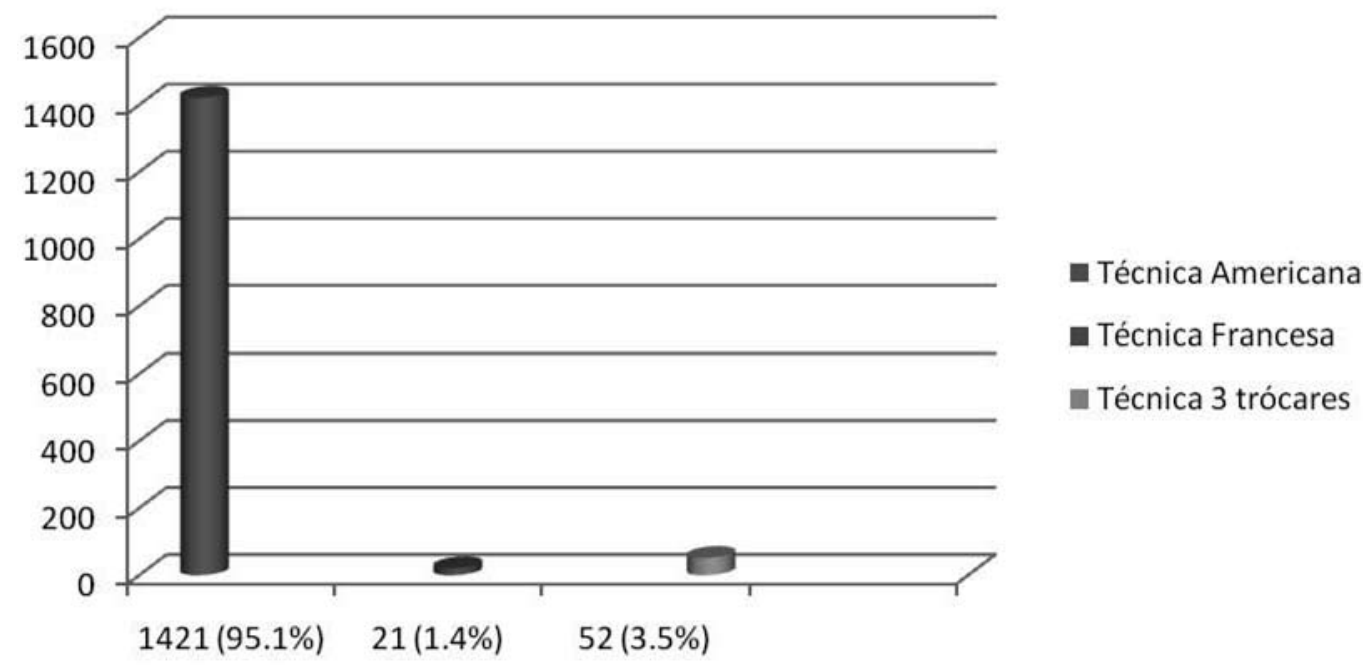

Gráfica 3. Técnicas quirúrgicas utilizadas.

\section{Cirugías laparoscópicas de la VB accesoria: colecistectomías}

De las 1391 colecistectomías realizadas, 288 fueron por colecistitis agudas ${ }^{1}$ y 1103 formas no agudas. 


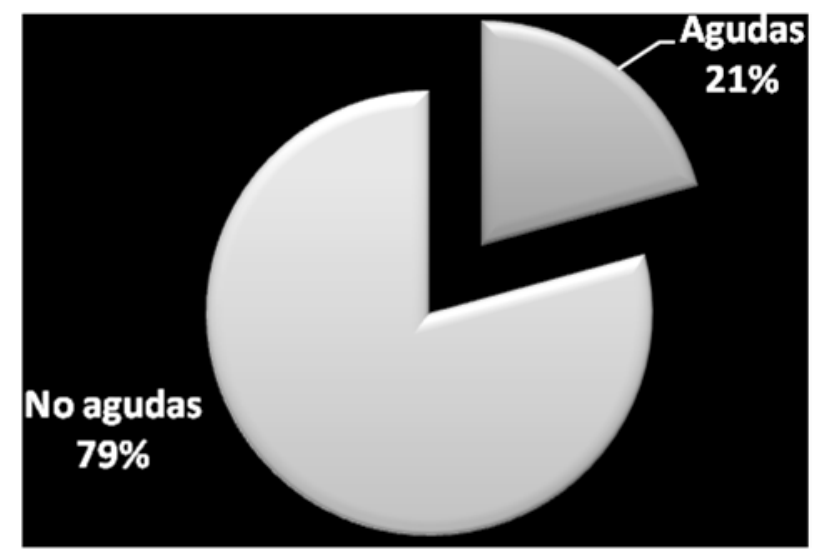

Gráfica 4. Colecistectomías realizadas.

De las 1103 colecistectomías laparoscópicas no agudas, se realizó colangiografía intraoperatoria en el $27 \%$ de los casos, con un criterio selectivo.

En 38 pacientes (3.4\%), se realizó una colangiografía endoscópica retrógrada (CER) preoperatoria, por la sospecha de tener una litiasis coledociana.

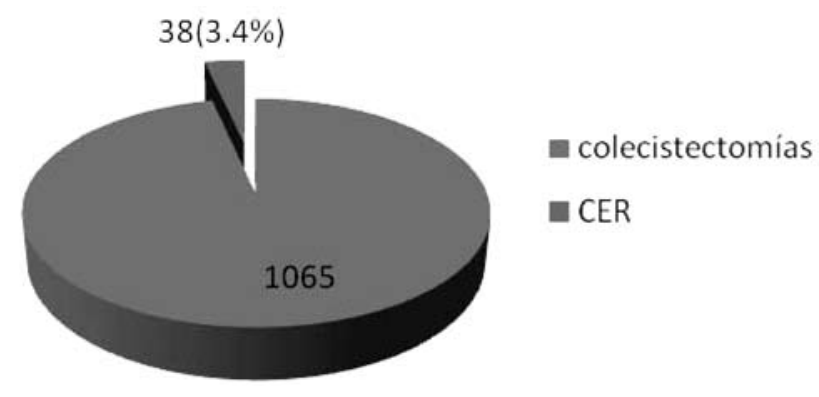

Gráfica 5. Colangiografía endoscópica preoperatoria en colecistectomías laparoscópicas.

En 12 de estos (32\%) se realizó la extracción de litiasis por vía endoscópica, a través de una papilotomía y con sondas Dormia. En los 26 casos restantes (68\%), no se encontraron litiasis de la vía biliar, seguramente debido a una migración espontánea de los cálculos.

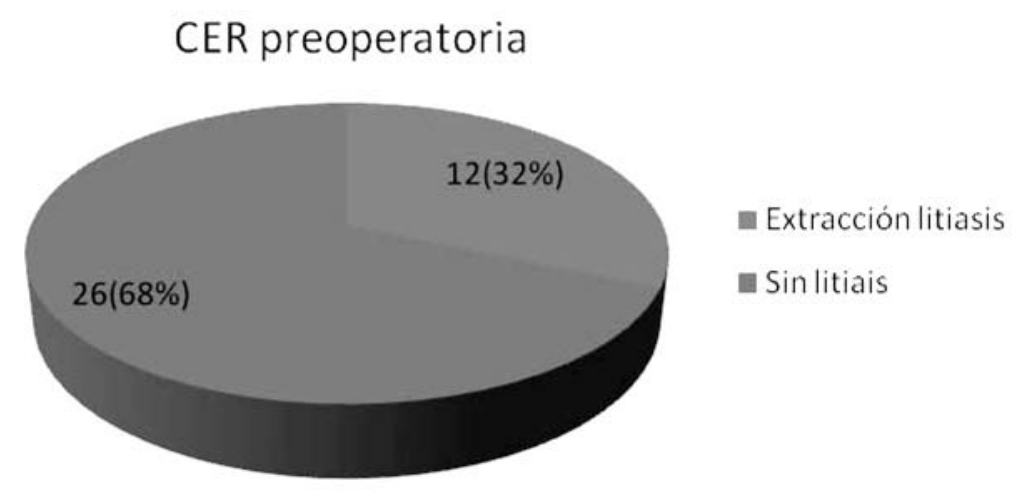

Gráfica 6. CER preoperatoria para diagnóstico y extracción de litiasis. 
En una paciente con una obesidad mórbida se relizó la endoscopía intraoperatoria (randez-vous), extrayéndose una pequeña litiasis que se encontaba en el colédoco distal, para luego realizarse la colecistectomía laparoscópica.

En cuanto a las formas anatomopatológicas de los pacientes operados por colecistitis aguda, 122 (42\%) fueron colecistitis edematosas, 85 (30\%) supuradas, 40 (14\%) gangrenosas y 41 (14\%) subagudas.

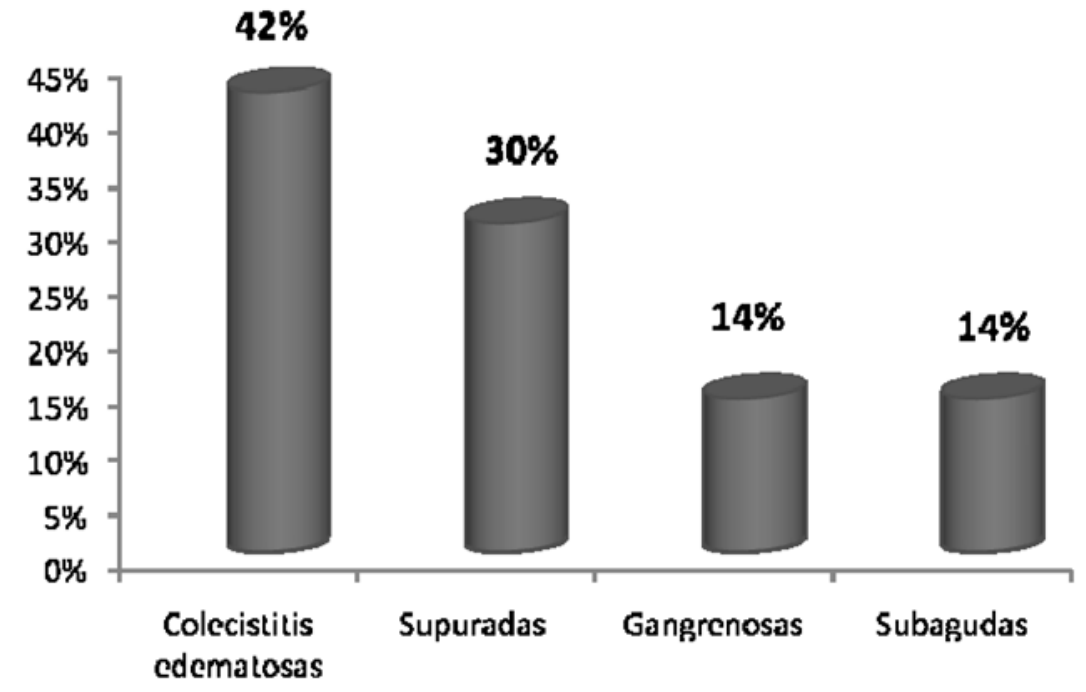

Gráfica. 7 Cirugías por colecistitis aguda de acuerdo a formas anatomopatológicas.

Se realizó colangiografía intraoperatoria en el 31\% de los casos.

En los pacientes con colecistitis agudas se puncionó el fondo y se evacuó la vesícula biliar para facilitar su prensión y disección.

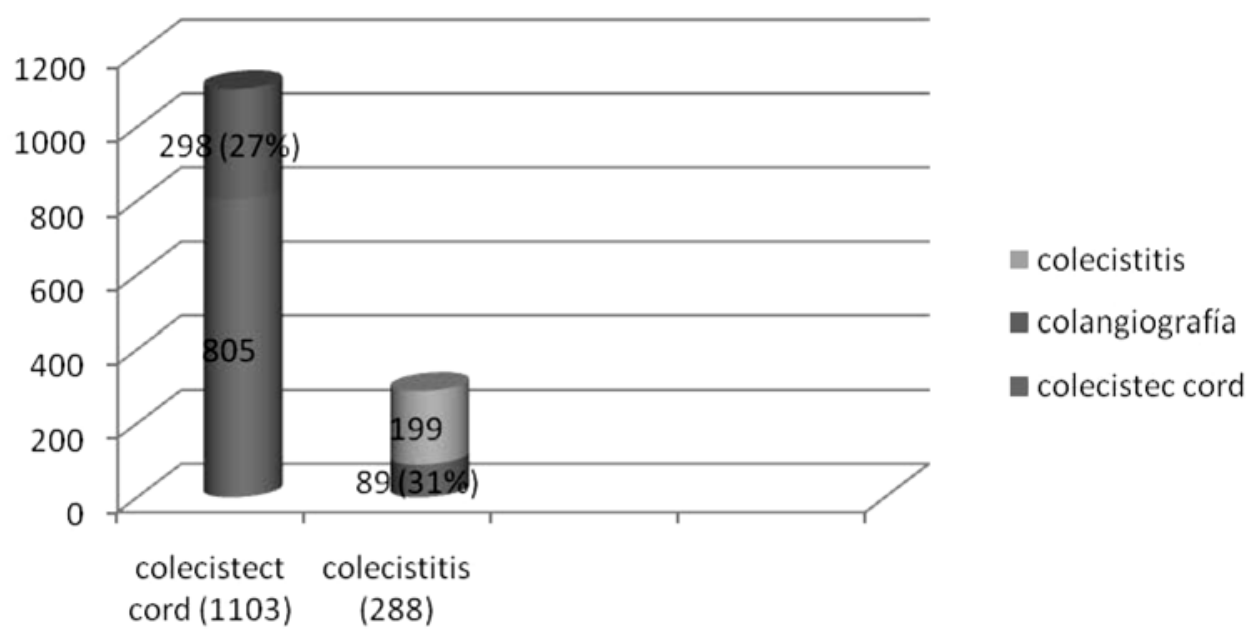

Gráfica 8. Colangiografía intraoperatoria. 


\section{Cirugía laparoscópica de la VBP}

Los pacientes operados por litiasis coledociana fueron $103^{2,3}$.

Excluimos de esta serie los 38 pacientes con elementos de sospecha de tener una litiasis coledociana, a los que se le realizó una CER preoperatoria, y fueron resueltos en 12 casos (32\%) con la extracción de los mismos en el preoperatorio.

Clínicamente 79 pacientes (77\%) se presentaron con elementos de alta sospecha de tener una litiasis coledociana, dado que tuvieron dolor en epigastrio, ictericia, fiebre y 8 casos de pancreatitis leve.

Tenían elementos ecográficos de sospecha de litiasis coledociana 67 pacientes (65\%).

En 7 pacientes (8\%) el diagnóstico se realizó en el intraoperatorio al realizarse la colangiografía transcística, sin tener elementos ecográficos de sospecha; 4 de estos pacientes se trataban de cuadros de colecistitis aguda. En todos estos casos el conducto cístico estaba francamente aumentado de calibre.

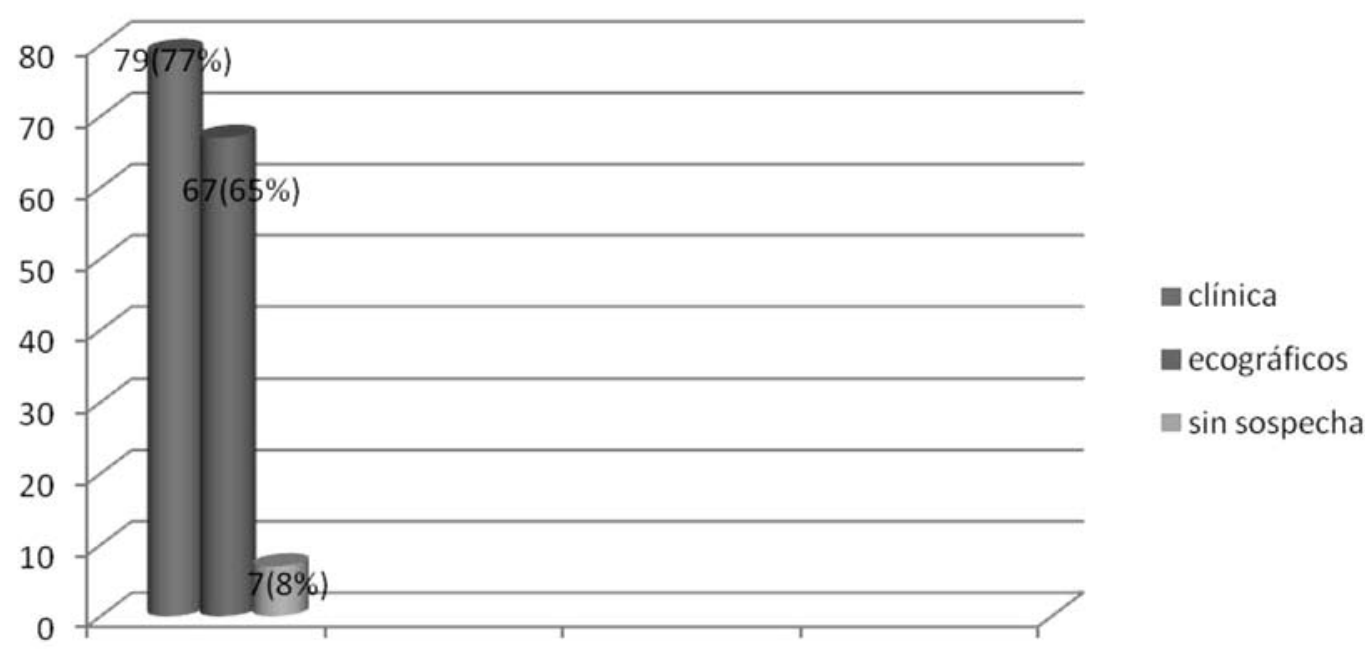

litiasis VBP

Gráfica 9. Diagnóstico de litiasis coledociana.

En 85 casos (83\%), se extrajeron los cálculos por vía transcística y en 18 (17\%) por coledocotomía.

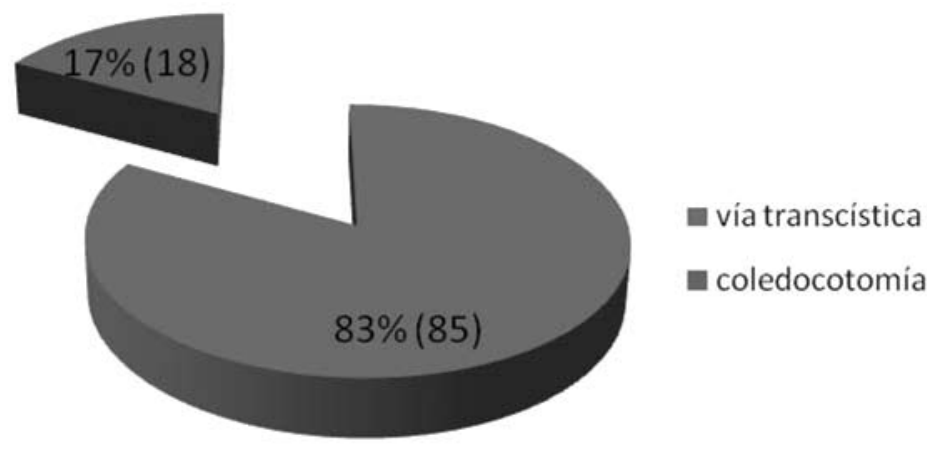

Gráfica 10. Vías utilizadas para la extracción de los cálculos. 
Se realizó un control radiológico colangiográfico, dejándose un drenaje transcístico con una sonda Nelaton de goma en 15 casos.

En los 18 pacientes en que se realizó una coledocotomía, los cálculos fueron extraídos con sonda Dormia y lavado por arrastre.

En los pacientes con litiasis coledociana, tratados por vía transcística, los cálculos se extrajeron con sondas Dormia, introducidas a través de la pared abdominal por una cánula de Teflón no 14 emplazada a nivel del epigastrio y en algunos casos fueron empujados al duodeno por arrastre con lavado.

La sonda Dormia la introducimos en el conducto cístico y la hacemos avanzar hasta la papila, sin franquear ésta, controlando su progresión en el amplificador. En este momento se abre la cestilla y se la retira progresivamente. Generalmente son necesarias varias tentativas para tener éxito con la maniobra y retirar los cálculos.

La cestilla se abre más allá del o los cálculos, no pasando la papila para evitar una incarceración accidental de ésta o de la mucosa duodenal y después se la retira progresivamente, dejándola abierta para que los cálculos se alojen en ella espontáneamente.

Cuando se practicó una coledocotomía, el cierre se hizo sobre un tubo de Kehr con puntos separados de material de sutura reabsorbible 4.0.

\section{Resultados}

La mortalidad global de la serie fue del $0.13 \%$, o sea 2 pacientes.

Uno de ellos se trataba de una paciente de 64 años, portadora de una obesidad mórbida, que en el postoperatorio luego de una colecistectomía laparoscópica de coordinación por la presencia de una litiasis vesicular sintomática sin complicaciones, presentó un cuadro compatible con un TEP mortal.

El otro caso se trata de un paciente de 65 años, de sexo masculino, con antecedentes personales de haber sido operado de un cáncer colorectal en oclusión, realizándose una colectomía subtotal con anastomosis colorectal por una laparotomía mediana. Portador de un pólipo vesicular que motivó la indicación de una colecistectomía laparoscópica de coordinación a los 2 años de esta cirugía. Se intentó el abordaje por laparoscopía con lo que se produjo la lesión de un asa intestinal adherida a la pared, lo que motivó la conversión a cirugía abierta. Se reparó la lesión del asa y se realizó la colecistectomía. En el postoperatorio fue re-intervenido a las 20 horas por la presencia de una peritonitis, constatándose una fuga a nivel del asa intestinal reparada, de una lesión no advertida. Se realizó la resección del asa, anastomosis y lavado peritoneal. Presentó una mala evolución postoperatoria y fallece en CTI al quinto día.

\section{Conversiones}

En el total de la serie (1494 pacientes), se produjeron 26 conversiones a cirugía abierta (1.7\%). 


\section{Conversiones}

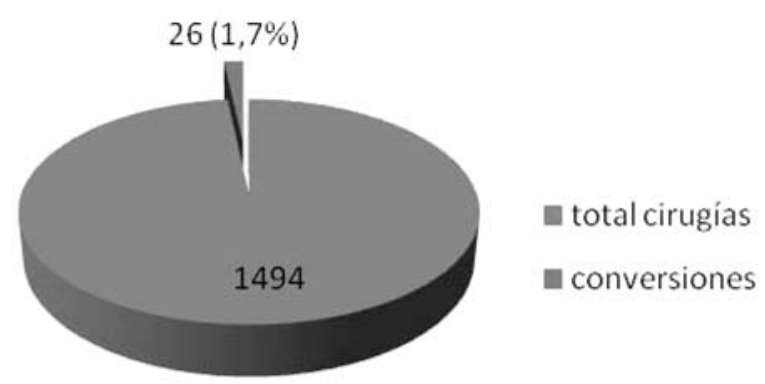

Gráfico 11. Total de conversiones.

Conversiones por grupo:

a) Colecistectomías de coordinación (1103 pacientes):

$6 \operatorname{casos}(0.5 \%)$ :

- Un caso por la realización de una coledocotomía parcial accidental, al inicio de la experiencia, en una colecistectomía de coordinación al seccionarse el conducto cístico.

- Un caso por la presencia de un tumor de conducto cístico (adenocarcinoma).

- Un caso por intolerancia al neumoperitoneo.

- Un caso por lesión de asa delgada.

- Un caso por lesión del colon sigmoide.

- Un caso por lesión de aorta.

b) Colecistectomías laparoscópicas en colecistitis agudas (288 pacientes):

12 casos (4.1\%), por la presencia de alteraciones inflamatorias del pedículo.

c) Cirugías laparoscópicas de la VBP (103 pacientes):

$8 \operatorname{casos}(7.7 \%)$ :

- Dos casos por la presencia de un cálculo enclavado a nivel de la papila

- Tres casos de panlitiasis

- Tres casos por alteraciones inflamatorias del pedículo

Se realizó la conversión a laparotomía, extrayéndose los cálculos por vía transcística en 2 casos y por coledocotomía en los 6 restantes.

En 2 casos el motivo fue la presencia de un cálculo enclavado en la papila que motivó la necesidad de realizar una papilotomía quirúrgica transduodenal para poder extraerlo. Se realizó en ambos casos una coledocotomía y colocación de un drenaje de Kehr con buena evolución postoperatoria.

En 3 casos las conversiones fueron realizadas por encontrarse alteraciones inflamatorias, con dificultades anatómicas en el reconocimiento de los elementos del pedículo hepático. 


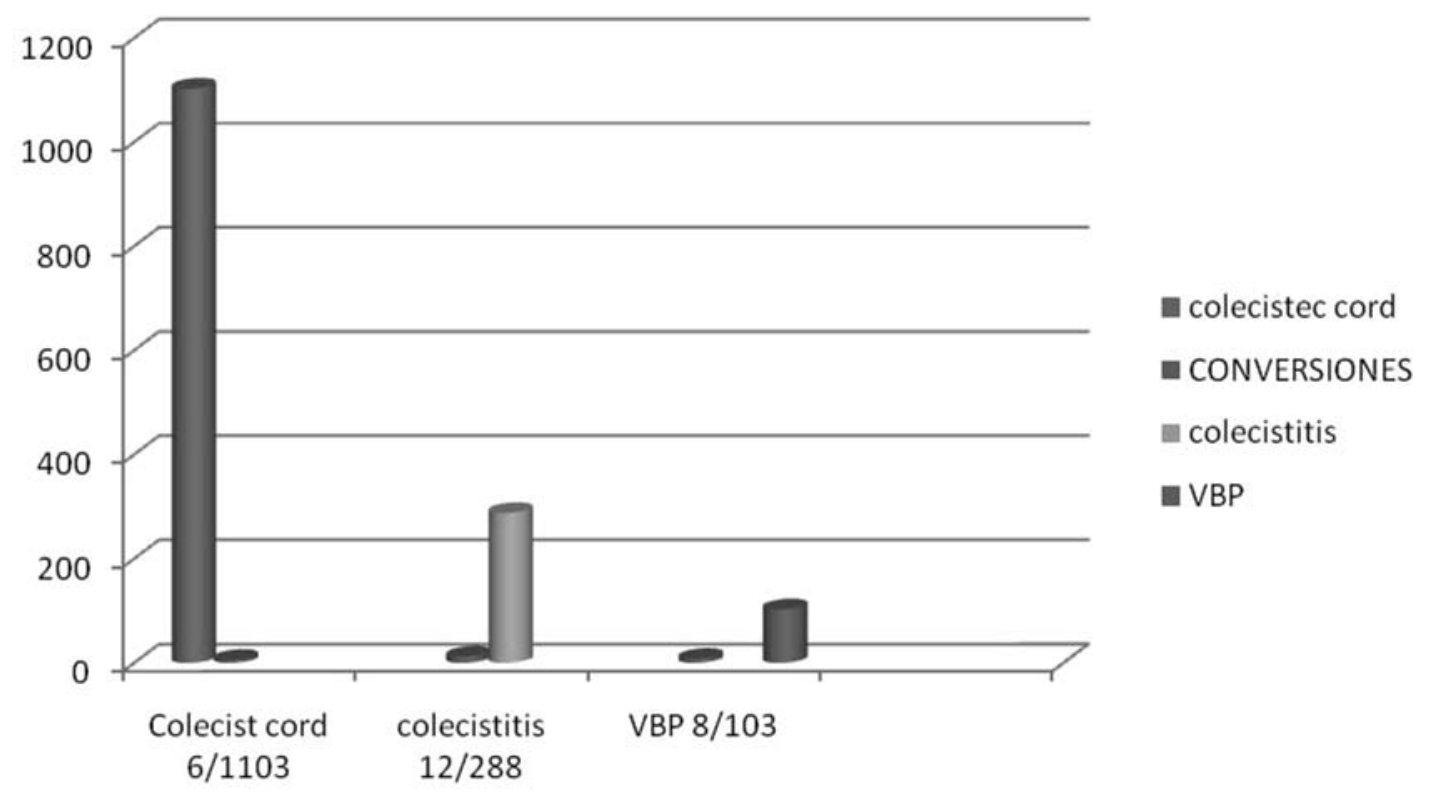

Gráfica 12. Conversiones por grupo en el total de pacientes operados.

\section{Conversiones}

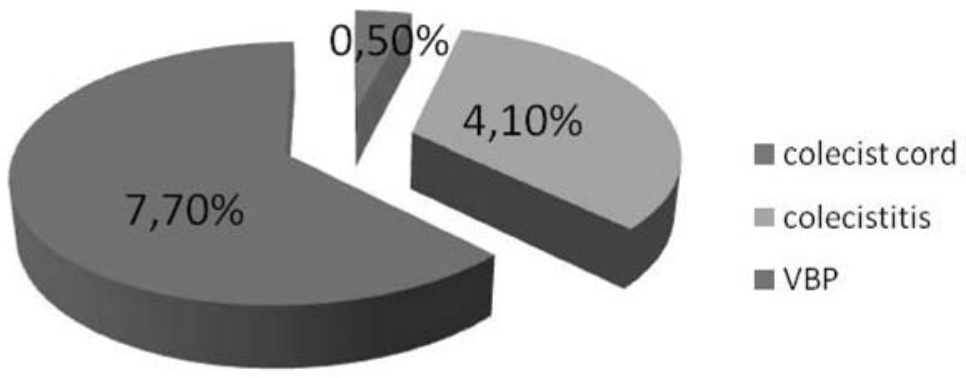

Gráfica 13. Conversiones por grupo según porcentajes.

\section{Complicaciones}

Se observaron las siguientes complicaciones:

\section{Complicaciones intraoperatorias:}

Lesión colon sigmoide por primer trócar (año 1998).

Hematoma mesentérico por la aguja de Veress (año 2001).

Lesión de asa delgada por primer trócar (año 2009).

Lesión de aorta al realizar la incisión de piel periumbilical (año 2012).

Lesiones biliares:

1) Lesión puntiforme del conducto cístico en el intento de realización de colangiografía (año 1999). Se solucionó con la colocación de clips próximos al conducto hepatocolédoco que permitieron ocluir la perforación. 
2) Coledocotomía accidental parcial al seccionar el conducto cístico que fue resuelta con la conversión y colocación de un drenaje de Kehr (año 2001) con buena evolución postoperatoria y en el seguimiento. Se trataba de una colecistectomía de coordinación por litiasis vesicular.

3) Coledocotomía accidental parcial en una paciente que presentaba un Síndrome de Mirizzi y un ambiente común. Se realizó la conversión a cirugía abierta y colocación de un drenaje de Kerh (año 2001).

4) Biloma postoperatorio al ser extraído el drenaje de Kehr a la sexta semana en una paciente operada por litiasis coledociana por coledocotomía laparoscópica (año 2002). Se solucionó por punción percutánea bajo ecografía. En el análisis del video de la cirugía se pudo detectar que uno de los puntos de cierre de la coledocotomía había tomado el tubo de Kehr, lo que motivó que al ser retirado produjera un desgarro del colédoco con bilirragia.

5) Peritonitis biliar por fuga a nivel del muñón cístico y litiasis coledociana residual en un paciente operado de una colecistitis aguda (año 2007).

En el postoperatorio presentó un cuadro de irritación peritoneal y un gasto biliar elevado por un drenaje subhepático. Fue resuelto realizándose a las 48 horas de la cirugía inicial, una extracción intraoperatoria por vía endoscópica de una litiasis coledociana residual y por una relaparoscopía con lavado peritoneal y cierre del muñon cístico con endoloop.

6) Coledocotomía accidental y litiasis residual (año 2010).

Se realizó la coledocotomía accidental al confundir el colédoco con el conducto cístico en el momento de realizar la colangiografía intraoperatoria.

La paciente presentaba un importante proceso inflamatorio a nivel del pedículo hepático y la vía biliar que hicieron muy difícil reconocer la anatomía y una litiasis coledociana múltiple con una vía biliar no dilatada.

Fue solucionada con la colocación de un drenaje de Kehr por laparoscopía y extracción de un cálculo residual en el postoperatorio por vía endoscópica.

7) Bilirragia postoperatoria en una paciente operada con una colecistitis subaguda, que se agotó en una semana a través de un drenaje subhepático dejado en la cirugía (año 2010).

8) Lesión puntiforme del hepático común en una paciente portadora de una colecistopatía obstructiva crónica en mayo de 2012, que fue solucionada con la colocación de un punto.

9) Fueron 4 los casos de litiasis persistentes en pacientes con litiasis coledocianas imposibles de extraerse en el intraoperatorio.

En un caso por litiasis coledociana múltiple con vía biliar no dilatada. Se dejó un drenaje transcístico y se extrajeron los cálculos por vía endoscópica en el postoperatorio (año 2010).

En 2 casos, por la presencia de un cálculo único en el colédoco distal, con un cístico espiralado que hacía imposible su manipulación y una vía biliar muy fina. Se resolvieron igual que el caso anterior, con la colocación de un drenaje transcístico y extracción por vía endoscópica postoperatoria (años 2004 y 2010).

El cuarto caso se trata de un paciente con litiasis coledociana múltiple resuelto con la realización de una coledocotomía y colocación de drenaje de Kehr (año 2011). Se detectó en la colangiografía postoperatoria a través del drenaje del Kehr, una litiasis coledociana distal, resolviéndose con su extracción por vía endoscópica en el postoperatorio.

10) En 3 casos de litiasis residual (casos 5,6 y un caso que se convirtió por panlitiasis). 


\section{Complicaciones postoperatorias:}

- Un absceso de pared abdominal en flanco izquierdo, por litiasis, a los 2 años de la cirugía.

- Un caso de supuración del puerto de epigastrio.

- Un caso de eventración de incisión de epigastrio.

- Un caso de hemoperitoneo, resuelto por laparoscopía, debido a rotura folicular.

- Un caso de peritonitis postoperatoria (caso 5), que fue solucionado por relaparoscopía y CER con papilotomía y extracción de litiasis residual.

\section{Conclusiones}

- Los porcentajes de conversión fueron mayores en las cirugías laparoscópicas de la VBP (7.7\%), en segundo lugar en las colecistectomías por colecistitis agudas (4.1\%) y en tercer lugar en las colecistectomías de coordinación (0.5\%).

- Las complicaciones vinculadas al neumoperitoneo y a la colocación de los puertos fueron pocas, pero en 2 casos graves.

- La realización de una coledocotomía accidental fue la LQVB más frecuente y ocurrió en casi todos los casos por confundir el conducto cístico con el colédoco antes de realizarse la colangiografía.

- La presencia de una litiasis coledociana persistente pudo ser resuelta por vía endoscópica en todos los casos sin tener necesidad de a recurrir a cirugía.

- La relaparoscopía debe ser tenida en cuenta como recurso terapéutico de menor morbilidad en pacientes con una peritonitis biliar.

- Del análisis de esta serie se puede concluir que no se produjo ninguna lesión grave de la vía biliar y que las lesiones producidas fueron pocas y se pudieron resolver adecuadamente.

- Las complicaciones postoperatorias alejadas por el abordaje por los trócares fueron pocas y con muy baja morbilidad.

\section{Bibliografía}

1) Salom A. Tratamiento de la colecistitis aguda por cirugía laparoscópica. Sesión científica de Sociedad de Cirugía del Uruguay. 12 mayo 2010 Montevideo, Uruguay. (De próxima aparición).

2) Salom A, Estapé Viana G, Acevedo C, Harguindeguy M, Etlin A, Alvez Da Cruz M, y col. Tratamiento de la litiasis coledociana. Cir Uruguay 2004; 74: 46-57.

3) Salom A, Estapé Viana G, Müller A, Peyroulou A. Tratamiento por cirugía laparoscópica de la litiasis coledociana. Actas del 750 Congreso Argentino de Cirugía; 2004: Buenos Aires, Argentina.

4) Salom A. Complicaciones biliares de la cirugía laparoscópica de la vía biliar. Sesión científica de Sociedad de Cirugía del Uruguay. 3 agosto 2011 Montevideo, Uruguay. (De próxima aparición). 


\title{
CASUÍSTICA ENDOSCÓPICA
}

\author{
Dr. Álvaro Piazze \\ Colaboradores: Dr. Ignacio Toscani, Dr. Carlos Adorno, \\ Dr. Sebastián Fraga, Dra. Susana Reyes
}

\section{Introducción}

En marzo del 2011, en la Sede de la Sociedad de Cirugía, en la primer reunión de trabajo para definir el tema y elegir responsables del Relato Oficial del 63․ Congreso Uruguayo de Cirugía a desarrollarse 20 meses después, su Presidente, Prof. Dr. Augusto Müller, me ofreció encargarme del tema tratamiento endoscópico de la litiasis de la vía biliar principal.

Posiblemente recayó en mi persona por una larga amistad, desde la preparación para el internado hasta ser tutor en mi formación como cirujano, siendo ya Residente de la Clínica Quirúrgica "1" del Hospital Pasteur a cargo del Prof. Dr. Bolivar Delgado, donde él integraba su staff docente junto a otros excelentes cirujanos. El destino marcó que casi la mitad de mi Residencia de Cirugía, la realizara en diferentes centros de entrenamiento en endoscopia diagnóstica y terapéutica en Hospitales y Clínicas de Chile, Francia, Alemania y Suecia. Siempre estuvo atento y en permanente comunicación, siguiendo mi formación. Luego de ello, han pasado ya 20 años. En este período miles de pacientes referidos por el Dr.Müller, entre el Hospital Central de las Fuerzas Armadas Hospital de Clínicas y CASMU para endoscopia digestiva alta y baja, fueron atendidos personalmente por mi, y en particular compartimos cientos de pacientes con la patología específica del Relato a quienes les realizamos CER y papilotomias.

Aceptamos el compromiso y proyectamos conocer la realidad de nuestra práctica personal en una población que entendíamos accesible para realizar el seguimiento a partir de dar inicio al trabajo. Atrás quedan varios miles de CER que llevaría años hacer el seguimiento y puede ser motivo para un trabajo titánico que deberá involucrar a un gran número de investigadores.

Para el Relato Oficial planificamos un estudio prospectivo descriptivo de todos los pacientes atendidos personalmente en forma consecutiva desde abril del 2011 a marzo de 2012, en que la CER con eventual papilotomía estaba indicada por algún colega, sea por sospecha, certeza o para descartar litiasis de la VBP, en preoperatorios de colecistectomías o en pacientes ya colecistectomizados recientemente o en forma alejada y excepcionalmente en el intraoperatorio. Por consiguiente se excluyeron todas las demás CER realizadas en ese período con otro objetivo.

En una planilla Excel se incluyeron los datos de la población asistida: nombre, edad, sexo, procedencia, médico referente, datos clínicos y paraclínicos (funcional y enzimograma hepático, leucocitosis, amilasemia, estudios imagenológicos: ecografía, tomografía, colangioresonancia, colangiografias intraoperatorias o postoperatorias), diagnóstico y tratamiento endoscópico realizado, existencia o no de cálculos, número, tamaño, calibre de la vía biliar, modo de ingreso a la vía biliar (por el ostium de la 
papila o por precorte del infundíbulo: infundibulotomia), papilotomía exclusiva o asociada a papiloesfinteroplastia con balón, cateterismo del Wirsung (número de veces, si fue solo con la guía, guía y contraste, solo contraste), éxito en la extracción de cálculos, fracasos y motivos de los mismos, accesorios utilizados (Dormia, balón extractor, prótesis, drenaje nasobiliar). Hallazgos de patología asociada insospechada (tumor de papila de Vater, estenosis biliares, fugas). Complicaciones inmediatas: sangrado por la papilotomia, tratamiento hemostático realizado, perforación, y un ítem de observaciones para situaciones que fueran relevantes (problemas técnicos, anestesiológicos, etc)

Cerrado el reclutamiento de pacientes, en la misma planilla Excel se hizo el seguimiento de esa población, destacando la evolución clínica, morbilidad y mortalidad de la CER, tratamientos quirúrgicos realizados, días de internación, controles diferidos, clínicos y paraclínicos.

No se logró hacer el seguimiento del total de la población enrolada, por proceder de diferentes ciudades del interior a las que no se pudo tener acceso a su historia clínica o hubo dificultades con identificación por lo que responsables de cada archivo de historias clínicas, no lograron encontrar las mismas en las fechas otorgadas para el estudio de las historias o hubo renuencia de colaboración de Archivo de historias Clínicas en casos particulares.

Esta tarea de investigación excede los limites de tiempo para el procesamiento de datos en vistas a la presentación de este capítulo en tiempo y forma para su publicación. El análisis estadístico de todas las variables registradas relacionadas a aspectos puramente técnicos y específicos, como el conocer el seguimiento de aquellos pacientes que para esta publicación no se consiguieron, será motivo de otra presentación.

Se incluyeron 317 pacientes, en los que se realizaron 324 procedimientos.

Fueron referidos desde 12 IAMC y 9 Hospitales públicos, de Montevideo e Interior del país. Las intervenciones fueron solicitadas por 90 cirujanos, 2 internistas, un intensivista y una gastroenteróloga hepatóloga.

\section{Equipamiento}

Fueron realizados con videoprocesadores electrónicos Olympus y videoduodenoscopios compatibles así como fuentes Olympus portátiles con duodenoscopios portátiles, cuyos canales operadores o de trabajo, comprenden desde 2.8 a $4.2 \mathrm{~mm}$ de diámetro. La utilización de ellos dependía si se atendían en centros donde contamos con torre de videoendoscopia fijos o se concurría con equipos portátiles a diferentes instituciones.

165 CER se realizaron con equipos portátiles y 157 con videoendoscopios. A 2 pacientes le realizamos extracción incruenta transfistular de la litiasis, evitando los riesgos de la CER.

En cuanto a los accesorios empleados: papilótomos estándar de triple lumen, guías hidrofilicas 0.035 in, Dormias comunes, Dormias litotriptoras, balones extractores, prótesis plásticas, procedentes de los distintos proveedores. Para el precorte utilizamos accesorios artesanales, transformando los papilótomos estándar que se rompen en papilótomos para precorte. en C).

Todos los procedimientos se realizaron en salas de operaciones con equipos de radioscopia (arco

Salvo excepciones, siempre hubo un anestesista a cargo de la sedoanalgesia de los pacientes. Ante la ausencia de anestesista por razones de fuerza mayor, hicimos la sedación en base a Midazolam intravenoso, tomando todos los recaudos de monitorización, oxigenoterapia y contando con el antídoto para despertar al paciente si fuera necesario y el material para intubación de la vía aérea. 
Según el lugar, día y hora de la CER, llegaron a actuar 6 asistentes de endoscopía en total, todos con experiencia en vías biliares.

\section{Población estudiada}

La muestra incluyó 317 pacientes, 193 del sexo femenino (60.9\%) y 124 masculino (39,1\%)

\section{Distribución por sexo}

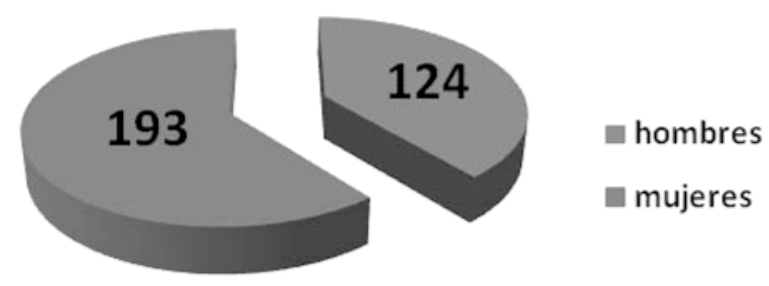

Se analizarán en tres grupos: preoperatorios 189 pacientes (59,6\%), postoperatorios 125 pacientes $(39,4 \%)$ e intraoperatorios 3 pacientes $(0.9 \%)$

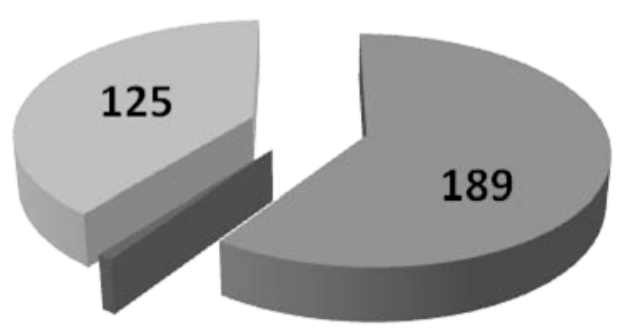

3

\begin{tabular}{|c|c|c|c|}
\hline & PREOP & POST & INIRAOP. \\
\hline menor 20 & 7 & 2 & \\
\hline $21-30$ & 6 & 5 & \\
\hline $31-40$ & 14 & 13 & 1 \\
$41-50$ & 29 & 14 & 2 \\
$51-60$ & 23 & 11 & \\
$61-70$ & 30 & 19 & \\
\hline $71-80$ & 36 & 37 & \\
$81-90$ & 39 & 19 & \\
mayorde90 & 5 & 5 & \\
& & & \\
\hline TOTALES & 189 & 125 & 3 \\
\hline
\end{tabular}

preoperatorios

- intraoperatorio

postoperatorio
Por edad se distribuyeron por décadas de la siguiente manera (ver gráfico)

141 pacientes integraron el grupo de 71 años o mayores, representando el $44,4 \%$.

Analizaremos primero los pacientes no colecistectomizados, luego los ya colecistectomizados y finalmente los casos de CER intraoperatorias. 


\section{Pacientes con vesícula in situ (preoperatorios)}

Incluye 189 pacientes (59,6\% del total) en quienes se realizaron 192 CER, al requerir 2 sesiones 3 de los pacientes.

Del punto de vista clínico, el $83 \%$ de los pacientes presentaban colangitis $(62,4 \%)$, pancreatitis $(16,4 \%)$ y sepsis biliar $(4,2 \%)$.

Una paciente de 97 años se presentó con un Bard y Pick litiásico, sin cálculos en la vesícula, con 3 cálculos de $10 \mathrm{~mm}$ en vía biliar dilatada, extraídos luego de la papilotomía. Del funcional y enzimograma hepático se destacaba BT de $7 \mathrm{mg} \%$ a predominio de directa (6.2), fosfatasa alcalina de 1836, GGT de 535 y 15000 de leucocitosis.

\section{Dato clínico}

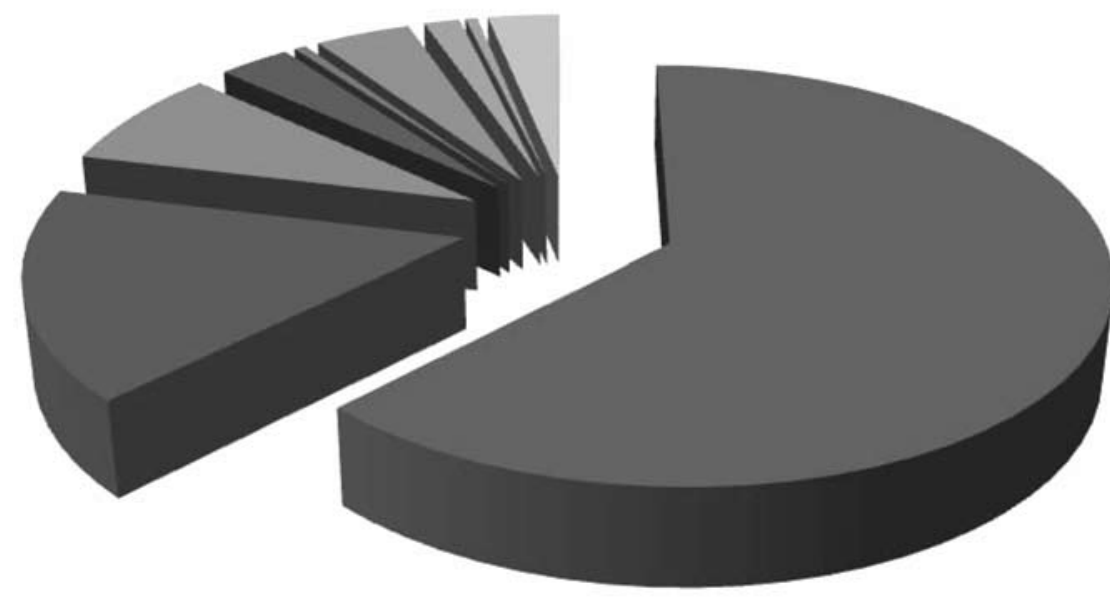

colangitis

mancreatitis

ictericias

a dolor

- Bard y Pick

- sepsis biliar

- litiasis por eco

- preop colelap

sin dato

La relación por grupos, entre vía biliar informada o no como dilatada por ecografía y los valores de bilirrubinas totales menores o mayores de $2 \mathrm{mg} \%$, a su vez relacionados con el dato clínico referido en la solicitud de la CER, se pueden apreciar en la siguiente tabla.

\begin{tabular}{|l|c|c|c|c|c|c|c|c|c|c|}
\hline & $\begin{array}{c}\text { colan- } \\
\text { gitis }\end{array}$ & $\begin{array}{c}\text { pancrea- } \\
\text { titis }\end{array}$ & $\begin{array}{c}\text { icteri- } \\
\text { cias }\end{array}$ & dolor & $\begin{array}{c}\text { Bard y } \\
\text { Pick }\end{array}$ & $\begin{array}{c}\text { sepsis } \\
\text { biliar }\end{array}$ & $\begin{array}{c}\text { litiasis } \\
\text { por eco }\end{array}$ & $\begin{array}{c}\text { preop } \\
\text { colelap }\end{array}$ & $\begin{array}{c}\text { sin } \\
\text { datos }\end{array}$ & Total \\
\hline $\begin{array}{l}\text { VB no dila- } \\
\text { tada } \\
\text { BT <2 }\end{array}$ & 18 & 10 & 1 & & & & 1 & 30 \\
\hline $\begin{array}{l}\text { VB no dila- } \\
\text { tada } \\
\text { BT >2 }\end{array}$ & 39 & 5 & 8 & & & & 1 & & & 53 \\
\hline $\begin{array}{l}\text { VB dilatada } \\
\text { BT <2 }\end{array}$ & 14 & 5 & & 5 & & & & & 1 & 25 \\
\hline $\begin{array}{l}\text { VB dilatada } \\
\text { BT >2 }\end{array}$ & 42 & 7 & 6 & & 1 & 7 & & & & 63 \\
\hline Sin datos BT & 1 & 2 & & & & & 2 & & 1 & 6 \\
\hline
\end{tabular}




\begin{tabular}{|l|c|c|c|c|c|c|c|c|c|c|}
\hline & $\begin{array}{c}\text { colan- } \\
\text { gitis }\end{array}$ & $\begin{array}{c}\text { pancrea- } \\
\text { titis }\end{array}$ & $\begin{array}{c}\text { icteri- } \\
\text { cias }\end{array}$ & dolor & $\begin{array}{c}\text { Bard y } \\
\text { Pick }\end{array}$ & $\begin{array}{c}\text { sepsis } \\
\text { biliar }\end{array}$ & $\begin{array}{c}\text { litiasis } \\
\text { por eco }\end{array}$ & $\begin{array}{c}\text { preop } \\
\text { colelap }\end{array}$ & $\begin{array}{c}\text { sin } \\
\text { datos }\end{array}$ & Total \\
\hline $\begin{array}{l}\text { Sin dato VB } \\
\text { por eco } \\
\text { BT <2 }\end{array}$ & 1 & 2 & 1 & & & & & & & \\
\hline $\begin{array}{l}\text { Sin dato VB } \\
\text { por eco } \\
\text { BT >2 }\end{array}$ & 3 & & & & & 1 & & & 3 & 7 \\
\hline & 118 & 31 & 15 & 6 & 1 & 8 & 3 & 1 & 6 & 189 \\
\hline
\end{tabular}

2 pacientes fueron estudiados con colangioresonancia previa a la CER: en uno existía sospecha de microcálculo coledociano, no corroborado posteriormente luego de la papilotomia y exploración de la vía biliar, y en otro informada como normal, coincidente con una CER diagnóstica posterior. Ambos pacientes dados de alta a las 24 y 48 horas. Una de ellas reingresó para colecistectomía laparoscópica 2 meses después, con buena evolución. El otro paciente no tenía cálculos en la vesícula, se controló en policlínica.

\section{Hallazgos endoscópicos en pacientes con vesícula in situ}

Al 98,5\% de pacientes fue posible ingresar a la vía biliar (186 pacientes). En 3 pacientes (1.5\%) no ingresamos a la vía biliar: en 2 de los casos por inyección submucosa de contraste seguido de intento de precorte con rezumamiento de sangre controlado con inyección de adrenalina diluida, en que si bien se planteó una segunda oportunidad de CER diferida, los cirujanos de guardia prefirieron realizar la colecistectomía, en un caso inmediatamente posterior al fracaso de la CER en sala de operaciones (colecistectomía abierta y coledocoduodenostomia) y al otro paciente el día siguiente (colecistectomía abierta y coledocolitotomia sobre Kehr), ambos con buena evolución y alta días después. El tercer paciente, mujer de 72 años que había tenido una colangitis leve que retrocedió con tratamiento médico y en quién la ecografía mostraba un cálculo de $16 \mathrm{~mm}$, pero totalmente asintomática al momento de la CER, ni intentamos canular la vía biliar al reconocer el ostium de la papila en el fondo mismo de un profundo divertículo duodenal, papila de Vater por otra parte pequeña, cuya apertura sea por papilotomia con o sin papiloesfinteroplastia comportaba mayor riesgo y potenciales complicaciones insospechadas por el cirujano referente, la paciente y sus familiares, quienes tenían la expectativa de un procedimiento sencillo seguido del alta. Fue operada días después (colecistectomía, coledocolitotomia sobre Kehr) falleciendo en el postoperatorio (hematoma retroperitoneal, derrame pleural, accidente vascular). Sumando un 4으 paciente al que no fue posible avanzar una prótesis (como drenaje biliar interno paliativo) por el costado de un voluminoso cálculo de $40 \mathrm{~mm}$ en ambiente común colecistocoledociano, representan $2.1 \%$ de fracasos en la población estudiada. A este último paciente se le realizó una coledocoduodenostomia con buena evolución y alta al 160 día.

En los pacientes que se ingresó a la vía biliar (189 procedimientos), en 86 la vía biliar estaba dilatada $(45,5 \%)$ y en 103 no (54,5\%), considerando el limite en $8 \mathrm{~mm}$ de diámetro, siempre en relación al diámetro del duodenoscopio utilizado vistos en la pantalla de radioscopia.

66 pacientes no tenían cálculos (34,9\%), realizando la CER diagnóstica por el ostium en 23 pacientes (34.8\%) y a través de precortes o infundibulotomias, papilotomias, orificios fistulosos (generados por migraciones espontáneas de cálculos), papilotomias previas, en 43 pacientes $(65,1 \%)$. En todos estos últimos casos la maniobra de CER fue seguida de exploración con Dormia o balón extractor, que certificó ausencia de cálculos o barro biliar. 
De los 123 pacientes restantes, en 3 no ingresamos a la vía biliar (tenían cálculos corroborados al ser operados y ya fueron analizados) por lo que falta analizar 120 pacientes. En uno de ellos hicimos referencia del fracaso al intentar colocar una prótesis por el costado de un cálculo de $40 \mathrm{~mm}$ que no lo permitió.

Quedan 119 pacientes con presencia de cálculos en la VBP para el análisis. En 113 se logró extraer la totalidad de los cálculos representando 94.5\% de éxito del tratamiento endoscópico. En los 6 restantes dejamos colocado un drenaje biliar interno (prótesis plásticas), sea por cálculos grandes, múltiples o engarzados que no permitían el despliegue de una Dormia, sea por cálculos encima de estenosis biliares, cálculo grande en paciente cursando colangitis séptica y síndrome de Mirizzi. Este último caso tratado en forma transitoria con prótesis por ser de alto riesgo, en que la recambiamos cuando se obstruía.

La extracción de cálculos preferentemente se realizó en la gran mayoría de pacientes con cestillas Dormias de diferentes tamaños. En menor proporción con balones extractores de $8.5 \mathrm{~mm}$ a $15 \mathrm{~mm}$ de diámetro pasados sobre guía. Litotricias mecánicas se realizaron en 8 pacientes (6.72\%) y papiloesfinteroplastia con balón de altas presiones asociadas siempre a papilotomia en 6 pacientes (5\%).

En 14 pacientes (11.7\%) se constató un cálculo impactado en la papila de Vater, resueltos con precortes solamente cuando era el único cálculo o asociando ampliación de papilotomia para extraer otros cálculos presentes en la vía biliar y que por su tamaño no salían por el precorte.

Esta población de pacientes constituye el grupo potencial de colecistectomía a posteriori, de acuerdo al riesgo quirúrgico y conducta decidida por el cirujano. En esta población, de solucionarse la litiasis de la VBP por endoscopia y evolucionar sin complicaciones, la técnica a realizar en principio será la colecistectomía exclusivamente. En cambio, si por el tamaño y número de cálculos presentes, no es posible la solución por CER, el cirujano deberá resolver en un mismo acto la colecistectomía y explorar la vía biliar sea por vía transcística o por coledocolitotomia o realizar una técnica combinada con el endoscopista en casos en que el paciente no pudo resolverse en el preoperatorio por CER, pero ésta puede que si sea exitosa con el pasaje de una guía por parte del cirujano ("rendez vous").

En nuestra experiencia, en aquellos pacientes con cálculos, surge que pudimos extraerlos en el $94,5 \%$ de casos. En el restante dejamos colocado un drenaje biliar interno.

Fracasamos en $2,1 \%$. Este porcentaje podría ser menor si en aquellos pacientes operados luego de un solo intento fallido de CER, hubiéramos tenido éxito en una segunda sesión, planteo teórico, no significativo.

Aquellos pacientes con clínica de obstrucción biliar mantenida en que se sospecha o se confirma por estudios de imagen, que hay un cálculo impactado en la papila de Vater, por lo general son fácilmente resueltos por endoscopía, facilitando la colecistectomía posterior, habida cuenta que el abordaje laparoscópico fracasa habitualmente en los intentos de extracción del cálculo impactado y el abordaje abierto comporta una duodenotomia y papiloesfinteroplastia, aumentando los riesgos de la cirugía. En esta casuística, incluyó 14 pacientes (11.7\%)

Igualmente cuando la vía biliar no está dilatada y existen cálculos en su interior, la solución por CER con papilotomía, previa a la colecistectomía, evitará maniobras quirúrgicas transcísticas, más difíciles en vías biliares finas, que de fracasar, obligaría a la realización de una coledocotomía que siempre se intenta evitar por conllevar mayor riesgo de estenosis biliar (en cirugía laparoscópica o abierta) o realizar papiloesfinteroplastia anterógrada con balón intraoperatoria como recomienda el Dr.Maglione (referenciado por el Dr.Salom) o por último dejar un drenaje transcístico para ulterior solución postoperatoria por algunas de las opciones disponibles. El 54.5\% de los pacientes integraban este grupo.

En casos de colangitis graves o sepsis biliar está particularmente indicado el tratamiento por CER con papilotomia y extracción de cálculos previos a la colecistectomia. Incluso puede enviarse una muestra de bilis o pus extraído del interior de la vía biliar para cultivo y antibioticograma y así poder dirigir con 
precisión el tratamiento antibiótico. Afectó a 8 pacientes (6.7\% de los pacientes con cálculos, 4,2\% en la muestra global de pacientes con vesícula in situ).

Si no se pueden extraer los cálculos de la VBP por endoscopia, paliativamente alcanza con dejar colocado un drenaje biliar interno (prótesis) o externo (drenaje nasobiliar) para degravitar la vía biliar. Este tratamiento endoscópico asociado a la antibioticoterapia y demás medidas de reposición, permitirá encarar posteriormente la colecistectomía en un paciente repuesto y con mejor riesgo anestésico quirúrgico. En 6 pacientes (5\%) se dejó drenada la vía biliar con una prótesis plástica, fracasando este intento en 1 paciente por las dimensiones del cálculo en ambiente común.

Los pacientes sin cálculos en la VBP fueron 66 (34,9\%). Considerando el rol actual de la CER que es terapéutico (no diagnóstico), representa un porcentaje elevado. Cabe preguntarse si no ha sido excesivo el envío de pacientes a explorar la VBP por CER antes de la colecistectomía. En aquellos pacientes con argumentos clínicos y paraclínicos de alta sospecha de litiasis en la VBP y mantenido con el paso de las horas o días previos a la CER, ésta encuentra indicación porque seguramente se comprueba la obstrucción litiásica y puede resolverse en la mayoría de pacientes. Pero del estudio de esta población surge que, en algunos pacientes, durante la espera de la CER, la clínica y paraclínica mejoró rápidamente, por lo que parece razonable plantear una posible resolución espontánea (migración litiásica). Coincidiendo que posteriormente el resultado de la CER fue normal, cabe preguntarse y recomendar si existe suficiente experiencia proceder a la colecistectomía con colangiografia intraoperatoria, y actuar en consecuencia, sin CER previa. Si no tiene cálculos, clipado o ligadura del cístico, fin de la intervención. Tiene cálculos: intentar la extracción transcística de preferencia, o hacer la papiloesfinteroplastia anterógrada con balón, pero si fracasa dejar un drenaje transcístico o proceder a la coledocolitotomia en vía biliar dilatada o en un escenario ideal contar con CER intraoperatoria para la extracción endoscópica con o sin "rendez vous".

Otros pacientes no presentaban ese sustento clínico y paraclinico, por lo que no estaba indicada la CER, cuyo resultado final (ausencia de litiasis en VBP) lo corrobora. Directamente pudieron ir a cirugía, sin estudio previo de la VBP. $O$ en última instancia solicitar una colangioresonancia, que no tiene los riesgos de una CER diagnóstica, que en el mejor de los casos pasa por un único intento de canulación del ostium papilar, directo a la vía biliar, pero en muchos pacientes implica ser aún más invasivo a través del acceso a la vía biliar realizando precortes (2/3 partes del acceso a la vía biliar en pacientes sin cálculos fueron por esta vía, con o sin ingresos previos indeseados el Wirsung, sea con guía sola o con contraste). Incluso hay casos que lograda la CER, se generan dudas de la existencia de cálculos en la VBP, sea por radioscopia o radiografías que no sean de buena definición, o porque hay aerobilia que confunde. En estos casos, que no podemos dilucidar a pesar de cambios posturales al paciente, obteniendo imágenes en distintas proyecciones, y persisten dudas, para tener certeza procedemos a explorar la VBP con Dormia o balón extractor previa papilotomia, agregando potencial morbilidad propia.

Posiblemente la solicitud de CER directamente puede deberse por un lado a la falta de disponibilidad o costos de la colangioresonancia, o a no ofrecer estudios de buena calidad de imágenes, en comparación con una CER de rápida disponibilidad, alto porcentaje de efectividad y que se acompañe de mínima morbilidad. Tal es la explicación (cuando le hacemos mención a evitar una CER diagnóstica dentro de lo posible) de muchos cirujanos con quienes trabajamos desde hace años en los mismos lugares y seguimos en conjunto la evolución de los pacientes.

Más adelante, en resultados y complicaciones de esta población a quienes realizamos CER con o sin papilotomia, puede encontrarse la justificación, pero no corresponde generalizar la conducta, desde que los estudios multicéntricos (donde se incluyen experiencias variadas en CER, con endoscopistas de poco, mediano y alto volumen de pacientes) informan mayor morbimortalidad de la técnica. En nuestra casuística, correspondiendo al alto volumen de pacientes y 20 años de experiencia, nos permite ofrecer elevado porcentaje de éxito y baja morbimortalidad, de acuerdo a los resultados de esta casuística. Aún 
así, nunca tendremos morbilidad cero y mortalidad cero, pues en el volumen aparecen siempre complicaciones, y a medida que intentamos resolver casos más difíciles, también.

Asi como se aplica un criterio selectivo, para definir si se hace o no una colangiografia intraoperatoria $(\mathrm{ClO})$ durante la colecistectomia, como explica el Dr. Salom en su casuística (realizaron $\mathrm{ClO}$ en $31 \%$ de pacientes operados por colecistitis aguda y en $27 \%$ de pacientes no agudos), hay que seleccionar muy bien que pacientes se verán beneficiados de una CER preoperatoria. Queda claro que esta población con CER normal en el preoperatorio inmediato de la colecistectomía, son candidatos a la colecistectomía de preferencia laparoscópica, sin colangiografia intraoperatoria, facilitando o simplificando la técnica quirúrgica.

\section{Complicaciones de la CER y seguimiento}

El seguimiento de esta población pudo lograrse en 139 pacientes que representan el 73,5 \% del grupo (189 pacientes).

Hemorragia sin traducción clínica, en 2 pacientes a los que se le realizó precorte, diagnosticada y tratada inmediatamente intraprocedimiento con inyección submucosa de adrenalina diluida 1/20000 en forma exitosa, sin necesidad de reposición ni tratamiento adicional.

Perforación no hubo comprobada durante las CER ni en el seguimiento.

No hubo pancreatitis en este grupo, no influyendo el haber ingresado al Wirsung, ni la realización de precorte, o papiloesfinteroplastia para extraer cálculos grandes o múltiples.

El precorte lo realizamos en forma precoz, para evitar seguir generando estímulos o agresiones al páncreas, por repetidos ingresos al Wirsung, con la intención de disminuir la aparición de pancreatitis.

Del grupo que se logró seguimiento,106 se operaron.

Posterior a la CER y en la misma internación se realizó colecistectomía laparoscópica a 64 pacientes. El alta promedialmente se otorgó a la semana (ingreso, CER, colecistectomía laparoscópica), habiendo casos de egresos a las 48 horas con ambas intervenciones.

10 pacientes se fueron de alta inmediatamente luego de la CER, reingresando en diferido (promedio 3 a 4 meses) para la colecistectomía laparoscópica.

El alta varió desde 48 horas hasta 32 días, no hubo complicaciones relacionadas directamente a la cirugía.

3 pacientes se convirtieron, uno por fistula colecistogástrica con apertura del hepático común, otro por litiasis coledociana procediéndose a la coledocolitotomia sobre Kehr, otorgándose alta a los 12 días pero reingresando para nueva CER y extracción de cálculos residuales evidenciados en colangiografia postoperatoria por el Kehr y un tercer paciente por hemorragia durante la disección.

Colecistectomias abiertas se realizaron a 29 pacientes, de las cuales 24 se realizaron en la misma internación, otorgándose el alta promedialmente 12 a 15 días después. Cuando se asoció otra intervención (quiste hidático hepático) la internación duró 37 días.

5 pacientes reingresaron a los 3 meses luego de la CER para colecistectomía abierta.

El paciente con prótesis en síndrome de Mirizzi, fue operado (colecistectomía y coledocoduodenostomia) con buena evolución, al igual que otro paciente con prótesis por estenosis biliar asociada a litiasis, en quién se realizó la colecistectomía y coledocolitotomia sobre un Kehr.

33 pacientes fueron dados de alta sin operar hasta el momento de la revisión, aunque algunos estaban en valoración preoperatoria, dilatada por el alto riesgo quirúrgico. Casi todos pacientes mayores de 80 años. 


\section{CER en pacientes con antecedentes de colecistectomia}

Pacientes colecistectomizados fueron 125. Comprende dos subgrupos, uno integrado por 58 pacientes $(46,4 \%)$ atendidos en el post-operatorio inmediato antes del alta, o diferidamente luego del alta pero que reingresaron por sospecha o confirmación clínica y paraclínica de obstrucción biliar, considerando hasta 2 años de la colecistectomía (laparoscópica, convertida o abierta). El otro subgrupo, de 67 pacientes $(53,6 \%)$ a los que se les realizó CER más allá de los 2 años de la colecistectomía.

En el primer subgrupo, de 58 pacientes, a 2 pacientes pudimos extraerles los cálculos por vía incruenta con la técnica Mazzariello, evitando la CER, ya que cumplían los plazos de maduración del trayecto para la realización de la instrumentación transfistular.

A los restantes 56 pacientes se le realizaron en total 59 CER, pues a 3 de ellos le realizamos la extracción de todos los cálculos en 2 sesiones, una primera para extraer los cálculos residuales por debajo del Kehr y en otra sesión diferida (en plazo suficiente para poder extraer el Kehr), se extrajeron los situados en la vía biliar proximal al Kehr.

Otros 16 pacientes tenían drenaje biliar externo (9 Kehr y 7 transcísticos) y se les realizó CER. De los pacientes con Kehr, 7 tenian cálculo único (uno de ellos grande que requirió litotricia mecánica y 5 de los casos eran cálculos menores de $10 \mathrm{~mm}$ ). Otro paciente tenia 2 cálculos y 1 con empedrado.

Los pacientes con transcisticos, 6 tenían litiasis única, 1 paciente tenia 3 cálculos.

El alta luego de la CER se realizó 48 horas después.

Realizar la CER con papilotomía el mismo día de la intervención, al día siguiente de la cirugía, o no bien pueda coordinarse, acorta los plazos para la solución de la litiasis de la VBP y el alta más rápida. Siempre que tenga éxito y evolucione sin complicaciones, por lo que resulta muy importante conocer la experiencia y resultados del responsable en llevar adelante la intervención endoscópica como en cualquier otra técnica por mini-invasiva que parezca.

A 42 pacientes (75\%) se le encontraron cálculos, únicos y pequeños en la mayoría. Algunos quedaron con empedrados y cálculos grandes, a pesar de la coledocolitotomia abierta sobre Kehr. La extracción fue exitosa por vía de una papilotomia estándar, o ingresando con precorte, luego ampliado, asociando papiloesfinteroplastia con balón si las dimensiones de los cálculos hacían preveer dificultad para ser extraídos. En tal sentido 1 solo paciente, de 80 años, requirió de litotricia con Dormia (utilizando el litotriptor de Soehendra), por su tamaño y consistencia estando la papila en 3er porción,en el postoperatorio ya que no se pudo extraer el cálculo por coledocotomia, dejándose un Kehr. Presentó buena evolución.

Existieron pacientes con y sin colangiografia intraoperatoria, incluso con diagnóstico de varios cálculos coledocianos, a los que se le clipó el cístico, confiando el cirujano en la solución por intermedio de una CER. 6 de ellos fueron colecistectomias laparoscópicas convertidas que quedaron con litiasis en la vía biliar.

Del punto de vista endoscópico no se afectó el éxito de ingreso a la vía biliar por encontrar papilas de Vater en relación a un divertículo duodenal. En casos difíciles recurrimos al pasaje de guías por los drenajes biliares externos, realizando cateterismos guiados anterógrados de la vía biliar.

Para el cirujano, colocar un drenaje biliar externo, significa mayor dificultad técnica y prolongar la cirugía. Además existe el riesgo de salida accidental del drenaje, con fuga biliar y biliperitoneo, obligando a reintervenciones o tratamientos complementarios. Por eso muchos cirujanos prefieren no dejar un drenaje biliar externo, aun cuando sepan que quedaron cálculos por los hallazgos de la colangiografia intraoperatoria y fallaron en su extracción. Puede confiarse en la eliminación espontánea hacia el duodeno en aquellos casos de microlitiasis en que se comprueba buen pasaje de contraste al duodeno o en la efectividad del endoscopista que realizará la CER con papilotomia. 
Pero la presencia de un drenaje biliar (como se explicó en el capítulo correspondiente) es de ayuda al endoscopista para resolver el caso en ciertas situaciones dificiles para cateterizar la papila de Vater, pasando una guía por el drenaje hacia el duodeno al realizar la CER en el post-operatorio. Hay veces que se intenta pasar una guía por el drenaje, sin éxito (Nelaton con punta roma, demasiado ajustada a la salida de la vía biliar con luz demasiado estrecha), y la CER no es posible técnicamente (fracaso). En tal caso, cabe aguardar las 6 semanas para extraer el drenaje y proceder con la extracción incruenta por el trayecto o combinar técnicas, configurando el "rendez vous". Una sonda Nelaton puede empujarse hacia el colédoco distal, para que sobrepase la papila hacia el duodeno. Por endoscopia, al observar directamente la sonda, permite dirigir un precorte encima de ella, la que "marca" la línea de corte, facilitando el ingreso a la vía biliar, para extraer luego el o los cálculos.

12 pacientes $(21,4 \%)$ no tenían cálculos en la CER, observando el relleno de la vía biliar con contraste (simplemente diagnóstico) o habiendo explorado la vía biliar luego de precorte o papilotomia, con Dormias o balón extractor. En estos pacientes se supuso una posible migración espontánea de litiasis por el aspecto de la papila de Vater con ostium amplio, deflecado, edematosa, con estrías hemáticas o a veces presentando orificio fistuloso o papilotomias previas.

A 1 de ellos, paciente de 67 años, portador de un shock séptico mantenido, que 5 días antes se realizó la colecistectomía convencional con colangiografia intraoperatoria normal, se sospechó litiasis residual (Bilirrubina total de $2.5 \mathrm{mg} \%, 2.4$ de directa, fosfatasa alcalina normal), que fue descartada por la CER. Falleció días después a consecuencia de múltiples perforaciones del intestino delgado constatadas durante la laparotomía por peritonitis manifiesta.

A 2 pacientes se le colocó una prótesis plástica: a uno por asociar un neoplasma de papila al que posteriormente se le realizó una duodenopancreatectomia cefálica con buena evolución, y otro por asociar una estenosis biliar postquirúrgica.

Al 100\% de los pacientes fue posible ingresar a la vía biliar y extraer los cálculos o para descartar la existencia de los mismos. Es decir no hubo fracasos en este subgrupo.

En este subgrupo hubo una pancreatitis secundaria a la CER, con amilasemia de 4600 unidades que requirió tratamiento médico (sin cirugía) e internación por 15 días. Se trataba de un joven de 20 años, que asociaba una herida de vía biliar reparada sobre un Kehr 4 meses antes y en una colangiografia de control por el Kehr se observaron 3 cálculos distales. Se realizó papilotomia y extracción, luego de un único ingreso previo al Wirsung con la guía, sin inyección de contraste.

En otro paciente fue necesaria la inyección de adrenalina diluida 1/20000 para hemostasis de un sangrado leve por la papilotomia, maniobra hemostática que resultó suficiente.

En el segundo subgrupo, se asistieron 67 pacientes a los que en total se realizaron 71 CER, ya que en un paciente requirió de 3 CER por presencia de cálculos múltiples y grandes, hasta resolver el caso, luego de papilotomia asociada a papiloesfinteroplastia con balón y drenaje biliar interno (prótesis) transitoria, y otros 2 pacientes requirieron de 2 sesiones.

A 42 pacientes $(62,6 \%)$ se le extrajeron los cálculos, en 17 no se encontró cálculos $(25,3 \%)$, en 7 se pusieron prótesis $(10,4 \%)$ por cálculos grandes (uno de ellos cursando sepsis biliar con tiempo de protrombina de $40 \%$ y plaquetopenia teniendo contraindicada la papilotomia, se logró dejar colocada la prótesis sin ella, ingresando la guía por el ostium).

Hubo 1 fracaso de extracción de cálculo asociado a estenosis post-quirúrgica muy estrecha, secuela de una herida de vía biliar reparada 4 años antes, que no dejó pasar la guía para dejar una prótesis o la Dormia para extraerlo. Se operó (coledocoduodenostomia) con buena evolución, alta al 160 día.

También al 100\% de pacientes fue posible ingresar a la vía biliar sea para extraer los cálculos o descartar litiasis o dejar una prótesis como tratamiento paliativo. 
Destacamos 1 paciente de 84 años, colecistectomizado por vía abierta 6 años antes, procedente del Hospital de Canelones que tenía 4 intentos fallidos de CER por colangitis, por lo que frente a un nuevo episodio, decidieron derivarlo al Centro de Cirugia endoscópica interdisciplinario, del Departamento de Cirugía del Hospital Policial, donde constatamos 2 cálculos de $15 \mathrm{~mm}$, extraídos previa papilotomia asociada a papiloesfinteroplastia con balón de $15 \mathrm{~mm}$ de diámetro.

Como complicación: un sangrado postpapilotomia, controlado con inyección local de adrenalina diluida.

Seguimiento de los pacientes colecistectomizados se realizó a 85 pacientes (68\%).

\section{CER intraoperatoria}

En 3 pacientes se realizó la técnica en el intraoperatorio, en 2 de ellos en forma programada por el cirujano por alta probabilidad de encontrar cálculos en la VBP, que efectivamente tenían y se extrajeron por endoscopía. En otro caso, mientras realizábamos una CER con colocación de prótesis transtumoral en sala de operaciones, nos convocaron de la sala de al lado, donde el cirujano intentaba encontrar la vía biliar operando una peritonitis biliar a 1 mes de la colecistectomía convencional. Constatamos un cálculo impactado y otros más arriba en la vía biliar no dilatada que salieron con Dormia previa papilotomia y además hicimos diagnóstico de sección del hepático posterior derecho, pues no se contrastaban los segmentos VI y VII en la CER y además no había fuga de contraste.

Salvo este caso complicado, los otros 2 pacientes se fueron de alta a las 48 horas.

La disponibilidad de endoscopía intraoperatoria es de gran valor en algunas situaciones para poder resolver la patología en un solo tiempo, cuando no se pudo extraer la litiasis quirúrgicamente. Pero salvo que se programe la presencia del endoscopista durante la colecistectomía, resulta difícil poder acceder a esta herramienta en forma generalizada en cada lugar de trabajo, hasta que existan suficientes endoscopistas expertos en la técnica, entre ellos cirujanos del equipo, y que se disponga de la tecnología necesaria. Mientras esto no acontezca, seguramente el perfeccionamiento técnico continuo del cirujano para resolver la situación en el intraoperatorio asociado a la conducta de dejar un drenaje biliar externo como recurso, para que en una segunda instancia pueda resolverse la presencia de cálculos en la vía biliar con algunas de las opciones ya expuestas, serán las mejores opciones disponibles.

\section{Fallecidos}

Del total de pacientes con seguimiento, fueron 4:

1) un paciente de 88 años, portador de litiasis vesicular múltiple y colangitis, a quién se le realizó una CER con papilotomia y extracción de varios cálculos menores de $10 \mathrm{~mm}$, en un procedimiento breve, presentó descompensación cardiorespiratoria brusca en las siguientes 24 horas.

2) una paciente de 89 años, con barro biliar en la vesícula y colangitis, se le extrajo sin incidentes un cálculo de $10 \mathrm{~mm}$, falleciendo 16 días después, por cuadró séptico peritoneal, constando en la historia clínica la expulsión de materia fecal por la vagina.

3) el paciente de 67 años, con shock séptico y múltiples perforaciones de delgado

4) la paciente de 72 años, a quién no le hicimos la CER por la papila de Vater en el fondo de divertículo, estando asintomática, y luego de la colecistectomía y coledocolitotomía, se complicó presentando hematoma retroperitoneal, derrame pleural y accidente vascular encefálico. 


\section{Capítulo 8}

\section{ALGORITMO DE TRATAMIENTO \\ Dres. Andrés Salom y Alvaro Piazze}

\section{Litiasis vesicular}

En la litiasis vesicular sintomática, la colecistectomía laparoscópica, es el tratamiento de elección y está destinado a tratar los síntomas y evitar la aparición de complicaciones. indica en:

En la litiasis vesicular asintomática, la colecistectomía laparoscópica, con criterio profiláctico, se

- niños y pacientes jóvenes

- vesícula en porcelana

- pacientes obesos

- pacientes con anemia de células falciformes

- en pacientes en lista de espera para trasplante de órganos sólidos

En la litiasis vesicular complicada:

- colecistítis aguda.

La colecistectomía laparoscópica se indica en la mayoría de los cuadros de colecistitis aguda. En algunos cuadros muy evolucionados o en pacientes muy graves se indica la colecistostomía, de elección por vía percutánea o por laparotomía.

- pancreatítis aguda de causa biliar, una vez que la enfermedad está en remisión y generalmente antes del alta del paciente, se indica la realización de la colecistectomía laparoscópica de elección.

- litiasis de la vía biliar principal (VBP)

Se debe realizar el tratamiento integral de litiasis biliar, mediante la realización de la colecistectomía, exploración y extracción de la litiasis de la VBP.

Actualmente proponemos el siguiente algoritmo de tratamiento de la litiasis de la VBP, basado en los siguientes elementos: 
- edad y estado biológico del paciente con respecto a enfermedades asociadas y al riesgo quirúrgico.

- cuadro clínico de la enfermedad: coledocolitiasis, colangitis aguda o séptica, pancreatitis.

- características anatómicas de la vía biliar: dilatada o no, colecistectomizado o no.

- experiencia e infraestructura con que cuenta el equipo quirúrgico tratante de cada centro asistencial: equipo de laparoscopía, sondas Dormia con canal operador, arco en C, endoscopistas con experiencia en VB.

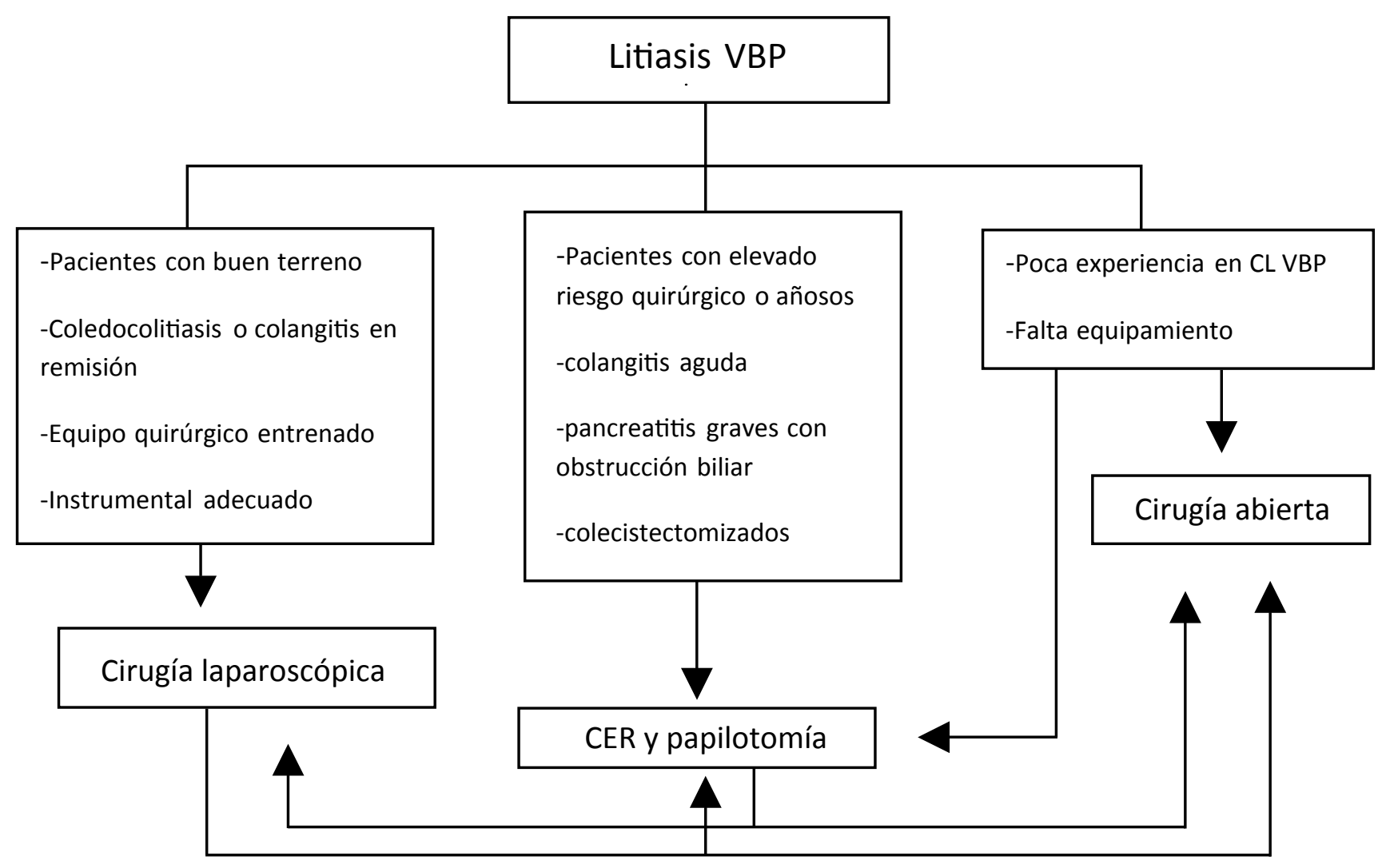

Figura 1

Basándonos en la bibliografía consultada y en nuestra experiencia, pensamos que en pacientes con buen estado general, no añosos, con cuadros no graves, con colangitis en remisión si el equipo quirúrgico tiene experiencia y entrenamiento en cirugía laparoscópica y cuenta con el instrumental adecuado; es posible tratar estos pacientes en un tiempo y resolver su patología litiásica en forma integral, por vía laparoscópica, realizándose la misma táctica quirúrgica que realizamos en cirugía abierta.

De elección intentamos realizar la extracción de los cálculos por vía transcística mediante la utilización de una canastilla de Dormia, bajo visión con arco en C. También es posible realizar una papiloesfinteroplastia anterógrada con un catéter vascular de angioplastia y el barrido por arrastre de los cálculos.

Otra opción válida es la de realizar la extracción de los cálculos por vía endoscópica intraoperatoria (rendez-vous).

Frente a la presencia de una VB no dilatada, con un colédoco menor de $7 \mathrm{~mm}$, y ante la imposibilidad de extraer los cálculos por vía transcística y no contar con endoscopía intraoperatoria, es conveniente realizar la extracción de la litiasis en el postoperatorio por vía endoscópica, pudiéndose dejar 
de preferencia, un drenaje transcístico, con sección de la punta para facilitar el pasaje de una guía para identificar la papila, especialmente en situaciones anatómicas adversas, lográndose de esta forma casi el $100 \%$ re resultados exitosos.

La conversión a laparotomía en estas situaciones generalmente no nos permite resolver la situación, y pensamos que no se debe realizar una coledocotomía para no exponer al paciente a que pueda presentar una complicación grave, como es la estenosis cicatrizal de la VBP.

Cuando el colédoco tiene un calibre mayor y hay una litiasis coledociana múltiple, creemos que puede intentarse en primera instancia la vía transcística; pero puede practicarse sin inconvenientes la extracción de los cálculos por coledocotomía laparoscópica.

Cuando no es posible resolver el caso por laparoscopía, debido a las siguientes causas: los tiempos quirúrgicos se prolongan de manera desmedida; hay una panlitiasis; existen alteraciones inflamatorias muy importantes con anatomía del pedículo hepático poco clara, creemos que la conversión a laparotomía no es una complicación, sino un signo de madurez, experiencia y buen criterio del equipo quirúrgico tratante, resolviéndose la enfermedad por cirugía abierta y en un tiempo.

No se debe perder de vista que el objetivo final es dejar al paciente libre de enfermedad con la menor morbimortalidad.

En la medida que la conversión se realiza de forma electiva, no forzada, se obtendrán los mejores resultados.

Cuando el equipo quirúrgico no tiene el entrenamiento adecuado en cirugía laparoscópica de la vía biliar principal y no cuenta con el instrumental adecuado, pensamos que no se deben operar a estos pacientes por laparoscopía y es más segura la vía abierta.

Otra opción, es realizar la extracción de los cálculos por vía endoscópica en el preoperatorio y luego realizar la colecistectomía laparoscópica, sobre todo cuando en los centros asistenciales donde hay endoscopistas con experiencia en vía biliar, y/o cirujanos con poca experiencia en el manejo por laparoscopía de la VBP, o no se cuenta con todo el instrumental necesario.

En pacientes con mal terreno, añosos, y/o cursando cuadros de colangitis o pancreatitis graves con obstrucción biliar, se debe indicar la extracción por vía endoscópica de los cálculos a través de una papilotomía, dada la elevada mortalidad de la cirugía y teniéndose en cuenta que en estos casos la prioridad es desobstruir la VBP.

Cuando estamos frente a un cuadro clínico de colangitis aguda que no remite, con valores de bilirrubinemia elevados, debemos sospechar la presencia de un cálculo enclavado en la papila. Esta es una situación compleja y difícil de solucionar, siendo el tratamiento por vía endoscópica de elección.

También proponemos que se indique la vía endoscópica en pacientes colecistectomizados. Se debe descartar la presencia de una panlitiasis, litiasis coledociana primitiva, megacolédocos y las estenosis vinculadas a enfermedades de la papila, en cuyo caso podría estar indicada la realización de operaciones de derivación biliodigestivas.

La colangioresonancia es actualmente el estudio diagnóstico de elección que debe solicitarse.

Gran proporción de estos pacientes pueden ser tratados exitosamente por vía endoscópica, particularmente indicada en pacientes añosos o con elevado riesgo quirúrgico, con baja morbimortalidad

En pacientes con un riesgo quirúrgico aceptable, que presenta un colédoco mayor de $2 \mathrm{~cm}$, una panlitiasis, una estenosis, o una enfermedad de la papila, puede realizarse una derivación biliodigestiva, de preferencia una coledocodudenostomía laterolateral.

No tenemos experiencia, ni hay datos en la bibliografía, que nos permitan plantear como método de elección, la realización de una derivación biliodigestiva por laparoscopía. 


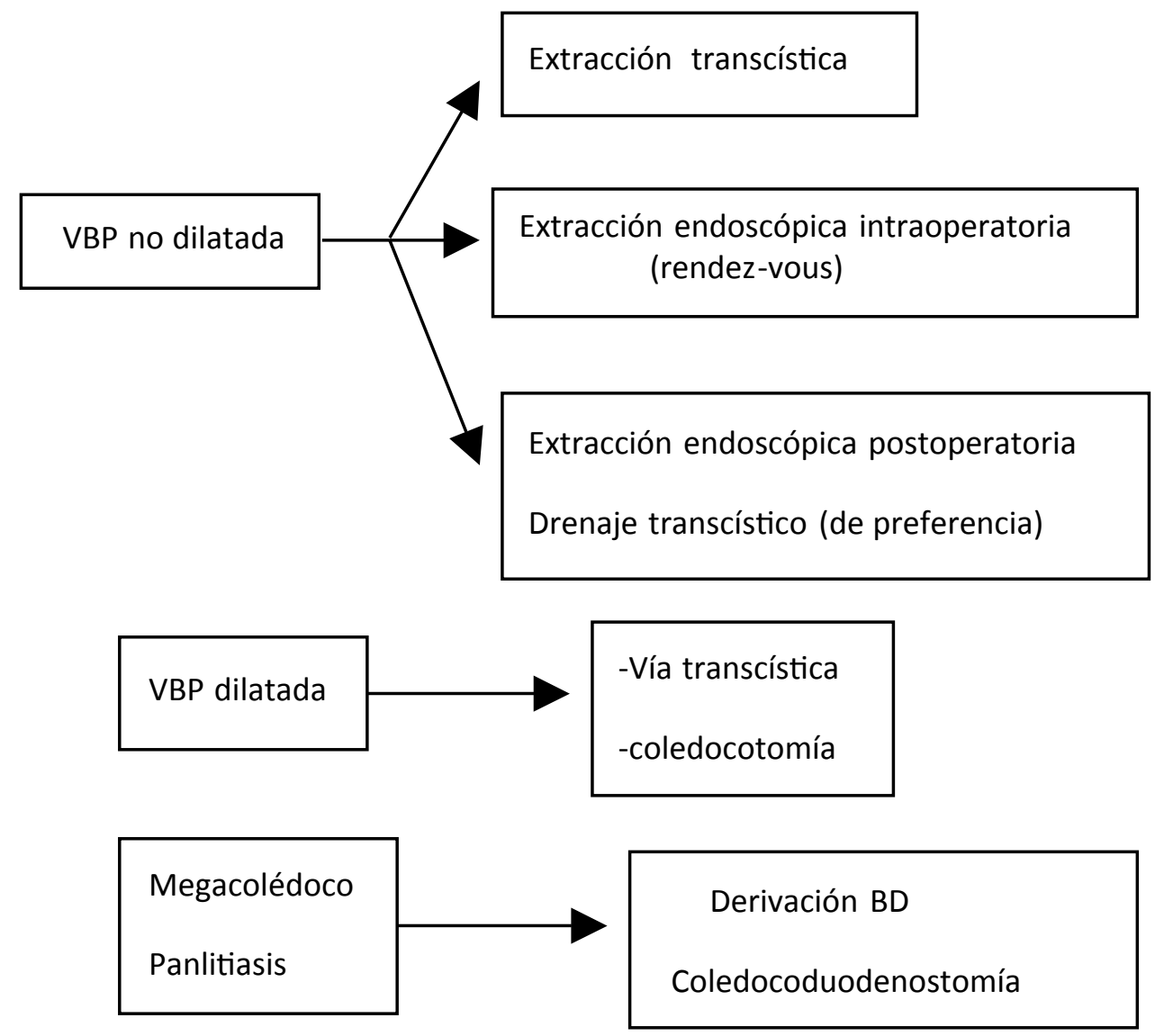

Figura 2

\section{Conclusiones}

1) En los pacientes portadores de una enfermedad litiásica de la vía biliar, el tratamiento quirúrgico mínimamente invasivo, por vía laparoscópica y/o endoscópica y en algunos casos percutáneo, es actualmente el de elección.

2) La cirugía abierta todavía continúa teniendo un lugar en la terapéutica, en las formas complicadas en las que existe una distorsión muy marcada de la anatomía biliar y hay gran friabilidad de los tejidos; cuando se debe resolver al paciente en un solo acto quirúrgico; en los centros que no se cuenta con la infraestructura y experiencia necesaria por vía laparoscópica y endoscópica; y en los casos en que es necesaria realizar la conversión por complicaciones.

3) El equipo médico que realiza el tratamiento de estos pacientes, debe estar capacitado para poder utilizar las diferentes vías de abordaje y tratamiento (laparoscopía, laparotomía, endoscópico y percutáneo), solas o combinadas, de manera de poder elegir y seleccionar en cada caso, la forma más eficaz, segura y que tenga la menor morbilidad y mortalidad.

4) La colecistectomía laparoscópica es el tratamiento quirúrgico de elección de la litiasis vesicular y se indica en los pacientes con: litiasis vesicular sintomática, casos seleccionados de pacientes asintomáticos y en las formas complicadas con colecistitis aguda, pancreatitis aguda de causa biliar y litiasis de la VBP.

5) El tratamiento por laparoscopía de la litiasis de la VBP es técnicamente posible con buenas condiciones de seguridad, cuando es realizado por un equipo quirúrgico con experiencia y entrenamiento en cirugía laparoscópica, y tiene como ventajas la menor morbilidad parietal, lo que condiciona menor dolor postoperatorio y una recuperación más rápida de los pacientes. 
6) La extracción de los cálculos puede realizarse por vía transcística o por coledocotomía, siendo a nuestro criterio cuando la situación es la indicada, la vía transcística la primera elección.

7) El tratamiento de la litiasis VBP por vía endoscópica se indica: en pacientes colecistectomizados; en los cuadros de colangitis o pancreatitis con obstrucción biliar; en pacientes con mal terreno o graves; cuando sospechamos la presencia de un cálculo enclavado; en pacientes con vía biliar no dilatada; y en los centros que cuentan con endoscopistas con experiencia en vía biliar y cirujanos con poca experiencia en cirugía laparoscópica de la VBP o que no cuentan con el instrumental necesario. En pacientes no colecistectomizados, el tratamiento inicial de la VBP por endoscopia previo a la colecistectomia laparoscópica es una opción de numerosos centros quirúrgicos, realizando la colecistectomía laparoscópica posteriormente a la endoscopia; o incluso el tratamiento endoscópico puede ser la única terapéutica, en pacientes inoperables, dejándose la vesícula in situ.

8) Finalmente proponemos un algoritmo terapéutico, en el cual planteamos realizar el tratamiento integral de la litiasis biliar, por cirugía laparoscópica y/o endoscópica de elección, y en algunos casos abierta, y en forma ideal en un tiempo; debiéndose seleccionar y combinar estas diferentes opciones terapéuticas de acuerdo a cada caso clínico, a la experiencia del equipo médico tratante y a la infraestructura con la que cuenta el centro asistencial. 